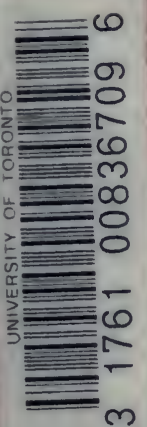




Digitized by the Internet Archive in 2008 with funding from Microsoft Corporation 


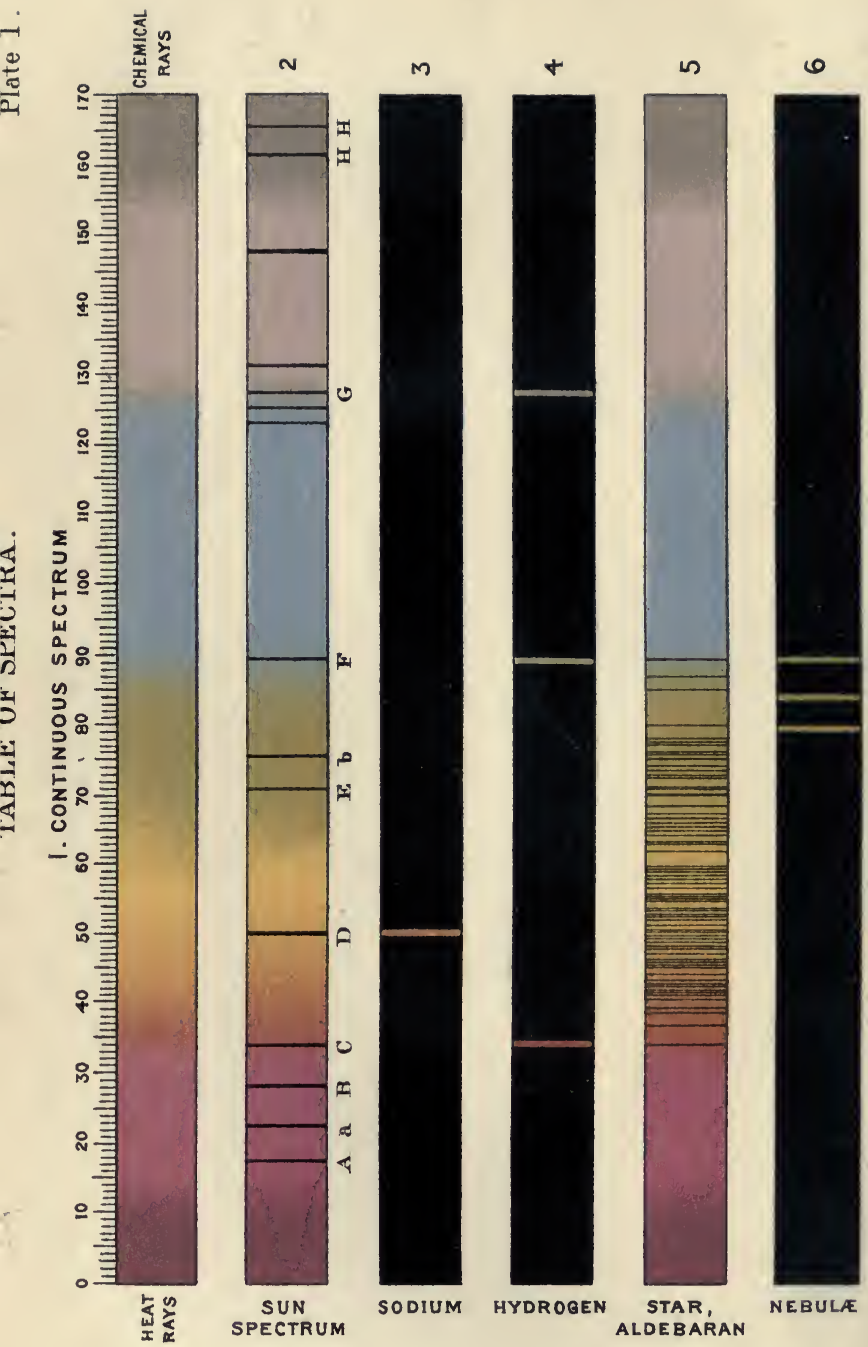




\title{
A SHORT HISTORY
}

\section{OF \\ NATURAL SCIENCE \\ AND OF THE}

PROGRESS OF DISCOVERY FROM THE TIME OF THE

GREEKS TO THE PRESENT DAY

FOR THE USE OF SCHOOLS AND YOUNG PERSONS

\section{BY ARABELLA B. BUCKLEI}

\author{
WITH ILLUSTRATIONS
}

NEW YORK:

D. APPLETON AND COMPANY,

x, 3, AND 5 BOND STREET.

I $88 \mathrm{I}$. 


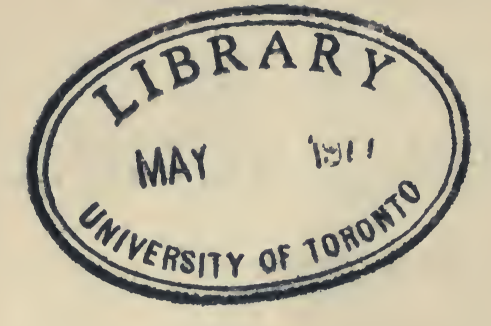

$Q 4$
15
1558
1881 
Co the athemory of

MY BELOVED AND REVERED FRIENDS

\section{SIR CHARIES AND LADY LYELL}

TO WHOM I OWE MORE THAN I CAN EVER EXPRESS

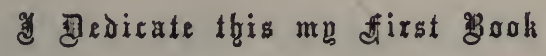

TRUSTING THAT IT MAY HELP

TO DEVELOPE IN THOSE WHO READ IT THAT

EARNEST AND TRUTH-SEEKING SPIRIT IN THE STUDY OF GOD'S

WORKS AND LAIVS WHICH WAS THE GUDING

PRINCIPLE OF TIIEIR LIVES 



\section{PREFACE}

IT is not without some anxiety that I offer this little work to the public, for it is, I believe, the first attempt which has been made to treat the difficult subject of the History of Science in a short and simple way.1

Its object is to place before young and unscientific people those main discoveries of science which ought to be known by every educated person, and at the same time to impart a living interest to the whole, by associating with each step in advance some history of the men who made it.

During the many years that I enjoyed the privilege of acting as secretary to the late Sir Charles Lyell, and was thus brought in contact with many of the leading scientific men of our day, I often felt very forcibly how many important facts and generalizations of science, which are of great value both in the formation of character and in giving a true estimate

1 Mr. Baden Powell's excellent little 'History of Natural Philosophy,' published in Lardner's 'Cyclopædia' in 1834, is scarcely intended for beginners, and does not extend farther than the seventeenth century. This is the only work of the kind I have been able to find. 
of life and its conditions, are totally unknown to the majority of otherwise well-educated persons.

Great efforts are now being made to meet this difficulty, by teaching children a few elementary facts of the various branches of science; but, though such instruction is of immense value, something more is required in order that the mind may be prepared to follow intelligently the great movement of modern thought. The leading principles of science ought in some measure to be understood; and these will, I believe, be most easily and effectually taught by showing the steps by which each science has attained its present importance.

It is this task which I have endeavoured to accomplish; and if teachers will make their pupils master the explanations given in these pages and, wherever it is possible, try the experiments suggested, I venture to hope that this little work may supply that modest amount of scientific information which everyone ought to possess, while, at the same time, it will form a useful groundwork for those who wish afterwards to study any special branch of science.

The plan adopted has been to speak of discoveries in their historical order, and to endeavour to give such a description of each as can be understood by any person of ordinary intelligence. This has made it necessary to select among subjects of equal importance those which could be dealt with in plain language, and to avoid passing allusions to such as did not admit of such explanation. 
The history of the nineteenth century has been a very difficult and I fear scarcely a successful task; for, while those who know anything of the subjects mentioned, will feel that the account is very defective owing to so much being left out, the beginner will probably find it difficult owing to so much being put in. The reproach on both sides would be just, yet it seemed better to give even a few of the leading discoveries and theories of our own time than to leave the student with such crude ideas of many branches of science as he must have had if the history had ended with the eighteenth century.

When treating of such varied subjects, many of them presenting great difficulties both as regards historical and scientific accuracy, I cannot expect to have succeeded equally in all, and must trust to the hope of a future edition to correct such grave errors as will doubtless be pointed out, in spite of the care with which I have endeavoured to verify the statements made.

As the size of the book makes it impossible to give the numerous references which would occur on every page, I have named at the end of each chapter a few of the works consulted in its preparation, choosing always in preference those, which will be useful to the reader if he cares to refer to them. I had also prepared questions on the work; but those competent to give an opinion, tell me that teachers in these days prefer to prepare their own lessons. I have therefore substituted, at p. 439, a chronological table of the 
various sciences, by means of which questions can be framed, either upon the discoveries of any given period, or on the progressive advance, through several centuries, of any of the five main divisions of science which are dealt with in this volume.

In conclusion, I wish to acknowledge my obligations to many kind friends, and especially to Mr. A. R. Wallace and Mr. J. C. Moore, F.R.S., who have rendered me very material and valuable assistance. I am also much indebted to the Rev. R. M. Luckock, of the Godolphin Grammar School, who read the whole work in manuscript, with a view to pointing out any portions which might be unintelligible to schoolboys.

LoNDon : December $\mathbf{1} 875$. 


\title{
CONTENTS.
}

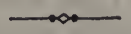

INTRODUCTION . • • • • • • • • • •

\section{PART I.}

SCIENCE OF THE GREEKS.

\section{CHAPTER I.}

\author{
639 To 470 B.c.
}

Ignorance of the Greeks concerning Nature-Ionian School of Learning-Thales discovers the Solstices and Equinoxes, and knows that the Moon Reflects the Light of the Sun-Anaximander invents a Sun-dial-Discovers the Phases of the MoonMakes a Map of the Ancient World-Pythagoras teaches that the Earth moves, and that the Morning and Evening Star are the same-He studies Geology, and knows that Land has in some places become Sea-True sayings of Pythagoras and his

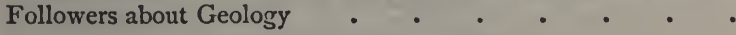

\section{CH A P T E R II.}

499 TO 322 B.C.

Anaxagoras studies the Moon-Describes Eclipses of the Sun and Moon-Is Tried and Condemned for Denying that the Sun is a God-Hippocrates the Father of Medicine-Separates the office of Priest and Doctor - Studies the Human Body Eudoxus has an Observatory-Makes a Map of the StarsExplains the Movements of the Planets-Democritus studies the Milky Way-Aristotle an Astronomer and ZoologistDivides Animals into Classes-Teaches that there is a Gradual Succession of Animal Life-Studies the Difference of the Life in Plants and Animals-Theophrastus the first Botanist 


\section{CHAPTER III.}

320 TO 212 B.C.

School of Science at Alexandria-The Ecliptic and the ZodiacGreeks believed that the Sun moved round the Earth-Aristarchus knew that it was the Earth which moved-He also knew of the Obliquity of the Ecliptic, and that the Seasons are caused by it-He knew that the Earth turns daily on its Axis-Euclid discovers that Light travels in straight lines-Archimedes discovers the Lever-Principle of the Lever-Hiero's Crown, and how Archimedes discovered the principle of Specific GravityScrew of Archimedes

\section{CHAPTER IV.}

\section{TO 120 B.C.}

Erasistratus and Herophilus study the Human Body-Eratosthenes the Geographer lays down the First Parallel of Latitude and the First Meridian of Longitude-He measures the Circumference of the Earth-Hipparchus writes on Astronomy-Catalogues I,080 Stars-Calculates when Eclipses will take place-Discovers the Precession of the Equinoxes . . . . . . .

\section{CHAPTER V.}

FROM A.D. 70 TO 200.

Ptolemy founds the Ptolemaic System-He writes on Geography -Strabo, a great traveller, writes on Geography - Studies Earthquakes and Volcanoes-Galen the greatest Physician of Antiquity - Describes the Two Sets of Nerves-Proves that Arteries contain Blood-Lays down a theory of MedicineGreece and her Colonies conquered by Rome-Decay of Science in Greece-Concluding remarks on Greek Science 


\section{PART II. \\ SCIENCE OF THE MIDDLE AGES.}

\section{CHAPTER VI. \\ SCIENCE OF THE ARABS.}

Dark Ages of Europe-Taking of Alexandria by the Arabs, and burning of the Library-The Arabs, checked in their conquests by Charles Martel, settle down to Science-The Nestorians and Jews translate Greek Works on Science-Universities of the Arabs-Chemistry first studied by the Arabs-Alchemy, or the attempt to make Gold-Hermes the first Alchemist-Hermetically-sealed Tubes-Gases and Vapours called 'Spirits' by the Arabs - The use of this Word retained by us . . .

\section{CHAPTER VII.}

\section{SCIENCE OF THE ARABS (CONTINUED).}

Geber, or Djafer, the founder of Chemistry-His Explanation of Distillation-Of Sublimation-Discovers that some Metals increase in weight when heated-Discovers strong Acids-Nitric Acid-Sulphuric Acid-Discovery of Sal-Ammoniac by the Arabs-Arabs mix up Astronomy with Astrology-Albategnuis calculates the Length of the Year-Mohammed Ben Musa, first writer on Algebra-Uses the Indian Numerals-Gerbert introduces them into Europe-Alhazen's discoveries in OpticsHis Explanation why only one image of each object reaches the Brain-His discovery of Refraction, and of its effect on the light of the Sun, Moon, and Stars-His discovery of the magnifying power of rounded glasses

\section{CHAPTER VIII.}

\section{SCIENCE OF THE MIDDI.E AGES IN EUROPE.}

Roger Bacon-His 'Opus Majus'-His Explanation of the Rainbow - He makes Gunpowder-Studies Gases-Proves a Candle will not burn without Air-His Description of a TelescopeSpeaks of Ships going without Sails-Flavio Gioja invents the 
Mariner's Compass-Greeks knew of the Power of the LoadPAGE stone to attract Iron-Use of the Compass in discovering new lands-Invention of Printing-Columbus discovers AmericaVasco de Gama sees the Stars of the Southern HemisphereMagellan's ship sails round the World-Inventions of Leonardo da Vinci.

PART III.

RISE AND PROGRESS OF MODERN SCIENCE.

\section{CHAPTER IX.}

\section{SCIENCE OF THE SIXTEENTH CENTURY.}

Rise of Modern Science-Dogmatism of the Middle AgesReasons for studying Discoveries in the order of their datesCopernican theory of the Universe-Copernicus goes back to the System of Aristarchus-Is afraid to publish his Work till quite the end of his Life-Work of Vesalius on Anatomy-He shows that Galen made many mistakes in describing Man's Structure-His Banishment and Death-The value of his Work to Science-Fallopius and Eustachius Anatomists-Gesner's Works on Animals and Plants-He forms a Zoological Cabinet and makes a Botanical Garden-His Natural History of Animals - His classification of Plants according to their Seeds-His work on Mineralogy-Crsalpinus makes the First System of Plants on Gesner's plan-Explains Diocious Plants-Chemistry of Paracelsus and Van Helmont

\section{CHAPTER X.}

\section{SCIENCE OF THE SIXTEENTH CENTURY (COŃTINUED).}

Baptiste Porta discovers the Camera Obscura-Shows that our Eye is like a Camera Obscura-Makes a kind of Magic Lantern by Sunlight-Kircher afterwards makes a Magic Lantern by Lamplight-Dr. Gilbert's discoveries in Electricity-Tycho Brahe, the Danish Astronomer-Builds an Observatory on the Island of Huen-Makes a great number of Observations, and 
draws up the Rudolphine Tables - Galileo discovers the principle of the Pendulum - Calculates the velocity of Falling Bodies, and shows why it increases-Shows that Unequal Weights fall to the Ground in the same time-Establishes the relations of Force and Weight-Stevinus on Statics-Summary of the Science of the sixteenth century

\section{CHAPTER XI.}

SCIENCE OF THE SEVENTEENTH CENTURY.

Astronomical discoveries of Galileo-The Telescope--Galileo examines the Moon, and discovers the Earth-light upon it-Discovers Jupiter's four Moons-Distinguishes the Fixed Stars from the Planets - The phases of Venus confirm the Copernican theory -Galileo notices Saturn's Ring, but does not distinguish it clearly-Observes the spots on the Sun-The Inquisition force him to deny the movement of the Earth-Blindness and Death of Galileo

\section{CHAPTER XII.}

SCIENCE OF THE SEVENTEENTH CENTURY (CONTINUED).

Kepler the German Astronomer-Succeeds Tycho as Mathematician to the Emperor Rudolph-His description of the EyeHe tries to explain the orbit of the planet Mars-And by comparing Tycho's tables with observation discovers his First and Second Law of the movements of the Planets-His delight at Galileo's discoveries-Kepler's Third Law-Comparison of the labours of Tycho, Galileo, and Kepler . . . . . 95

\section{CHAPTER XIII.}

SCIENCE OF THE SEVENTEENTH CENTURY (CONTINUED).

Francis Bacon, 1561-1626-He teaches the true method of studying Science in his 'Novum Organum'-René Descartes, I 596-1650--He teaches that Doubt is more honest than Ignorant Assertion-Willebrord Snellius discovers the Law of Kefraction, 1621-Explanation of this Law 


\section{CHAPTER XIV.}

SCIENCE OF THE SEVENTEENTH CENTURY (CONTINUED).

Fabricius Aquapendente discovers Valves in the Veins--Harvey's discovery of the Circulation of the Bluod-Discovery of the Vessels which carry nourishment to the Blood-Gaspard Asellius notices the Lacteals-Pecquet discovers the Passage of the fluid to the Heart-Rüdbeck discovers the Lymphatics . . . I10

\section{CHAPTER XV.}

SCIENCE OF THE SEVENTEENTH CENTURY (CONTINUED).

Torricelli discovers the reason of Water rising in a Pump-Uses Mercury to measure the Weight of the Atmosphere-Makes the First Barometer-M. Perrier, at Pascal's suggestion, demonstrates variations in the pressure of the atmosphere-Otto Guericke invents the Air-pump-Working of the Air-pumpGuericke proves the Pressure of the Atmosphere by the experiment of the Magdeburg Spheres-He makes the first Electrical Machine-Foundation of Royal Society of London and other Academies of Science . . . . . . . . Ii6

\section{CHAPTER XVI.}

\section{SCIENCE OF THE SEVENTEENTH CENTURY (CONTINUED).}

Boyle's Law of the Compressibility of Gases-This same Law discovered independently by Marriotte-Hooke's theory of Air being the cause of Fire-Boyle's experiments with Animals under the Air-pump-John Mayow, the greatest Chemist of the Seventeenth Century-His experiments upon the Air used in Combustion-Proves that the same portion is used in Respiration-Proves that Air which has lost its Fire-air is LighterMayow's 'Fire-air' was Oxygen, and his Lighter Air Nitrogen - He traces out the effect which Fire-air produces in Animals when Breathing 


\section{CHAPTER XVII.}

SCIENCE OF THE SEVENTEENTH CENTURY (CONTINUED).

Malpighi first uses the Microscope to examine Living Structures

- He describes the Air-cells of the Lungs-Watches the Circulation of the Bloud - Observes the Malpighian Layer in the Human Skin-Describes the structure of the Silkworm-Leeuwenhøck discovers Animalcules-Grew and Malpighi discover the Cellular Structure of Plants-The Stomates in Leaves-They study the Germination of Seeds-Ray and Willughby classify and describe Animals and Plants-The Friendship of these two Men . . 137

\section{CHAPTER XVIII.}

SCIENCE OF THE SEVENTEENTH CENTURY (CONTINUED).

1642, Birth of Newton-His Education-1666, His three great Discoveries first occur to him-Method of Fluxions and Differential Calculus-First Thought of the Theory of Gravitation -Failure of his Results in consequence of the Faulty Measurement of the size of the Earth-1682, Hears of Picart's new Measurement-Works out the result correctly, and proves the Theory of Gravitation-Explanation of this Theory-Establishes the Law that Attraction varies inversely as the squares of the distance-1687, Publishes the 'Principia'-Some of the Problems dealt with in this Work. . . . . . . 147

\section{CHAPTER XIX.}

\section{SCIENCE OF THE SEVENTEENTH CENTURY (CONTINUED)}

Transits of Mercury and Venus-Kepler foretells their occurrence -1631, Gassendi observes a Transit of Mercury-1639, Horrocks foretells and observes a Transit of Venus-1676, Halley sees a Transit of Mercury, and it suggests to him a method for Measuring the Distance of the Sun-1691-1716, Halley describes this method to the Royal Society-Explanation of Halley's method 


\section{CHAPTER XX.}

SCIENCE OF 'THE SEVENTEENTH CENTURY (CONTINUED).

Newton's Discovery of the Dispersion of Light-Traces the amount of Refraction of each of the Coloured Rays-Makes a Rotating Disc turning the colours of the Spectrum into White Light-Reason why all Light passing through glass is not Coloured-Mr. Chester More Hall discovers the Difference of Dispersive Power in Flint and Crown Glass-Newton's Papers destroyed bv his pet dog-Last years of Newton's life

\section{CHAPTER XXI.}

SCIENCE OF THE SEVENTEENTH CENTURY (CONTINUED).

Roemer measures the Velocity of Light-Newton's Corpuscular Theory of Light-Undulatory or Wave Theory proposed by Huyghens-Invention of Cycloidal Pendulums by HuyghensDiscovery of Saturn's Ring-Sound caused by Vibration of AirLight by Vibration of Ether-Reasons why we see LightReflection of Waves of Light-Cause of Colour-Refraction explained by the Undulatory Theory-Mr. Tylor's Illustration of Refraction-Double Refraction explained by HuyghensPolarisation of Light not understood till the nineteenth century . 172

\section{CHAPTER XXII.}

Summary of the Science of the Seventeenth Century • 182

\section{CHAPTER XXIII.}

\section{SCIENCE OF THE EIGHTEENTH CENTURY.}

Great spread of Science in the Eighteenth Century-Advance of the Sciences relating to Living Beings-Foundation of Leyden University in 1574-Boerhaave, Professor of Medicine at Leyden, I 70 - Foundation of Organic Chemistry by BoerhaaveInfluence of Boerhaave upon the study of Medicine-Belief of the Alchemists in 'Vital Fluids'-Boerhaave's Experiments on the Juices of Plants-Dr. Hales's Experiments on Plants-Boerhaave's Analyses of Milk, Blood, \&c.-Great popularity of his Chemical Lectures . 


\section{CHAPTER XXIV.}

SCIENCE OF THE EIGHTEENTH CENTURY (CONIINUED).

Childhood of Haller-Foundation of the University of Göttingen in 1736-Haller made Professor of Anatomy-Haller's Anatomical Plates-He discovers the power of Contraction of the Muscles-Rise of Comparative Anatomy-John Hunter's industry in Dissecting and Comparing the Structures of different Animals-His Museum and the arrangement of his CollectionBonnet's Experiments on Plants-Experiments upon Animals by Bonnet and Spallanzani-Regrowth of different parts when cut off-Bonnet's theory of Gradual Development of Plants and Animals-Anatomical Works of Haller-He discovers the power of the Muscles to contract . . . . . .

\section{CHAPTER XXV.}

\section{SCIENCE OF THE EIGHTEENTH CENTURY (CONTINUED)}

Birth and Early Life of Buffon and Linnæus compared-Buffon's Work on Natural History-Daubenton wrote the Anatomical Part-Buffon's Books very interesting, but not always accurateHe first worked out the Distribution of Animals-Struggles of Linnæus with Poverty-Mr. Clifford befriends him-He becomes Professor at Upsala-He was the first to give Specific Names to Animals and Plants-Explanation of his Descriptions of Plants - Use of the Linnæan or Artificial System-Afterwards superseded by the Natural System-Linnæus first used accurate terms in describing Plants and Animals-Character of Linneus-- Sale of his Collection, and Chase by the Swedish Man-of-war . . 204

\section{CHAPTER XXVI.}

SCIENCE OF THE EIGHTEENTH CENTURY (CONTINUED).

The Study of the Earth neglected during the Dark Ages-Prejudices concerning the Creation of the World-Attempts to Account for Buried Fossils-Palissy, the Potter, first asserted that Fossil-shells were real Shells-Scilla's Work on the Shells of Calabria, 1670-Woodward's Description of Different Formations, 1695-Lazzaro Moro one of the first to give a true expla- 
nation of the facts-Abraham Werner lectures on Mineralogy and Geology, 1775-Disputes between the Neptunists and Vulcanists-Dr. Hutton first teaches that it is by the Study of the Present that we can understand the Past-Theory of HuttonSir J. Hall's Experiments upon Melted Rocks-Hutton discovers Granite Veins in Glen 'Tilt-William Smith, the 'Father of English Geologists'-His Geological Map of England . . 214

\section{CHAPTER XXVII.}

SCIENCE OF THE EIGHTEENTH CENTURY (CONTINUED).

Birth of Modern Chemistry-Discovery of 'Fixed Air,' or Carbonic Acid, by Black and Bergmann-Working out of 'Chemical Affinity' by Bergmann-He tests Mineral Waters, and proves 'Fixed Air' to be an Acid-Discovery of Hydrogen by Cavendish-He investigates the Composition of Water-Oxygen discovered by Priestley and Scheele-Priestley's ExperimentsHe fails to see the true bearing of his Discovery-His Political Troubles and Death-Nitrogen described by Dr. RutherfordLavoisier lays the Foundation of Modern Chemistry-He destroys the Theory of 'Phlogiston' by proving that Combustion and Respiration take up a Gas out of the Air-Discovers the Composition of Carbonic Acid and the nature of the DiamondFrench School of Chemistry-Death of Lavoisier

\section{CHAPTER XXVIII.}

SCIENCE OF THE EIGHTEENTH CENTURY (CONTINUED).

Doctrine of Latert Heat, taught by Dr. Black in $1760-$ Water containing Ice remains always at $0^{\circ} \mathrm{C}$., and Boiling Water at $100^{\circ} \mathrm{C}$., however much Heat is added-Black showed that the lost Heat is absorbed in altering the condition of the WaterWatt's Application of the Theory of Latent Heat to the Steamengine-Early History of Steam-engines-Newcomen's Engine -Watt invents the Separate Condenser-Diagram of Watt's Engine-Difficulties of Watt and Boulton in introducing Steamengines : $. \quad . \quad . \quad . \quad . \quad . \quad \cdot$. 


\section{CHAPTER XXIX.}

SCIENCE OF THE EIGHTEENTH CENTURY (CONTINUED).

Benjamin Franklin, born 1706-His Early Life-Du Faye disPAGE covers two kinds of Electricity-Franklin proves that Electricity exists in all Bodies, and is only developed by Friction-Positive and Negative Electricity-Franklin draws down Electricity from the Sky-Invents Lightning-conductors-Discovery of Animal Electricity by Galvani-Controversy between Galvani and Volta -Volta proves that Electricity can be produced by the Contact of two Metals-Electrical Batteries-The Crown of Cups-The Voltaic Pile . . . . . . . . . . 253

\section{CHAPTER XXX.}

SCIENCE OF THE EIGHTEENTH CENTURY (CONTINUED).

Bradley and Delisle, Astronomers-Aberration of the Fixed Stars - Nutation of the Axis of the Earth, Delisle's Method of Measuring the Transit of Venus-Lagrange and Laplace-Libration of the Moon accounted for by Lagrange-Laplace works out the Long Inequality of Jupiter and Saturn-Lagrange proves the Stability of the Orbits of the Planets-Sir William Herschel constructs his own Telescopes-Discovery of a New PlanetDiscovery of Binary Stars-Herschel studies Star-clusters and Nebulæ-Theory of Nebulæ being matter out of which Stars are made-The Motion of our Solar System through SpaceWeight of the Earth determined by the Schehallien Experiment - Summary of the Science of the Eighteenth Century . . 265

\section{CHAPTER XXXI. \\ SCIENCE OF THE NINETEENTH CENTURY.}

Difficulties of Contemporary History-Discovery of Asteroids and Minor Planets between Mars and Jupiter-Dr. Olbers suggests they may be fragments of a larger Planet-Encke's Comet, and the correction of the size of Jupiter and Mercury-Biela's Comet, noticed in $\mathrm{I} 826$ - It divides into two Comets in 1845 
Irregular movements of Uranus-Adams and Leverrier calculate the position of an Unknown Planet-Neptune found by these calculations in $1846-A$ Survey of the whole Heavens made by Sir John Herschel-His work in Astronomy-Comets and Meteor-systems

\section{CHAPTER XXXII.}

SCIENCE OF THE NINETEENTH CENTURY (CONTINUED).

Discoveries concerning Light made in the Nineteenth CenturyBirth and History of Dr. Young-He explains the Interference of Light-Cause of Prismatic Colours in a Shadow-And in a Soap-bubble-Malus discovers the Polarisation of Light caused by Reflection-Birth and History of Fresnel-Polarisation of Light explained by Young and Fresnel-Complex Vibrations of a Ray of Light-How these Waves are reduced to two separate Planes in passing through Iceland-spar-Sir David Brewster and M. Biot explain the colours produced by Polarisation .

\section{CHAPTER XXXIII.}

SCIENCE OF THE NINETEENTH CENTURY (CONTINUED).

History of Spectrum Analysis-Discovery of Heat-rays by Sir W. Herschel-And of Chemical Rays by Ritter of Jena-Photography first suggested by Davy and Wedgwood-Carried out by Daguerre and Talbot-Dark Lines in the Spectrum first observed by Wollaston-Mapped by Fraunhofer-Life of Fraunhofer-He discovers that the Dark Lines are different in Sunlight and Star-light-Experiments on the Spectra of different Flames-Four new Metals discovered by Spectrum AnalysisArtificial Dark Lines produced in the Spectrum by Sir David Brewster-Bunsen and Kirchhoff explain the Dark Lines in the Solar Spectrum-Metals in the Atmosphere of the Sun-Huggins and Miller examine the Stars and Nebulæ by Spectrum Analysis . 


\section{CHAPTER XXXIV.}

SCIENCE OF THE NINETEENTH CENTURY (CONTINUED).

Early Theories about Heat-Count Rumford shows that Heat can

be produced by Friction-He makes Water boil by boring a Cannon-Davy makes two pieces of Ice melt by Friction-His conclusion about Heat-How 'Latent Heat' is explained on the theory that Heat is a kind of Motion-Dr. Mayer suggests the Determination of the Mechanical Equivalent of Heat-Dr. Joule's Experiments on the conversion of Motion into Heat-Dr. Hirn's Experiments on the conversion of Heat into Motion-Proof of the Indestructibility of Force and Conservation of Energy - 329

\section{CHAPTER XXXV.}

\section{SCIENCE OF THE NINETEENTH CENTURY (CONTINUED).}

Oersted discovers the Effect of Electricity upon a Magnet-ElectroMagnetism-Experiments by Ampère on Magnetic and Electric Currents-Ampère's Early Life-Direction of the North Pole of the Magnet depends on the course of the Electric CurrentsMagnetic Currents set up between two Electric Wires-ElectroMagnets made by means of an Electric Current-Arago magnetises a Steel Bar with an ordinary Electrical Machine-Faraday discovers the Rotatory Movement of Magnets and Electrified Wires-Produces an Electric Current by means of a Magnet-Seebeck discovers Thermo-Electricity, or the production of Electricity by Heat-Schwabe discovers Periudicity of the Spots on the Sun-Sabine suggests a connection between Sun-spots and Magnetic Currents-This proved in 1859 by Observations of Carrington and Hodgson-Electric Telegraph-WheatstoneCooke-Steinheil-Morse-Bain . . . . . .

\section{CHAPTER XXXVI.}

SCIENCE OF THE NINETEENTH CENTURY (CONTINUED).

Davy discovers that Nitrous Oxide produces Insensibility-Laughing-gas-Safety-lamp, 1815-Nicholson and Carlisle discover Decomposition of Water, 1800-Davy discovers the effect of Electricity upon Chemical Affinity-Faraday's Discoveries in 
Electrolysis-Indestructibility of Force-Various Modes discovered of Decomposing Substances-John Dalton, chemistLaw of Definite Proportions-Law of Multiple ProportionsDalton's Atomic Theory-The Study of Organic ChemistryLiebig, the great teacher in Organic Chemistry . . . 362

\section{CHAPTER XXXVII.}

\section{SCIENCE OF THE NINETEENTH CENTURY (CONTINUED).}

The Organic Sciences are too difficult to follow out in detailJussieu's Natural System of Plants-Goethe proves the Metamorphosis of Piants-Humboldt studies the Lines of Average Temperature on the Globe-Extends our knowledge of Physical Geography-Writes the 'Cosmos'-Death of Humboldt in 1858

\section{CHAPTER XXXVIII.}

\section{SCIENCE OF THE NINETEENTH CENTURY (CONTINUED).}

The three Naturalists, Lamarck, Cuvier, and Geoffroy St.-Hilaire - Cuvier begins the Museum of Comparative Anatomy-Lamarck's History of Invertebrate Animals-G. St.-Hilaire brings Natural History Collections from Egypt-Lamarck on the Development of Animals-G. St.-Hilaire on 'Homology,' or the similarity in the parts of different animals-Cuvier's 'Règne Animal' and his Classification of Animals-Cuvier on the Perfect Agreement between the Different Parts of an animal- $\mathrm{He}$ Studies and Restores the Remains of Fossil Animals-His 'Ossemens Fossiles'-Death of Cuvier-Von Baer on the Study of Embryology-His History of the Development of Animals, 1828

\section{CHAPTER XXXIX.}

SCIENCE OF THE NINETEENTH CENTURY (CONTINUED).

Prejudices which retarded the study of Geology-Sir Charles Lyell traces out the Changes going on now-Mud carried down by the Ganges-Eating away of Sea-coasts-Eruption of Skaptar Jokul-Earthquake of Calabria-Rise and Fall of Land- 
'Principles of Geology' published in 1830-Louis Agassiz: his early life-De Saussure's Study of Glaciers-Agassiz on Europe and North America being once covered with Ice-Boucher de Perthes on Ancient Flint Implements-McEnery on Flint Implements in Kent's Cavern, with Bones of Extinct AnimalsSwiss Lake-dwellings-'Antiquity of Man' . . . . 404

\section{CHAPTER XL.}

SCIENCE OF THE NINETEENTH CENTURY (CONTINUED).

Facts which led Naturalists to believe that the different kinds of Animals are descended from Common Ancestors-All Animals of each class formed on one Plan-Embryological StructureLiving and Fossil Animals of a country resemble each otherGradual Succession of Animals on the Globe-Links between different species-Darwin's Theory of Natural SelectionWallace worked out the same Theory independently-Sketch of the Theory of Natural Selection-Selection of Animals by ManSelection by Natural Causes-Difficulties in Natural History which are explained by this Theory-Foolish Prejudices against it-Concluding Remarks on the History of Science . 



\section{A SHORT HISTORY}

\section{oF NATURAL SCIENCE.}

INTRODUCTION.

As THIs little work is to be a history of Natural Science, it will be as well to begin by trying to understand what Science is.

The word itself comes from scio, I know, and means simply knowledge. The science of botany is therefore the knowledge of plants ; and the science of astronomy, the knowledge of the heavenly bodies.

But now comes the question, What kind of knowledge is required? You might be able to tell the names of all the plants in the world, and of all the stars in the sky, and yet have scarcely any real knowledge of botany or astronomy. You will easily understand this if we compare it with something you meet with in daily life. Suppose I took you into a large school and told you the names of all the children there; even if you learnt these names by heart, you could not say you knew the children, or anything about them, beyond their names. One might be ill-tempered, another good-tempered; one might have a home and a father and 
mother, another might be an orphan and homeless, and you would find their mere names of no use to you if you wished to choose one of them to do any work, or to be your friend and companion. For this you would want to learn their character, their habits, and other real facts about them.

Now this last is just the kind of knowledge which is required in science. If, besides the name of a plant, you know its different parts, the shape of its leaves, the number of its seeds, and how they are arranged in the seed-vessel, the number of stamens or thread-like bodies in the middle of the flower, the number and colour of its petals or flowerleaves, and many other points like these, then you know something of structural botany. If you know, besides, how a plant takes up food, how it breathes, and how the sunlight acts upon the leaves and alters the juices of the plant, then you know something of the life of the plant, or physiological botany. If you know where the plant grows best, in what soil, in what climate, and in what countries, then you know something of geographical botany; and if your knowledge is accurate and carefully learnt it is real science.

By this you will see that science means not merely knowledge, but an accurate and clear knowledge about the things which we see around us in the universe. In the present day, people are beginning to teach children much more on these. subjects than they did forty years ago, and every intelligent boy or girl probably knows that Astronomy is the science of the sun, stars, and planets; Physics and Mechanics, the sciences which teach the properties of bodies and their laws of motion; Biology the science of life ; Geology the science of the earth, teaching us how the different rocks have been formed; and Chemistry the science which treats of the materials of which all substances are made, and shows the 
changes which take place when two substances act upon one another so as to make a new substance.

There are many simple books written now to explain these sciences, and those who wish can read these books and study the examples and experiments given in them. They tell us what science now is, and the explanations given by the best men about the universe in which we live. But they do not tell us how science has become what it is, and it is this which I hope to tell you in the present book.

A man who wishes to understand a steam-engine can do so by going to an engineer and having each part explained to him ; but if he wishes to know the history of the steamengine he must go back to the first one ever made, and study each new improvement as it arose. And so if we go back to the first attempts made by thoughtful men to understand nature, and then trace up step by step the knowledge gained from century to century, we shall have at least a more intelligent understanding of that which is taught us now. But if we have any true love of knowledge we shall gain far more than this ; for in studying the history of those grand and patient men who often spent their lives and made great sacrifices to understand the works of God, the merest child must feel how noble it is to long and strive after truth.

When we go back to very early ages we do not find that people understood much of what we now call science. So long as men were chiefly occupied in protecting themselves against other savage men and wild beasts, and had to struggle very hard to get food and clothing, they had very little time or wish to study nature. Still they learnt many things which were necessary for their life. They learnt, for instance, at what times the sun rose and set, for upon this 
their day's work depended. They learnt at what time in the month the moon was full, so that they could see their way by moonlight ; and they remarked very early the times when spring, summer, autumn, and winter came round, because the sowing of their seeds and the gathering of their fruits depended upon these seasons.

In this way we find that as far back as history goes men have always had some knowledge of the facts of nature; and those nations, like the Egyptians and Chinese, which long ago had become highly civilized, had learnt a very great deal, and must probably have known some things of which we are still ignorant.

There has been a great deal written about the science of the Chinese, Indians, and Egyptians, but I shall not tell you anything about them here, because their knowledge has had very little to do with the science which has come down to us, and it would besides be difficult to give you any real idea of what they knew without writing a book on the subject.

We will start, therefore, with the Greeks, at the time when they first began to try and explain some of the natural events which they saw taking place every day. This was about the year 700 B.C., when Thales, one of the seven wise men, was living, and you will see in the next chapter that even at this time, when Greece was famous for its learning, the people had still some very strange ideas about the working of the universe. 


\title{
PART I.
}

\section{SCIENCE OF THE GREEKS}

\author{
FROM R.C. 639 TO A.D. 200
}


Chief Men of Science among the Grecks.

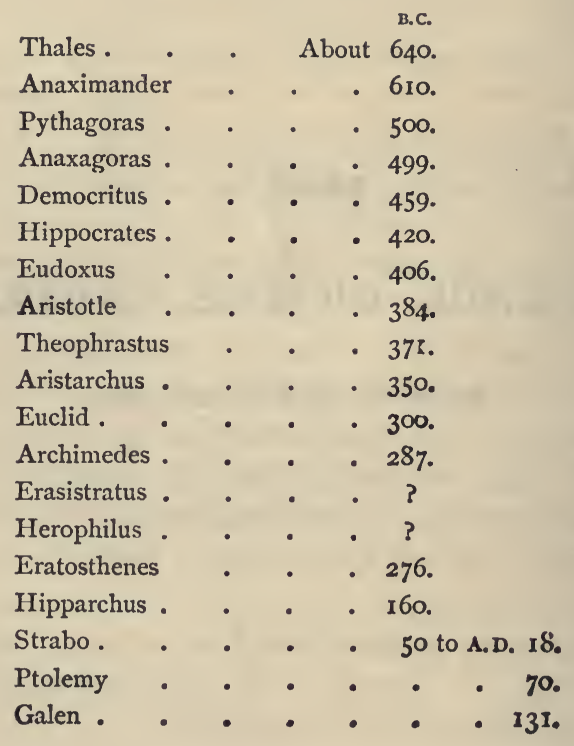




\section{CHAPTER I.}

$$
639 \text { TO } 470 \text { в.C. }
$$

Ignorance of the Greeks concerning Nature-Ionian School of Learning - Thales discovers the Solstices and Equinoxes, and knows that the Moon Reflects the Light of the Sun-Anaximander invents a Sundial-Discovers the Phases of the Moon-Makes a Map of the Ancient World-Pythagoras teaches that the Earth moves, and that the Morning and Evening Star are the same-He studies Geology, and knows that Land has in some places become Sea-True sayings of Pythagoras and his Followers about Geology.

ABout 600 years before Christ was born, the Greeks were the most learned people in Europe. They were naturally a handsome and clever race, and their young men were trained to be both good soldiers and good scholars. An English boy, if he could be carried back to those days, would find that the young Greeks could read, write, draw, and argue as well as himself, and probably that they could leap, wrestle, and run far better than himself or any of his schoolfellows.

But on some points he would find that their ideas were very strange. If he spoke to them of the world as a round globe they would stare in astonishment, and tell him that such an idea was absurd, for everyone knew that the world was flat with the sea flowing all round it. If he asked them, in his turn, about Mount Etna, they would surprise him by replying that the god Vulcan had his smithy underneath the mountain, where he was forging thunderbolts for Jove, and 
that Etna was the chimney of his forge. But if he spoke of the sun as a globe of light, they would turn away from him in horror as a wicked unbeliever in the gods, for who among the Greeks did not know that the sun was the god Apollo, who drove his chariot every day across the sky from east to west? In fact, the Greeks, though learned and brave, were quite ignorant of what we now call 'natural knowledge;' they did not know that the rising and setting of the sun, and the eruption of a volcano, are things which happen from natural causes ; but everything which was not done by man, they thought was the work of invisible beings or gods.

It was not long, however, before some wise men began to think more deeply about these things. You will have read in Grecian history how the Greeks, after the taking of Troy, crossed over the Hellespont and founded colonies on the coast of Asia Minor; one of the largest of these colonies was called Ionia, and the Ionians became famous for their learning and wisdom.

Thales, 640.-Here Thales, one of the seven wise men of Greece, was born at Miletus, about 640 B.c. Thales travelled in Egypt, and learned many things from the Egyptians, and then returned to his own land and founded a school of learning. He was the first Greek who studied astronomy, and although, like his countrymen, he believed that the earth was flat and floated on the water, yet he made several great discoveries.

The Greeks had always divided their year into two parts only, summer and winter, but Thales discovered that there are four distinct divisions marked out by the sun. $\mathrm{He}$ noticed that in the middle of winter the sun, instead of passing overhead, reached at mid-day only a certain low point in the heavens, and then began to set again, so that 
the day was short and the night long. This went on for a few days, and because the sun stood at the same height every day, the name of winter sol-stice, or sun-standing, was given to these days in the middle of winter. Afterwards the sun began to rise a very little higher every day, till in three months, when winter had passed away and the plants and trees began to bud, the sun took exactly twelve hours to pass across the sky from sunrise to sunset, so then the day was twelve hours long, and the night also twelve hours; this was called the spring equi-nox, or equal night, meaning that the day and night were of equal length. After this the sun still rose higher every day, and in three months more stood for some days nearly overhead at mid-day, thus making a long journey from sunrise to sunset, and causing the day to be long and the night short. This was the summer solstice. Then the sun began to rise less high every day, and in another three months there was again equal day and equal night-the autumn equino.x had arrived. Finally, in another three months, the shortest day arrived again, and the whole round began afresh. This was how Thales marked out the solstices and the equinoxes; we still call them by the same name as he did, and you may watch these changes of the sun in the sky for yourself.

Thales knew that the sun and stars were not gods, and thought they were made of some fiery substance; he knew also that the moon receives its light from the sun and reflects it like a looking-glass. He was very learned in mathematics, and invented several problems now found in the 'Elements of Euclid.' He is also said to have foretold an eclipse, but this is probably not true, as it requires more knowledge than he is likely to have had.

Anaximander of Miletus, 610 B.c., the friend of Thales, 
was the next Greek who made some important discoveries in science. He invented a sun-dial, by making a flat metal plate with the hours of the day marked upon it in a certain order, so that a large pin, or style as it is called, standing in the middle of the plate, cast a shadow on the right hour whenever the sun shone upon it. You can understand that as the sun is low down in the morning and gradually passes overhead during the day, it will cause the pin to throw its shadow in a different direction at different hours.

In this way Anaximander taught the Greeks to measure the time of day. He is also said to have been the first astronomer who understood why we see the bright face of the moon growing from a crescent to a full moon and then diminishing again. To know this he must also have known that the moon moves round the earth every month. You can imitate the changes of the moon if you take a round stone and hold it just above your head between you and the sun; you will then have its shady side towards you; pass it slowly round your head, you will find that you see first a bright edge appearing, then more and more of the bright side, till when the stone is on one side of your head and the sun the other, you will see the whole of one side of the stone reflecting the sun's light-this is a full moon. Pass it on slowly round, and you will see this bright side disappear gradually till you bring it back to its old position between you and the sun, when it will be again dark. This is what the moon does every month, producing what are called the phases of the moon. Anaximander also made a map of the world, or at least of as much of it as was known in his time.

Pythagoras, one of the most celebrated of the learned men of Greece, is the next who tells us anything about science. The time and place of his birth is uncertain, but he lived 
somewhere between 566 and 470 B.c. He travelled in Egypt, and learnt much there, and afterwards settled at Tarentum, in Italy, where he founded a famous sect called the Pythagoreans. You will read of the opinions of Pythagoras in books of philosophy, but we are only concerned with what he taught about nature.

He was the first to assert that the earth was not fixed, but moved in the heavens, but he did not know that it moves round the sun. He also discovered that the evening and morning star are the same planet; he called this planet Eosphorus, for it did not receive the name of Venus till some time afterwards.

Some of the most remarkable truths taught by Pythagoras were about geology, or the study of the earth. He noticed that seashells were sometimes to be found far inland imbedded in solid ground in a way that showed they were not brought there by man. Therefore, he argued that to bury sea-shells in the rocks, the sea must once have been there. He had also probably watched the sea eating away the cliffs on the shores of Italy, as you may see it doing now on the shores of Norfolk and Suffolk; and when he was in Egypt he must have seen the Nile carrying mud and laying it down at its mouth, or delta, to form new land. From all these and other observations he, and his pupils who followed him, drew some very true conclusions which are given in Ovid's 'Metamorphoses' :-

I. Solid land has been converted into sea.

2. Sea has been changed into land. .Marine shells lie far distant from the deep.

3. Valleys have been excavated by running water, and floods have washed down hills into the sea.

4. Islands have been joined to the mainland by the 
growth of deltas and new deposits, as in the case of Antissa joined to Lesbos, Pharos to Egypt, \&c.

5. Peninsulas have been divided from the mainland and have become islands, as Leucadia ; and according to tradition Sicily, the sea having carried away the isthmus.

6. Land has been submerged by earthquakes; the Gre. cian cities of Helice and Buris, for example, are to be seen under the sea, with their walls inclined.

7. There are streams which have a petrifying power, and convert the substances which they touch into marble.

8. Volcanic vents shift their position; there was a time when Etna was not a burning mountain, and the time will come when it will cease to burn.

These, and other sentences of the same kind, show how carefully Pythagoras and his followers must have observed nature, for the changes that are going on upon the earth take place so very slowly that it is only by very careful comparison that we can prove they are happening at all. Pythagoras was the first man who was called a philosopher, or lover of wisdom. He made many discoveries about musical notes, and succeeded in stretching strings so that when struck they gave the right notes of the octave in succession. 


\section{CHAPTER II.}

499 то 322 в.с.

Anaxagoras studies the Moon-Describes Eclipses of the Sun and Moon-Is Tried and Condemned for Denying that the Sun is a God-Hippocrates the Father of Medicine-Separates the Office of Priest and Doctor--Studies the Human Body-Eudoxus has an Observatory-Makes a Map of the Stars-Explains the Movements of the Planets-Democritus Studies the Milky Way-Aristotle an Astronomer and Zoologist-Divides Animals into Classes-Teaches that there is a Gradual Succession of Animal Life-Studies the Difference of the Life in Plants and Animals.

Anaxagoras, who was the next great teacher after Pythagoras, was born in Ionia about 499 B.C., but he went when quite young to Athens. He loved to study nature for its own sake, and was once heard to say that he was born to contemplate the sun, moon, and heavens. Although there were no telescopes in those days, he managed to observe that there were mountains, plains, and valleys in the moon. $\mathrm{He}$ believed it to be a second earth, perhaps with living beings in it. He did not know, as we do now, that the moon has no atmosphere round it, such as living beings like ourselves require in order to breathe. He discovered that an eclipse of the sun is caused by the moon coming directly between the earth and the sun, and an eclipse of the moon by the earth coming between the moon and the sun. When the moon comes exactly between our earth and the sun, we see the moon's dark body pass over the sun, so as to 
eclipse or shut it out; and when our earth comes exactly between the moon and the sun we cut off the sun's light from the moon, and see our own shadow passing over the moon's face, and thus we eclipse the moon.

Anaxagoras knew that the planets Jupiter, Saturn, Venus, Mars, and Mercury move in the heavens, and that the stars do not move. He believed that all the heavenly bodies were fiery stones; the sun he thought was a huge fiery stone as big as the Peloponnesus. He was the first scientific man who was persecuted for declaring boldly what he believed to be the truth. The Greeks were very angry with him for teaching that the sun was not a god; so he was tried at Athens, when quite an old man, and condemned to death. His friend Pericles pleaded for him, and the sentence was changed to a fine and banishment, and he retired to Lampsacus, where he went on teaching science and philosophy till his death.

Anaxagoras was the first Greek philosopher who taught that there must be one Great Intelligence ruling over the universe. So that the Greeks punished as an atheist the man who first taught them of a Supreme God. This example should teach us to be very careful how we condemn the opinions of others, for fear that we, like the Greeks, should think another wicked only because his thoughts are nobler than we can understand.

Hippocrates, 420.-While Anaxagoras was studying the heavens, another man, born about 420 B.C. in the little island of Cos, was studying men, and how to make their lives healthier and happier. Hippocrates, the Father of Medicine, belonged to a family of doctors and priests. The Greeks did not understand that illness comes to us because we do not know how to take care of our bodies. 
They thought that every illness was a punishment sent because one of their gods was angry, so when they were ill they sent a present to the temple of Esculapius, the god of medicine, and then went to the priests of Æsculapius to cure them. The ancestors of Hippocrates were all priests of Esculapius, but he separated himself from the priesthood and devoted his time to studying the human body, and finding out the causes of disease. He studied the effect that heat and cold have upon us, and taught physicians to pay attention to the kind of food given to sick people, and especially to watch carefully in sickness for the critical point when the fever is at its height. He wrote many learned works on the human body, and you should remember his name as the Founder of the science of Medicine.

Eudoxus, 406-Democritus, 459.-The next great astronomer after Anaxagoras was called Eudoxus. He was born about 406 B.C., at Cnidos, in Asia Minor, where he had an observatory, from which he could watch the heavens, and by this means he made a map of all the stars then known. He was the first Greek astronomer who explained how the planets Jupiter, \&c., moved round in the heavens, and the time at which they would appear again exactly in the same place as before. The great philosopher Democritus, of Abdera (459 B.c.), who lived about the same time as Eudoxus, made the remarkable guess that the beautiful bright band called the 'Milky Way,' which stretches every evening right across the sky, is composed of millions of stars scattered like dust over the heavens.

Aristotle, 384, one of the most famous philosophers of Greece, was also a great student of nature. He was born at Stagira, in Thrace, $3^{8}+$ B.C., but studied at Athens under Plato, and afterwards became the tutor of Alexander the 
Great. Aristotle did much for astronomy, by collecting and comparing the discoveries of the astronomers who came before him. He is the first of the Greek writers who states very decidedly that the earth must be a round globe, and he discovered an eclipse, or occultation as it is termed by astronomers, of the planet Mars by the moon.

But the best scientific work of Aristotle was his study of animals. He persuaded Alexander the Great, who governed Greece at that time, to employ several thousand people to collect specinens of animals in all parts of Europe and Asia and to send them to Athens. Here Aristotle examined them and arranged them under different classes according to their organs, or different parts of their body, and the manner in which they used them. Many of Aristotle's divisions of the animal kingdom are still in use, and he may fairly be called the Founder of Zoology. He pointed out that we can trace an unbroken chain from the lowest plant up to the highest animal, each group being only divided from the next by very slight differences; nor can we tell, he said, where plants end and animals begin, for there are some forms which are so like both plants and animals that we cannot decide in which division to place them.

$\mathrm{He}$ also pointed out that the life in plants is much lower than in animals, for if you cut a plant into pieces, each piece will grow, showing that the parts of a plant are simple and do not depend very closely upon each other. But an animal, and especially one of the higher animals, is a most complicated piece of machinery. If you hurt or destroy any of the most important parts the whole body dies, and if you cut off any part whatever, that part dies as soon as it is separated from the rest. These and many other very interesting facts about animals are to be found in Aristotle's great 
work on Natural History, which, however, you must remember, was only one out of many great works written by him on subjects which do not concern us here.

Theophrastus, 371.-Among the pupils of Aristotle was a man named Theophrastus, who was born at Eresus; 37 I B.C. Theophrastus devoted himself chiefly to the study of plants, and is the first botanist whose name has been handed down to us. The Greeks understood very little about plants except those which they used for medicine; but Theophrastus described about 500 different kinds of plants, and divided them into trees, herbs, and shrubs. We know, however, very little about his writings. 


\section{CHAPTER III.}

\section{0 to 212 B.C.}

School of Science at Alexandria-The Ecliptic and the Zodiac-Greeks believed that the Sun moved round the Earth-Aristarchus knew that it was the Earth which moved-He also knew of the Obliquity of the Ecliptic, and that the Seasons are caused by it-He knew that the Earth turns daily on its Axis-Euclid discovers that Light travels in straight lines-Archimedes discovers the LeverPrinciple of the Lever-Hiero's Crown, and how Archimedes discovered the principle of Specific Gravity.

While Aristotle was studying science at Athens, the Greeks under Alexander the Great were making great conquests in Egypt, where Alexander founded a city bearing his own name on the shores of the Mediterranean. After Alexander's death this city, called Alexandria, fell to the portion of Ptolemy Lagus, one of Alexander's generals, who was succeeded by a number of princes of the same name. The Ptolemies were all patrons of learning and science, and the school of Alexandria became one of the most famous the world has ever known. By this time the Greeks had learnt many astronomical facts, some of them probably from the Egyptians. They had traced the ecliptic, or the sun's apparent yearly path through the heavens, and, dividing this path into twelve parts, they called each division by the name of a constellation or cluster of stars. These constellations received most of them the names of animals, and therefore the circle of the twelve constellations was called the Zodiac, 
or circle of animals. The names of the twelve signs are: I. Aries, the Ram; 2. Taurus, the Bull ; 3. Gemini, the Twins ; 4. Cancer, the Crab ; 5. Leo, the Lion; 6. Virgo, the Virgin ; 7. Libra, the Balance ; 8. Scorpio, the Scorpion; 9. Sagittarius, the Archer; I0. Capricormus, the Goat; II. Aquarius, the Water-bearer ; 12. Pisces, the Fishes.

It was by no means an easy thing to trace the sun's path among the stars, because the sun and the stars are never in sight at the same time, so they were obliged to notice the constellations as they appeared close to the sun after he sank at night or before he rose in the morning. These, they found, varied a little each night, till when a whole year had passed away, all the twelve signs had been in turn close to the sun, and the round began again. Thus they learnt that the sun passed over each of the twelve signs in the course of the year; and they thought from this that the sun travelled round the sky while the earth stood still in the middle. We know now that it is the sun which stands still in the middle while the earth moves round, and it is worth while to make an experiment to see how the Greeks were deceived.

Put twelve chairs round in a circle to represent the signs of the Zodiac, and put yourself in the middle for a person standing on the earth. Then swing a ball round you just on a level with the chairs. You will see that the ball passes between you and each chair as it makes a circle round you. The Greeks believed that the sun moved round in this way between us and the stars. But now to represent what really takes place, change places with the ball. Hang the ball (the sun) up in the middle just on a level with the chairs, and walk round it. Keep your eye fixed on the ball, and you will see it will pass between you and each chair, just as it did before. The effect is the same, though it is 
you who are moving this time and not the ball. Thus the Greeks made the same mistake which a child does in a railway train when he thinks the houses and trees are flying past, while it is he himself who is moving.

Aristarchus.-There was, however, one Greek astronomer named Aristarchus, who discovered the real movement as we know it now. Aristarchus was born in Samos, some time in the third century before Christ, but he came to Alexandria, and was tutor to the sons of one of the Ptolemies. He taught that the sun was immovable like the fixed stars, and that it was the earth which travelled round the ecliptic. He knew also that our earth does not stand quite upright in its journey round the sun, but that a line drawn through the earth from the north to the south pole would be sloping or oblique to the ecliptic, and that this obliquity is the cause of our four seasons.

If you do not understand this you can work it out with your ball, using a lamp to represent the sun. First draw an ink-line round the middle of your ball for the equator, then put your finger and thumb at the two ends of the ball to represent the two poles. Do not hold the ball upright, but bring your thumb nearer to you than your finger. A line drawn through the ball from your finger to your thumb will now be inclined, and will represent the inclined axis of the earth. Now look at the light and shade on the ball : the north pole, which is turned towards the lamp, will be in full light, and will have the long days of summer; the south pole turned towards you will be in the dark, enduring its long winter night. Pass the ball on to your right, and when you have gone round a quarter of a circle the poles will both have equal light, and the southern spring and northern autumn have arrived. Pass on again, and at the next quarter 
the south pole will be in summer and the north pole in winter, while at the fourth and last point you have the northern spring and the southern autumn. This was what Aristarchus discovered, namely, that the changing seasons are entirely caused by the earth having its axis (or the line from pole to pole) oblique to its path round the sun, called the ecliptic. This is called the obliquity of the ecliptic.

Aristarchus appears also to have been the first Greek who understood that day and night were caused by the earth turning round on its axis every day. If the Greeks had understood his teaching, especially about the earth moving round the sun, they would have made much more progress in astronomy. But no one believed him, and more than I 700 years passed away before Copernicus, of whom you will read in chapter ix., discovered this great truth over again. This Greek theory of the earth moving round the sun is often called the Pythagorean system, for it was thought that Pythagoras taught it; but we have seen that, though Pythagoras knew that the earth moves, he did not believe that it went round the sun.

Euclid, 300. We must not pass through the third century before Christ without mentioning Euclid, the great mathematician and geometer, who collected together the problems in the 'Elements of Euclid,' known to every schoolboy. He was born at Alexandria about 300 B.C. His works are too difficult for us to examine, and the only discovery of his we can mention is, that light travels in straight lines called 'rays.' Thus, if you look at a sunbeam shining across a dusty room, you can see the light reflected in a straight line along the particles of dust, and if you let sunlight through a hole in the shutter into a dark room, it will light up a spot on the wall or floor exactly opposite to 
the sun-the middle of the sun, the middle of the hole in the shutter, and the middle of the spot of light, will all be in a straight line.

Archimedes, 287.-Another famous geometer, Archimedes of Syracuse, born 287 B.c., lived about the same time as Euclid. He studied for many years at Alexandria, but afterwards returned to his native country. One of the greatest discoveries made by Archimedes was that of a lever. If you place a book upright on the table and lay a ruler or any flat piece of wood or metal across it, you will find there is one point at which the ruler will balance. When you have balanced it, put an ounce weight on each end and it will still balance at the same point, which is called the fulcrum. But now change the ounce at one end for a weight of two ounces; that end will sink at once, and to make it balance you will have to shift the ruler and make the light end twice as long, because the heavy end has treice the weight upon it. Put a three ounce, and you must again lengthen the light end to three times the length of the heavy one. You may go on doing this till the heavy end is quite close to the fulcrum or resting-point of the ruler, and still the light weight will balance the heavy one.

This is the principle of the lever, and it is of great use in lifting weights. A heavy block of stone which no set of men could lift by taking hold of it may be easily raised by fastening it to the short end of a lever, and then the weight of the men at the end of the long arm will balance it, as the one-ounce weight balances the four-ounce. Archimedes was so delighted when he made this discovery that he is said to have exclaimed: 'Give me a place on which to stand, and I will raise the world.'

Another remarkable discovery made by Archimedes con- 
cerns the weight of bodies immersed in water. Hiero, king of Syracuse, had given a lump of gold to be made into a crown, and when it came back he suspected that the workmen had kept back some of the gold and had made up the weight by adding more than the right quantity of silver; but he had no means of proving this, because they had made it weigh as much as if it had been pure gold. Archimedes, puzzling over this problem, went to his bath, which was filled to the brim with water. As he stepped in he saw the water, which his body displaced, pouring over the edge of the bath, and to the astonishment of his servants he sprang out of the water and ran home through the streets of Syracuse alinost naked, crying Eureka ! Eureka! ('I have found it, I have found it.')

What had he found? He had discovered that any solid body put into a vessel of water displaces its own bulk of water, and therefore, if the sides of the vessel are high enough to prevent it running over, the water will rise to a certain height. He now got one ball of gold and another of silver, each weighing exactly the same as the crown. Of course the balls were not the same size, because silver is lighter than gold, and so it takes more of it to make the same weight. He first put the gold ball into a basin of water, and marked on the side of the vessel the height to which the water rose. Next, taking out the gold, he put in the silver ball, which, though it weighed the same, yet, being larger, made the water rise higher; and this height he also marked. Lastly, he took out the silver ball and put in the crown. Now, if the crown had been pure gold, the water would have risen only up to the mark of the gold ball, but it rose higher and stood between the gold and silver mark, showing that silver had been mixed with it, making it more bulky. This was the first attempt to measure the specific 
gravity of different substances, that is, the weight of any particular substance compared to an equal bulk of water.

It will be quite sufficient if you remember the experiment as I have explained it; but as you may perhaps be puzzled to see how it can have anything to do with weight, you can, if you wish, try to master the following explanation of Fig. I,

F1G. ז.

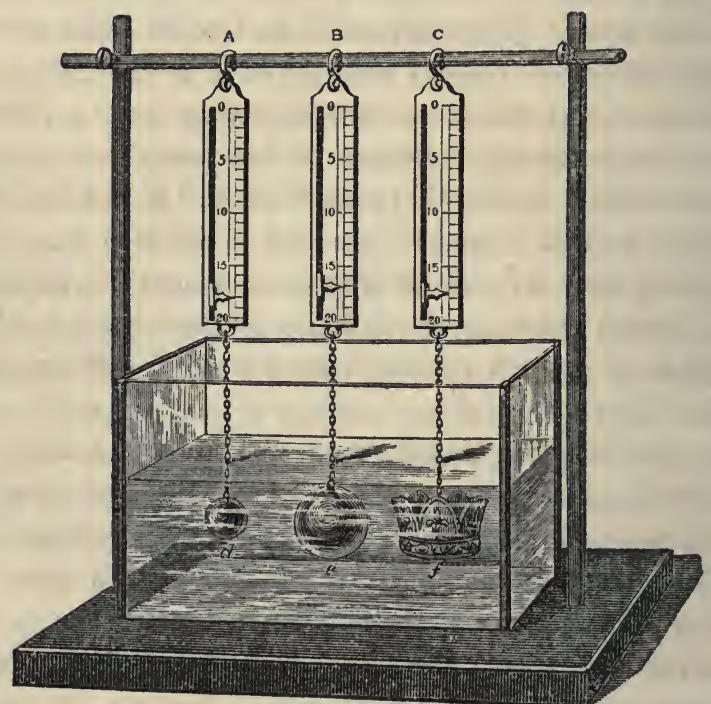

Diagram showing the difference of specific gravity between equal weights of gold, silver, and mixed metal.

A B c, Spring balances. $d$, Gold ball weighing $\mathrm{r}_{9} \mathrm{oz}$. e, Silver ball weighing $\mathrm{ig} \mathrm{oz}$, $f$, Crown of mixed metal weighing $19 \mathrm{oz}$.

which shows how specific gravity is measured. You must begin by remembering that the crown, the gold ball, and the silver ball, when weighed in the air, will all pull the marker of the spring balances A, B, C, down to 19 ; that is, they will all weigh 19 ounces. But when they are immersed in water they 
will no longer weigh the same, because the water round them buoys them up just as much as it would buoy up the quantity of water which they displace.

Now, the gold ball takes the place of as much water as would weigh one ounce if you could take it out and weigh it in the air. So the gold ball is buoyed up one ounce by the water round it, and accordingly you see it only pulls the marker down 18 ounces instead of 19 . But the silver ball, although it weighs the same, is larger, and takes the place of nearly two ounces of water, therefore it is buoyed up nearly two ounces, and only pulls the marker down to $\mathrm{r} 7$. Now, as the crown weighs the same as the two balls, its shape is of no consequence ; if it was made all of gold it would take as much room, and be buoyed up as much as the gold ball. If it was all silver it would be buoyed up as much as the silver ball, and therefore, as it pulls the marker down half-way between 17 and 18 ounces, it must be half gold and half silver.

In this way Archimedes showed how we can learn the weight of any substance compared to an equal bulk of water, and this is called the 'specific gravity' of the substance.

$\mathrm{He}$ also invented a screw for pumping up water, which is still called the 'screw of Archimedes.'

Archimedes was unfortunately killed in the city of Syracuse when it was besieged by the Romans during the second Punic war. The General Mæcenas had given special orders that his life should be spared; but he was so deeply engaged in solving a problem that he heard nothing of the din of war around him, and a common soldier not being able to get any answer from him, killed him without knowing who he was. 


\section{CHAPTER IV. \\ 280 TO I 20 B.C.}

Erasistratus and Herophilus study the Human Body-Eratosthenes the Geographer lays down the First Parallel of Latitude, and the First Meridian of Longitude- $\mathrm{He}$ measures the Circumference of the Earth-Hipparchus writes on Astronomy-Catalogues I,080 Stars -Calculates when Eclipses will take place-Discovers the Precession of the Equinoxes.

Erasistratus and Herophilus.-At the time when Archimedes was studying in Alexandria, two physicians were teaching there, who are famous in the history of anatomy, or the structure of the body. The one was Erasistratus and the other Herophilus. The birthplaces and dates of these two physicians are doubtful, but we know that they were the first men who dissected the human body, and gave a clear account of its parts. Erasistratus, in particular, described the brain and its curious windings or convolutions, and the division between the cerebrum or front part and the cerebellum or hinder and lower part. He seems also to have known that it is in our brain that we feel everything, and that it is the nerves which carry messages from different parts of our body to our brain. Herophilus traced out the tendons or strong cords which fasten the muscles to the bones, the ligaments or fibrous cords which unite one bone to another; and the nerves. $\mathrm{He}$ is the first physician who pointed out that in feeling a pulse you must notice three 
things : Ist, how strongly it throbs ; 2nd, how quickly ; 3rd, whether the beats are regular or irregular. Many of the names which Erasistratus and Herophilus gave to parts of the body are still used by anatomists, and the school of medicine founded by them in Alexandria was renowned for more than six hundred years.

Eratosthenes, 276.-We must now turn to the science of geography, which at this time began first really to be studied by a Greek named Eratosthenes, born at Cyrene 276 B.C. Like all men of science of that day, he too came to Alexandria, where the king, Ptolemy Evergetes, made him keeper of the Royal Library. He made a map of all the world that was then known, and described the countries of Europe, Asia, and Libya. But his two great works were, laying down the first parallel of latitude, and trying to measure the circumference of the earth. He laid down the parallel of latitude in the following manner. $\mathrm{He}$ knew that at all places on the equator the day was exactly the same length all the year round, and that the length of the days and nights varied more and more as you went northwards; therefore he reasoned that, if he could draw a line east and west through a number of places whose longest day was exactly the same length, those places would all be at the same distance from the equator. He began at the Straits of Gibraltar, where the longest day was exactly $14 \frac{1}{2}$ hours, and then observing all those places whose longest day was also I $4 \frac{1}{2}$ hours, he drew a line through the south coast of Sicily, across the south of the Peloponnesus, the island of Rhodes, the bay of Issus, and across the Euphrates and Tigris, out to the mountains of India. If you follow this line on a map you will find it is the 36 th parallel of north latitude, and that Eratosthenes' observation was perfectly correct. 
This discovery led him on to try and measure the circumference of the earth. Having found a line straight round the earth from east to west, he knew that if he drew a line at right angles to it, that is exactly north and south, he should have a line which would describe a circle round the earth from pole to pole, as the equator marks a circle round the earth midway between the two poles. This second line he drew from Alexandria, and it passed right through Syene, now called Assouan, one of the southern cities of Egypt, and thus he knew that Alexandria and Syene were on the same meridian of longitude.

Now he found that at Syene the sun was exactly overhead at midday, at the time of the summer solstice. He knew this by means of a gnomon, or upright pillar (B, Fig. 2), which was used by the Greeks to measure the height of the sun in the sky. At Syene this pillar cast no shadow at noon of the summer solstice, proving that the sun shone straight down upon the top of it; and this was further proved by the sun shining down to the bottom of a deep well, which it would not do unless it were directly overhead. But at Alexandria the gnomon did cast a shadow, because, as Alexandria was further north and the earth is round, the sun there was not directly overhead. Now, as light travels in straight lines (see p. 21), a line drawn from the extreme point of the shadow cast by the pillar or gnomon up to the top of the pillar itself would, if carried on, run straight into the sun, and thus the angle between this line and the pillar showed at what angle the sun's rays were falling at Alexandria. By measuring this angle, Eratosthenes found that Alexandria was $\frac{1}{50}$ th of the whole circumference of the earth north of Syene, where the rays were perpendicular. You can form an idea of this from the accompanying diagram, Fig. 2. 
Let the large circle represent the earth ; $\mathrm{B}$ the gnomon at Syene, and $\mathrm{A}$ the gnomon at Alexandria. The length of the shadow C D of the gnomon A, will bear the same proportion to the circumference of the small circle (drawn from the top of the gnomon as a centre), that the distance from Alexandria to Syene (D to E) does to the whole circumference of the globe. This is true only if the rays from the sun to Alexandria and to Syene are parallel (or run at equal distances). They are not really quite parallel because they meet in the sun, but Fratosthenes knew that the sun was at such an enormous distance that their approach to each other was quite unimpor-

FIG. 2 .

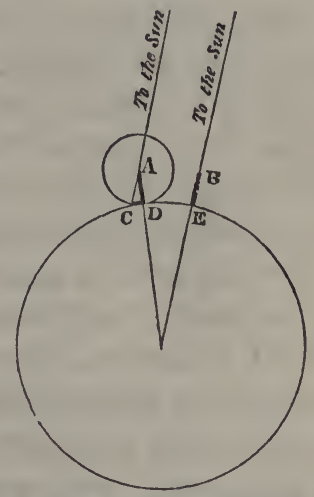

Diagram showing how Eratosthenes measured the circumference of the earth.

A, Gnomon at Alexandria. B, Gnomon at Syene. C D, Length of shadow of gnomon. D E, Distance from Alexandria to Syene. tant. He now measured the distance between Alexandria and Syene and found it to be 5,000 stadia, or about 625 miles, and multiplying this by 50 he got $625 \times 50=31,250$ miles as the whole circumference of the earth, measured round from pole to pole. This result is not quite correct, but as nearly as could be expected from a first rough attempt. Eratosthenes also studied the direction of mountain-chains, the way in which clouds carry rain, the shape of the continents, and many other geographical problems.

Hipparchus, 160.-Nearly one hundred years after Eratosthenes, the great astronomer Hipparchus was born, I60 B.c. Hipparchus was the most famous of all the astro- 
nomers who lived before the Christian era. He collected and examined all the discoveries made by the earlier observers, and made many new observations ; but astronomy had now become so complicated that the problems are too diffcult to be explained here. Hipparchus made a catalogue of r,080 stars, and showed how they are grouped with regard to the ecliptic. $\mathrm{He}$ also calculated accurately when eclipses of the sun or the moon would take place. But his great discovery was that called the 'Precession of the Equinoxes.' This is a very complicated movement which you can only understand by reading works on Astronomy ; but I will try to give a rough idea of it, in order that you may always connect it with the name of Hipparchus.

We have seen that the earth has two movements-one, turning on its own axis causing day and night; the other, travelling round the sun, causing the seasons of the year. But besides these it has a third curious movement, just like a spinning-top when it is going to fall. Look at a top a little while before it falls, and you will see that, because it is leaning sideways, the top of it makes a small circle in the air. Now our earth, because it is pulled at the equator by the sun, moon, and planets, makes just such a small circle in space ; so that, instead of the north pole pointing quite straight to the polar star, it makes a little circuit in the sky, with the polar star in the centre. The pole moves very slowly, taking twenty-one thousand years to go all round this circle. To understand the effect of this movement we must examine more closely what the equinoxes are. Take your ball again and make it go round the lamp with its axis inclined (see p. 20). When you have it in such a position that the north pole is in the dark, or the northern winter solstice, you will find that a straight line drawn from 
the sun to the centre of the earth will not meet the equator but a point to the south of it. But now pass the ball on to the next point when neither pole is in shade, and when it is equal day and equal night over the globe (our spring equinox), a line now drawn from the sun will fall directly upon the equator, so that the sun's path meets the equator at this point, which is called the equinoctial point. Pass on till the south pole of your ball is in the dark, the sun will now fall directly on a point north of the equator (making our summer solstice). Pass on again to the point of equal day and equal night, and the sun again falls direct on the equator, causing our autumn equinox. Now, if the earth did not make that small circle in space like the top, the sun would always touch the equator at exactly those same points of the earth's orbit or path round the sun; but the effect of that movement is to pull the equator slightly back, so that the points where the ecliptic and the equator cut each other are $50 \frac{3}{4}$ seconds more to the west every year, and in this way the equinoxes travel all round the orbit from east to west in 21,000 years. Hipparchus discovered this pre-cession (or going forward) of the equinoxes; though he did not know, what Newton afterwards discovered, that it is caused by the sun and moon pulling at the mass of extra matter which is gathered round the equator. 


\section{CHAPTER V.}

FROM A.D. 70 TO 200.

Ptolemy founds the Ptolemaic System-He writes on GeographyStrabo, a great traveller, writes on Geography-Studies Earthquakes and Volcanoes-Galen the greatest Physician of AntiquityDescribes the Two Sets of Nerves-Proves that Arteries contain Blood-Lays down a theory of Medicine-Greece and her Colonies conquered by Rome-Decay of Science in Greece-Concluding remarks on Greek Science.

Ptolemy, A.D. 70:-After Hipparchus there were many good astronomers at Alexandria, but none whom we need notice until the year 70 after Christ, when Ptolemy Claudius, a native of Egypt, was born. He was not one of the Ptolemies who governed Alexandria, and the place of his birth is unknown, but he is famous for having made a regular system of astronomy founded upon all that the Greeks had learnt about the heavens. His discoveries, like those of Hipparchus, are too complicated for us to discuss here ; they related chiefly to the movements of the moon and the planets; but the one great thing to be remembered of him is, that he founded what is called the Ptolemaic System of astronomy, which tries to explain all the movements of the sun, stars, and planets, by supposing the earth to stand still in the centre of them all. This system is contained in Ptolemy's great work called 'the Syntaxis.' It may seem strange that, as it is not true that the earth is the centre, Ptolemy should have been able to explain so much by his system, but you 
must remember that it had the same effect whether you moved round the ball, or the ball round you in our experiment on page 19 ; and Ptolemy's explanations were apparently so near the truth that astronomers were satisfied with them for I,400 years, till Copernicus discovered the real movements.

Ptolemy was a geographer as well as an astronomer; he wrote a book on geography which was used in all the schools of learning for nearly fourteen hundred years. $\mathrm{He}$ drew maps of all the known parts of the world, and laid down on them lines of latitude and longitude, which he calculated by the rules Eratosthenes had discovered. In his geography he describes the countries from the Canary Islands on the west to India and China on the east, and from Norway to the south of Egypt. He describes our island under the name of Albion, or Britain, and traces out many of the coastlines and rivers. $\mathrm{He}$ also gives the names of the various towns, with their latitude and longitude.

Strabo.-A little before the time of Ptolemy there lived a famous traveller named Strabo, who wrote a great deal on geography. He was born at Amasia, in Cappadocia, and was probably living when Christ was born. Strabo in his book describes the countries which he visited and read about. $\mathrm{He}$ also studied earthquakes and volcanoes, and pointed out that, when the hot vapour and lava hidden in the crust of our earth cannot escape, they cause earthquakes, but that when they find their way out through a volcano, like Etna, the country is not so often disturbed and shaken.

Galen, 131.-There is still one more great man of science whom we must mention as belonging to the Greek school at Alexandria. This was Galen, one of the most celebrated physicians of antiquity. He was born A.D. I3 I, at Pergamos, in Asia Minor, and during his life he is said to have 
written more than 500 valuable essays on medicine and the human body. You will remember that Erasistratus and Herophilus dissected the human body; but in the time of Galen this seems to have been forbidden, and he was obliged to work upon monkeys and other animals. Even from these, however, he learnt some very important facts. For instance, he discovered the difference between the two sets of nerves which we have in our body, called the nerves of sensation and the nerves of motion.

Our bodies are provided with two sets of fine cords or threads called nerves; one set running from different parts of the body to the spine and the brain, and the other set running back from the spine and brain to the body. If you touch a hot iron with your finger, the nerves of sensation, that is, of feeling, carry the message to your brain that the iron is hot, and then instantly the nerves of motion carry the message back from your brain to your finger, and you snatch it away. If you were to cut the nerves of your finger you would not feel pain nor draw your finger away. You will remember that Erasistratus had an idea that it is in our brain that we feel ; Galen proved this by many experiments, though he did not understand clearly the whole action of the nerves. He also proved that the veins of our body contain blood, and he described the two muscles which by their contraction pull down the lower jaw as we open and pull it up as we shut our mouths. Besides these and many other discoveries, Galen worked out a whole theory of medicine, and how doctors were to treat their patients, and his rules were the guide of physicians for many hundred years.

Concluding Remarks on Greek Science.-We have now come to an end of the science of the Greeks. You will 
read in Grecian history how Greece and the Greek colonies were conquered by the Romans more than a hundred years before Christ was born; and when the Greeks ceased to be a free people they gradually lost their love of discovery and of science. The school at Alexandria continued to be famous for many centuries after Christ, but the professors who taught there only repeated the sayings of Ptolemy, Aristotle, Galen, and the other great discoverers, and did not find out new facts for themselves; and at last, in the year 640 after Christ, the Arabs took possession of the city, and it soon ceased altogether to be Greek.

You must remember that in these five chapters we have only been able to speak of some of the greatest men, and then only of a few of the discoveries they made. You will hear of many celebrated Greek philosophers, as, for example, Socrates and Plato, whose names are not mentioned here because they wrote on subjects such as the mind and the soul, which belong to higher philosophy, and not to Natural Science. You will also hear of many strange and absurd notions about the causes of things which in those early days were held, even by such men as Pythagoras or Galen; but in this book we have only to try to understand the real facts which have been discovered; and there is no doubt that the Greeks, by a patient study of nature, and by making real and careful observations and experiments, laid the foundation of much of the knowledge which we have carried so much further in modern times. The moment they began merely to repeat the teachings of others, instead of trying and proving the truth of them, they made no more discoveries, but lost a great deal they had gained. For a mere reading of books will not teach science; and if you admire these men for making great discoveries, and would like to 
be a discoverer yourself, you must not be content with knowing what has been done, but must set to work as they did, and observe and make experiments for yourself.

Chief Works consulted.-Draper's 'Intellectual Development in Europe;' Lewis's 'Astronomy of the Ancients;' 'Encyclopædia Britannica,' art. 'Astronomy ;' Herschel's 'Astronomy ;' Baden Powell's 'History of Natural Philosophy;' Lardner's 'Cyclopædia,' 1834; Sprengel's 'Histoire de la Médecine,' 1815; Grant's 'History of Physical Astronomy ;' Lange's 'Geschichte des Materialismus ;' Rees's 'Encyclopædia ;' Whewell's 'History of Inductive Sciences.' 


\title{
PART II.
}

\section{SCIENCE OF THE}

\section{MIDDLE OR DARK AGES}

\author{
FROM A.D. 700 TO A.D. 1500
}


Chief Men of Science in the Middle Ages.

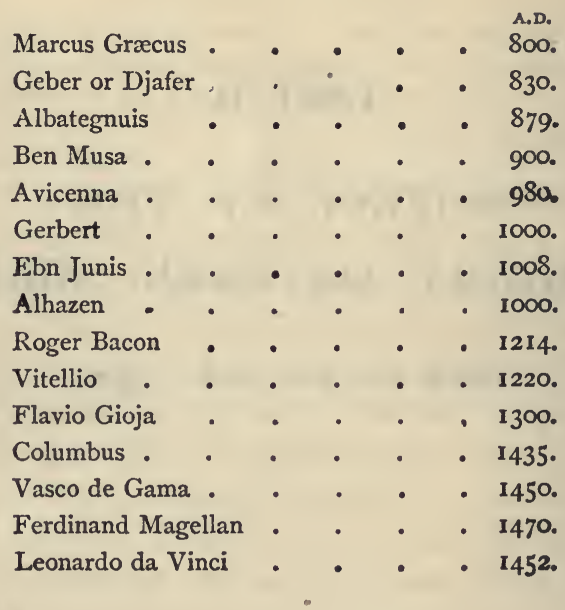




\section{CHAPTER VI.}

SCIENCE OF THE ARABS.

Dark Ages of Europe-Taking of Alexandria by the Araos and burning of the Library-The Arabs, checked in their conquests by Charles Martel, settle down to Science-The Nestorians and Jews translate Greek Works on Science-Universities of the Arabs-Chemistry first studied by the Arabs - Alchemy, or the attempt to make Gold - Hermes the first Alchemist - Hermetically-sealed TubesGases and Vapours called 'Spirits' by the Arabs-The use of this Word retained by us.

Arabian Science.-We have now arrived at what have been called the 'Dark Ages,' because for several hundred years Europe was too much engaged in wars and disputes to pay any attention to learning or science. You have, no doubt, read in history how the Goths and Vandals, a barbarous people from north-eastern Asia, spread themselves over Europe, conquering the Romans, and taking possession of all their colonies. They even crossed over into Africa, but were driven out again by the famous General Belisarius, in the reign of Justinian, Emperor of Constantinople. This was in the year A.D. 534, and the Romans held Alexandria again for about one hundred years, and then came the Arabs or Saracens, pouring out of Arabia, and they took possession of Alexandria in the year A.D. 639 , only seven years after the death of their great leader Mahomet.

The first thing they did on taking the city was to burn the famous library of Alexandria, and it seemed as if they 
were going to destroy the last remnant of the science of the Greeks. But it proved otherwise : they went on conquering and destroying till they had overrun all the north of Africa up to the Straits of Gibraltar, had taken a great part of Spain and even of the south of France as far as the river Aude, in Languedoc, and then when Charles Martel, mayor of the Franks, conquered them at Tours in 732, and stopped them from going any farther, they settled down and began to give their attention to science and learning.

They found in Arabia and in Egypt two classes of people who were able to teach them the science of the Greeks. These were the Nestorians and the Jews. The Nestorians, or followers of Nestorius, Bishop of Constantinople, were a peculiar sect of Christians, who had fled into Arabia about the year $45^{\circ}$, that they might found a Church of their own. They became very powerful and learned, and translated many of the Greek works of science into the Arabian language. The Jews, after the fall of Jerusalem, had also taken refuge in Syria and Mesopotamia, and they were very skilful in medicine, and founded many medical colleges. The Arabian schools of Bagdad, Cairo, Salerno in the south of Italy, and Cordova in Spain, soon became famous all over the world. The Arabs were not able to practise anatomy in their medical schools, because the Koran, that is the Mahommedan Bible, taught that it was not right to dissect the human body, so they turned their attention chiefly to medicine, trying to discover what substances they could extract from plants and minerals, at first to serve as medicines but soon for very different uses.

Arabian Alchemists.-They found something in the old Greek writings about the way to melt stones or minerals, so as to get out of them iron, mercury, and other metals ; and 
also how to extract many beautiful colours out of rocks and earths. But the chief thing which interested them in the books of the Egyptians, Chaldeans, and Greeks, was the attempts these nations had made to turn other metals into gold, a discovery which tradition said had been made by Hermes Trismegistus about 2,000 years before Christ. We know very little of this Hermes, and indeed we are not sure whether he is not altogether an imaginary person; but the alchemists, as the people were called who tried to make gold, considered themselves followers of Hermes, and often called themselves Hermetic philosophers. To melt the mouth of a glass tube so as to close it was called securing it with 'Hermes, his seal,' and even to this day a bottle or jar which is closed so that it is air-tight is said to be hermetically sealed.

The Arabs were a very superstitious people, and believed in all kinds of charms; and this idea of making gold in a mysterious way took a great hold of them. Many thousands of clever men occupied themselves in the supposed magic art of alchemy. We need not study it here, but only observe how very useful it was in teaching the first facts of chemistry. These men, who were many of them learned, clever, and patient, spent their lives in melting up different substances and watching what changes took place in them. In this way they learnt a great deal about the materials of which rocks, minerals, and other substances are made.

One of the first things they discovered was that by heating some substances, such as nitre or saltpetre, they drove something out of them which was invisible, and yet that they could collect this invisible something in bottles; and in some cases, if they put a light to it, it exploded violently, breaking the bottle to atoms. Now, because this was invisible and yet so powerful, they thought it must be 
like the spirit of man, which can do so much and yet cannot be seen, and for this reason they called it 'spirit.' We know now that when we heat substances we separate part of the matter of which they are made into very small portions, which float off as steam or gas into the air; so that this spirit noticed by the Arabs was vapour or gas.

It seems almost certain that the Arabs knew a great deal about gunpowder and some other mixtures which explode when they are set on fire. An Arab named Marcus Græcus, who lived about the beginning of the ninth century, says that if you mix together one pound of sulphùr, two of charcoal, and six of saltpetre, it will explode when you light it and drive things into the air. This is one of the ways in which gunpowder is still made. 


\section{CHAPTER VII.}

SCIENCE OF THE ARABS (CONTINUED).

Geber, or Djafer, the founder of Chemistry-His Explanation of Distillation-Of Sublimation-Discovers that some Metals increase in weight when heated-Discovers strong Acids-Nitric AcidSulphuric Acid-Discovery of Sal-Ammoniac by the Arabs-Arabs mix up Astronomy with Astrology-Albategnuis calculates the Length of the Year-Mohammed Ben Musa, first writer on Algebra -Uses the Indian Numerals-Gerbert introduces them into Europe -Alhazen's discoveries in Optics-His Explanation why only one image of each object reaches the Brain-His discovery of Refraction, and of its effect on the light of the Sun, Moon, and Stars-His discovery of the magnifying power of rounded glasses.

Geber's discoveries in Chemistry, 800-900.-The greatest of the Arabian alchemists was a man named Geber, or Djafer, who was born in Mesopotamia about A.D. 830 . He has been called the 'Founder of Chemistry,' for though, like his countrymen, he spent much of his time in trying to make gold, yet he is the first who, as far as we know, made really useful chemical experiments.

He explains in his works many of the methods we now use in chemistry. For example, he states that if you boil water, the vapour (or spirit as he calls it) will rise up, and you can collect it and cool it down again in another vessel ; and it will then be pure, because any solid matter such as sand or salt, which does not turn readily into vapour, will remain behind in the first vessel. Again, if you heat wine or 
brandy gently, a vapour called alcohol or spirits of wine will rise up, because the alcohol turns into vapour more easily than the other materials of the wine. If you collect and cool down this vapour in another bottle, you will have the liquid spirits-of-wine. This process is called distillation, and is used by chemists to separate substances which turn readily into vapour from others, which do not boil so easily. You can distil vapours from solid things as well as from liquids : if you heat sugar over a fire, it will soon boil, and a vapour will rise up from it.

But if you put a piece of camphor in a flask with a stopper to it, and heat it very gently either by placing it in the sun or at some distance above a lighted candle, the camphor will gradually disappear from the bottom of the flask, and collect in little crystals on the inside of the neck. This is because camphor at an ordinary heat changes straight into a dry invisible gas, without first becoming liquid as ice does. The process by which substances are turned directly from a solid state into a dry gas is called sublimation, and Gefer describes it in his book as 'the elevation of dry things by fire.' He knew that if you take a kind of stone called cinnabar, and heat it, a dry gas rises from it, which you can collect, and which cools down into drops of mercury or quicksilver.

Geber made another remarkable experiment, though he did not thoroughly understand it. He states in his book that if you take a certain weight, say a pound, of iron, lead, or copper, and heat it in an open vessel, the metal will weigh more after it has been heated than it did before, which seems very strange, as we cannot see that anything has been added to it. We shall learn the reason of this when we come to the discoveries of Priestley (chap. xxvii.); but Geber 
carefully noticed the fact, though he could not explain it. But the discovery which most of all gives Geber the right to be called the 'founder of chemistry' was that of strong acids. Most of the chemical experiments we make now would be impossible without acids, but before Geber's time vinegar seems to have been the strongest acid known. He found, however, that by heating copperas (or sulphate of iron) with saltpetre and alum, he could distil off a vapour which cooled down into a very strong acid, now called nitric acid. He used this to dissolve silver, and by mixing it with sal-ammoniac he found it would even dissolve gold. Sal-ammoniac was a kind of salt which was known to the Arabs before Geber's time. They made it by heating the dung of camels, and the name ammoniac was given to it because they made it first in the desert near the temple of Jupiter Ammon. Geber also made sulphuric acid by distilling alum. When we remember that all these experiments were made more than a thousand years ago, we must acknowledge that Geber deserves great honour for the discoveries which he made.

Albategnuis, 879.-We have seen that in chemistry the Arabs learned very little from the Greeks, but in mathematics and astronomy they found a great deal written, and the Arabian astronomers spent much of their time in translating Greek works. Unfortunately they mixed up astronomy, or the study of the heavenly bodies, with astrology, a kind of magic art, by which they imagined they could foretell what was going to happen by studying the stars. In spite of this, however, there were several very celebrated Arabian astronomers, one of whom, called Albategnuis, born A.D. 879, made a great many good observations. He calculated the length of the year more exactly than Ptolemy had done, 
making it 365 days, 5 hours, 46 minutes, 24 seconds, which was only two minutes shorter than it really is, and he corrected many more of Ptolemy's observations. After him the next famous Arabian astronomer was Ebn Junis, A.D. 1008, who drew up several valuable astronomical tables.

Ben Musa, 900.-Of mathematicians, one of the most celebrated was Mohammed Ben Musa, who lived about A.D. 900. He is the earliest Arabian writer on algebra, or the working of sums by means of letters. This name 'Algebra' is an Arabian word, and the Arabs were very clever at this way of making calculations. Ben Musa is the first writer we know of who used the Indian numerals $\mathrm{r}, 2,3,4,5,6,7,8,9$, o, instead of the clumsy Roman numerals I, II, III, IV, \&c. If you try to do a sum with the Roman numerals you will see what a troublesome business it is and what a great gain the Indian numerals are. The Arabs learned these numbers from the Hindoos, and always used them after the time of Ben Musa, so that they are now generally called the Arabic numerals. About the year 1000: a Frenchman named Gerbert, Archbishop of Rheims, and afterwards Pope Sylvester the Second, who had been educated at the famous Arabian University of Cordova in Spain, introduced them into Europe. The word cipher, which we use for o, comes from an Arabic word, ciphra, meaning empty or void.

Alhazen's discoveries in 0ptics, 1000.-Another Arabian whom we must specially mention was an astronomer and mathematician named Alhazen, who was born at Bassora, in Asiatic Turkey, about the year A.D. I000, but who spent most of his life in Spain. He made discoveries chiefly in optics, or the science of sight. He was the first to teach that 
we see things because rays of light from the objects around us strike upon the retina or thin membrane of our eye, and the impression is carried to our brain by a nerve. When the object is itself a light, like the flame of a candle, it gives out the rays which reach our eye ; but when, like a book or a chair, it is not luminous, then the rays of the sun or any other light-giving body are reflected from it to our eye and make a picture there. Alhazen also explained why we do not see two pictures of one object although we look at it with two eyes; he pointed out that, as the reflection of any given point of the object is formed on the same part of the one eye as of the other, only one united picture reaches the brain. This is the best explanation which has ever been given of why we only see one image, but even to this day we are not quite certain that it is satisfactory.

Alhazen discovered another wonderful thing about light. If you take a straight stick and hold it in a slanting direction in a basin of water so that half of it is under water, the stick will appear to bend at the point $\mathrm{A}$, where it touches the surface of the water, and instead of going along the dotted line to $\mathrm{B}$, will look as if it went FIG. 3. to the point $\mathrm{c}$. This is because rays of light are bent in a slanting or oblique direction when they pass through substances of different density. Water is more dense than air, and therefore the rays of light reflected from the stick are bent as they pass out of the water into the air on their way to your eye. This is called refraction, or the breaking-back of a ray, and the discovery of it led Alhazen to find the explanation of a very curious natural fact. 
He knew that the air round our globe grows denser as it gets nearer the earth, so he argued that the slanting rays from the sun, moon, and stars must become bent as they approach the earth and pass through the denser air. This, he said, causes us to see the sun after it has really sunk below our horizon at night, and before it rises in the morning; for the rays are gradually curved by passing through the denser air round our earth. Fig. 4 explains this.

FIG. 4.

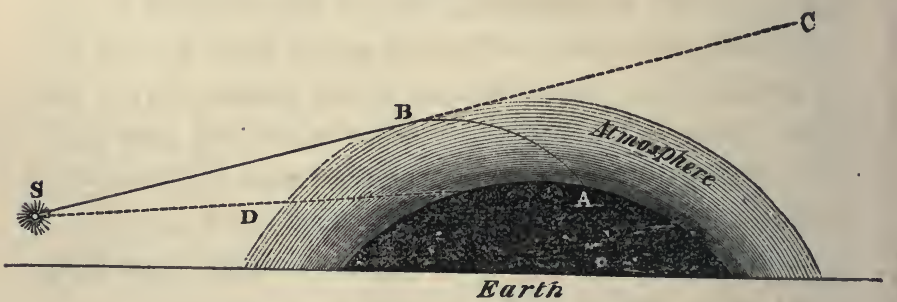

Rending of the Sun's rays by the atmosphere.

S, Sun. S C and S In, Rays as they would travel if there were no atmosphere. $S$ B A, Ray bent so that the sun becomes visible at $A$.

Supposing the sun to be at $\mathrm{S}$, and a person at A, it is clear that any straight ray from the sun, such as $S \mathrm{D}$, could not reach $A$, because part of the earth is in the way; neither could a ray, s c, reach the earth, because it would pass above it. But when the rays from $\mathrm{S}$ to $\mathrm{C}$ strike the atmosphere at $\mathrm{B}$, they are bent out of their course, and are gradually curved more and more by the denser air till they are brought down to the earth at $\mathrm{A}$, and so the sun becomes visible.

Alhazen was also the first to remark that a convex lens, that is, a glass with rounded surfaces, such as our common magnifying glasses and burning glasses, will make things appear larger if held at a proper distance between the eve 
and any object, because the two surfaces of the glass, becoming more and more oblique to each other as they approach the sides, bend the rays inwards, so that they come

FIG. 5.

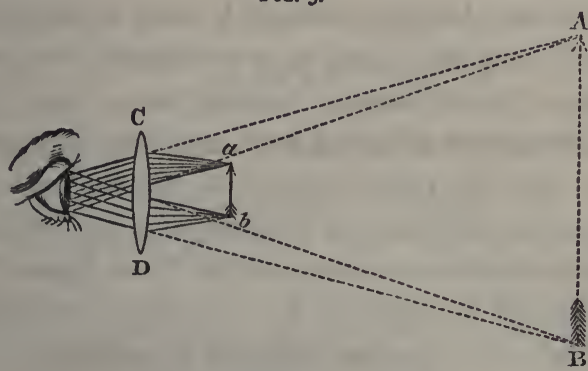

Arrow magnified by 3 convex lens.

to a focus in the eye. To understand this, draw a line of any kind, say a little arrow, on a sheet of paper, and bring your eye near to it. Your arrow being so close would look very large if you could see it distinctly, but just because it is so near, your eye cannot focus or collect together the rays coming from it so as to make a picture on the retina at the back of the eye; therefore you see nothing but an indistinct blur. But now take a magnifying glass, $\mathrm{C} \mathrm{D}$, fig. 5 , and hold it between your eye and the arrow. If you hold it at the right distance you will now see the arrow distinctly, because the greater part of the rays have been bent or refracted by the rounded glass so as to come into focus on your retina. But now comes another curious fact. It is a law of sight, that when rays of light enter our eye we follow them out in straight lines, however much they may have been bent in coming to the eye. So your arrow will not appear to you as if it were at $a b$, but, following out the dotted lines, you will see a magnified arrow, A B, at the 
distance at which you usually see small objects distinctly. This observation of Alhazen's about the bending inwards or converging of rays through rounded glasses was the first step towards spectacles.

Besides the Arabians whom I have mentioned here, there were many who were very celebrated, but we know very little of their works. Among them was Avicenna A.D. 980, whom you will often hear mentioned as a writer on minerals. But the chief thing to be remembered, besides the discoveries of Geber and Alhazen, and the introduction of the Indian numerals, is that in the Dark Ages, when all Europe seemed to care only for wars and idle disputes, it was the Arabs who kept the lamp of knowledge alight and patiently led the way to modern discoveries. 


\section{CHAPTER VIII.}

SCIENCE OF THE MIDDLE AGES (CONTINUED).

Kogrer Bacon-His 'Opus Majus'-His Explanation of the Rainbow He makes Gunpowder-Studies Gases-Proves a Candle will not burn without Air-His Description of a Telescope-Speaks of Ships going without Sails-Flavio Gioja invents the Mariner's Compass-Greeks knew of the Power of the Loadstone to attract Iron - Use of the Compass in discovering new lands - Invention of Printing-Columbus discovers America-Vasco de Gama sees the Stars of the Southern Hemisphere-Magellan's ship sails round the World-Inventions of Leonardo da Vinci.

WE must now return to Europe, where the nations were struggling out of the Dark Ages; and though there were many learned men in the monasteries, very few of them paid any attention to science: while those who did, often lost their time in alchemy, trying to make gold; or in astrology, pretending to foretell events by the stars.

Roger Bacon, 1214. - In the year I 2 I 4, however, a man was born in England whom every Englishman ought to admire and revere, because in those benighted times he gave up his whole life to the study of the works of nature, and suffered imprisonment in the cause of science. This was Roger Bacon, a great alchemist, who was born at Ilchester in Somersetshire, educated at Oxford and Paris, and then became a friar of the order of St. Francis. For this reason he is often called Friar Bacon. Bacon's great work, called the 'Opus Majus,' is written in such strange language that it 
is often difficult to find out how much he really knew and how much he only guessed at. We know, however, that he made many good astronomical observations, and that he explained the rainbow by saying that the sun's rays are refracted or bent back by the falling drops of rain, as was also noticed about the same time by Vitellio, a Polish philosopher.

Bacon is famous as the first man in Europe who made gunpowder ; we do not know whether he learnt the method from the Arabs, but it is most likely, for he gives the same receipt for making it as Marcus Græcus did-namely, saltpetre, charcoal, and sulphur. He also knew that there are different kinds of gas, or air as he calls it, and he tells us that one of these puts out a flame. He invented the favourite schoolboy's experiment of burning a candle under a bell-glass to prove that when the air is exhausted the candle goes out.

Bacon seems also to have known the theory of a telescope. We do not know whether he ever made one, but he certainly understood how valuable it would be. This is what he says about it in his 'Opus Majus,' or 'Great Work': 'We can place transparent bodies (that is, glasses) in such a form and position between our eyes and other objects that the rays shall be refracted and bent towards any place we please, so that we shall see the object near at hand, or at a distance, under any angle we please ; and thus from an incredible distance we may read the smallest letter, and may number the smallest particles of sand, by reason of the greatness of the angle under which they appear.' This is at least a very fair description of a telescope. In the same book he says that one day ships will go on the water without sails, and carriages run on the roads without horses, and that 
people will make machines to fly in the air. This shows that he must have imagined many things which were not really discovered till more than 300 years afterwards; but they were all dreams which he could not carry out himself. Before we leave Roger Bacon I must warn you not to confuse him. with Francis Bacon, Chancellor of England, who was quite a different man, and lived more than 200 years later.

\section{Flavio Gioja discovers the Mariner's Compass, 1300.-} About ten years after the death of Bacon, a man was born in a little village called Amalfi, near Naples, who made a discovery of great value. The man's name was Flavio Gioja, and the discovery was that of the mariner's compass. Long before Flavio's time people knew that there was a kind of stone to be found in the earth which attracted iron. There is an old story that this stone was first discovered by a shepherd, who, while resting, laid down his iron shepherd's crook by his side on a hill, and when he tried to lift it again it stuck to the rock. Although this story is probably only a legend, yet it is certain that the Greeks and most of the ancient nations knew that the loadstone attracted iron; and a piece of loadstone is called a magnet, from the Greek word magnes, because it was supposed to have been first found at Magnesia, in Ionia.

A piece of iron rubbed on a loadstone becomes itself a magnet, and will attract other pieces of iron. But Flavio Gioja discovered a new peculiarity in a piece of magnetised iron, which led to his making the mariner's compass. He found that if a needle or piece of iron which has been magnetised is hung by its middle from a piece of light string, it will always turn so that one end points to the north and the other to the south. He therefore took a 
piece of round card, and marking it with north, south, east, and west, he fastened a magnetised needle upon it pointing

Fig. 6.

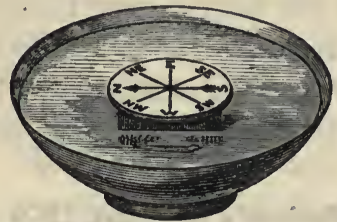

Flavio's Compass floating on water. from $\mathrm{N}$. to $\mathrm{S}$; , he then fastened the card on a piece of cork and floated it.in a basin of water. Whichever way he turned the basin the needle turned the card round till the N. of the needle pointed to the north, and the $s$. to the south, and from the other marks on the card he could then tell the direction of the west, north-west, \&c.

You will see at once how important this discovery was ; for when a ship is at sea, far from land, there is nothing to guide the captain except the stars, and they cannot always be seen, so that before he had a compass he was obliged to keep in sight of land in order to find his way. But as soon as he had an instrument which pointed out to him which way his ship was going, he could steer boldly and safely right across the sea.

There has been much dispute as to who first discovered the compass, and some people think that the Chinese used it in very early times; but learned men now agree that Gioja discovered it independently, and it is certain that he was the first to use it in a ship. Of course it would have been very inconvenient to have it always floating in a basin of water; so the card was fitted, by means of a little cap, on to the top of a pin, round which it could turn easily, and this is the way it is still made. As the king of Naples belonged at that time to the royal family of France, Gioja marked the north point of the needle with a fleur-de-lys in his honour, and the mariner's compass of all nations still bears this mark. The 
territory of Principiato, where Gioja was born, has also a compass for its arms, in memory of his discovery.

Invention of Printing, 1438.-Before we go on to speak of the wonderful voyages which followed the invention of the compass, we must pause a moment to notice another great change which took place about a hundred years after the time of Bacon and Gioja. This was the invention of printing, in the year 1438 . In the early part of the fifteenth century some people began to engrave, that is, to cut on wood, pictures and texts of Scripture, and then to rub them over with ink, and take an impression of them on paper. One day it occurred to a man named John Gutenberg, of Strasburg, that if the letters of a text could be made each one separate, they might be used over and over again. $\mathrm{He}$ began to try to make such letters, and with the help of John Faust of Mayence, and Peter Schoeffer of Gernsheim, both of them working mechanics like himself, he succeeded in making metal letters, or types as they are called. These men finished printing the first Bible in the year 1455 . In 1465 the first printing-press was started in Italy, and another in Paris in 1469 , while Caxton introduced printing into England in 1474 .

It is easy to see what a great step this invention was towards new knowledge. So long as people were obliged to write out copies of every work, new books could only spread very slowly, and old books were very dear and rare; but as soon as hundreds of copies could be printed off and sold in one year, the works of the Greeks on science were collected and published by clever men, and were much more read than before; and what was still more important, books about new discoveries passed quickly from one country to another, and those who were studying new truths were able 
to learn what other scientific men were also doing. Thus printing was one of the first steps out of the ignorance of the Dark Ages.

Voyages round the World.-The next step, as I said just now, was made by the use of the mariner's compass. The Greeks, as you will remember, knew that the earth was a globe, but all this had been forgotten in Europe since the Goths and Vandals came in, and people actually went back to the old idea that the world was flat like a dinner-plate, with the heavens in an arch overhead. Nevertheless, the sailors, who saw ships dip down and disappear gradually as they sailed over the sea, could not help suspecting that it must be a round globe after all ; and Christopher Columbus, a native of Genoa, was convinced he could find a way round to the East Indies by sailing to the west across the Atlantic. Full of this idea, he started on August 3, I492, with three small ships and ninety men, from Palos, near Cadiz, in Spain, and sailed first to the Canary Islands. From there he sailed on for three weeks, guided by his compass, but without seeing any land; the food in the ship began to run short, and his men became frightened and threatened to throw him overboard if he would not turn back; but he begged them to continue for three days longer, and a little before midnight on October II there was a cry of 'land! land !' and next morning at sunrise they disembarked on one of the Bahama Islands in the New World.

Columbus thought that he had sailed right round and reached the other side of Asia, but if you look at your map you will see he only went a quarter of that distance. He died in 1506 , without finding out his mistake, though he made several other voyages. During these he made a very remarkable discovery about the magnetic needle of the compass. It 
had long been known that the needle did not point due north, but a little to the east of the north. Columbus, however, found that, as he went westward, the needle gradually lost its eastward direction, and pointed due north, and then gradually went a little way to the west. It remained like this till, on his return, he came back to the same place where it had changed, and then it passed gradually back to its first position. From this he learnt that, although the magnetic needle always points towards the north, it varies a little in different parts of the world. The reason of this is not even now clearly understood, and we must content ourselves here with knowing that it is so.

The next grand voyage of discovery was made by Vasco de Gama, a Portuguese, who set sail July 9, I497, to try whether it was possible to sail round the south of Africa. He succeeded, and during the voyage he could not help remarking the new constellations or groups of stars, never seen in Portugal, which appeared in the heavens. This proved to him that the earth must certainly be a globe, for if you were to sail for ever round a flat surface, you would always have the same stars above your head.

At last there came a third discoverer, Ferdinand Magellan (or Magalhaens), of Spain, who set off August ro, 1519, determined to sail right round the world. He steered westward to South America, and discovered the Straits which separate Terra del Fuego from the mainland, and which were called after him the Straits of Magellan. Then he sailed northwards, across the equator again, till he came to the Ladrone Islands, where he was killed fighting a battle to help the native king. Sebastian del Cano, his lieutenant, then took the command of the ship, which arrived safely back in the port of St. Lucar, near Seville in Spain, on September 7, 
PT. IT.

1522. This ship, guided by Magellan, was the first which ever sailed quite round the world; and all these voyages, proving that the earth is a round globe, and bringing back accounts of new stars in the heavens, set men thinking that there was much still to be learnt about the universe.

Leonardo da Vinci, 1452.-We must not pass on into the sixteenth century without mentioning Leonardo da Vinci, the great painter, who was also very remarkable for the number of interesting inventions which he made in mechanics. Leonardo was born in $\mathbf{r}_{42}$ at Vinci, in Tuscany; he is so generally spoken of as a painter that many people do not know that he left behind him fourteen valuable works on Natural Philosophy. He invented watermills and water-engines, as well as locks to shut off the water, such as are now used on our canals and rivers. $\mathrm{He}$ studied the flight of birds, and tried to make a machine for flying, and, besides being one of the best engineers of his day, he made many curious machines, such as a spinningmachine, a water-pump, and a planing-machine. Some of these things were only models which he made for his own pleasure, but they show that he, like Roger Bacon, was very much in advance of his age; and he did good service to science by the careful experiments which he made, and by insisting that it was only by going to Nature herself that men can really advance in knowledge.

Chief Works consulted.-Draper's 'Hist. of Intellectual Development ;' Baden Powell's 'Hist. of Natural Philosophy,' 1834; Sprengel 'Histoire de la Médecine,' 1850 ; 'Penny Cyclopædia,' art. 'Arabians ;' 'Encyclopædias Metropolitana and Britannica;' Redwell's 'Birth of Chemistry,' I874 ; 'The Works of Geber,' Englished by R. Russell, 
1678 ; Whewell's 'History of the Inductive Sciences;' Priestley's 'History of Vision,' 1772 ; Smith's 'Optics,' 1778 ; 'Edinburgh Encyclopædia,' art. Chemistry ; Bacon's 'Opus Majus,' by Dr. Jebb, 1733; Bacon, 'Sa Vie, ses Ouvrages, et ses Doctrines,' by M. Charles, 186r ; Ventura, 'Ouvrages Physico-mathématiques de Léon. ardo da Vinci,' 1797; Draper's 'Conflict between Religion and Science,' 1875 . 



\section{PART III.}

\section{RISE AND PROGRESS OF MODERN SCIENCE}

FROM A.D. I5OO TO THE PRESENT DAY 
Chief Scientific Men of the Sixtenth Contury.

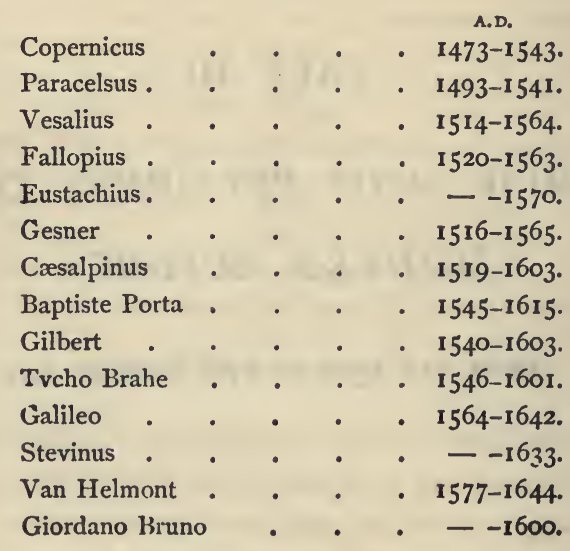




\section{CHAPTER IX.}

\section{SCIENCE OF THE SIXTEENTH CENTURY.}

Rise of Modern Science-Dogmatism of the Middle Ages-Reasons for studying Discoveries in the order of their dates-Copernican theory of the Universe-Copernicus goes back to the System of Aristarchus-Is afraid to publish his Work till quite the end of his Iife- Work of Vesalius on Anatomy-He shows that Galen made many mistakes in describing Man's Structure-His Banishment and Death-The value of his Work to Science-Fallopius and Eustachius Anatomists-Gesner's Works on Animals and PlantsHe forms a Zoological Cabinet and makes a Botanical GardenHis Natural History of Animals-His classification of Plants according to their Seeds-His work on Mineralogy-Cæsalpinus makes the First System of Plants on Gesner's plan-Explains Diœecious Plants-Chemistry of Paracelsus and Van Helmont.

WE have now arrived at the beginning of Modern Science, when the foundations were laid of that knowledge which we possess to-day. With the exception of some original discoveries made by the Arabs, learned men during the Dark Ages had spent their time almost entirely in translating and repeating what the Greeks had taught; till at last they had come to believe that Ptolemy, Galen, and Aristotle had settled most of the scientific questions, and that no one had any right to doubt their decisions. But as Europe became nore civilised, and people had time to devote their lives to quiet occupations, first one observer and then another began to see that many grand truths were still undiscovered, and 
that, though the Greeks had learned much about nature, yet their greatest men had only made the best theories they could from the facts they knew, and had never intended that their teaching should be considered as complete or final.

And so little by little real observations and experiments began to take the place of mere book-learning, and as soon as this happened science began to advance rapidly-so rapidly that from this time forward we can only pick out the most remarkable among hundreds of men who have added to the general stock of knowledge. A detailed account of all the steps by which the different sciences progressed would fill many large volumes, and would only confuse you, unless you already knew a great deal about the subject. In this book we can only throw a rapid glance over the last four centuries of modern science, and try to understand such new discoveries as ought to be familiar to every educated person. But you cannot bear in mind too often that when we come to a great man who discovers or lays down new laws, there have always been a number of less-known observers who have collected the facts and ideas from which he has formed his conclusions, although to mention all these men would only fill your mind with a string of useless names.

I must also explain here why I have adopted the plan of giving new discoveries in the order in which they occurred. You would no doubt have understood each separate science better if the account of it had been carried on without any break-if, for example, Astronomy had been spoken of first, then Optics, then Mechanics, and so on. But by this arrangement you would not see the gradual way in which our knowledge has grown from century to century, nor how the work done in one science has often helped to bring out new truths in another. Therefore, although by 
following the order of dates we shall be forced sometimes to pass abruptly from one subject to another, it will, I think, be the best way to teach you the 'History' of Modern Science.

Copernican Theory of the Universe, 1474-1543. - It was stated (p. 32) that about the year A.D. roo Ptolemy formed a 'System of the Universe' which supposed our little earth to be the centre of all the heavenly bodies ; and the sun, together with all the stars and planets, to move round us for our use and enjoyment. This system had been held and taught in all the schools for nearly fourteen hundred years, when, in the beginning of the sixteenth century, a man arose who set it aside, and proposed a better explanation of the movements which we see in the heavens.

In 1473 , a few years before Columbus sailed for America, Nicolas Copernicus, the son of a small country surgeon, was born at Thorn, in Poland. From his earliest boyhood he had always a great love for science, and after taking a doctor's degree at Cracow, he went as Professor of Mathematics to Rome. About the year 1500 he returned to his own country and was made a canon of Frauenberg, in Prussia. Here he set himseif to study the heavens from the window of his garret, and often all night long from the steeple of the cathedral. At the same time he read carefully the explanations which Ptolemy and other astronomers had given of the movements of the sun and planets. But none of their theories satisfied him, for he could not make them agree with what he himself clserved; until at last, after twenty years of labour, he came to the conclusion that the real explanation was the one which Aristarchus had given (p. 20), and which was called the Pythagorean System, namely, that the sun stands still in the centre of our system, and that the earth and other planets revolve round it. 
He now made a large quadrant, that is, an instrument for measuring the angular height of the sun and stars, and with this he made an immense number of observations on the different positions of the sun during the year, all proving how naturally the movements of the different planets are explained by supposing the sun to stand still in the middle. This he wrote down in his great work called 'The Revolutions of the Heavenly Bodies,' in which he taught that the earth must be round, and must make a journey every year round the sun. He gave his reasons why Ptolemy was mistaken in believing the earth to be the centre of the universe, and added a diagram of the orbits of our earth and of the planets round the sun. He then went on to found upon this a whole system of Astronomy, too complicated for us to follow here; but he did not publish it, because he was afraid of public opinion; for people did not like to believe that our world is not the centre of the whole universe. At last his friends persuaded him to let his book be printed, and a perfect copy reached him only a few days before his death, which occurred in $\mathbf{1}_{543}$, when he was seventy years of age.

This work was the foundation of modern astronomy, and the theory that the earth and the planets move round the sun has ever since been called the Copernican Theory; but at the time it was published very few persons believed in it, and it was not till more than sixty years after the death of Copernicus that Galileo's discoveries brought it into general notice.

Work of Vesalius on Anatomy, 1542.-While Copernicus was proving to himself that Ptolemy's theory of the heavens was not a true one, a Belgian, named Vesalius, was beginning to suspect that Galen, though a good physician, 
had described the structure of man's body very imperfectly, because he had only been allowed to dissect animals.

Andreas Vesalius was born at Brussels in r 5 r4. When he was quite a boy he had a passionate love for anatomy, and, as he had some little fortune, he gave up all his time to this study, and often ran great risks in order to get bodies to dissect ; for in those days it was still considered wicked to cut up dead bodies. In the year 1540 he became Professor of Anatomy at the University of Padua, in Northern Italy, and two years afterwards, when he was only twenty-eight years of age, he published his 'Great Anatomy,' in which Human Anatomy, or the structure of man's body, was carefully studied and described; the different parts being illustrated by the most beautiful and accurate wood engravings, drawn by the best Italian artists.

In this book Vesalius pointed out that Galen, having learnt his anatomy from the bodies of animals, had described incorrectly almost all the bones which are peculiar to man. For example, in animals the middle part of the upper jaw, which holds the front and eye-teeth, is a separate bone from the sides of the jaw, and even in monkeys it remains separate while they are young; but man is born with the upper jaw all joined into one solid piece. Now Galen had described man's upper jaw as composed of separate bones, and therefore it was clear that he had made his description from the skull of an animal. In all instances like this, and there are many, in which man differs from animals, Vesalius showed that it was necessary to examine the human skeleton, and not to trust merely to Galen's teaching.

This was a great step in science, and yet people had become so accustomed to follow authority blindly that Vesalius made many enemies by venturing to think that 
Galen could be wrong. It happened, unfortunately, that one day when he was dissecting the body of a Spanish gentleman who had just died, the bystanders thought that they saw the heart throb. His enemies seized upon this circumstance and accused him of dissecting a living man, and the judges of the Inquisition would have condemned him to death, if Charles V. of Spain, whose physician he had become, had not persuaded them instead to send him on a pilgrimage to Jerusalem. On his return from this pilgrimage he was shipwrecked on the island of Zante, in the Grecian Archipelago, and died of hunger when he was only fifty years of age. There are of course many faulty descriptions in Vesalius's work, for the study of anatomy was at that time only beginning; but he made the first attempt to appeal to facts instead of merely repeating what others had taught, and by this he earned the right to be called the Founder of Modern Anatomy.

There lived at the same time as Vesalius two other very celebrated anatomists, Gabriel Fallopius, of Modena, and Barthélémy Eustachius, of San Severino, near Naples, who both did a great deal to advance anatomy. Eustachius described the tube running between the mouth and the ear which is still called the Eustachian tube, and made many very useful experiments; but, on the other hand, he attacked Vesalius very bitterly for his criticisms of Galen's anatomy.

Gesner's Works on Animals and Plants, 1551-1565. -We now come to one of the most interesting lives of the sixteenth century. Many of us know very little of astronomy or anatomy, but any child who has gathered flowers in the country or looked at wild animals in the Zoological Gardens must feel interested in Gesner, the first 
man since the time of Aristotle who wrote anything original about animals and plants.

Conrad Gesner was born at Zurich in 1516 . He was the son of very poor parents, and, being left an orphan, was educated chiefly by the charity of an uncle and other friends; but his love of knowledge was so great that he conquered all difficulties, and after taking his degree as a medical man in 1540 , earned enough by his profession, and as Professor of Natural History at Zurich, to carry on his favourite studies. He learnt Greek, Latin, French, Italian, English, and even some of the Eastern languages, and read works of science in all these tongues ; and, although he was very delicate, he travelled all over the Alps, Switzerland, Northern Italy, and France, in search of plants, and made journeys to the Adriatic and the Rhine in order to study marine and fresh-water fish. He employed a man exclusively to draw figures of animals and plants, and he made a zoological cabinet, which contained the dried parts of animals arranged in their proper order. This was probably the first zoological cabinet which ever existed. $\mathrm{He}$ also founded a botanical garden at Zurich, and paid the expenses of it himself. He took great interest in studying the medical uses of plants, and often hurt his health by trying the effects of different herbs. His friends once thought that he had killed himself by taking a dose of a poisonous plant called 'Doronicum,' or 'Leopard's Bane,' but he recovered and gave them a most interesting account of his own symptoms.

Between the years $155^{1}$ and 1565 , Gesner published his famous ' History of Animals,' in five parts ; two on quadrupeds, one on birds, one on fish, and one on serpents. In this book he describes every animal then known, and gives the 
countries it inhabits and the names it has been called, both in ancient and modern languages. He calculates the average length of its life ; its growth, the number of young ones it will bring up, and the illnesses to which it is subject; its instincts, its habits, and its use ; and to all this he adds careful drawings of the animal and its structure. Part of his information he gathered from books and friends, but a great part he collected himself with great care, and to him we owe the first beginning of the Natural History of Animals in modern times.

In Botany he made the first attempt at a true classification of plants, and pointed out that the right way to discover which plants most resemble each other is to study their flowers and seeds. Before his time plants had been arranged merely according to their general appearance; but he showed that this system is very false, and that, however different plants may look, yet, if their seeds or flowers are formed alike, they should be classed in the same group. He did not live to publish his great work on plants, but left drawings of 1,500 species, which were brought out after his death.

Gesner also wrote a book on Mineralogy, in which h: traced out the forms of the crystals of different minerals and drew many figures of fossil shells found in the crust of the earth. The same year that this book was published he died of the plague. When he knew that his death was certain, he begged to be carried into his museum, which he had loved so well, and died there in the arms of his wife.

There is something very grand and loveable in the life of Gesner. Born a poor boy, he struggled manfully upwards to knowledge, and became rich only to work for science. Everyone loved him, and he was well known as a peacemaker among his literary and scientific friends, and for the 
readiness with which he would lay aside his own work to help others. Yet, though he had to earn his own living and died before he was forty-nine, he became the first botanist and zoologist of his time, and left remarkably large and valuable works behind him. He was one of the bright examples of what may be done by a true desire for knowledge, and a humble, honest, loving nature ; for while he helped others, he could never have done what he did in zoology and botany if he had not made friends all over the world, who were ready to send him information whenever and wherever they were able.

First Classification of Plants by Cæsalpinus, 1583.Nearly thirty years after Gesner's death, Dr. Andrew Cæsalpinus, a physician and Professor of Botany at Padua, first tried to carry out his system of grouping plants according to their seeds. He began by dividing plants into trees and herbs, as Theophrastus had done (see p. 17). Then he divided the trees into two classes-rst, those which have the germ at the end of the seed farthest from the stalk, as in the walnut, where you will find a little thing shaped like a tiny heart lying just at the pointed end; 2nd, those which have the germ at the end of the seed which is nearest the stalk, as in the apple. The herbs he divided into thirteen classes, according to the number of their seeds and the way in which they are arranged in the seed.vessels. Some plants, for example, have a single pod or seed-vessel, with a number of seeds inside it, as our common pea ; others, like the poppy, have a seed-veşsel divided into a number of little cells, each filled with seeds.

By grouping together all the plants which had the same kind of seed-vessel, Cæsalpinus made thirteen classes, and formed a system of plants which would have been a great 
help to botanists, and would soon have led them to make better systems if they had followed it ; but it was not generally adopted, and for nearly a hundred years longer many went on in the old way, collecting and naming plants without trying to classify them. Cæsalpinus knew about $I, 500$ species of plants, 700 of which he had collected himself. $\mathrm{He}$ was the first to point out that the use of flowers which have no seed-vessels but only stamens (or little thread-like stalks, tipped with yellow powder), is to drop the powder or pollen on flowers which have only seed-vessels and no stamens, and by this means to cause the seeds to grow and ripen. Such plants which have the stamens in one flower and the seed-vessel in another are now called Diœcious plants.

Chemistry of Paracelsus and Van Helmont, 1520 1600. - There is very little worthy of notice in the chemistry of the sixteenth century; but we must mention in passing two famous men : Paracelsus, who was born 1493 at Einsiedel in Switzerland, and Van Helmont, born at Brussels in 1577.

Paracelsus was at one time Professor of Physic and Surgery at Basle, but he gave up his professorship and travelled about Europe during the greater part of his life. Among other things, he pointed out that air feeds flame, and that, if you put iron into sulphuric acid and water, a peculiar kind of air rises from it. He also succeeded in separating gold out of a mixture of gold and silver by using aquafortis or nitric acid, which dissolves the silver and lets the gold fall to the bottom of the vessel. He did not, however, make many discoveries which are valuable now, and he taught a great deal that was absurd and bombastic.

Van Helmont was also a wandering physician, but as a chemist he was more careful in his experiments than Paracelsus. He seems to have known a great many different gases, 
though he did not describe them clearly, and he particularly mentions the gas which rises from beer and other liquids which ferment. He called this Gas syluestre. The chief thing to remember about Van Helmont is that he was the first writer to use the word 'gas,' which he took from the German word 'geist,' meaning 'spirit.'

Chief Works consulted.-Rees's 'Encyclopædia,' art. 'Copernicus ;' 'Encyclopæedia Metropolitana,' art. 'Astronomy ;' 'Biographie Universelle,' art. 'Copernicus;' Gassendi's 'Life of Copernicus ;' 'Encyclopædia,' art. 'Anatomy;' Cuvier, 'Histoire des Sciences Naturelles,' 1845; D’Orbigny, 'Dict. des Sciences Naturelles'--Introduction; 'Encyclopædia,' art. 'Botany ;' Hoefer, 'Histoire de la Plysique et de la Chimie,' 1850. 


\section{CHAPTER X.}

\section{SCIENCE OF THE SIXTEENTH CENTURY (CONTINUED).}

Baptiste Porta discovers the Camera Obscura-Shows that our Eye is like a Camera Obscura-Makes a kind of Magic Lantern by Sunlight - Kircher afterwards makes a Magic Lantern by Lamplight -Dr. Gilbert's discoveries in Electricity-Tycho Brahe, the Danish Astronomer-Builds an Observatory on the Island of Huen-Makes a great number of Observations, and draws up the Rudolphine Tables-Galileo discovers the principle of the Pendulum-Calculates the velocity of Falling Bodies, and snows why it increases-Shows that Unequal Weights fall to the Ground in the same time-Establishes the relations of Force and Weight-Summary of the Science of the sixteenth century.

Baptiste Porta's discoveries about Light, 1560.-The next discovery in science was about Light, and it was made by a boy only fifteen years of age. Baptiste Porta was born in Naples in 1545. He was so eager for new knowledge that when quite a boy he held meetings in his house for any of his friends to read papers about new experiments. These meetings were called 'the Academy of Secrets,' and in the year 1560 , when Porta was fifteen, he published an account of them in a book called 'Magia Naturalis,' or 'Natural Magic.' In the seventeenth chapter of this book he relates the following experiment which he had made himself.

He says he found that by going into a darkened room when the sun was shining brightly, and making a very small hole in the window-shutter, he could produce on the wall of 
the room, opposite the hole, images of things outside the window. These images were exactly the shape of the real objects, and had always their proper colours ; as for example, if a man was standing against a tree outside the house, the green leaves of the tree and the different colours of the man's clothes would be clearly shown on the wall. There was only one peculiarity about the picture, it was always upside down, so that the man stood on his head, or the tree with its trunk in the air. The smaller the hole was, the clearer

FIG. 7.

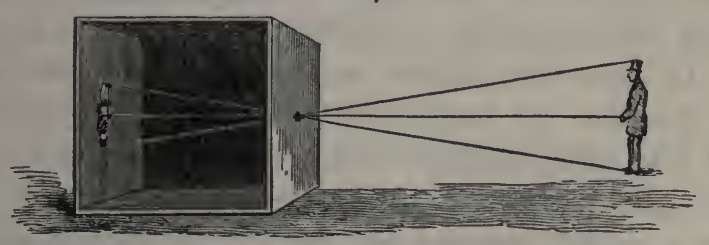

were the outline and the colours of the image, and Porta found that by putting a convex lens (that is, a glass with its surfaces bulging in the centre, see p. 49) into the hole he could get a still brighter and clearer picture at a particular point in the room.

Porta knew from the works of Alhazen that rays of light are reflected in all directions from every object, and he explained this image on the wall quite correctly, by saying that the small hole lets in only one ray from each point of an object outside; the other rays and those from the sky and other objects being kept out by the shutter. Thus these single rays fall directly on the wall without being mingled with others, and so make a clear picture. It is easy to see from fig. 7 that the image must be upside down, because the rays cross in going through the hole. This simple discovery of Porta's is called the 'Camera Obscura,' or 'Dark Chamber.' 
You may perhaps have been into one at the sea-side, where they build them for visitors to watch the coloured reflection of the passers-by. In the camera obscura, as it is now made, the glasses are so arranged that the figures are upright.

Porta saw at once how useful this invention would be for making accurate drawings of objects ; for, by tracing out with colours on the wall the figure of the man or tree as it stood, he could get a small image of it with all its proportions and colours correct. But, what is still more important, he was led by this experiment to understand how we see objects, and to prove that Alhazen was right in saying that rays of light from the things around us strike upon our eye. For, said Porta, the little hole in the shutter with the lens in it, is like the little hole in our eye, which also contains a natural convex lens; and we see objects clearly because the rays pass through this small hole. He did not, however, know which part of our eye represents the wall on which the figure is thrown, nor why we see objects upright ; we shall see (p.96) that Kepler discovered this many years afterwards.

When Porta had succeeded in getting clear images of real things on the wall, he began to try painting artificial pictures on thin transparent paper and passing them across the hole in the shutter, and he found that the sun threw a very fair picture of them on the wall. In this way he produced representations of battles and hunts, and so made a step towards the Magic Lantern. He seems, however, never to have tried it by lamplight ; this was done by Kircher, a German, about fifty years later. There is no doubt that Porta had a very good notion of how to use two magnifying glasses so as 
to make objects appear nearer and larger, but it is not certain that he ever really made a telescope.

Dr. Gilbert, the Founder of the Science of Electricity, 1540-1603. - It was about this time, while Baptiste Porta was making experiments on light in Italy, that an Englishman named Gilbert made the first step in one of the most wonderful and interesting of all the sciences, namely, that of Electricity. So long ago as the time of the Greeks it was already known that amber, when rubbed, will attract or draw towards it bits of straw and other light bodies, and it is from the Greek word electron-amber, that our word electricity is taken.

Until the sixteenth century, however, no one had made any careful experiments upon this curious fact, and it was Dr. Gilbert, a physician of Colchester, who first discovered that other bodies besides amber will, when rubbed, attract straws, thin shavings of metals, and other substances. You can easily try this for yourself by rubbing the end of a stick of common sealing-wax on a piece of dry flannel, and then holding the rubbed end near to some small pieces of light paper, or some feathers or bran. You will find that these substances will spring towards the sealing-wax and cling to it for short time, being held there by the electricity which has been produced by rubbing the sealing-wax.

Gilbert showed that amber, jet, diamond, crystal, sulphur, sealing-wax, alum, and many other substances, have this power of attraction when they are rubbed, and he also proved that the attraction was stronger when the air is dry and cold than when it is warm and moist. This may seem very little to have discovered compared to the wonderful facts which we now know about electricity; but it was the first step, and Gilbert's book on 'Magnetism' (as he called 
it), which was published in 1600 , must be remembered as the earliest beginning of the study of electricity.

Tycho Brahe, Astronomer, 1546--1601.-We must now return to Astronomy, in which during the next eighty years wonderful discoveries were made by three celebrated men, Tycho Brahe the Dane, Galileo the Italian, and Kepler the German.

Tycho Brahe was born in the year 1546, at Helsinborg, a town in Sweden, which at that time belonged to the Danes. When he was only fourteen he was so much astonished that the astronomers had been able to foretell exactly the moment when an eclipse of the sun took place in 1560 , that he determined to learn this wonderful science, which could predict events. His father had intended him to be a lawyer, but Tycho bought a globe and books with his own money, and studied astronomy in secret; till at last his family consented to let him follow his own inclination, and from that time he gave himself up to that science, planning and making the most beautiful instruments for taking observations in the heavens.

At this time the theory of Copernicus had made very little impression, and Tycho Brahe rejected it altogether and made a theory of his own called the Tychonic system, which was, however, soon laid aside and forgotten. This, however, mattered very little, for the useful work which Tycho did was not to lay down new laws, but to collect an immense number of accurate facts which were invaluable to the astronomers who came after him. For twenty-five years he lived in the little island of Huen, in the Baltic, which the King, Frederick II. of Denmark, had given him, making accurate observations of the different movements of the planets, and determining the positions of the fixed stars, 
of which he catalogued 777. He built there a magnificent observatory, which he called Uranienburg, or the City of the Heavens, and filled it with instruments of every kind, which enabled him to keep a register of the different positions of the heavenly bodies night after night.

When Frederick II. died, Tycho was persecuted and driven into exile by some envious people who grudged him the pension he was receiving. He then went to Bohemia, under the protection of the Emperor Rudolph II., and here he drew up the valuable astronomical tables called the Rudolphine tables, which, as we shall afterwards see, were of immense use to Kepler. Tycho died in 1601 , before Galileo and Kepler made their greatest discoveries.

Galileo's discovery of the principle of the Pendulum, and of the rate of Falling Bodies, 1564-1600.-Galileo dei Galilei was born at Pisa in ${ }^{1564}$. His father, though of good family, was poor, but being himself a man of talent and education, he made great exertions to send his son to the University of Pisa, meaning to educate him as a doctor. Here Galileo studied medicine under the famous botanist Cæsalpinus; but having also begun to learn geometry, he became so wrapt up in this pursuit that his father found it was useless to check him, and therefore wisely let him follow his natural bent. It was while he was still at the University, and before he was twenty years of age, that Galileo made his first discovery. When watching a lamp one day which was swinging from the roof of the cathedral, he noticed that, whether it made a long or a short swing, it always took the same time to go from one side to another. To make quite sure of this he put his finger on his own pulse, and, comparing its throbs with each swing of the lamp, found that there was always the same number of beats to every swing. Fol- 
lowing up this simple observation he discovered that a weight at the end of a cord will always take the same time to swing backwards and forwards so long as the cord is of the same length and the arc through which the weight moves is snall. This was the beginning of pendulums, such as we now have to our clocks, but at first they were only used by physicians to count the rate at which a patient's pulse beats.

In ${ }_{5} 89$ Ferdinand de' Medici, Duke of Tuscany, having heard of Galileo's talents, made him Lecturer of Mathematics at Pisa, and it was while he held this post that he made his next discovery, which was about falling bodies. He observed that a stone or any other body, dropped from a height, falls more and more quickly from the time it starts till it reaches the ground, and after many experiments he succeeded in calculating at what rate its falling increases. At the end of the first second it will be falling at the rate of $3^{2}$ feet per second, at the end of two seconds it will be falling at the rate of 64 feet per second, at the end of three seconds at the rate of 96 feet per second, and so it will continue, falling 32 feet faster every second till it reaches the ground.

Galileo explained this increase of velocity, or quickness of falling, in the following way : It is the weight of the stone, he said, which drags it down; and when it had been once started downwards by its weight, it would go on moving at the same rate for ever, without any more dragging. But the weight still goes on pulling it down just as much at the end of the first second as it did when it started, and so the stone falls, first with the drag of its start, then with the drag of the first second added, then of the next, and the next all added together, until it reaches the ground.

This was quite a true explanation, so far as it went, and Galileo went on to prove another fact, which sounds very 
strange at first, namely, that if you let two weights, one light and the other heavy, drop from the same height, they will both take exactly the same time in falling to the ground. Galileo could not make the learned men of Pisa believe this, because Aristotle had said that a ten-pound weight would fall ten times as fast as a one-pound weight; so to convince them he carried different weights up to the top of the Tower of Pisa, and let them fall before their eyes. Still, though they saw them reach the ground at the same moment, they would not believe, so obstinately were they determined to think with Aristotle; and they actually annoyed Galileo so much on account of his opinions that he left Pisa and became a professor at Padua in 1592.

The best way for you to convince yourself that Galileo was right and they were wrong will be to take some large soft clay balls, say five, each exactly the same weight, and let them drop at the same moment from the same heightyou can see at once that they will all reach the ground together. Then press four of the balls one against the other so that they stick together. They will now be four times heavier than the remaining ball, and yet if you let them drop from the same height again, there is no reason why the four should fall any faster merely because they are stuck together than when they were separate, and so the five will reach the ground together as they did before. I have said take large balls, because if they are not tolerably heavy the air will interfere with their falling accurately; indeed, to make the experiment very truly it ought to be made in a vacuum, that is, a space from which the air has been pumped out, for it is easy to see that air, like water, will buoy up a light body more than a heavy one, and so would cause it to be longer in falling. But air-pumps were not invented in 
Galileo's time, so he could not make the experiment very accurately.

In the year 1592 Galileo established another law in mechanics which is of great value, namely, that any force which will lift a weight of two pounds up one foot will lift a weight of one pound up two feet, or in other words, just as much as you make a weight lighter, so much higher the same force can lift it. If you double the weight, the same force will only lift it half as high ; if you treble the weight, it will only lift it one-third as high, and so on. This law is of immense value in determining the balance of machines, but we cannot examine it further here. At about the same time that Galileo was discovering these laws of motion, a famous engineer, named Stevinus, of Bruges, published a little book, in which he made known some very important laws about the rest and motion of bodies, which formed the foundation of the modern science of statics, or the study of bodies at rest.

Summary of the Science of the Sixteenth Century.And now we must pause for a moment in the history of Galileo, for his astronomical discoveries belong to the next century, and before entering upon them we must reckon up the advances which had been made in science during the past hundred years.

I think you will agree with me that at least one grand step had been made when men learned to examine for themselves, and were no longer content merely to repeat like parrots what the Greeks had handed down to them. Copernicus had shown in astronomy, Vesalius in anatomy, and Galileo in mechanics, that it was no longer enough to quote passages from Ptolemy, Galen, and Aristotle ; but men must take the trouble to examine the works of nature for themselves, if 
they wished really to understand the laws of the Great Creator.

This, in itself, was a great advance; but beyond this Copernicus, by his new system, had opened the way for grand astronomical discoveries which you will see followed quickly in the next century, and Tycho, by his long and patient observations, had stored up facts for the use of those who came after him. In the same way Vesalius in anatomy, and Gesner and Cæsalpinus in natural history, had laid a foundation for the regular study of living beings, and had roughly sketched out a plan of classification. In the subject of light, Porta had invented the camera obscura, explained the principle upon which it acts, and in doing this had made important discoveries about the action of light upon our eye, and the use of lenses, or convex and concave glasses, in magnifying objects. Lastly, Galileo had discovered the principle of the pendulum and the rate of falling bodies, and was now on the brink of the discovery of the telescope and all the wonders which it has revealed.

Meanwhile the sixteenth century closed with one very sad event, which must be mentioned here. Giordano Bruno, a Dominican friar, who was born about the year $155^{\circ}$, at Nola, in Italy, was one of the first people who openly taught that the Copernican system was true. He ought to be peculiarly interesting to us, because he was the first person to teach in England that the earth moves round the sun. But poor Bruno was a very plain outspoken man, and his bold language brought him to a sad but noble death. When people said he should not spread the Copernican system because it was contrary to the Bible, he answered boldly that the Bible was meant to teach men how to love God and live rightly, and not to settle questions of science. 
Most people now would say that Bruno was right, but the judges of the Inquisition did not think so, and were so alarmed at his opinions that they condemned him to death. In the year 1600 , just after the century closed, Bruno was burnt at the stake in Rome as an atheist, partly because he insisted on repeating that the earth is not the centre of the universe, and that there may be other inhabited worlds besides ours.

Chief Works consulted. - Whewell's 'Inductive Sciences ;' Brewster's 'Optics;' Brewster's 'Martyrs of Science,' 1874; 'Encyclopædia Britannica,' art. 'Astronomy;' Drinkwater's 'Life of Galileo;' Rossiter's 'Mechanics,' 1873; Cuvier, 'Histoire de Sciences Naturelles ;' Baden Powell's 'Natural Philosophy.' 
SCIENCE OF THE

SEVENTEENTH CENTURY 
Chief Men of Science in the Seventeenth Century.

\begin{tabular}{|c|c|c|c|c|c|c|}
\hline Galileo & - & - & - & - & - & $1564-1642$ \\
\hline Kepler & - & - & - & - & - & $157 \mathrm{I}-1630$. \\
\hline Gassendi & - & - & - & - & - & I 592-1655. \\
\hline Horrocks & - & - & - & - & - & I6I9-I64I. \\
\hline Newton & - & - & - & . & . & $1642-1727$ \\
\hline Halley & - & - & - & - & - & $1656-1742$. \\
\hline \multicolumn{2}{|c|}{ Francis Bacon } & • & - & - & - & $1561-1626$. \\
\hline Descartes & - & - & - & - & - & I 596-1650. \\
\hline Snellius & - & - & - & - & - & I $591-1626$. \\
\hline Drebbel & - & - & - & - & - & I $572-1634$. \\
\hline Torricelli & - & - & - & - & - & $1608-1647$. \\
\hline Guericke & - & - & - & - & - & $1602-1686$. \\
\hline Boyle & - & - & - & - & - & $1626-1691$. \\
\hline Hooke & - & - & - & - & - & $1635-17 C_{2}$ \\
\hline Huyghens & - & - & - & - & - & $1629-1695$ \\
\hline Roemer & - & - & - & - & - & I644-I 7 IO. \\
\hline Mayow & - & - & - & - & - & $1645-1679$. \\
\hline Beecher & - & - & - & - & - & $1625-1682$ \\
\hline Stahl & - & - & - & - & . & $1660-1734$ \\
\hline Steno & • & - & • & - & - & $163^{8}-1687$ \\
\hline Scilla & - & - & - & - & - & 1639-1 700. \\
\hline Woodward & & - & - & - & - & $1661-1727$ \\
\hline Harvey & • & • & • & - & - & $1578-1657$ \\
\hline Asellius & - & • & - & - & . & $1581-1626$. \\
\hline Rüdbeck & - & - & - & - & - & I630-I 702. \\
\hline Malpighi & $\cdot$ & • & : & - & - & I628-I694. \\
\hline Leeuwenhc & oeck & - & - & - & - & $1632-1723$ \\
\hline Grew & - & - & - & - & - & I628-I 7 I I. \\
\hline Ray . & . & . & - & - & . & 1628-1705. \\
\hline Willughby & & - & - & - & - & $1635^{-1}$ \\
\hline
\end{tabular}




\section{CHAPTER XI.}

SCIENCE OF THE SEVENTEENTH CENTURY.

Astronomical discoveries of Galileo-The Telescope--Galileo examines the Moon, and discovers the Earth-light upon it-Discovers Jupiter's four Moons-Distinguishes the Fixed Stars from the Planets-The phases of Venus confirm the Copernican theory-Galileo notices Saturn's Ring, but does not distinguish it clearly-Observes the spots on the Sun-The Inquisition force him to deny the movement of the Earth-Blindness and Death of Galileo.

Astronomical Discoveries of Galileo, 1609-1642. - The seventeenth century was not many years old when Galileo startled the world with discoveries such as had never been heard of before. He relates that when quite a young man he was so struck with.an account given by some of his companions of a lecture on the Copernican theory, that he determined to study it, and he soon became convinced of its truth. Nevertheless he saw how difficult it would be to prove that the earth moves round the sun, and not the sun round the earth.

When he went to Padua he gave a great deal of time to the study of astronomy, and had already made some remarkable observations, when one day, in the year 1609 , being in Venice, he heard that a Dutch spectacle-maker had invented an instrument which made distant things appear close at hand.

This discovery, which Bacon and Porta had foreseen, was made at last almost by accident in Holland, by two spectacle-makers, Zacharias Jansen and Henry Lippershey. 
It is related that Jansen's children when playing one day with two powerful magnifying glasses, happened to place them one behind the other in such a position that the weathercock of a church opposite the house seemed to them nearer and larger than usual, and their father, when he saw this, fixed the glasses on a board and gave them as a curiosity to Prince Maurice of Nassau. Whether this story be true or not, it is certain that in the year 1609 , both Jansen and Lippershey made these rough telescopes as toys, though they did not know how useful they might be. But when Galileo heard of it he saw at once what valuable help it might afford in studying the heavens ; and he set to work immediately, and soon succeeded in making a useful instrument.

A diagram of Galileo's telescope is given in Fig. 8. It was made on the same principle as opera-glasses are now, with one convex lens A B, which makes the rays from the object bend inwards or converge, and one concave lens C D, which makes them bend outwards or diverge before they come to a focus. In Fig. 8 one complete cone of rays is drawn coming from the point $m$, and the outline of another cone from the point $n$; there are really similar cones coming from all points along the arrow, but it is impossible to give these in a diagram. Each set of rays as they fall on the lens A B, are made to converge, so that they would end in a point or focus, if they were not caught by the lens C D. But this lens having its surfaces curved inwards makes the rays bend outwards or diverge again, so that the end of the cone $m$ reaches the eye in parallel lines at $m^{\prime} m^{\prime}$ and the cone $n$ at $n^{\prime} n^{\prime}$. From here, as you will remember (see p. 49), we follow them out in straight lines, and see the image at the angle $\mathrm{M} O \mathrm{~N}$, so that it appears greatly magnified. If you look at any object through one tube of an opera-glass, and 
keep the other eye open so as to see the object at its natural distance, you can cover the real image with the magnified one, and thus see the magnifying power of your glass. But when you do not compare them in this way you do not realise how much the object is enlarged, because it appears

Fig. 8 .

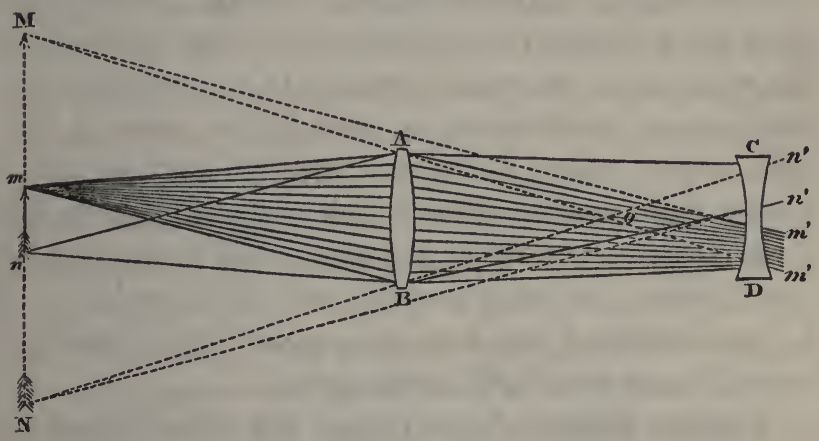

Galileo's Telescope.

A B, Convex lens: $\mathrm{C} D$, concave lens next the eye; $m n$, real arrow; $\mathrm{M} \mathrm{N}$, apparent size of arrow; $m^{\prime} \boldsymbol{m}^{\prime}$ and $n^{\prime} n^{\prime}$, end of the cones of rays $m$ and $\boldsymbol{n}$ as they reach the eye; $M O N$, angle at which the magnified arrow is seen.

to come nearer, so as to be at some point between $\mathrm{M} N$ and $o$, and to be less magnified in consequence. I must warn you that both in this diagram and the one at p. 97 the proportions are very much distorted, because a star or even a house would be an immense distance off as compared with the length of a telescope, whereas the arrow is obliged to be drawn here as near to the lenses as they are to each other.

Secondary Light of the Moon.-Galileo's first telescope only magnified three times, that is, made an object three times larger; but he made a second which magnified eight times, and then he turned it to the moon and began to 
examine the surface of that satellite. He saw the mountains of the moon, and the deep hollows buried-in darkness, and the wide plains which he mistook for oceans. Then he noticed that curious light called the secondary light, which may be seen on the dark side of the moon when only one quarter of it is bright and shining. Galileo discovered that this curious light is a reflection from the earth ; for you must know that we reflect the sun's light back to the moon just in the same way as the moon does back to us, and at the time when we see a new moon, the man in the moon (if there were such a person) would see a large full earth and could wander about at night by earth-light as we do by moonlight. Look up at the new moon just about dusk in the evening, and if it is a clear night you will most likely be able to see a faint outline of the dark side of the moon, which is caused by our earth-light shining upon it.

Jupiter's Moons.-When Galileo had studied the moon and gazed with intense delight on the myriads of tiny stars in the Milky Way, he next turned his telescope to the planet Jupiter. To his great surprise he saw three small shining bodies like stars close to Jupiter which were quite invisible to the naked eye. Two of them were on the east side of the planet and the other on the west. He waited eagerly for the second night, to see if Jupiter would move away from these stars, but he found them still together, only the two stars which had been on the east side had now moved round to the west, and they were nearer to each other than they had been before. He was quite puzzled as to how this could have happened, and watched and watched for many nights whenever the clouds would allow him; and at last, on the fourth night after he had first seen them, he came to the conclusion that all three stars were moving round and round 
Jupiter, as the moon goes round our earth. A few nights later he found that there was a fourth star which went round with them; and so Galileo discovered Jupiter's four moons in the year 16 ro.

This was the first fact in favour of the Copernican theory which ordinary people could understand. The planets had till now been looked upon simply as lights in the sky moving round the earth; but now it could not be doubted that Jupiter at least was something more than this, for he had a system like our own, with four moons, to give him light by night, instead of one. As usual there were a great number of people who were alarmed at the fact that our little earth should not be the central body in the heavens, and many astronomers would not believe that Galileo had really seen Jupiter's moons; one was even so foolish as to refuse to look through the telescope, for fear he should see them.

Phases of Venus.-Galileo, however, now felt sure that his new instrument would help him to read wonderful truths in the beautiful universe of God, and he threw his whole heart and soul into this grand study. It was not long before he discovered another proof that the planets move round the sun and not round the earth. When he first saw the planet Venus through the telescope she was round, but happening to look at her one day when she was almost between the earth and the sun, he saw her in the form of a crescent like a new moon. Struck by this, he continued to observe her night after night till she had made the whole journey round the sun, and he proved to himself that she went through the same changes as our moon, from a crescent shape to a full round face. This was just what she would be expected to do if she and we both travelled round the sun. Thus for the second 
time Galileo proved that the Copernican theory was the true one.

He next turned his attention to Saturn, and before the end of the year he had made out that this planet was not single, but had something on each side of it which he thought were two small stars. This was Saturn's ring, but Galileo's telescope was not powerful enough for him to see it clearly. In the year. 1659 another famous astronomer, named Huyghens, saw the ring through a much better telescope, and described it (see Chapter XXI.).

Sun-spots.-Galileo had now a great wish to go to Rome, so that he might show the new wonders he had discovered to the learned men who lived in that city. He accordingly carried his telescope there in 1611 , and set it up in the Quirinal Garden. It was there that he first noticed the dark spots on the face of the sun, and observed that they were not always of the same shape, but that two or three would sometimes run into one, or that one would divide itself into three or four. These spots, which even now puzzle astronomers, were observed by several other men, especially by an English astronomer named Harriot, about the same time as by Galileo. But Galileo made a special use of his discovery, for he pointed out that the spots moved round regularly in about twenty-eight days, disappearing on one side of the sun and reappearing after some time on the other. This proved that the sun turns round upon its own axis in twentyeight days.

Galileo before the Inquisition.-And now we come to the sad part of Galileo's history. He was well received in Rome, and the Pope even gave him a pension of a hundred crowns; but the judges of the Inquisition, whu nad caused 
Bruno to be burnt alive, became uneasy that Galileo should teach so many new things, and especially that he should prove that our earth was not the centre of everything, but a mere speck among the numberless stars and planets in the heavens. They therefore sent for Galileo, in the year 1616 , and threatened to punish him unless he would promise to hold his tongue about this new theory. Galileo, however, would not be silent ; surrounded by his little circle of admiring pupils, he could not refrain from spreading wherever he went the grand facts he had discovered and the truths they taught. He was impatient that the world should not see as clearly as he did how glorious the universe is when rightly understood, and he often spoke and wrote sharply and sarcastically of those who would not listen to truth.

At last, in $16_{32}$, he wrote a book called 'The System of the World of Galileo Galilei,' in which he clearly proved the truth of the Copernican theory, and alluded very angrily to the attempt which the Inquisition had made to force him to be silent. This book convinced many people, but at the same time it roused the anger of the judges of the Inquisition. They summoned Galileo (then an old man seventy years of age) to appear again before them; and this time they made him kneel, clothed in the sackcloth of a penitent, and swear with his hands upon the Gospels that 'it was not true that the earth moved round the sun, and that he would never again in words or writing spread this damnable heresy.' It is very sad to think that Galileo should thus swear to what he knew was a lie; but it is still more sad that men holding their power in the name of God should force him to choose between telling a lie or being put to torture or to death as Giordano Bruno had been. When 
Galileo rose from his knees it is said that he stamped his foot and whispered to a friend: 'E pur si muove' ('Nevertheless it does move').

After a time he was allowed to go back to his own home, but never again to leave it without the Pope's permission. He went on with his studies, and made many useful observations ; but in the year 1636 his sight began to fail, and he soon became totally blind. At this time he wrote to an acquaintance these touching words : 'Alas! your dear friend and servant has become totally and irreparably blind. These heavens, this earth, this universe, which by wonderful observation I had enlarged a thousand times beyond the belief of past ages, are henceforth shrunk into the narrow space I myself occupy. So it pleases God, it shall therefore please me also.' He died January 28,1642 , in his seventy-eighth year ; having accomplished his work. In spite of all opposition, his discoveries had firmly established the truth of the Copernican system of the universe.

Chief Works consulted.-Brewster's 'Martyrs of Science ;' Drinkwater's 'Life of Galileo;' Herschel's 'Astronomy;' Whewell's 'Inductive Sciences ;' 'Enclyclopædia Britannica,' art. 'Astronomy ;' Baden Powell's 'Hist. of Natural Philosophy;' Ganot's 'Physics,' edited by Atkinson. 


\section{CHAPTER XII.}

SCiENCE of the SETENTEenth Century (CONTINUED).

Kepler the German Astronomer-Succeeds Tycho as Mathematician to the Emperor Rudolph--His description of the Eye-He tries to explain the orbit of the planet Mars-And by comparing Tycho's tables with observation discovers his First and Second Law of the movements of the Planets-His delight at Galileo's discoveriesKepler's Third Law-Comparison of the labours of Tycho, Galileo, and Kepler.

Kepler, 1571-1630.-While Galileo was occupied in discovering unknown worlds with his telescope, another famous astronomer, named Johannes Kepler, was working out three grand laws abo'st the movements of the planets. John Kepler was born in $157 \mathrm{r}$. His parents, though noble, were poor, and always in difficulties, but in spite of all obstacles he managed to educate himself, and even to take his degree at the University of Tübingen. In 1594 he was made Professor of Astronomy at Gratz, in Styria, and while there he began his attempts to discover the number, size, and orbits of the planets, but at first with no success. In 1597 , when the Catholics at Gratz rose against the Protestants, Kepler, being a Protestant, was forced to leave the city, and would have been in great difficulties if his friend Tycho Brahe had not invited him to come to Prague as his assistant in the observatory. Here Kepler worked with Tycho at his astronomical tables, called the 'Rudolphine Tables,' in honour of the Emperor Rudolph; and when Tycho died, 
in $160 \mathrm{r}$, he succeeded him as principal mathematician to the Emperor.

Kepler on Optics, 1604.-Although Kepler is chiefly known as an astronomer, his first work, published in 1604 , was on Optics, and in it he points out most beautifully the true use of the different parts of the eye. He was much struck with Porta's idea that the eye is like a camera obscura, and he proved that the rays of light, after passing through the lens of the eye, form a real picture upside down on the fine network of nerves called the retina, at the back of the eye, and are then conveyed by the optic nerve to the brain. $\mathrm{He}$ also pointed out that the reason why we do not see things upside down is that since our mind follows out each ray in a straight line, the rays appear to cross back again on the lens of the eye, and we see them as if they had never been inverted. This is, however, a question still undecided by physiologists.

Kepler invented a much more powerful telescope than the one which Galileo had made. You will see by turning back to p. 88 that the fault of Galileo's telescope was that it made the rays diverge or bend outwards, just as they reached the eye, and in this way many of them passed outside and were lost. Kepler avoided this by using two convex lenses. In his telescope (see Fig. 9), the rays from the object $m n$, after converging on the lens A B come to a focus at $m^{\prime} n^{\prime}$, where they make a real image of the arrow upside down. If you could put a piece of thin transparent paper at the point $m^{\prime} n^{\prime}$ in a telescope, you would see a picture of the object upon it. The rays from this image falling on the lens $C D$, are again bent inwards, as by the ordinary magnifying glass (see p. 49), and thus by following them out in straight lines the eye sees a magnified arrow upside down at some point 
between $\mathrm{C} \mathrm{D}$ and $\mathrm{M} \mathrm{N}$. Kepler's telescope is called the 'Astronomical telescope.' It has a much larger 'field of view' than Galileo's; that is, it enables you to see over a larger space at one time; but, on the other hand, it turns

Fig. 9.

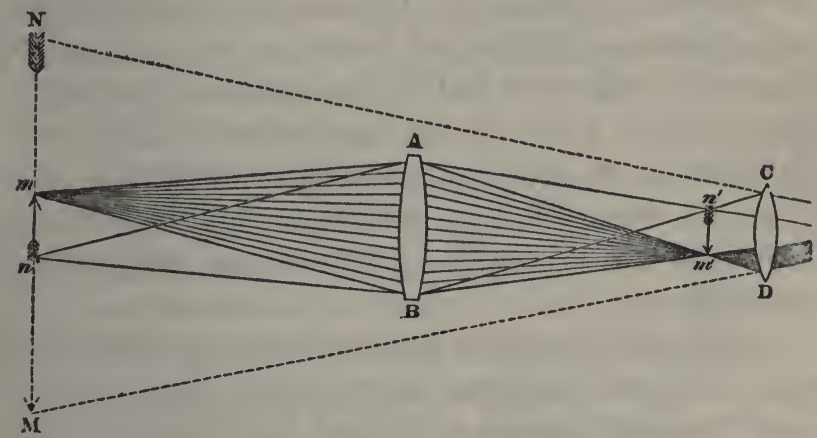

Kepler's Telescope. ${ }^{2}$

A B, Ohject glass. C D, Eye-piece. $m n$, Real arrow. $m^{\prime} n^{\prime}$, Picture of the arrow furmed at the focus of the rays. M N, Magnified arrow.

everything upside down. In making astronomical observations it is not of much importance which part of a star is uppermost ; but for terrestrial telescopes another lens has to be put in to bring the images back to their right positions, and since Kepler's time many other improvements have been made.

Kepler's first Law, 1609.-After Tycho Brahe's death Kepler went on working at the 'Rudolphine Tables,' and this led him to consider again the movements of the planets, and to try and find a theory to explain the path or orbit of the planet Mars. Mars is the planet which stands fourth from the sun; thus Mercury is nearest to the sun, then

' This figure and also fig. 8 were kindly drawn for me by Mr. A. R. Wallace. 
comes Venus, then our earth, and then outside our earth is Mars. Tycho had noted in his tables the places at which the planet had been seen at certain periods; and from these observations Kepler calculated where it ought to arrive at other fixed times if it moved in a circle, as the earlier astronomers had supposed. But he found that it did not arrive there as computed, and he was so sure that Tycho's observations were exact that he said boldly, 'All the theories must be wrong if they do not agree with what Tycho saw.' So he puzzled on, trying one explanation after another, until at last he discovered three remarkable laws, by which the movements not only of Mars, but of all the other planets, are explained.

The first of these laws is that planets move round the sun in ellipses or ovals, and not in circles. You know that to draw a circle you put one leg of the compasses into a spot and draw the other leg round it, and the middle spot is called the centre or focus. But to draw an ellipse you must have two focuses or foci. To understand this, stick two pins a little distance apart in a piece of paper, and fasten a string to them by its two ends. Place a pencil upright in the string, so as to keep it tightly stretched, and draw the pencil round first on one side then on the other. You will then have an ellipse, and the two pin-holes will be the two foci. Draw the sun in one of the foci and a round globe on some part of the ellipse, and you will have a figure of the path of our earth or any of the planets round the sun. You will find that the farther you put the pins apart the flatter the ellipse will be. The path or orbit of the planet Mercury is much more elliptical than the orbit of the Earth. Another difference in the orbits of the planets is that they do not all lie in the same direction, though they all have the sun as one of their foci. For instance in Fig. ro, the orbit 
of the planet $\mathrm{A}$ has the sun for one focus and the $\operatorname{dot} c$ for the other, while the orbit of the planet $\mathrm{x}$ has the sun for one focus and the $\operatorname{dot} d$ for the other, and this makes the two orbits lie in a different direction. Kepler's first law, then, was that planets move in ellipses.

\section{Kepler's Second Law,} 1609.-His second law was about the rate at which planets move. He found from Tycho's tables that they all moved more

FIG. Io.

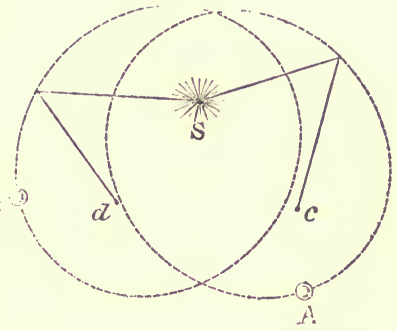

quickly when they were near the sun than when they were far from it, and after an immense number of calculations he found the following rule. If you could draw a line from the sun to any planet on the first day of each month of the year, you would enclose a number of spaces, such as $a, b, c, d$, \&c., in Fig. I I, and each of these spaces would be the same size, although not the same shape. For instance, the planet, when travelling from I to 2 near the sun, would go very quickly and pass over a number of miles,

FIG. II.

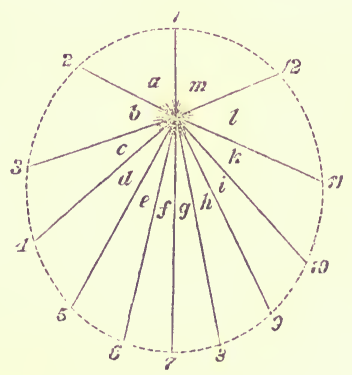

while when travelling from 6 to 7 it would go slowly and pass over comparatively few miles. And yet the space $f$ will be exactly the same size as the space $a$, only it will be long and thin instead of short and broad. Kepler's 
second law, therefore, was that planets describe equal areas about their centre in equal times.

Not many months after Kepler published these two laws, he heard of Galileo's discoveries with his telescopethat Jupiter had four satellites, and that Venus was proved to move round the sun by having phases like our moon. You may imagine how delighted he was to find the Copernican theory made so much more certain, and to see that the telescope was opening the way for so many new discoveries. 'Such a fit of wonder,' he said, 'seized me at this report, and I was thrown into such agitation, that between the joy of the friend who told me, my imagination, and the laughter of both, confounded as we were by such a novelty, we were hardly capable, he of speaking or I of listening.'

For many years after this Kepler was beset with troubles. The Emperor, being at war with his brother Matthias, had no money to spare for salaries. Kepler was thus harassed by poverty; his favourite son died of the small-pox, which the troops had brought into the city, and his wife died of grief not long afterwards. It was not till the year 1618 , after he had re-married and had been rescued from his poverty by the new Emperor Matthias, that the unfortunate astronomer had energy and leisure to turn again to his favourite planets.

Kepler's Third Law, 1618.-It was in that year that he worked out with immense labour his third and most famous law-by which he showed how much longer the planets were going round the sun, according as they were farther off from it. This is difficult to understand, but we must try to form some idea of it. He did not know in figures how far each planet was from the sun, but he knew the proportion of their distances, as for example. that Mars is 4 times and 
CH. xII. TYCHO BRAHE, GALILEO, AND KEPLER. IOI

Jupiter $13 \frac{1}{2}$ times farther off from the sun than Mercury, and he also knew how long each one was in going round the sun, and from these two facts he worked the following rule.

If you take any two planets and cube their distances from the sun and then square the time each takes in going round the sun, the two squares of the time will bear the same proportion to each other as do the two cubes of the distance. For instance, Mars is 4 times as far from the sun as Mercury, and therefore it is 8 times as long going round it, because the cube of 4 (or $4 \times 4 \times 4$ ) is 64 , and the square of 8 (or $8 \times 8$ ) is also 64 . Thus the cube of Mercury's distance as compared with that of Mars is I to 64, and the square of their periodic times of going round is also as I to 64. This law holds equally true of all the planets, and is expressed in scientific language thus: 'The squares of the periodic times of the planets areproportional to the cubes of their distances.

These three laws of Kepler were very great discoveries; especially the last one, which cost him years of labour and calculation. He was so astonished and delighted when he proved it, that he told a friend he thought at first it must be only a happy dream that he should have succeeded at last after so many failures.

After this Kepler wrote and published many books, but he made no more important discoveries. The Rudolphine Tables were at last published in 1628 , and Kepler received a gold chain from the Grand Duke of Tuscany for his services to Astronomy ; but still he could not obtain the payment of his salary, and money difficulties pressed upon him. His anxiety threw him into a violent fever, and he died in ${ }^{6} 63^{\circ}$ at sixty years of age.

Work done in Science by Tycho Brahe, Galileo, and 
Kepler-It will be instructive to notice here how very different these three astronomers, Tycho, Galileo, and Kepler were, and yet how they each did their own part to add to our knowledge. Tycho was a man who collected facts : his work was dry, and his tables a mass of figures, such as most people would think very uninteresting; yet if Tycho had not spent his life in this dry conscientious work, Kepler could never have discovered his laws. Galileo was a warmhearted enthusiastic observer: he loved the beauty of the heavens, and knew how to make others love it too; every observation he made he told in popular language to the world, and taught people the truth of the Copernican theory by showing them plainly how they could prove it for themselves, if they chose to look at the heavens. Kepler was quite different from either Tycho or Galileo; he was a mathematician, and worked everything out in his own brain by accurate methods. He took Tycho's observations, which he knew were true, and turned them this way and that way, working out now one calculation, now another, and always throwing them aside if they were not exactly true. He spent years over his attempts, but it was worth while, for he arrived at three true laws, which will remain for ever. There was only one point he had not reached; he knew that his laws were true, but he did not know why they were true. This was left for Newton to demonstrate nearly fifty years afterwards.

Chief Works consulted.-Brewster's 'Martyrs of Science ;' Herschel's 'Astronomy ;' Denison's 'Astronomy without Mathematics ;' Airy's 'Popular Astronomy;' Drinkwater's 'Life of Kepler;' Baden Powell's 'History of Natural Philosophy.' 


\section{CHAPTER XIII.}

SCiENCE OF THE SEVENTEenth CENTURy (CONTINUED).

Francis Bacon, 1561-1626-He teaches the true method of studying Science in his 'Novum Organum'-René Descartes, 1596-1650-He teaches that Doubt is more honest than Ignorant AssertionWillebrord Snellius discovers the Law of Refraction, 1621Explanation of this Law.

Bacon's Influence upon Science. - Although this book is a history of scientific discovery and not of philosophy, yet we must now mention in passing two philosophers who lived about this time, and whose writings had great influence upon science. These were Francis Bacon in England, and René Descartes in France.

Francis Bacon, commonly known as Lord Bacon, was born in London in $156 r$, and died in 1626 . He was made Lord Chancellor of England in 1618 , in the reign of James I., with the title of Lord Verulam and afterwards Viscount St. Alban's, and was a great political character. Bacon devoted much of his time to science, and, like his namesake Roger Bacon in the fifteenth century, he seens to have foreseen many of the discoveries which were afterwards made. But his most useful work was a book called the 'Novum Organum,' or 'New Method,' published in 1620, in which he sketched out very fully how science ought to be studied. He insisted that no knowledge can be real but that which is founded on experience, and that the only 
true way to cultivate science is to be quite certain of each step before going on further, nor to be satisfied with any general law until you have exhausted all the facts which it is supposed to explain.

For example, if you require to understand what heat is, and how it acts, you must not be satisfied, he says, by merely making a few experiments on the heat of the sun and that of fire, and trying from these to lay down some general rule of how heat works. 'No, you must exarnine it in the sun's rays both when they fall direct and when they are reflected ; in fiery meteors, in lightning, in volcanoes, and in all kinds of flame ; in heated solids, in hot springs, in boiling liquids, in steam and vapours, in bodies which retain heat, such as wool and fur; in bodies which you have held near the fire, and in bodies heated by rubbing; in sparks produced by friction, as at the axles of wheels ; in the heating of damp grass, as in haystacks ; in chemical changes, as when iron is dissolved by acids; in animals ; in the effects of spirits of wine; in aromatics, as for example pepper, when you place it on your tongue. In fact, you must study every property of heat down to the action of very cold water, which makes your flesh glow when poured upon it. When you have made a list,' says Bacon, 'of all the conditions under which heat appears, or is modified, of the causes which produce it, and of the effects which it brings about, then you may begin to speak of its nature and its laws, and may perhaps have some clear and distinct ideas about it.'

You will see at once that this method of Bacon's had been followed already to a great extent by Copernicus, Tycho Brahe, Galileo, and Kepler; but Bacon was the first to insist upon it as the only rule to follow, and in doing this he rendered a great service to science. 
Descartes' Condemnation of Ignorant Assertion.-René Descartes, by his philosophy, assisted science in another way. He was a Frenchman, born in Touraine in 1596 , and he became one of the most famous philosophers of France. He wrote a great deal on science, especially on mathematics and geometry, and also on the nature of man; but the point which we have to notice here was his belief that to arrive at the real truth was the only thing worth living for.

You will remember how the men of science of the sixteenth century had thought it a sufficient answer to Vesalius or to Galileo to say that Galen or Aristotle had decided questions of anatomy and physics ages ago ; and how the judges of the Inquisition thought they had crushed the Copernican theory when they made Galileo recant. Authority was the idol to which these people bowed down, and they considered it rank heresy to doubt anything which had been taught by their forefathers. But Descartes said, 'It is not true to say we know a thing simply because it has been told us. It is a duty to obey authority, to submit to the laws and religion of our country and parents, and in matters where we are not able to judge, it is wise to receive what is told us by those who know more than we do. But to knowe anything requires more than this, and unless the reasons for any belief are so clear to our minds that we cannot doubt them, we have no right to say we know it to be true, but only that we have been told so.'

I think you can see how this rule of Descartes, that it is often more honest to doubt than to be quite sure without good grounds, would influence science. If scientific men in the time of Galileo, instead of saying ' We know that a heavy weight falls more quickly than a light one because Aristotle said so,' had said more modestly, 'We do not know, because 
we have never tried, but we think it probable Aristotle was right until someone shows us that he was mistaken ;'-if they had gone to the Tower of Pisa in this spirit, they would not have denied the truth of Galileo's experiment when it succeeded before their very eyes. And even now, in the present day, you will see that the greatest and best men who make the most discoveries, are those who are always willing to examine a new fact, even though it may contradict much that they have held before; and who never pretend to inow for certain anything which they have not studied with sufficient care to be convinced of its truth.

These last few pages may be rather difficult for you to follow, but the chief lessons which it is necessary you should remember may be summed up in a few words. Bacon and Descartes both did great service to Science-Bacon by teaching that any true theory must be built up upon facts and careful experiments; Descartes by insisting that it is more honest to acknowledge we are ignorant, and to wait for more light, than to pretend to know that which we have not clearly proved.

Snellius Discovers the Law of Refraction, 1621.Among other things, Descartes wrote much upon Optics, and you will often see it stated that he discovered the law of refraction. This law had, however, been laid down before, in $162 \mathrm{r}$, by a Dutch mathematician named Willebrord Snellius, and Descartes only stated it more clearly. You will remember that the Arab Alhazen first pointed out that rays of light are bent or refracted when they pass from a rarer into a denser substance or medium (see p. 47), as for instance from air into water; and that the denser the medium is into which they pass the more the rays are refracted. Vitellio and Kepler had measured some of the 
angles at which rays are refracted in water and glass, but they did not know of any law by which they could calculate how much any particular ray would be bent out of its course.

For instance, in Fig. 12 , suppose $w$ w to be the surface of water in a glass vessel, upon which the rays $\mathrm{A}$ and $\mathrm{B}$ fall at

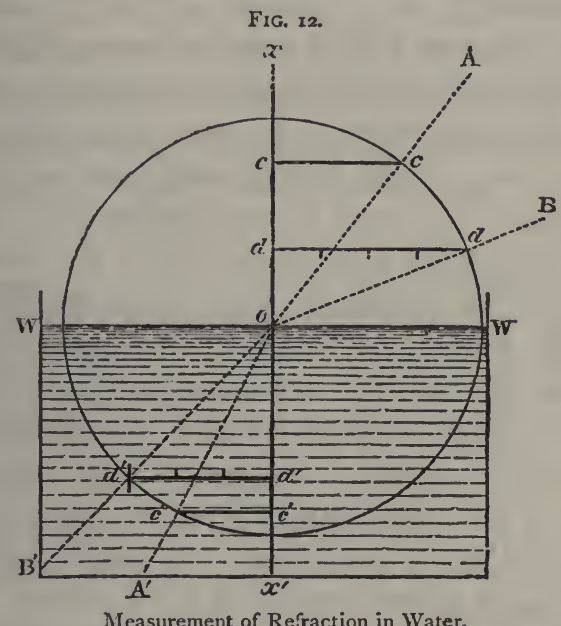

w $w$, Water. A $\mathrm{A}^{\prime}, \mathrm{B}^{\prime}$, Rays passing from air into water. $c c^{\prime}$, Line from the ray $\mathrm{A}$ to the perpendicular $x^{\prime}$, in the water, three-fourths the length of $c c$ from the ray $A$ in the air. $d^{n} d^{\prime \prime}, d d$, Similar lines from the ray $\mathbf{B}$.

the point $O$, and are refracted $A$ to $\mathrm{A}^{\prime}$ and $\mathrm{B}$ to $\mathrm{B}^{\prime}$. It is evident that $\mathrm{B}$ is bent much more out of its course than $\mathrm{A}$, as you will see at once if you lay a straight ruler from end to end of each ray; and if we were to draw other rays between these they would all be refracted at different angles, those being most bent which were farthest from the perpendicular.

Now in making telescopes it is very important to know how much each ray is refracted; and as the rays are infinite in number, it was impossible to know this unless some 
general rule could be found. Snellius set himself this task, and after a great number of very delicate experiments he arrived at a law which has proved to be always true. This law is best explained by the following experiment, which is not difficult to understand although it is troublesome to perform it accurately.

Draw a circle on a black board with an upright line $x x^{\prime}$ through it, and then place the board upright in a vessel of water so that the surface of the water crosses the centre 0 . Then pass a ray of light through a tube so placed that the ray falls across the board in the direction $A o$; it will then pass on through the water to some point $\mathrm{A}^{\prime}$. The line $\sigma \mathrm{A}$ will now cut the circle at the point $c$, and the line $o \mathrm{~A}^{\prime}$ will cut it at $c^{\prime}$. From these two points draw horizontal lines $c c$ and $c^{\prime} c^{\prime}$ on the board to the upright line $x x^{\prime}$. Then if you compare the length of these two lines you will find that $c^{\prime} c^{\prime}$ in the water is exactly three-fourths of $c c$ in the air.

Again, if you throw the light from your tube in the direction $\mathrm{B} o$, the result is the same. The length of $d^{\prime \prime} d^{\prime}$ in the water will again be three-fourths of $d d$ in the air. And this is equally true of all rays passing from air into water. When a vertical line is drawn through the point where the ray falls on the water, the two horizontal lines drazen to the place where the circle cuts the ray will always be in the same proportion, at whatever angle the ray strikes the water. Therefore, $\frac{3}{4}$ ths is said to be the index of refraction for water, meaning that every ray which passes from air into water will have these two horizontal lines in the proportion of 4 to 3 . In passing from air into glass they would always be in the proportion of 3 to 2 , and every different substance, such as ice, amber, diamond, \&c., has its own angle of refraction. These have been calculated, and tables made, from which you can learn 
at once what is the index of refraction for any particular substance.

It was this law of the proportion between the two horizontal lines in the air and in the denser substance which Snellius discovered. It is expressed in mathematical language, thus: 'The ratio between the sines of the incident and refracted rays is always the same for the same substance;' sine being a mathematical term for the measurement we have been making, which you will understand more fully when you have studied trigonometry.

Chief Works consultcd. - Herschel's 'Study of Natural Philosophy ;' Lewes's 'Biugraphical History of Philosophy ;' Cuvier, 'Hist. des Sciences Naturelles ;' Bacon, 'Ncvum Organum;' Huxley on 'Descartes,' Macmillan's Magazine; 'Encyclopæedia Metropolitana,' art. 'Light ;' Herschel's 'Familiar Lectures,' art. 'Light.' 


\section{CHAPTER XIV.}

SCIENCE OF THE SEVENTEENTH CENTURY (CONTINUED).

Fabricius Aquapendente discovers Valves in the Veins-Harvey's discovery of the Circulation of the Bluod-Discovery of the Vessels which carry nourishment to the Blood-Gaspard Asellius notices the Lacteals-Pecquet discovers the Passage of the fluid to the Heart-Rüdbeck discovers the Lymphatics.

Harvey's Discovery of the Circu'ation of the Blood, 1619. - In the year 1600, when Galileo and Kepler were still at the beginning of their discoveries, a young Englishman of two-and-twenty, named Harvey, who was born at Folkestone in 1578 , went to Padua to study anatomy under the famous professor Fabricius Aquapendente. Although anatomists had by this time learnt a great deal about the bones and parts of a dead body, yet they were still very ignorant about the working of a living one. They knew that arteries throb, like the pulse in the wrist, which is an artery ; and that veins (that is, the blue branching tubes which you can see under the skin in your hand and arm) contain blood and do not throb like the arteries, but they had no clear idea of the use of either arteries or veins. Vesalius had believed, like Aristotle, that the arteries contained chiefly a kind of air called 'vital spirits,' which they carried from the heart to all parts of the body; and that the blood was purnped backwards and forwards from the veins to the heart by the act of breathing. A Spaniard named Servetus, an Italian named 
Columbus, and the botanist Cæsalpinus, who all lived in the sixteenth century, had indeed suggested that blood from the heart flowed through the lungs (or the part we breathe with), and came back again to the heart; and Cæsalpinus had even noticed that if you tie up a vein it swells on the side of the bandage away from the heart; but the notions of all these men were very vague and unsatisfactory.

The subject remained quite obscure till, while Harvey was studying at Padua, his master Fabricius discovered that many of our veins have curious valves inside them, made by the folding of the lining of the vein. These valves, which are just like little transparent pockets, lie open towards the heart so long as the blood is flowing in that direction; but if you press on a vein-in your arm for instance-and force the blood away from the heart towards the fingers, the valves close at once, and the vein swells up because the blood cannot flow on.

Fabricius thought that the use of these valves was merely to prevent the blood escaping too quickly into the branches of the vein ; but this explanation did not satisfy Harvey, and he determined to try to discover which way the blood moved in the different vessels which held it. In order to do this he laid bare the artery of a living animal, say in its leg, and tied it round tight, so that the blood could not flow past the bandage. He found that the artery became very full of blood and throbbed strongly above the place where he had bound it, but in the lower part of the leg it did not throb at all. This proved to him that the blood in the artery was flowing from the heart to the leg of the animal, and was stopped on its way down by the bandage. He then tied up a vein in the same way, and this time the swelling was in the lower part of the leg, belone where the vein was tied. 
Therefore it was clear that the blood in the vein was flowing from the leg to the heart, and was stopped from flowing upwards by the bandage. When he tied an artery and a vein in the arm the same thing happened; the blood in the artcry was flowing towards the hand, while in the vein it was flowing from the hand towards the heart.

This led Harvey to suspect that the blood is always making a continuous journey round and round, first out of the heart through the arteries to all parts of the body, and then back through the veins to the heart again. And now the use of the little valves became evident. While the blood flows, as it should do, towards the heart, they lie open and offer it no resistance, but dircctly anything drives it in the wrong direction they close at once, and prevent it from flowing backwards. The throbbing of the arteries was also explained by this theory, for the blood being pumped into them by a regular movement of the heart, they swell at each rush of blood, and contract again before the next, and so rise and fall in exact time with the beating of the heart.

Harvey also found that Cæsalpinus and his contemporaries had been right in suspecting that the blood makes a small circuit from the heart through the lungs and back again. We will try to understand all this with the assistance of a diagram, which, however, you must remember is only to help you, and not a real drawing of the parts. Starting from the left lower chamber $a$ of the heart, the blood is pumped out of the left top corner of this chamber into an artery in the direction of the arrow $\mathrm{I}$. This artery soon divides into two branches, one going downwards by the arrow 2 to the lower part of the body, the other upwards by the arrow 2 ' to the arms and neck; and, after flowing into the different parts of the body, the blood in the lower artery 
returns by the lower vein, while the blood of the upper artery is returning by the upper vein, and both streams pour into the right upper chamber of the heart, $b$.

The blood has now made one round, but it does not stop here. It escapes through some valves down into the lower chamber $c$; out of the right top corner of which it starts again in the direction of arrozes 8 and 9, and passes through the lungs, returning by the lung-veins, or pulmonary veins as they are called, in the direction of arrow 10, back into the left top chamber of the heart, $d$. From there it passes down into

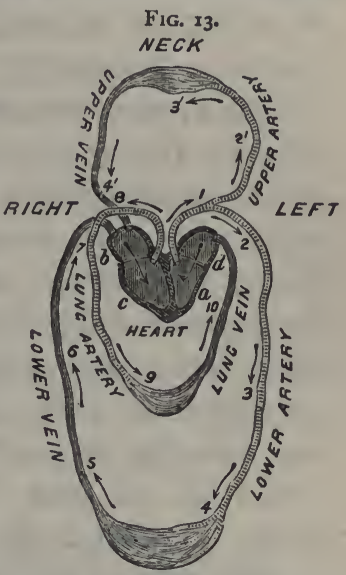
the chamber $a$, from which it first $a c$, Lower chambers of the heart, started, and the whole round begins again. The first journey of

Diagram of Heart and Blood-vessels front. called ventricles. $b \quad d$, Upper chambers of the heart, called auricles. The arrows and numbers show the course of the blood. the blood round the whole body is called the gencral circulation, and the second journey through the lungs is called the pulmonary circulation; when Harvey had traced these two journeys he had proved the double circulation of the blrod.

Although this discovery as stated here appears very simple, yet it took Harvey nineteen years to trace the blood through all the channels of the body, before he felt quite certain that he had hit upon the truth. Meanwhile he had returned to London, and had been made physician at St. Bartholomew's Hospital. Here he taught his theory in his Lectures of 1619 , and at last published a small book on the 
PT. III.

circulation of the blood in 1628 . Yet none of the older physicians would believe he was right, and Harvey told a friend that he lost many patients in consequence of his new doctrine. It is greatly to the credit of the unfortunate King Charles I., who was reigning at this time, and whose private physician Harvey was, that he gave him many opportunities of making physiological experiments on the animals in the royal parks, and took great interest in his discoveries. Harvey wrote several other valuable books, and traced the development of the chicken in the egg. He was of a very gentle and modest disposition, and disliked controversy so much that he could scarcely be persuaded to publish his later investigations when he found what disputes were occasioned by his great discovery of the circulation of the blood. He died in 1657 , in his eightieth year.

Discovery of the Vessels which carry Nourishment to the Blood, 1622-1649.-Harvey's doctrine of the circulation of the blood was the real starting-point of physiology, or the science of living bodies, and when the true action of the arteries and veins was known, many other vessels of the body were soon better understood. The most important of these were the vessels which carry nourishment from all parts of the body to make fresh blood. In 1622 Gaspard Asellius, Professor of Anatomy at Pavia, saw a white fluid flowing from some thread-like tubes in the body of a dog which he was dissecting. This dog had been eating food just before he died, and Asellius found that the fluid came from the intestines and was the nourishing matter of the fond. He called these fine tubes lacteals, because the fluid in them looked like milk. Some years later, in 1647, Jean Pecquet, an anatomist of Dieppe, discovered that these lacteals empty themselves into a large tube called the thoracic duct, which 
carries the fluid into the principal vein, and so to the heart ; and finally, in I649, a Swede named Olaüs Rüdbeck discovered an immense number of fine thread-like tubes running from all the principal parts of the body, and carrying nourishing matter to the thoracic duct, and so through the great vein to the heart. He called these tubes lymphatics; but in reality the lymphatics and lacteals are the same vessels, coming from different parts of the body and supplying the material for new blood. You will easily understand that when physiologists knew not only how the blood circulates through the body, but also how a fresh supply of blood, is being constantly provided, they had made a great step towards tracing out the working of a living body.

Chicf Works consulted.-Sprengel, 'Hist. de la Médecine,' 1815; Harvey's 'Anatomical Exercises,' 1673; Aikin's 'Biog. Mem. of Medicine till the Time of Harvey,' I780; Huxley's 'Elementary Physiology ;' Carpenter's 'Physiology ;' Kirke's 'Physiology ;' Cuvier, 'Hist. des Sciences, \&c. ;' D'Orbigny, 'Dict. des Sciences.' 


\section{CHAPTER XV.}

SCIENCE OF THE SEVENTEENTH CENTURY (CONTINUED).

Torricelli discovers the reason of Water rising in a Pump-Uses Mercury to measure the Weight of the Atmosphere-Makes the First Barometer-M. Perrier, at Pascal's suggestion, demonstrates varia-

- tions in the pressure of the atmosphere-Otto Guericke invents the Air-pump - Working of the Air-pump-Guericke proves the Pressure of the Atmosphere by the experiment of the Magdeburg Spheres-He makes the first Electrical Machine-Foundation of Royal Society of London and other Academies of Science.

Torricelli's Invention of the Barometer, 1644.-We must now turn to quite another subject on which new light was being thrown at this time. Among the many different mechanical experiments which Galileo made during his life, there had been one with a common pump which puzzled him very much, and which he had never been able to explain.

You know that if you put the mouth of a squirt in water and pull back the handle, the water rises up into the tube. That is to say, as soon as you leave a space inside the squirt quite empty without any air in it, the water rushes in. In the same way, water may be made to rise up a long tube standing with its open end in a pond or basin, by drawing up a tight-fitting stopper A, Fig. 14, called a piston, and so driving the air out at the top and leaving a vacuum inside the tube. But Galileo found that as soon as the water had risen up to the height of about 
34 feet it would not mount any higher, even though the tube between the surface of the water $\mathrm{C}$, and the piston $\mathrm{A}$, had no air in it. He could not, however, find out why the water should stop rising just at this point, and it was not till after his death that his friend and follower Torricelli (born 1608), who was a mathematical professor at Florence, hit upon the reason.

Torricelli asked himself, 'Why does the water rise in the tube at all? something must force it up.' Then it occurred to him that air must weigh something, and that it might be this weight on the open surface of the water which forced the water up the pump where there was no air pressing it down. To understand this you must picture

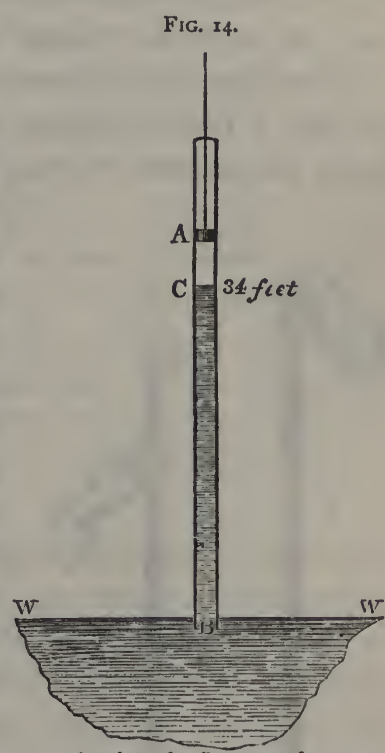

Section of a Suction-tube.

A, Tight-fitting piston. c, Greatest height to which the water will rise. W B W, Natural level of the water. to yourself all the air round our globe to be pressing down upon the surface of the earth. Now, so long as the tube also is full of air the surface of the water will all be equally pressed down, and so will remain at one level at $\mathrm{W}$ B $\mathrm{W}$. But when the piston $\mathrm{A}$ is drawn up, it pushes the air above it out of the tube, and so lifts the weight off the water at $\mathrm{B}$, which will immediately be forced up the tube by the pressure of the air on the water outside from $w$ to $w$. This will go on till the water has risen about 34 feet to $c$ and 
then the column of water $\mathrm{C} \mathrm{B}$ in the tube will press as heavily on the water at $\mathrm{B}$ as the air does on the water outside from $\mathrm{w}$ to $\mathrm{w}$, so all the water $\mathrm{w} \mathrm{B} \mathrm{w}$ will again be equally pressed upon, and no further rise will take place in the tube.

When Torricelli had made this discovery it occurred to him that if it was really the weight of the air which supported the column of water it ought to lift mercury or

\section{FIG. 15.}

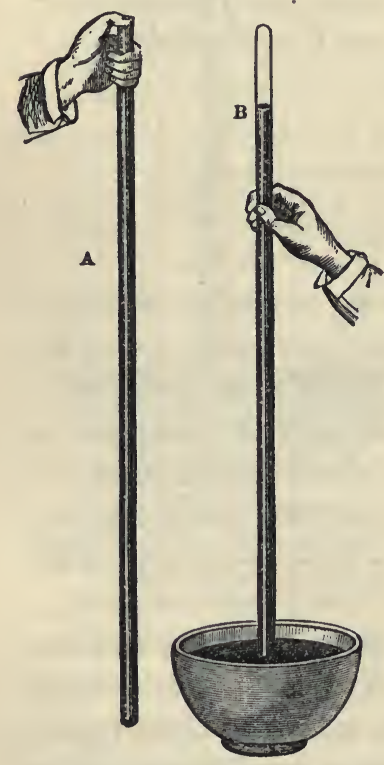

Torricelli's Experiment (Ganot). quicksilver, which is fourteen times heavier, to one-fourteenth of the height. So he took some mercury, and filling a tube $\mathrm{A}$, about 34 inches long, with it, he turned the tube upside down into a basin of mercury, which being open was under the pressure of the atmosphere. The mercury began at once to sink in the tube, and finally settled down at $\mathrm{B}$, about 30 inches above that in the basin. From this Torricelli knew that the weight of ordinary air is sufficient to keep a column of mercury at a height of 30 inches in vacuum. He had now therefore made an instrument which would measure the weight of the air, and as our atmosphere varies in weight according as the weather is cold or hot, or damp or dry, a column of this kind would be higher when the air was heavy and lower when it was light. He kept this apparatus always in one 
place, and observed that the mercury rose above the 30 inches whenever the air was heavy, and sunk below whenever the air was light. When once this was discovered it was easy to mark off inches and parts of inches on the side of the tube so as to reckon how much the mercury rose and fell each day.

This was the beginning of the barometer, by which we measure the weight of the atmosphere. It was a long time before people would believe that anything so invisible as air could affect the mercury, but this was at last clearly proved by a man named $\mathbf{M}$. Perrier, who carried a barometer to the top of a mountain called the Puy de Dôme, in Auvergne. As the summit of a mountain reaches to a great height in the atmosphere, it has, of course, less air resting upon it than the valley below has, and so the mercury when carried to this height not being pressed so much up the tube, fell nearly 3 inches, and then rose again gradually as M. Perrier came down into the valley below where there was a greater weight of air. This experiment, which was suggested by the famous French writer Pascal, proved beyond doubt that it was the weight of the air which caused the mercury to rise.

If now, after reading this account, you go and look at an ordinary upright barometer, you will perhaps be puzzled by finding it all enclosed in wood, and you will ask how the air can get to the mercury to press it down; but if you look carefully at the wooden box at the bottom, you will find a small hole in the wood, often having a small plug of paper in it to keep out the dust, and through this hole, even stuffed up as it is, the pressure of the air can act. The space between the top of the column of mercury (B, Fig. 15) and the end of the tube is a vacuum, or a space without any air in it, and is still called a Torricellian vacuum. 
PT. III.

Invention of the Thermometer.-The date of the invention of the thermometer (or instrument to measure heat) is so uncertain that it will be best to speak of it here in connection with the barometer. Galileo is said to have made the first thermometer, which was simply a tube with a bulb at the end standing upside down in a basin of water. The bulb was filled with air, and when heat was applied to it, it expanded and drove back the water in the tube. A few years afterwards a Dutchman named Drebbel made thermometers with spirits of wine in them, and finally, in 1670 , mercury was used. Mercurial thermometers have the bulb and part of the tube filled with mercury, and the rest of the tube is quite empty, all the air being driven out by heating the mercury till it completely fills the tube, and then melting the end so as to close it. When the mercury cools it contracts and a vacuum is left above it. Afterwards, when the bulb of this thermometer is heated, the mercury expands and rises in the tube; when it is chilled it contracts and falls.

The thermometer was not of any great use till early in the eighteenth century, when three men, Fahrenheit, Celsius, and Réaumur, measured off the tube into degrees, so that the exact rise and fall could be known. Celsius and Réaumur took the freezing-point of water as their lowest point ; but Fahrenheit took the greatest cold he could obtain by a mixture of snow and salt. For this reason $32^{\circ}$ is the freezing point of water in a Fahrenheit thermometer, and his other divisions are different from those of Celsius or Réaumur. Celsius's scale is now the one used all over the Continent, and scientific men wished to introduce it into England, because it is so much more simple than Fahrenheit's. It is called ' centigrade,' or a hundred steps, because the freezing- 
point of water is $0^{\circ}$, and the tube is so divided that there are exactly $100^{\circ}$ degrees between the freezing and the boiling point.

Otto Guericke invents the Air-pump, 1650.-The Torricellian vacuum in the barometer, was made, as we have seen, by simply filling a glass tube more than 30 inches long with mercury, and then turning it upside down into a basin of the same, so that the mercury in the tube fell to 30 inches, and an empty space was left at the top. But in $165^{\circ}$, a very few years after Torricelli's experiment, Otto Guericke, a magistrate of Magdeburg, in Prussia, made another step in advance and invented an air-pump, by which air can be drawn out of a vessel, leaving it almost empty. Fig. 16 is the simplest kind of air-pump, and the way it works is not difficult to understand. At the bottom is a glass jar which has a round barrel or cylinder, B B, fixed on the top of it. In the cylinder is a tight-fitting piston, $c c$, like the one in the suction-tube p. II 7 , only that this one has in it a valve or door, $d$. There is also another valve, $e$, at the place where the cylinder and glass jar meet, and both these valves open

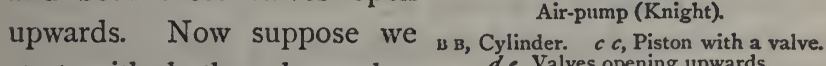
start with both valves shut

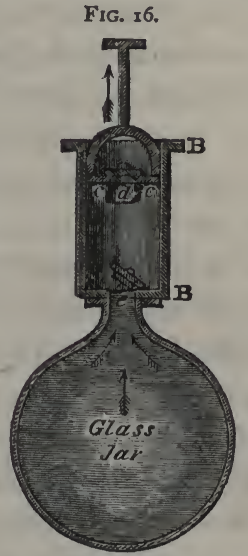
and the piston $c c$ down at the bottom of the cylinder resting on the valve, $e$. Then if we pull the piston gradually up, the valve $d$ will be kept shut by the air outside pressing 
upon it, and so the piston will force the air between $\mathrm{B}$ and $\mathrm{B}$, out of the top of the cylinder. If the valve $e$ remained also shut there would now be a vacuum, or space without air, in the cylinder B; but this will not be so, because the air in the jar below, being no longer kept down by air above it, will expand, and forcing up the valve $e$ will fill the whole of the jar and the cylinder with expanded air.

Now bring down the piston $c c$ again and observe what will happen. The thin air in the cylinder will be pressed down upon the valve $e$ and will shut it, and then, not being able to get down into the jar, it will force up the valve $d$ again, and escape out at the top. The piston will now be resting once more upon the valve $e$; but the glass jar will have much less air in it than it had at first, because it will have lost all that which went up into the cylinder and was pressed out at the top. You have only to repeat this process and more air still will be drawn out, and thus by moving the piston up and down you gradually empty the glass jar. You cannot get quite all the air out, because there must be enough left to push open the valve $e$ when you pull the piston up, but you can go on till there is very little indeed. Air-pumps are now constructed, by which the air can be entirely drawn out and a perfect vacuum left ; but we are speaking of the one Guericke made, which was like the one I have described, only more complicated, and he worked it under water to make quite sure that no air should creep in at the cracks.

The Experiment of the Magdeburg Hemispheres 'The first experiment which Guericke made with his airpump was to prove that the atmosphere round our earth is pressing down upon us heavily and equally in all directions. To do this he took two hollow metal hemispheres, like the 
two halves of an orange with the inside taken out. These hemispheres fitted tightly together, so that no air could pass in or out when they were shut. Outside he fastened rings to hold by, so as to pull them apart, and at the end of one hemisphere he fixed a tap which fitted on to his air-pump. Now, as long as there was air inside the closed globe the two halves came apart quite easily; but when he had drawn out the air with the air-pump and turned off the tap so as to leave a vacuum inside, it required immense strength to drag the globe into two parts. This showed that the atmosphere was pressing heavily on every side of the globe, forcing the two halves firmly together, and as there was no air inside to resist this pressure, the person trying to separate them had to force back, as it were, the whole weight of the atmosphere to get them apart. As Guericke was burgomaster of Magdeburg, this experiment has always been called 'the experiment of the Magdeburg hemispheres.'

The first Electrical Machine made by Guericke.-You will remember that Gilbert had shown in 1600 that sulphur and many other bodies, when they are rubbed, will attract light substances. Since his time very little notice had been taken of this fact, till Guericke invented the first rough electrical machine in $\mathrm{r}_{672}$. He made a globe of sulphur which turned in a wooden frame, and by pressing a cioth against it with his hand as it went round he caused the sulphur to become charged with electricity. His apparatus was very rough, but it led to better ones being made; and some

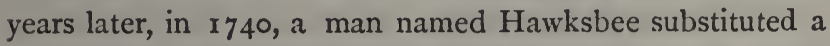
glass globe for the sulphur and a piece of silk for the cloth, and in this way electrical machines were made much like those we now use.

Guericke also discovered that bodies charged with the 
same kind of electricity repel each other. If you hang a piece of paper, or better still, a pith ball $a$, upon a silk thread $b$, and hold near to it a piece of sealing-wax $c$ rubbed with dry flannel, you will find that the ball will at first be attracted towards the sealing-wax as in $\mathrm{r}$, Fig. $\mathrm{x} 7$, but after a few moments it will be repelled and will draw back as in 2 ; nor will it approach the sealing-wax again till it has been near sorne other body, and given up part of the electricity it has received. Thus an electrical body, as Guericke pointed out,

Fig. 17.
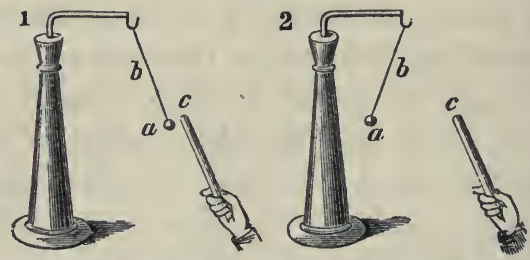

Pith-ball, attracted and repelled by rubbed sealing-wax.

attracts one that is not electrified, but repels it again as soon as it has filled it with electricity like itself. He was also the first to notice the spark of fire and crackling sound which are produced by electricity when it passes between two bodies which do not touch each other.

Foundation of the Royal Society of London and other Academies of Science, 1645.-We must now return to England, where about this time an event took place which, though it seened insignificant at the time, had in the end a great influence upon science. In the year 1642 the unfortunate King Charles I. began that civil war with his people which ended in his being beheaded on January 30,1649 . During these years all England was in a state of turmoil and confusion, and in London especially the riots and disturb- 
ances made it almost impossible for quiet and studious people to live in peace. It was under these circumstances that a small group of scientific men, among whom were Robert Boyle, son of the Earl of Cork, and Dr. Hooke, an eminent English mathematician, began to meet together privately to try and forget public troubles in discussing science. They assembled first in London in 1645 , but soon moved to Oxford to be out of the way of the constant riots, and continued to meet there till 1662 , after the restoration of Charles II., when they settled in London and formed themselves into a regular Society under a charter from the king.

This was the beginning of the Royal Society of London, which has done so much for science during the last two hundred years, and which is still the leading scientific society of England. The following account of its early meetings is thus given by Dr. Wallis, one of the first members, ' Our business,' he says, 'was (precluding matters of theology and State affairs) to discourse and consider of philosophical enquiries, and such as related thereunto: as Physick, Anatomy, Geometry, Astronomy, Navigation, Staticks, Magneticks, Chymicks, Mechanicks, and Natural Experiments; with the state of these studies, and their cultivation at home and abroad. We then discoursed of the circulation of the blood, the valves in the veins, the venæ lactæ, the lymphatic vessels, the Copernican hypothesis, the nature of comets and new stars, the satellites of Jupiter, the oval shape (as it then appeared) of Saturn, the spots on the sun and its turning on its own axis, the inequalities and selenography of the moon, the several phases of Venus and Mercury, the improvement of telescopes and grinding of glasses for that purpose, the weight of the air, the possibility or impossibility of vacuities 
and Nature's abhorrence thereof, the Torricellian experiment in quicksilver, the descent of heavy bodies and the degrees of acceleration therein, with divers other things of like nature, some of which were then but new discoveries, and others not so generally known and embraced as they now are; with other things appertaining to what hath been called the New Philosophy, which, from the times of Galileo at Florence and Sir Francis Bacon (Lord Verulam) in England, hath been much cultivated in Italy, France, Germany, and other parts abroad, as well as with us in England.'

How well we can picture from this account (written in 1696), the pleasure which this little group of men, weary of the quarrels and bloodshed of the times, felt in discussing and investigating those laws of nature which seem to bring us into the calm presence of an Almighty Unchanging Power far above the petty wranglings of man! The Royal Society has become, as I have said, one of the grandest scientific bodies in the world; but it has probably never held more earnest or enthusiastic meetings than in the small lodgings at Oxford where it first took its rise in the midst of civil war.

England was not long the only country which had a scientific society. Italy had already had two in the time of Galileo and Torricelli, but they had soon been broken up again. In Germany, the 'Imperial Academy of the Curious in Nature' was founded in 1662 ; and in 1666 the famous 'French Academy of Sciences' was legally established by the French Government in Paris.

All these societies were a great help in spreading the knowledge of scientific discoveries. Men who before were unable to publish what they knew, now sent or read their 
papers to those who could understand and appreciate them. The Royal Society began from the first to publish useful memoirs in their Philosophical Transactions; and in 1669 we find them bringing out the works of an Italian anatomist, Malpighi, of whom we shall speak presently, and who sent to them works which he could not afford to publish in Italy. By this means the information scattered about the world was gathered together, and men were encouraged to seek out new truths when there was a chance of their being known and appreciated.

Among the earlier members of the Royal Society there were some whose discoveries we must now consider. These were Boyle and Hooke, whom we have already mentioned; John Mayow, whose experiments in chemistry are especially interesting; Ray, Grew, and Malpighi, naturalists and anatomists; the Dutch astronomer Huyghens; the English astronomer Halley, and last, but not least, Fngland's great philosopher, Sir Isaac Newton.

Chief Works consulted. -Ganot's 'Physics,' 1873; Baliour Stewart on 'Heat,' 1871 ; Rossiter's 'Physics,' 1870 ; Baden Powell's 'Histtory of Nat. Philosophy,' \&c. ; Cuvier, 'Histoire des Sciences,' \&c. ; Birch's 'Hist. of Royal Society ;' Thomson's 'Hist. of Royal Society,' 1812 . 


\section{CHAPTER XVI.}

SCIENCE OF THE SEVENTEENTH CENTURY (CONTINUED).

Boyle's Law of the Compressibility of Gases-This same Law discovered independently by Marriotte-Hooke's theory of Air being the cause of Fire-Boyle's experiments with Animals under the Air-pump-John Mayow, the greatest Chemist of the Seventeenth Century-His experiments upon the Air used in CombustionProves that the same portion is used in Respiration - Proves that Air which has lost its Fire-air is Lighter-Mayow's ' Fire-air' was Oxygen, and his Lighter air Nitrogen-He traces out the effect which Fire-air produces in Animals when Breathing.

Boyle's Law of the Compressibility of Gases, 1661.-The Hon. Robert Boyle, seventh son of the Earl of Cork, and one of the principal founders of the Royal Society, was born in 1626 . He had very delicate health, and when quite young travelled much abroad and learned there a great deal about science even before he was eighteen years of age. He was deeply interested in Galileo's discoveries, and was in Florence when that great astronomer died in 1642 .

After his return to England, when he was at Oxford, he read an account of Guericke's air-pump, and was so delighted with this new discovery that he set to work at once to make one without ever having seen the original. He succeeded so well, with the help of his friend and assistant Dr. Hooke, that his air-pump became famous, and many writers have by mistake given him the credit of being the 
inventor. We have seen, however, that Guericke was the first to hit upon this instrument; Boyle only improved it, and made with it many very valuable experiments upon the weight and nature of air. These are too many and lengthy for us to examine here; but there is one law about the compression of gases which you will find connected with Boyle's name in all books on physics, and which you ought to understand. Boyle knew from Torricelli's experiment that the weight of the atmosphere upon the air, close down to our earth is about equal to the weight of 30 inches of mercury in a tube (see p. ri 8). Now he wished to find out how much air is compressed, or forced into a smaller space, when more weight is put upon it, and to prove this he devised the following experiment. He took a tube $\mathrm{A}^{\mathbf{1}}$, open at the long end and full of ordinary air, and by putting a little mercury into the tube and shaking it carefully till it settled at the bottom, he cut off a small quantity of air between $b$ and $c$. This air was of course still under the usual weight of the atmosphere, which pressed down upon the mercury through the open end of the tube. But the mercury did not add to

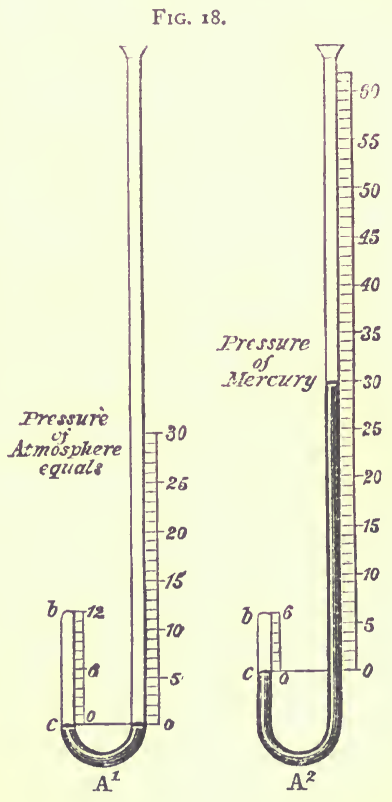
the weight because it stood at the same height on both sides of the tube, and so was evenly balanced. 
He next added more mercury, till it stood 30 inches higher in the long end than in the short one (as seen in $\mathrm{A}^{2}$ ). The air between $b$ and $c$ was now pressed down twice as much as before, for it had the 30 inches of mercury weighing upon it, as well as the atmosphere, which equalled another $3 \circ$ inches. Boyle found that this double pressure had squeezed it into half the space $\left(b c\right.$, fig. $\left.\mathrm{A}^{2}\right)$; in other words, $b y$ doubling. the pressure he had halved the volume of the air. $\mathrm{He}$ then poured in 30 inches more mercury, making the pressure three times as great as at first, and he found the air was now compressed into one-third of the space it had filled at first. And this he proved to be the law of compression of air and of all gases, that the volume of a gas (that is, the space it fills) is decreased in proportion as the weight upon it is increased. If you double the pressure you halve the volume; if you halve the pressure you double the volume.

This law of the compressibility of gases is known as Boyle's Law, or sometimes as Marriotte's Lawe, because a Frenchman named Marriotte also discovered it some years later without knowing that Boyle had done so. It is not always absolutely true, but we cannot stop to discuss the exceptions here; you will find them in books on physics and chemistry.

Boyle and Hooke both gave much time to the study of chemistry. Hooke published a theory in 1665 that air acts upon substances when they are heated, and so produces fire ; for, said he, in making charcoal, although the wood is intensely heated and glows brightly, yet so long as the air is kept away it will not be consumed. Boyle also proved that a candle will not burn, nor animals breathe, without air. He found that when he put mice and sparrows into his airpump, and then drew out the air, they died ; and that flies, 
bees, and even worms, became insensible; while fish, though they lived longer than the mice, soon turned on their backs and ceased to live. He also put a bird under a glass vessel full of air, and it died after three-quarters of an hour. It was clear, therefore, that fresh air is necessary to life, and Boyle began to think that just as a candle-flame cannot be kept up without air, so there must be some vital fire in the heart which is extinguished when air is shut out from it.

This opinion he discussed at the Oxford meetings, and a young physician named John Mayow listened very eagerly, and then went home and set himself to try and find out what this strange power in the air could be, without which neither fire nor animals could exist.

Mayow's Experiments on Respiration and Combustion, 1645-1679.-John Mayow's private history is very short. He was born in Cornwall in 1645 ; he became a Fellow of All Souls', Oxford, and practised as a physician in Bath ; and finally he died at the house of an apothecary in York Street, Covent Garden, in 1679 , before he was thirty-four years of age. This is all we know about his life; but he must have been a diligent worker and a real lover of science, for though he died so young he left behind him an account of a number of experiments and discoveries which entitle him to be called the greatest chemist of the seventeenth century. I wish we could go through all his experiments, for they form a most beautiful lesson of the earnest and painstaking way in which Gud's laws should be investigated. Mayow never made a careless experiment; he never thrust in his own guesses when it was possible to work out the truth; he went on patiently step by step, taking every care to avoid mistakes, and never resting till he had got to the bottom of his difficulties. Let us now take some of his experiments on 
PT. III,

combustion, or burning, and respiration, or breathing, and try and follow them as carefully as he did.

It seemed to him clear from the experiments of Boyle and Hooke that there must be something in the air which gave rise to flame and breath, and that this could only be a small part of the air, since a candle when put under a bellglass went out long before all the air was gone. He first of all satisfied himself by experiments that this gas which burnt, and which he called fire-air, was not only in the atmosphere, but existed in nitre, or saltpetre, and also in many acids; and then he set to work to discover how much of it there was in ordinary air. To do this he took a piece of camphor, with some tinder dipped in melted sulphur, and placed it on a little platform hung inside a bell-jar (see Fig. 19). He then lowered the bell-jar into a basin of water, having first put a siphon or bent tube under the bell-jar to let enough air out for the water to rise. Then he took the tube out, leaving the water at the same height inside and outside the jar, while the rest. of the jar above the water was

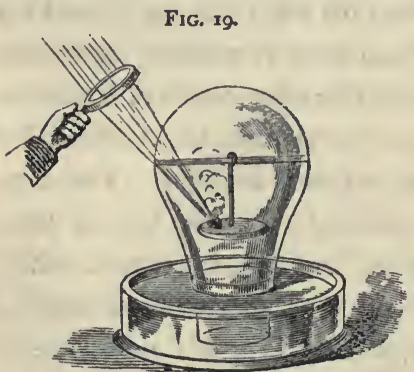

Fig. 20 .

Mayow's experiments on combustion and respiration (Yeats).

full of air. He now held up a burning-glass, and brought the sun's rays to a focus upon the camphor and tinder till it grew hot and burst into a flame. As it burnt he noticed that 
at first the water inside the jar sank down, because the air, being heated, expanded and took up more room. Then after a time the camphor ceased to burn, the jar cooled down, and the water rose again higher than before, till it stood above the water outside. The camphor was not all consumed, but when he tried to light it again he could not succeed. Why was this? 'Because,' said Mayow, 'there are no fire-air particles left in the jar to make the camphor burn, and the using up of these particles has made the rest of the air shrink and take up less space.'

He now wished to compare burning with breathing, so he put a mouse in a cage and hung it inside the bell-jar, which he arranged over the water as before. Little by little as the mouse breathed the water crept up inside the jar, until when it had risen to a certain height the mouse drooped and died. It was clear, therefore, that animals in breathing use up some portion of the air. But is it the same portion which the flame uses? Many people would have jumped at this conclusion, but Mayow was not content till he had proved it by another experiment. He put a lighted candle and a mouse together inside the bell-jar. The water now rose much faster than before; the candle went out first, and then the mouse drooped as soon as the water had risen to the same height as in the other experiment. He was now certain that the candle and mouse both used up the same fire-air particles ; but to make still more sure, he put a candle under a bell-jar where the air had been spoiled by breathing, and it went out directly.

His next step was to try whether air was lighter or heavier after the fire-air had been used up. To do this he put two mice into the jar, one at the top and the other at the bottom; the one at the top drooped and died, while the 
other was still breathing. This proved that the air which had lost its fre-air particles was lightest and 'rose to the top, so that the top mouse could no longer breathe. By these and a great many other experiments Mayow proved that air is made up of two portions - one heavy, which supports flame and life ; the other light, and which is useless for burning or breathing, and this last was the largest portion. I want you to notice this particularly, because you will see by-and-by that Mayow had really discovered and described two gases. The one which he called fire-air was oxygen, which was not known to other chemists for more than one hundred years later, and the other and lighter one is now called nitrogen.

Having now proved that an animal in breathing uses up the same part of the air which a candle does in burning, Mayow wanted next to know what this fire-air did inside the animal. Harvey, as you remember, had proved that the blood passes through the lungs and there meets the air which we draw in at each breath. Here then, said Mayow, the fire-air particles must come in contact with the blood, and, joining with it in the same way as they do with the fat of a candle, must cause the heat of the blood. If anyone wants to prove this let him run fast. He will find that he is obliged to breathe more quickly and draw more air into his lungs, which will soon make his blood hotter and move more quickly, till his whole body glows with warmth. But if this mixture of the air with the blood does really take place, the arteries into which blood has just flowed from the lungs and heart ought to be full of air ; and this is easily proved to be the case by putting warm arterial blood under an airpump, where, as soon as the pressure of the outside air is taken off, innumerable bubbles rise out of the blood as fast as they can come. 
In this way, by careful experiments and reasoning Mayow succeeded in proving that fire-air (or oxygen) is the chief agent in combustion and respiration. If he had not died so young he might have become more known, and men might have studied his discoveries, which he published in 1674. Unfortunately, however, he did not live to spread his knowledge, and a false theory of combustion caused his work to be forgotten for many a long year.

Theory of 'Phlogiston,' 1680-1723.-This mistaken theory was proposed by two very eminent chemists, John Joachim Becher (1625-1682) and Ernest Stahl (16601734). Ernest Stahl in particular was a man of great talent and perseverance, and he did a great deal for the study of chemistry by collecting a great number of facts about the way in which different substances combine together, and by arranging these facts into a system. But his theory of combustion was quite mistaken, and it seems very surprising that it should have been received by the chemists of that day in the face of the facts so carefully proved by Mayow. Stahl imagined that all bodies which would burn contained an invisible substance which he called 'Phlogiston,' and that when a body was burnt it gave up its phlogiston into the air, and could only regain it by taking it out of the air or some other substance. It would only confuse you to try and understand how this theory explained some of the facts of chemistry. You will see at once one which it did not explain, namely, why a body should grow heavier when it is burnt, as Geber, 1,500 years before, had shown it does. This fact alone ought to have been sufficient to prevent the theory gaining ground; but Stahl's fame was so great, and his imaginary 'Phlogiston' seemed to answer so well in a great many problems, that chemists believed in it 
for nearly a hundred years, and Mayow's true explanation was forgotten till the eighteenth century, when fresh experiments proved Stahl's theory to be false.

Chief Works consulted.-Brande's 'Manual of Chemistry'-Introduction; Rodwell's 'Birth of Chemistry ;' Yeats 'On Claims of MIoderns to discoveries in Chemistry and Physiology,' 1798; Birch's 'Life of Boyle,' I 744 ; Shaw's 'Philosophical Works of Boyle,' I 725. 


\section{CHAPTER XVII.}

\section{SCIENCE OF THE SEVENTEeNTH CENTURY (CONTINUED).}

Malpighi first uses the Microscope to examine Living Structures-He describes the Air-cells of the Lungs-Watches the Circulation of the Blood-Observes the Malpighian layer in the human Skin-Describes the structure of the Silkworm-Leeuwenhøek discovers Animalcules-Grew and Malpighi discover the Cellular Structure of Plants-The Stomates in Leaves-They study the Germination of Seeds-Ray and Willughby classify and describe Animals and Plants -The Friendship of these two Men.

Use of the Microscope by Malpighi, 1661.-We have now fairly left behind us the first fifty years of the seventeenth century ; indeed, the experiments of Boyle and Mayow were all made after 1650 . But I wish especially here to remind you that we have just begun the second half of the century, because it will help you to remember an important study which began very quietly about this time, but which has in the end opened out to us an entirely new world of discovery. In the year 1609 , at the beginning of the century, Galileo brought distant worlds into view by the use of the tclescope; and in like manner in the year 1661 , or about the middle of the century, Malpighi, by the use of the microscope, revealed the wonders of infinitely minute structures, or parts of living bodies ; enabling men to see fibres, vessels, and germs, which were as much hidden before by their minuteness as the moons of Jupiter had been by their distance. It is not quite

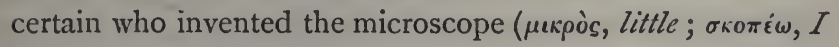
look); but as the first which were made were only telescopes 
(see p. 97), with lenses of such a focus as to look at an object near instead of far off, anyone may easily have hit upon the idea. The important point was the use made of them, and this, as far as regards the structure of living beings, we owe to Malpighi.

Marcello Malpighi was born at Crevalcuore, near Bologna, in the year 1628 ; he became Professor of Medicine at the University of Bologna in 1656 , and was early distinguished for his discoveries in Anatomy, made chiefly by the use of the microscope. It is not possible for us, without a knowledge of anatomy, to understand thoroughly the structures which he described, but we may be able to form a general idea of the work be did.

One of his first experiments was the examination of the general circulation of the blood in the stomach of a frog, and he succeeded in demonstrating the fact that the arteries are connected with the veins by means of minute tubes called capillaries, thus proving beyond doubt the truth of Harvey's doctrine. His next work was to study the passage of the blood through the lungs (see p. Ir 3 ), and to describe the air-cells from which the blood derives its oxygen. If you can get anyone to show you properly under the microscope a section of a frog's lung, you will see a number of round spaces bordered by a delicate partition; these are sections of air-cells, and round them you will see a network of minute tubes. Through these tubes or capillaries the blood flows in a living creature, and takes up oxygen from the air through the coverings or membranes of the aircells and capillaries, giving back in exchange carbonic acid to be breathed out into the atmosphere. Malpighi was the first to point out these air-cells and to describe the way in which the blood passes over them. After this he turned his 
attention to the tongue, and published in 1665 a careful description of all its nerves, vessels, and coverings. He also pointed out that the outside layer of the skin or epidermis of the negro is as white as yours or mine, and that the colouring matter which gives him his dark colour is contained in a deeper layer just at the point where the epidermis joins the dermis or real fibrous skin beneath (see Fig $2 \mathbf{I}$.) This soft layer is still called the 'Malpighian layer,' and the different colours of the skins of animals are caused by little cells of colouring matter which lie buried in it.

After Malpighi had examined many other minute structures of the human body, he began next to study insects, and in 1669 he published a

Fig. 21.

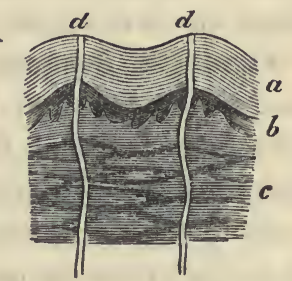

Section of the Skin (Huxley).

$a$, Epidermis. b, Its deeper layer, or Malpighian layer. $c$, Upper part of the dermis, or true skin. $d d$, Perspiration ducts. beautiful description of the silkworm. With his microscope he discovered the small holes or pores which are to be seen along both sides of the body of insects, and he found that these pores were openings into minute air-tubes, which pass into every part of the insect's body, and form a breathing apparatus. He also described the peculiar vessels in which the silkworm secretes the juice from which its silk is made, and he traced the changes which the different parts of the worm undergo as it turns into the moth. In fact, he was the first man who attempted to trace out the anatomy of such small creatures as insects; a study to which men now often devote their whole lives.

But grand as Malpighi's discoveries were, a Dutchman named Leeuwenhœek (born 1632, died 1723 ) made the micro- 
PT. III.

scope tell even a more wonderful tale, for he detected in water and in the insides of animals those extremely minute beings which he called animalcules. He showed that a piece of the soft roe of the cod-fish not bigger than an ordinary grain of sand might contain ten thousand of these living creatures. When such tiny beings as these could be seen and examined, I think you will acknowledge that I did not speak too strongly when I said that the microscope has opened out to us a new and marvellous world of life.

Vegetable Anatomy, Grew and Malpighi, 1670.From insects Malpighi next turned to plants; and it is curious that at about the same time an English botanist named Nehemiah Grew (born 1628, died I 71r), who was secretary to the Royal Society, also took up the same study ; and the papers of the two men were laid before the Royal Society on the same day in 1670. Malpighi's complete work was afterwards published in 1674 , and Grew's in 1682 .

The investigations of these two men agreed in many remarkable points; they had both of them examined with great care the flesh (if we may call it so) of plants, and they described for the first time the tiny bags or cells of which every part of a plant is made, and which you may easily see

Fig. 22.

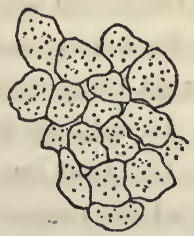

Cellular tissue from the pith of the elder (Oliver). for yourself if you put a very thin piece of the pulpy part of an apple, or better still, of the pith of elder under the microscope (see Fig. 22). They had also noticed the long tubes which lie among the woody fibres in the stringy or fibrous part of a plant and in the veins of the leaves, and Grew had pointed out quite truly that these tubes, which are called vessels or ducts, are composed of 
strings of cells which have grown together into one long cell or tube.

Grew also first saw those beautiful little mouths in the skin of the leaves called stomates, which open when the air is damp, and serve for taking in and giving out air and moisture. To see these you must take a very thin piece of the skin of the under part of a leaf, and place it in water under the microscope ; you will see a number of very small roundish or oval spaces (a, Fig. 23), and if you watch carefully you will most likely see some of Fic. 23. them open in the water. Grew discovered these stomates and pointed out their use. He also studied very carefully the way in which seeds begin to sprout ; but on this point Malpighi did the most, for he watched under the microscope the whole process of the growth of seeds, and described all the different states of the germ, comparing

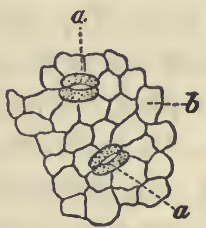

Piece of the outer skin taken from the underside of an apple leaf. $a$ a. Stomates. $b$, Cells of the skin (Carpenter). them to the growth of a chicken in the egg, and showing how much an egg and a seed resemble each other in many particulars.

By these few examples you can form an idea how much Grew and Malpighi did towards the study of the structure of plants or Vegetable Anatomy, a science which they may almost be said to have founded, and one which you may work at yourself with the help of a fairly good microscope and an elementary book on Botany. If you will do this. with patience and care you will be well repaid; for some of the most beautiful and delicate of the contrivances of Nature lie hid in those frail flowers which we gather for their scent and beauty, and fling away without imagining what 
wonderful structures they can reveal to us even when dead and withered.

\section{Classification of Plants and Animals by Ray and} Willughby, 1693-1705.-We now come to the history of two friends, which is in itself a pleasure to dwell upon, even if they had not both been great men; but which becomes much more interesting when we remember that it was their love of the study of Nature which first brought them together, and which made them inseparable, not only in life, but in their works after death.

John Ray, one of the greatest botanists of the seventeenth century, was born near Braintree, in Essex, in the year 1628 . Though only the son of a blacksmith, he received a good education at the grammar school of the town, and went afterwards to Cambridge, where he remained as a tutor after he had taken his degree. Here one of his first pupils was a Mr. Francis Willughby, of Middleton Hall, in Warwickshire, a man seven years younger than himself, and belonging to quite a different rank in society. These two men, however, had one great interest in common-they were both passionately fond of Natural History, and spent all their spare time in studying it together.

They soon found that the descriptions and classifications of plants and animals which had been drawn up by earlier naturalists were very imperfect, and they formed the project of drawing up a complete classification of all known plants and animals, describing them as far as they were able, and arranging them in groups according to their different characters. Willughby undertook the birds, beasts, and fishes, while Ray devoted himself chiefly to plants; but they worked together in all the branches, and Ray, as we shall see, ended by doing far more than his share of the work. 
From 1663 to 1666 the two friends travelled together over England, France, Germany, and Italy, making collections of animals and plants, and Willughby took a pleasure in using his wealth to add to the knowledge of his poorer companion. Soon after their return Ray was made a fellow of the Royal Society, and Willughby was not long before he received the same honour. Willughby now married, and though Ray continued his travels alone, yet a great part of his time was spent at Middleton Hall, where the two friends made experiments upon sap in the trees and the way it flows.

In this way they worked together till, in $1672, \mathrm{Mr}$. Willughby died of a fever, leaving a sum of sixty pounds a year to Ray, and begging him to bring up his two little sons and to continue his works on Zoology, which he had left unfinished. The way in which Ray fulfilled these requests fully showed the affection which he felt for his lost friend. $\mathrm{He}$ brought up the boys till they were removed from his care by relations ; and as to the works, he edited them with so much care and such a touching desire to give every credit to Willughby, that much of the work which must have been Ray's stands in his friend's name, and in fame, as in life, it is impossible to separate them.

I can only give you a very general idea of the kind of classifications which Ray and Willughby adopted, for a mere list of classes would be neither interesting nor useful to you. The first book, which was on Quadrupeds, was published by Ray in 1693 . He divided these first, as Aristotle had done, into oviparous, or those that are born from eggs, like frogs and lizards; and viviparous, or those which are born alive, like lambs and kittens. He then divided the viviparous quadrupeds into those which have the hoof all in one piece, 
like the horse, and those with a split hoof, like the ox and goat. Those with split hoofs he divided again according as they chewed the cud, like the ox, or did not, like the pig. Then came the animals whose hoofs are split into many parts, as the hippopotamus and rhinoceros ; then those which have nails only in place of toes, as the elephant ; then those which have toes but no separation between the fourth and fifth toes, as the eat, dog, and mole; and lastly, those which haves the fifth finger, or toe, quite separate, as the monkeys. After this he divided them more fully, by their teeth, and thus made a very fair classification of quadrupeds.

The book upon Birds, which comes next in order, had already been published by Ray in 1677 , four years after Willughby's death. In it birds were divided first into landbirds and water-birds, and then were classified by the shape of their beak and claws, and according as they fed upon flesh like the vulture, or upon fruit and seeds like the parrot. The water-birds were also divided into those which were longlegged, as the flamingo, or short-legged, as the duck, and according as the web between their toes was more or less complete.

The 'History of Fishes' is given as the joint work of Ray and Willughby; the groups into which they divided them are nearly the same as those now used, but they are too difficult to explain here.

The 'History of Insects' was Ray's work, and was published by friends after his death, in the same way as he had published Willughby's. He divided insects into-first, those which undergo metamorphosis (that is, turn from the caterpillar into the moth), as the silkworm, and all moths and butterflies ; and second, those which do not change their form; and then he sub-divided them according to the number of their feet, the shape of their wings, and many other characters. 
But Ray's greatest work was upon Plants, which he classified much more perfectly than Cæsalpinus had done. He divided them first into imperfect plants, or those whose flowers are invisible, as mosses and mushrooms; and perfect plants, or those having visible flowers. The perfect plants he divided into two classes-first, the dicotyledons, or those whose seeds open out into two seed-leaves, like the wallflower or the bean, in which last you can see the two cotyledons very clearly if you take off the outer skin; and secondly, the monocotyledons, or those whose seeds have only one large seed-leaf, like a grain of wheat. The dicotyledons he again divided into those having simple flowers, like the buttercup, and those whose flowers are compound, like the daisy; for if you pick a daisy to pieces you will find that the centre is made up of a number of little flowers, each of them perfect in itself. It will have its own green calyx and coloured corolla, and its own stamens and seed-vessel ; therefore each daisy is a branch of little flowerets, or a compound Hower. Ray went on next to class the simple flowers according to the number of seeds they bore, and the way in which the seeds were arranged in the seed-vessel. In this way he made a rough but complete classification of all the known plants. Linnæus, the great botanist of the eighteenth century, adopted many of Ray's divisions, which had meanwhile been made more perfect by Joseph Tournefort, a Frenchman, born at Aix, in Provence, in 1656.

Ray outlived his friend Willughby more than thirty years, and died in 1705 at the age of seventy-seven. His death brings us to the end of the Natural History of the seventeenth century, so far as we have been able to notice it. But I cannot too often remind you that these four men, Malpighi, Grew, Ray, and Willughby, are merely a few among an 
PT. III.

immense number of observers in the same line of study. I have picked out those whose work you could best understand, and whose names ought to be known to you; but I could have selected not four but forty others who ought to have been mentioned, if my book and your knowledge had been greater. We must be content to catch here and there a glimpse of the advance that was being made, always remembering that an almost inexhaustible store of further information remains behind when we have opportunity to seek for it.

Chief Works consulted. - Cuvier, 'Hist. des Sciences Naturelles ;' Carpenter's 'Physiology ;' Sprengel, 'Histoire de la Médecine;' Whewell's 'History of Inductive Sciences ;' Carpenter, 'On the Microscope ;' 'Memorial of John Ray,' E. Lankester, 1846 ; 'Life of Ray and Willughby,' Naturalists' Library, vol. xxxv. ; Lardner's 'Encyclopædia'-Classification of Animals. 


\section{CHAPTER XVIII.}

SCIENCE OF THE SEVENTEENTH CENTURY (CONTINUED).

1642, Birth of Newton-His Education-1666, His three great Discoveries first occur to him-Method of Fluxions and Differential Calculus-First thought of the Theory of Gravitation-Failure of his Results in consequence of the Faulty Measurement of the size of the Earth-1682, Hears of Picart's new Measurement-Works out the result correctly, and proves the Theory of Gravitation-Explanation of this Theory-Establishes the Law that Attraction varies inversely as the squares of the distance-1687, Publishes the 'Principia'-Some of the Problems dealt with in this Work.

Newton, 1642.-We must now leave the living creation to return to physical science, for, during all those years with which we have been occupied since the time of Galileo and Kepler, a boy had been growing up into manhood, who was to become one of the greatest men of science that England has ever known. In $\mathbf{1 6}_{42}$, the same year in which Galileo died, a child was born at Woolsthorpe, near Grantham in Lincolnshire, who was so tiny that his mother said 'she could put him into a quart mug.' This tiny delicate baby was to become the great philosopher Newton.

We hear of him that he was at first very idle and inattentive at school, but, having been one day passed in the class by one of his schoolfellows, he determined to regain his place, and soon succeeded in rising to the head of them all. In his play hours, when the other boys were romping, he amused himself by making little mechanical toys, such as a 
water clock, a mill turned by a mouse, a carriage moved by the person who sat in it, and many other ingenious contrivances. When he was fifteen his mother sent for him home to manage the farm which belonged to their estate; but it was soon clear that he was of no use as a farmer, for though he tried hard to do his work, his mind was not in it, and he was only happy when he could settle down under a hedge with his book to study some difficult problem. At last one of his uncles, seeing how bent the boy was upon study, persuaded his mother to send him back to school and to college, where he soon passed all his companions in mathematics, and became a Fellow of Trinity College, Cambridge, in 1667 . But even before this, in the year 1666 , his busy mind had already begun to work out the three greatest discoveries of his life. In that year he invented the remarkable mathematical process called the 'Method of Fluxions,' which is almost the same as that now called the 'Differential Calculus,' invented about the same time by Leibnitz, a great German mathematician. In that year he also made the discoveries about Light and Colour, which we shall speak of by-and-by ; and again in that year he first thought out the great Theory of Gravitation, which we must now consider.

Theory of Gravitation, 1666.-In the course of his astronomical studies, Newton had come across a problem which he could not solve. The problem was this. Why does the moon always move round the earth, and the planets round the sun? The natural thing is for a body to go straight on. If you roll a marble along the floor it moves on in a straight line, and if it were not stopped by the air and the floor, it would roll on for ever. Why, then, should the bodies in the sky go round and round, and not straight forward?

While Newton was still pondering over this question, the 
plague broke out in Cambridge in the year 1665 , and he was forced to go back to Woolsthorpe. Here he was sitting one day in the garden, meditating as usual, when an apple from the tree before him snapped from its stalk and fell to the ground. This attracted Newton's attention; he asked himself, Why does the apple fall ? and the answer he found was, Because the earth pulls it. This was not quite a new thought, for many clever men before Newton had imagined that things were held down to the earth by a kind of force, but they had never made any use of the idea. Newton, on the contrary, seized upon it at once, and began to reason farther. If the earth pulls the apple, said he, and not only the apple but things very high up in the air, why should it not pull the moon, and so keep it going round and round the earth instead of moving on in a straight line? And if the earth pulls the moon, may not the sun in the same way pull the earth and the planets, and so keep them going round and round with the sun as their centre, just as if they were all held to it by invisible strings?

You can understand this idea of Newton's by taking a ball with a piece of string fastened to it, and swinging it round. If you were to let the string go, the ball would fly off in a straight line, but as long as you hold it, it will go round and round you. Thus Newton imagined that everything near the earth is pulled towards it by an invisible force, as you would pull the ball by the string; but the ball does not come to you, although the string pulls it, because of the other force which is carrying it onwards; and in the same way the moon would not come to the earth, but would go on revolving round it.

Newton felt convinced that this guess was right, and that the force of gravitation, as he called it, kept the moon going 
round the earth, and the planets round the sun. But a mere guess is not enough in science, so he set to work to prove by very difficult calculations what the effect ought to be if it was true that the earth pulled or attracted the moon. To make these calculations it was necessary to know exactly the distance from the centre of the earth to its surface, because the attraction would have to be reckoned as strongest at the centre of the earth, and then as gradually decreasing till it reached the moon. Now the size of the earth was not accurately known, so Newton had to use the best measurement he could get, and to his great disappointment his calculations came out zorong. The moon in fact moved more slowly than it ought to do according to his theory. The difference was small, for the pull of the earth was only onesixth greater than it should have been : but Newton was too cautious to neglect this error. He still believed his theory to be true, but he had no right to assume that it was, unless he could work it out correctly. So he put away his papers in a drawer and waited till he should find some way out of the difficulty.

This is one of many examples of the patience men must have who wish to make really great discoveries. Newton waited sixteen years before he solved the problem, or spoke to anyone of the great thought in his mind. But more light came at last ; it was in 1666 , when he was only twentyfour, that he saw the apple fall ; and it was in 1682 that he heard one day at the Royal Society that a Frenchman named Picart had measured the size of the earth very accurately, and had found that it was larger than had been supposed. Newton saw at once that this would alter all his calculations. Directly he heard it he went home, took out his papers, and set to work again with the new figures. 
Imagine his satisfaction when it came out perfectly right! It is said that he was so agitated when he saw that it was going to succeed, that he was obliged to ask a friend to finish working out the calculation for him. His patience was rewarded; the attraction of the earth exactly agreed with the rate of movement of the moon, and he knew now that he had discovered the law which governed the motions of the heavenly bodies.

This law of Newton's is called the 'Law of Gravitation,' and we must now try to understand what it is. Gravitation means the drawing of one thing towards another, or towards a centre. All the objects upon our earth are held there by gravity, which pulls or attracts them towards the centre of the earth. If there were no such thing as gravity there would be nothing to prevent our chairs and tables, and even ourselves, from flying into space; but they are all held to the earth by gravity, and if you dig a hole under them they fall directly nearer to the centre.

Now let us see how this attraction of gravitation affects the planets. Every one of the bcdies in the heavens pulls or attracts all the other bodies, just in the same way as the earth attracts the apple on the tree. But as they are all moving rapidly along (like the ball swung round your head) they do not fall into each other, but the smaller bodies move round the larger ones which are near them, just as if they were fastened to them by invisible elastic threads. The smaller ones move round the larger one, because it is not only each body as a whole which pulls the other bodies, but every tiny atom of matter in each planet is pulling at all the atoms in all the other planets; so that the bigger a body is, and the more atoms it has in it, the more it will draw other bodies towards it. Our sun pulls the planets, 
and the planets pull, the sun; but our sun has 700 times more atoms in it than all the planets put together, and so it keeps them moving round it. In the same way our earth has eighty times more atoms in it than our moon, and so it keeps the moon moving round it.

In this way the force of gravity keeps all the different planets in their paths or orbits. It does not set them moving ; some other force unknown to us first started them across the sky - gravitation is only the force which determines the direction in which they move.

It was a grand thing to have discovered this force, but it would have been of little value to Astronomy to know that the heavenly bodies attracted each other unless it could also be known how much influence they have upon each other. This also Newton worked out accurately. You will remember that Kepler had shown that planets move in ellipses, having the sun in one of the two foci (see fig. 10, p. 99). Knowing this, Newton was able to calculate how much the sun attracts a planet when it is near, and how much when it is far off, so as to make it move in an ellipse; and he found

FIG. 24.

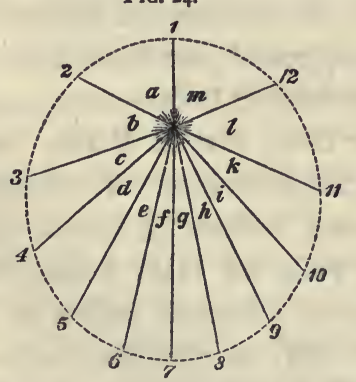
that exactly as much as the square of the distance increases, so much the attraction decreases; that is, the attraction grows less and less at a regular rate as you go farther away from the body that is pulling.

For instance, suppose that at the point I, fig. 24 , a planet was one million of miles away from the sun, and was being attracted with immense force. When it arrived at the point 
3 it would be about twice as far, or two millions of miles distant ; and the square of 2 being $4(2 \times 2=4)$, the attraction of the sun at this point will be only one-fourth as much as it was at the point $r$. At the point 7 the planet would be about three times as far, or three millions of miles from the sun, and as the square of 3 is $9(3 \times 3=9)$, the attraction here will be only $\frac{1}{9}$ th of the attraction at the point I. And so the calculation goes on ; if the planet went 12 millions of miles off, the attraction would be $\frac{1}{4} 4$ what it was at first, and at 92 millions of miles the attraction would be $\frac{1}{8464}$, so that when the planet is very far away the attraction becomes very slight indeed, but it will never entirely cease. In scientific language this law is expressed by the words, The attraction varies inversely as the square of the distance. When once this law was known, it explained in a most beautiful and complete way not only the three laws of Kepler, but all the complex movements of the heavenly bodies. These Newton worked out with the greatest accuracy by the help of his 'Method of Fluxions,' which enabled him to calculate all the varying rates at which the planets move in consequence of their mutual attraction; and he showed that whenever we know clearly the position and mass of all the bodies attracting a planet, the law of gravitation exactly accounts for the direction in which it moves.

If you will consider for a moment what a labour it must be to calculate how much all the different planets pull each other at different times-when they are near together and when they are far off, when they are near each other and near th sun, or near each other and far from the sun, in fact in all the different positions you can imagine-you may form some idea of the tremendous work he did. When he published his great book, the 'Principia,' in 1687 , there were 
not more than eight people in the world who were able to understand the full meaning of his calculations and reason:ings; and though his theory of gravitation was well received, and his name became one of the most renowned and honoured in the world, yet it was more than fifty years before his work was thoroughly appreciated.

It may therefore easily be imagined that it is not possible to give a simple sketch of what is contained in the 'Principia;' but some idea may perhaps be formed of the grandeur of the law of gravitation from an enumeration of some of the problems which Newton explained by its action.

I. He explained those laws of motion which Galileo had proved by experiment, and showed that it is the force of gravity which causes the weight of bodies; and determines, when combined with other laws, the rate at which they fall, and the path they describe.

2. He worked out the specific gravity of the planets, showing, for example, that the matter of which Saturn is composed is about nine times lighter than the matter of our earth.

3. He showed how the attractions of the sun and of the moon cause the tides of the sea, and worked out accurately the reason of the spring and neap tides.

4. He proved that the earth could not be a perfect globe, and measured almost exactly how great the bulge at the equator and the flattening at the poles must be. And this he did entirely by calculation, for no measurements had then been made, to lead anyone to doubt that the earth was a perfect globe.

5. He gave a complete explanation of the cause of the 'precession of the equinoxes,' the occurrence of which, as you will remember, Hipparchus had discovered (see p. 30 ). 
6. He not only showed why the planets move in ellipses while a line joining the sun and a planet cuts off equal areas in equal times; but he also accounted for many irregularities in these movements, arising from their mutual attractions, thus showing that gravitation explains not only the general laws but even apparent exceptions.

7. Of all bodies comets are apparently the most irregular, yet Newton calculated that they probably move in a peculiar curve called a parabola, and since his time it has been proved that the motions of all comets can be sufficiently well explained by this theory, with the exception of a few which move in ordinary ellipses like the planets, and return periodically. These and many other problems of the universe Newton showed could all be referred to the action of gravitation; and he concluded his work with a grand description of the mechanism of the heavens, dwelling with deep reverence upon the thought of that Infinite Mind which gave rise to such a wonderful and complex machinery, working in perfect order.

Chief Works consulted. -Brewster's 'Life of Newton;' 'Lives of Eminent Persons'--Lib. of Useful Knowledge; Airy's 'Elementary Astronomy ;' Airy, 'On Gravitation.' 


\section{CHAPTER XIX.}

SCIENÇE OF THE SEVENTEENTH CENTURY (CONTINUED).

Transits of Mercury and Venus-Kepler foretells their occurrence1631, Gassendi observes a Transit of Mercury-1639, Horrocks foretells and observes a Transit of Venus-1676, Halley sees a Transit of Mercury, and it suggests to him a method for Measuring the Distance of the Sun-1691-1716, Halley describes this method to the Royal Society - Explanation of Halley's method.

First transits ever observed of Mercury and Venus, 16311639.-We must now pause for a moment before passing on to Newton's discoveries in Optics, in order to mention a remarkable astronomical suggestion made about this time by the astronomer Halley (born 1656 , died 1742 ), who was the friend and disciple of Newton.

You cannot fail to have heard and read something about the expeditions sent last December, 1874 , into all parts of the world to observe the Transit (or Passage) of Venus across the sun. The object of these observations was to measure the sun's distance from the earth ; and Halley was the first to propose this method of measurement, in 1691 , and to show how it might be accomplished.

You know that the two planets Mercury and Venus are nearer to the sun than our earth is, and are therefore constantly passing between us and it. But usually they pass either below or above the sun, and it is only rarely that they cross over the bright disc, so as to be seen through 
the telescope as a round black spot upon the sun's face. With Mercury this happens at intervals of from seven to thirteen years; but with Venus it is much more rare, for though two transits generally come together with an interval of only eight years between them, yet after this there is a gap of more than a hundred years before another transit occurs.

After Kepler had finished the famous Rudolphine Tables he was able to use them to calculate when these transits would take place; and he showed that both Mercury and Venus would cross the sun's disc on certain days in the year 1631. A French philosopher named Gassendi took advantage of this prediction, and managed to observe Mercury passing across the face of the sun on November 7,1631 . He was the first who ever observed a transit. With Venus he was not so fortunate, for the transit of that planet took place when it was night at Paris, and so Gassendi had no chance of observing it.

It was not long, however, before this too was seen. You will remember that two transits of Venus occur close together with only eight years between them. Now Kepler had imagined that in $\mathbf{r}_{39}$ Venus would pass a little to the south of the sun, and so no transit would take place. A young Englishman, however, named Jeremiah Horrocks, only twenty years of age, after going carefully over Kepler's tables, felt convinced that there would be a transit, and he even calculated within a few minutes the time when Venus would enter upon the sun's face. Full of enthusiasm at the chance of seeing this grand sight, he wrote to a friend at a distance, begging him also to watch through the telescope at three o'clock on the afternoon of December 4, 1639. His expectations were not disappointed, for at fifteen minutes 
past three on that day the planet began to creep over the face of the sun. For twenty minutes Horrocks watched it, and then the sun set and he could see no more. He had been able to notice, however, that Venus was much smaller in comparison with the sun than had been formerly supposed. Horrocks and his friend Crabtree were the only people in the whole world who saw this transit of Venus, the first one ever observed.

Halley suggests that the Sun's distance may be measured by the Transit of Venus, 1691.-This was all that was known about transits when Halley went to St. Helena in 1676 to study the stars of the southern hemisphere. Here he also observed a transit of Mercury, and after watching the small black spot travelling across the face of the sun, and noting the time it took in going from one side to the other, the idea occurred to him that it would be possible to learn the distance of the sun by measuring the path of a planet across its face. As Mercury, however, is very far from us, and near to the sun, it would not answer the purpose so well as Venus, which is much nearer the earth.

Halley knew that another transit of Venus would take place in 1761 , and as he could not hope to live till then, he read a paper to the Royal Society in 1691, and another in I 7 1 6 , beseeching the astronomers who should live after him not to let such an opportunity pass, and describing the way in which the observations should be made. It is this method which we must now try to understand as far as it is possible without mathematics.

First of all I must tell you two facts which astronomers knew already. The proportion of the distances of the planets was ascertained, as you will remember, by Kepler (see p. 100). Therefore it was known that Vemus is (in round 
numbers) $2 \frac{1}{2}$ times as far from the sun as she is from the earth. It was also known by the apparent size of the sun that the sun's distance is about 108 times his diameter, or, in other words, if you could measure the number of miles across the face of the sun and multiply that number by 108, it would give you the sun's distance from the earth. Therefore you see the one point to be learnt was, Hoze many miles wide is the face of the sun?

Now suppose you place a globe or any other object upon the table in the middle of the room, as at G, Fig. 25, and place yourself at the point $A$.

The globe will then hide from you (or eclipse) the point $\mathrm{c}$ on the opposite wall. Move your position to $\mathrm{B}$, and the globe will then hide the point D. If the globe is (as at G) exactly half-way between you and the FIG. 25.

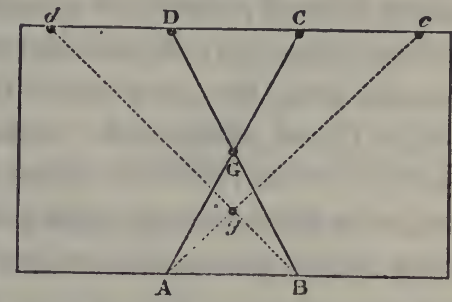

Diagram showing how the distance between the points $D$ and $d c$ can be known without wall, the two points $\mathrm{D}$ G, A globe half-way between D C and A B. $g, A$ and $\mathrm{c}$ will be the same globe three times as far from $\mathrm{D} C$ as from $\mathrm{A} B$. distance apart as the points A and B. But if you move the globe to $g$, which is three times as far from the opposite wall as it is from you, then the points $d$ and $c$ will also be three times as far apart as the points A and B. So that by knowing how much farther the globe is from the wall than it is from you, you can tell accurately the distance between the points hidden without measuring them.

It is exactly in this way that Halley proposed to measure off a certain number of miles upon the face of the sun. We are able to learn accurately how many miles distant any two places are upon our globe. Suppose, therefore, that two 
PT. III.

men go to places 7,200 miles apart, and each observes Venus at a particular moment upon the sun's face. Just as you, from two different positions, saw the globe cover two

Fig. 26.

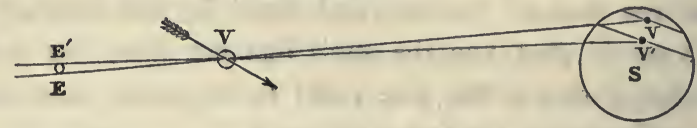

Venus as seen upon the sun by two observers, one at $\mathrm{B}^{\prime}$ and one at $\mathbf{E}$. (Proctor.) s. The sun. $v v^{\prime}$, Appearance of Venus on the sun's face. Venus is travelling in the direction of the arrow.

different points of the wall, so these men will see Venus against different points in the sun, as in Fig. 26 ; and since the distance between Venus and the sun is $2 \frac{1}{2}$ times her distance from the earth, the two points will be $2 \frac{1}{2}$ times 7,200 miles, that is 18,000 miles apart. Here, then, we have a certain number of miles measured off on, the sun's face. But how are we to tell accurately what proportion this interval between the spots bears to the whole diameter of the sun?

By Halley's method the whole time that Venus takes in crossing the sun is used as the means of measurement. The observer at each of the two stations notes exactly the time when Venus begins to cross the face of the sun, and the moment when she passes off it again, and so reckons exactly how long she has taken in making the whole transit.

It was already known, from the rate at which Venus moves, exactly how long she would take in crossing the centre or widest part of the sun. We will call this time 6 hours, so as to use whole numbers. But it is clear that in crossing a narrower part of the disc she will take less time. Suppose, therefore, that one man says she was exactly 5 
hours crossing from A to B, Fig. 27 , and the other that she was $5 \frac{1}{4}$ hours crossing from $C$ to $D$. This will give us the measurement necessary to lay down the position of the two transits on paper.

Draw a circle any size you please, and, ruling a line across the centre, divide it into six parts (as in Fig. $27^{1}$ ), to represent the 6 hours which Venus would take in crossing the centre; each of those parts will then represent the distance which she travels in an hour ; $5 \frac{1}{4}$ of these, therefore, will be the distance she travels

FIG. 27.

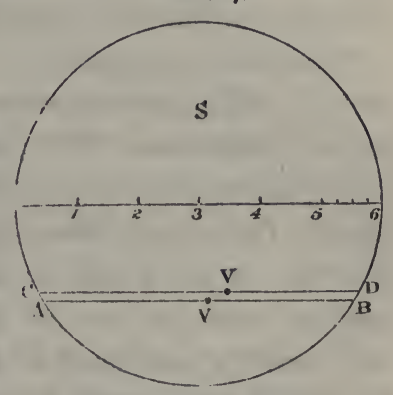

Transit of Venus.

S, Face of the sun. $\mathbf{v}$, Venus. A $\mathbf{B}$, Transit observed so as to occupy five hours. C D, Same transit observed so as to occupy five-and-a-quarter hours.

in $5 \frac{1}{4}$ hours. Take this length in your compasses, and place it at any part of the circle where it will meet the edge at both ends, and in that position draw the line $\mathrm{C} \mathrm{D}$. Then take a second length of five parts only, and placing it below the other, rule the line A B parallel to $\mathrm{C}$ D. These two lines express the path of Venus, as observed by the two men, and we already know that the distance between them is $2 \frac{1}{2}$ times 7,200 , or 18,000 miles.

It is now easy to compare this interval with the stin's diameter. Suppose for instance that 47 such spaces will cover the whole diameter of the circle, as they would if the lines were drawn accurately in the observed positions, then $18,000 \times 47$, or 846,000 miles, would be the measure of the sun's diameter. Now, we saw (p r 159 ) that the sun's dis-

1 It must be drawn very much larger to approach to anything like accuracy. This figure merely indicates the method. 
tance is 108 times his diameter; therefore $846,000 \times 108$, or $91,368,000$ miles would, by these measurements, be the distance of the sun from the earth; and this is as near as we can arrive at the truth when taking whole numbers.

You will perhaps ask, if the measurement of the transit is such a simple process, why it takes months to make the proper calculations. But you must remember that in our description we have neglected all the difficulties which really occur. Our earth is not standing still as we have supposed it to be. It is not only moving along in its orbit, but it is turning round on its axis all the time, and this has to be very carefully considered in choosing stations for observing the transit, and allowed for in the results. Then, since our earth moves in an ellipse, we are not always at the same distance from the sun; this also has to be allowed for. Such simple difficulties as these you can understand, but there are a great number of others which make the calculations very complicated indeed. Therefore you must not imagine that you know all about the transit of Venus when you have read this description of Halley's method. If you have some general idea of the way by which the sun's distance is found out, you will have learnt more than many people; and you must wait till you have studied mathematics before you can expect to have a thorough knowledge of the matter.

You will be glad to hear that Halley's advice was not neglected. Several transit expeditions were sent out in $\mathbf{1} 7$ (ir, and again in 1769 , when the celebrated Captain Cook made a voyage to the Pacific Ocean for this purpose and; it is to correct these observations that no less than forty-six expeditions were sent out last year from Europe and America. Halley made many other valuable astronomical observa- 
tions. He was the first astronomer who foretold the return of a comet. Before his time it was thought that they went away and never came back again; but when the comet of 1682 appeared, Halley began to search for former records of comets and found that one had been seen about every seventy-six years, reckoning backwards from 1682 . Therefore he thought these must all be the same comet, and he

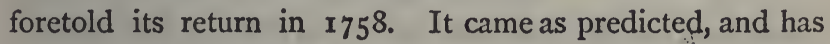
ever since been called 'Halley's comet.' Halley died in I 742, and with him ends the astronomy of the seventeenth century.

Chief Works consulted.-Proctor's 'Transits of Venus ;' Herschel's 'Astronomy ;' Denison's 'Astronomy without Mathematics;' Airy's ' Popular Astronomy.' 


\section{CHAPTER XX.}

SCIENCE OF THE SEVENTEENTH CENTURY (CONTINUED).

Newton's Discovery of the Dispersion of Light-Traces the amount of Refraction of each of the Coloured Rays-Makes a Rotating Disc turning the colours of the Spectrum into white Light -Reason why all Light passing through glass is not ColouredMr. Chester More Hall discovers the Difference of Dispersive Power in Flint and Crown Glass-Newton's Papers destroyed by his pet dog - Last years of Newton's life.

Newton publishes his Discovery of the Dispersion of Light, 1671.-We must now return to Newton, and consider his third great discovery, which was about light. You will remember that he had to wait sixteen years between his first attempt to investigate the law of gravitation, and that new measurement of the earth which enabled him to prove the truth of his theory. During this time he had by no means been idle. He once said that the reason he had succeeded in making discoveries was that he gave all his attention to one subject at a time; from 1666 to $167 \mathrm{~J}$, when his papers on gravitation were quite laid aside, the subject to which he devoted himself was Light.

In the early part of the seventeenth century several people had tried to find out what it was that gave rise to different colours. An Italian archbishop named Antonio de Dominis (died 1625) had given a better explanation of the rainbow than Roger Bacon had given before him ; and 
Descartes had gone farther, and had pointed out that a ray of light seen through a clear, angular, polished piece of glass, called a prism (see Fig. 28), is spread Fig. 28. out into colours exactly like the rainbow; but no one had yet been able to say what was the cause of these different tints. Newton was the first to

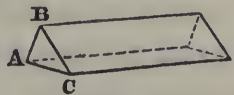

Glass Prism. work this out in his usual accurate and painstaking way.

$\mathrm{He}$ tells us that in $\mathrm{x} 666 \mathrm{he}$ ' procured a triangular glass prism, to try therewith the celebrated phenomena of colours,' and in the very first experiment he was struck by a very curious fact. He had made a round hole F (Fig. 29),

Fig. 29.

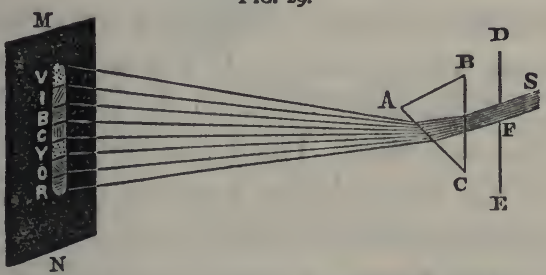

Newton's first Experiment on Dispersion of Light.

D E, Window shutter. $F$, Round hole in it. A B C, Glass prism. M N, Wall on which the spectrum was thrown.

about one-third of an inch broad, in the window-shutter, D E, of a dark room, and placed close to it a glass prism, A B C, so as to refract the sun-light upwards towards the opposite wall of the room, $\mathrm{M} \mathrm{N}$, making the line of colours (red, orange, yellow, green, blue, indigo, and violet), which Descartes had pointed out, and which Newton called a spectrum, from specto, I behold.

While he was watching and admiring the beautiful colours, the thought struck him that it was curious the spectrum should be long instead of round. The rays of 
light come from the sun, which is round, therefore, if they were all bent or refracted equally, there ought to be a round spot upon the wall ; instead of which it was long with rounded ends, like a sun drawn out lengthways. What could be the reason of the rays falling into this long shape? At first he thought that it might be because some of them passed through a thinner part of the prism, and so were less refracted; but when he tested this by sending one ray through a thin part of the prism, and another through a thick part, he found that they were both equally spread out into a spectrum. Then he thought that there might be some flaw in the glass, and he took another prism; still, however, the spectrum remained long, as before. Next he considered whether the different angles at which the rays of the sun fell upon the prism had anything to do with it, but after calculating this mathematically he found the difference was tno small to have any effect. Finally, he tried whether it was possible that the rays had been bent into curves in passing through the prism, but he found by measurement that this again was not the reason.

At last, after carefully proving that none of these explanations was the true one, he began to suspect that it musbe something peculiar in the different coloured rays themselves, which caused them to divide one from the other. To prove this he made the following experiment :- He made a hole, F, in the shutter, as before, and passed the light through the prism, A B C, throwing the spectrum upon a screen, $\mathrm{M} \mathrm{N}$. He then pierced a tiny hole through the screen at the point $g$, Fig. 30 ; the hole in this board was so small that the rays of only one colour could pass through at a time. Newton first let a red ray pass through, so that it was bent by the prism, H I K, and made a shaded red spot on 
the wall at $\mathrm{R}$; here he put a mark. He now moved the first prism, A B C, a little, so as to let the second, or orange ray, pass through the hole $g$. This ray fell upon exactly the same spot of the second prism, $\mathrm{H} \mathrm{I} \mathrm{K,} \mathrm{as} \mathrm{the} \mathrm{red} \mathrm{ray} \mathrm{had} \mathrm{done,} \mathrm{but}$ it did not go to the same spot on the wall; it was more bent in passing through the prism, and made an orange spot at $\mathrm{o}$,

Fig. 30.

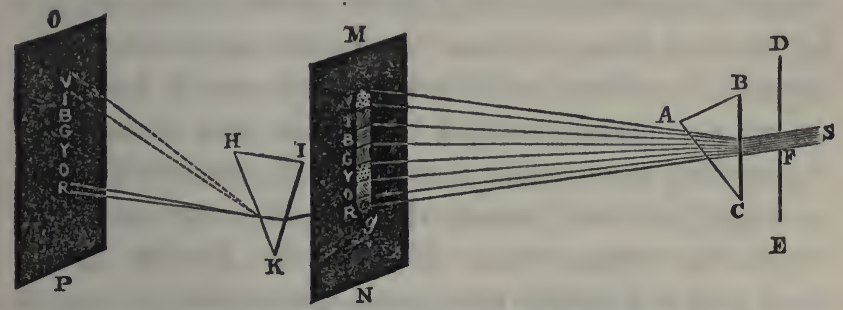

Diagram showing the Different Refraction of Rays of Different Colours.

D E, Shutter. F, Round hole. A B C, First prism. M N, Screen receiving the spectrum. $g$, Small hole through which the rays of only one colour can pass. н $1 \mathrm{~K}$, Second prism refracting those rays.

above the point $\mathrm{R}$. By this Newton knew that an orange ray is more refracted in passing through a prism than a red ray is. He moved his prism, A B C, again, so as to let the yellow ray through. This was still more bent, and fell above 0 on the point $\mathrm{y}$. In this way he let all the different coloured rays pass through the hole, marking the points on which they fell, and he found that each ray was more bent than the last one, till he had marked out a second complete spectrum on the wall. Only the two extreme rays, red and violet, are traced out in Fig. 30, to avoid confusion.

This experiment proved clearly, Ist, that light is made up of differently coloured rays; and $2 \mathrm{nd}$, that these rays are differently refracted in passing through a prism. The red rays are least bent, and the violet ones most, while each of the other rays 
between these have their own course through the prism. I must warn you, however, not to think that there are exactly seven colours : there are really an infinite number, passing gradually into each other; Newton only divided them roughly into seven for convenience.

This spreading out of the different coloured rays is called the dispersion of light. I wish I could give you the many beautiful experiments which Newton made to prove it, but I have only room for one, which you can easily try for yourself, by which the different colours which make up the spectrum can be turned back again into white light. You will see at once that if it true that white light can be divided up into colours, those same colours when reunited must make white. To show this Newton took a round card and painted upon it the seven colours, as pure as possible, five times over, like a spectrum five times repeated (A, Fig. 3I), and then spun it round rapidly, so that the eye received the impression of all the seven colours at once (B, Fig. 31). If you do this you will see the card looks a

Fic. 31.
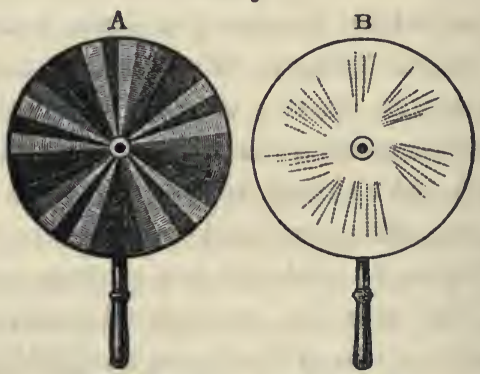

A, Newton's disc. B, Disc rotating.

dirty white, because the colours blend together just as they do in a ray of light. You will not get a pure white, because 
the artificial colours are not pure, and also because it is difficult to paint each colour in the proper proportion.

But now that we have proved that light is broken up into colours in passing through a denser medium, you may perhaps ask how it is that we do not see coloured rays whenever we look at the sun through glass or any other transparent substance. The reason is that when the two sides of the glass are parallel (that is, lie always at the same distance from each other), the ray of light is bent just as much in going out from the glass into the air as it was when it came in from the air into the glass, and so it remains just as it was at first. When the two sides are not parallel, as in a rounded lens, colours do appear in the thin edges of the glass, and these used to be very troublesome in telescopes and microscopes. Newton thought that they could never be got rid of, for he did not know that light is spread out or dispersed more in one kind of glass than in another. But two years after his death, in $1729, \mathrm{Mr}$. Chester More Hail, of Essex, found that two kinds of glass (flint-glass and crown-glass) disperse light differently, so that when you put them together they correct each other, and the coloured rays at the edges are blended into white light. Telescopes and microscopes which are made in this way are called achromatic (from $a$, without; chroma, colour). A patent for such instruments was taken out by a Mr. Dollond in $\mathrm{I} 757$, and he probably invented them without having heard of Mr. Hall's discovery.

It would require a whole volume to give you all Newton's investigations into the nature of light, and his experiments on the coloured rings of the soap-bubble and other transparent substances. His work on Optics was read before the Royal Society in 1671 and 1672 , but the ideas were so new that many clever men, who should have known better, 
attacked him with a number of foolish and ignorant objections, till at last he told his friend Huyghens that he was almost sorry he had ever made them public.

After his great work, the 'Principia,' had been published in 1687 , he next turned his attention to chemistry, but unfortunately all the results of his labour in this science were destroyed by an accident. One day when he was in chapel, his pet dog Diamond turned over a lighted taper, which set fire to all the papers on which his work was written. When he returned and found the charred heap it is said that he merely exclaimed, 'Oh Diamond, Diamond! thou little thinkest the mischief thou hast done !' but his grief at the loss of his work affected his brain, and though he recovered and lived another forty years, publishing many editions of his works, yet he never made any more great discoveries.

Newton received many honours in his old age : in 1699 he was elected Master of the Mint, and a member of the French Royal Academy of Sciences; in 1703 he was made President of the Royal Society, and in 1705 he was knighted by Queen Anne. Like all truly great men, he was modest as to his own abilities, and always willing to be taught by others. He felt so strongly how much we have still to learn about the Universe, that he considered his own discoveries as very trifling indeed. A short time before his death he said of himself, 'I know not what the world may think of my labours; but to myself I seem to have been only like a boy playing on the sea-shore, and diverting myself in now and then finding a smoother pebble or a prettier shell than ordinary, whilst the great ocean of truth lay all undiscovered before me.' Yet this man who spoke so humbly was the discoverer of the greatest and most universal law 
known to mankind! He loved to seek out new laws, but he was more anxious to collect facts and to make sure that he was right, than eager to publish his conclusions. It was the truth he loved, and not the fame which it brought. His patience and perseverance were unbounded; he was never in a hurry, but turned a subject over and over in his mind for years together, seizing upon every new light shed upon it, and waiting patiently for more. And through all his labours he looked reverently up to the One Great Light whose guiding power he loved to trace and to acknowledge in all the wonders of the universe. He died in 1727 at eighty-five years of age, and was buried in Westminster Abbey, his pall being borne by the first nobles of the land.

Chief IVorks consulted. - Newton's 'Optics,' I721; Ganot's 'Physics ;' Rossiter's 'Physics;' Brewster's 'Encyclopæedia,' art. 'Optics ;' Herschel's 'Familiar Lectures.' 
PT. III.

\section{CHAPTER XXI.}

SCIENCE OF THE SEVENTEENTH CENTURY (CONTINUED).

Roemer measures the Velocity of Light-Newton's Corpuscular Theory of Light-Undulatory or Wave-theory proposed by Huyghens Invention of Cycloidal Pendulums by Huyghens-Discovery of Saturn's Ring - Sound caused by Vibration of Air-Light by Vibration of Ether-Reasons why we see Light-Reflection of Waves of Light-Cause of Colour-Refraction explained by the Undulatory Theory-Mr. Tylor's Illustration of Refraction-Double Refraction explained by Huyghens - Polarisation of Light not understood till the nineteenth century.

Olaus Roemer measures the Velocity of Light, 1676.While Newton was dispersing light in prisms, and finding out its nature, Olaus Roemer, a famous Danish astronomer (born 1644, died 1 710), was engaged in something almost as wonderful. He was measuring the rate at which light travels across the sky! It seems at first as if this would be impossible, but we now know three different ways of accomplishing it; Roemer's was the first attempt ever made, and his measurement was very near indeed to the truth.

You will remember that Jupiter has four moons, which move round it as our moon moves round our earth. Three of these moons are so near Jupiter and move round it in such a manner that they pass through its shadow and are eclipsed every time they go round. Now it became very 
useful, for certain astronomical reasons, to know exactly when these eclipses happened, and the time of their occurrence was therefore calculated very carefully ever since Galileo first discovered them. There was no difficulty in doing this, and yet, strange to say, the eclipses rarely happened exactly at the right moment. Sometimes they were too early, sometimes too late, and they varied according to some regular rule as much as 16 minutes 36 seconds on each side of the exact moment when they ought to have happened.

At last it occurred to Roemer, and to an Italian astronomer named Cassini, that, as Jupiter is farther away from the earth at one time than at another, the eclipses might be seen some minutes later whenever the rays of light from the moons had to cross a greater distance to reach the earth. Cassini seems to have put the thought aside and not to have worked it out ; but Roemer seized upon it, and by careful calculations proved that it was the true answer to the difficulty. If the earth was at E (Fig. 32) for example, when Jupiter

FIG. 32 .

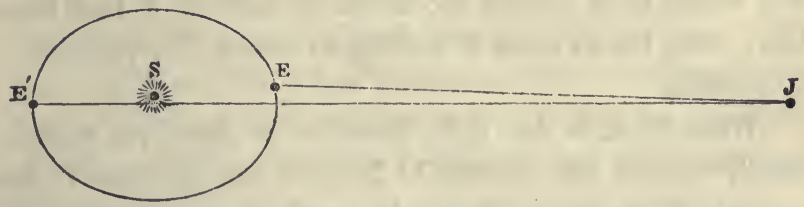

Different Distances at which Jupiter's Light reaches the Earth.

J, Jupiter. $\quad \mathrm{E} \mathrm{E}^{\prime}$, The earth.

was at $\mathrm{J}$, the light would not have nearly so far to travel as if the earth was at $\mathrm{E}^{\prime}$; and in this last position the 16 minutes $3^{6}$ seconds would be taken up by the light crossing the earth's orbit from $\mathrm{E}$ to $\mathrm{E}^{\prime}$. This distance was known to be about $190,000,000$ miles, so that light travels at the rate 
of $190,000,000$ miles in 996 seconds, or about 190,000 miles in a second. This is seven million times as fast as the quickest express train.

Huyghens and Newton-Theories of Light.-The time had now come when so much was known about the way in which light behaves, that philosophers began to ask themselves, 'What is Light?' - a question by no means so easily answered as you may think; for though it is by means of light that we see everything, yet light in itself is invisible. You will exclaim at once that you can see a sunbeam shining through a crack in a window-shutter. But what you see is not light itself, it is the particles of dust or smoke which are acted upon by light so that they shine. There is one very simple way of proving to yourself that rays of light are not visible lines. When the moon is shining you know that it is reflecting the light of the sun, therefore there must be light crossing the sky and falling upon its surface. But now look up some other night when the moon is not there. All is darkness; yet the light must be there just the same, and would have caused the moon to shine if it had been there also, but as there is nothing to reflect it to your eye it is invisible.

What, then, is this light, invisible in itself, yet without which we can see nothing? Newton thought that it was composed of minute invisible particles of matter which darted out in straight lines from luminous or light-giving bodies, and falling upon our eyes caused the sensation which we call light. This is called the Corpuscular, or sometimes the Emission, Theory of Light. It was very ingenious, and accounted for a great many of the facts, but there were many others which it did not explain; and I will not attempt to describe it to you, because another theory, called 
the Undulatory (or Wave) Theory of Light, has now been found to be much more complete and satisfactory. This last theory was first proposed by a Dutch mathematician and astronomer named Christian Huyghens, the son of Constantine Huyghens, Counsellor to the Prince of Orange.

Christian Huyghens was born at the Hague, in Holland, in the year 1629 ; when he was only thirteen years old he was already passionately fond of mathematics, and examined every piece of machinery that fell in his way. $\mathrm{He}$ received a very good education, and wrote some able treatises upon geometry when he was only two-and-twenty. From this time he advanced very rapidly, both writing valuable papers and making grand discoveries. In 1658 he invented a peculiar kind of pendulum called the cycloidal pendulum, which would keep accurate time when swinging over wide spaces; and he was also the first to apply pendulums to clocks. In 1659 he made a telescope ten feet long, with which he discovered one of Saturn's satellites, ind described accurately Saturn's ring, which Galileo had mistaken for two stars. In 1660 he came to England, and solved some questions which the Royal Society had proposed about the laws of motion. Then he was invited to settle in France, and it was there, in 1678 , that he read before the 'Académie des Sciences' the theory of light which we must now try to understand.

Undulatory Theory of Light, 1678.-I must first tell you that Newton, among his many other investigations, had shown that sound is caused by a trembling or vibration of the air. Thus, when you strike the wire of a harp, the trembling of the string shakes the air, and the quivering motion travels along like waves upon a pond, until some wave strikes the drum of your ear and produces the sen- 
sation we call sound. The tighter and shorter the string is, the more rapid the vibrations or waves will be, and the more shrill will be the note which you hear.

Now Huyghens said, 'We can only explain light by supposing it to be a vibration like sound.' But here at the very outset came a difficulty. We know that light is not a vibration of the air, for if you draw the air completely out of a.glass vessel, light will still pass across it; and besides, we get light from the sun and the distant stars, so that it has to come across a great airless space before it reaches the atmosphere of our earth. And yet, if light is a vibration, it is clear there must be something between the sun and us to vibrate. To meet this difficulty Huyghens supposed the whole of space between our earth and the most distant stars to be filled with an elastic invisible substance which he called 'ether.' He assumed this substance to be so fine and subtle that it passes between the atoms, even of solid objects, and that the sun and all luminous bodies cause it to vibrate so that its undulations or waves strike upon our eyes and give rise to the sensation we call light.

Thus, according to this theory, when you look at the sun, the invisible ' ether' filling the whole space between you and it, is moving up and down in rapid vibrations, just as if the sun held one end of a cloth and you the other, and the sun was shaking the cloth so that the waves travelled along it to your eye ; and every wave that hit you would cause the sensation called light.

This theary explains very well how light-waves may be in the sky and yet we may not see them; for if a stick is moving rapidly to and fro in the air, and you go within reach of it you feel pain, but if you keep out of reach no pain is produced. In the same way, when the vibration of 
this invisible ether strikes your eye you feel light, but though the waves may be travelling rapidly across the sky, so long as they do not fall upon your eye, no light will be produced to you.

But suppose you were not looking at the sun, but at the ground, why should you still see? Because the waves from the sun which strike the ground cannot travel on so easily through the solid earth as through the pure ether, so a great number of them bound off and vibrate back along the ether again, from the ground to your eye ; and as they vibrate differently according as the ground is rough or smooth, hard or soft, wet or dry, they make a different impression upon your eye, and cause you to see a picture of the ground as it is.

Clear white glass and other perfectly transparent bodies let nearly all the waves of light pass through them and send hardly any back to your eye ; and people have in consequence been known to walk right up against glass doors without seeing them. Bright polished surfaces, on the contrary, like steel and mercury, turn nearly all the waves back again, and this is why we see our own faces reflected so clearly in a looking-glass, where it is the mercury at the back which is the real mirror.

If we had room we might follow out these light-vibrations in a very interesting manner. For instance, why does a leaf look green and a soldier's coat red? Because, as in sound the kind of note you hear depends upon the quickness of the vibrations of the air, so in light it depends upon the quickness of the vibrations of the ether what colour you see. The vibrations which produce violet, indigo, blue, green, yellow, orange, and red, have travelled all together as white light through the ether, but they are differently treated by the leaf. All except the green waves are quenched, or 
absorbed as it is called, by the material of the leaf, and only the green waves bound back upon your eye. In other words, the vibrations of the ether coming from the leaf move exactly fast enough to produce upon your eye the sensation you call green, just as the vibration of the air caused by a particular string of a harp produces on your ear the sensation of the note you call the middle $\mathrm{C}$.

Refraction of Light explained by Huyghens.-But we must now go back to Huyghens, and point out how beautifully he explained by his undulatory theory the refraction or bending-back of rays of which we have already spoken so much. When a wave of light is travelling onwards, he said, if it passes vertically into glass or any denser substance, the wave will move more slowly, but it will still go straight on, because both ends of the wave will be equally checked. But if the wave goes into the glass obliquely (see p. 47), one end of it will reach the glass first before the other, and will move slowly, while the other end goes on unchecked, and so the wave will swing round and will have its direction altered. In the same way, when it passes out again from the glass, one end will pass out first, and will move more easily in the air than the end that is still in the glass, and so it will swing round again and make another bend.

You must not be disappointed if you do not understand this at once, for it is very difficult ; to make it easier we will borrow a very ingenious illustration given last year ( $\mathrm{Jan}$. I, I874) by Mr. E. B. Tylor, in a periodical called 'Nature.' Take two small wheels about 2 inches round, and mount them loosely upon a stout iron axle measuring about half-aninch round. This will make a runner like two wheels of a cart, and if you let it roll down a smooth board it will represent very fairly the crests or tops of the waves of light in 
the ether. Let your board be about $2 \frac{1}{2}$ feet long, and at one end of it glue on pieces of thick-piled velvet of the shape of lenses (see $\mathbf{1}, 2,3$, Fig. 33). Let your runner first go straight down the board upon the velvet; it will then run through the velvet without changing its course, as a vertical ray does through a lens. Then start it obliquely across the board so that it will reach the lens $I$ in the position B. Here the left wheel of the runner will touch the velvet first, and will be checked by the rough pile, while the right wheel moves on quickly as before, and thus the runner will swing round or be refracted towards the thick part of the lens. Then, as it passes out again the right wheel will come out of the velvet first and will move more quickly on the Fig. 33.
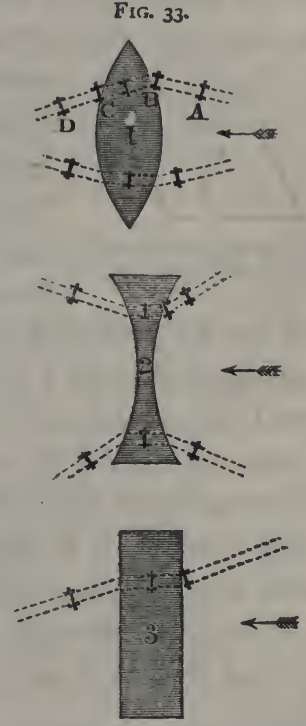

Figures illustrating the passage of the waves of light through difierentshaped lenses (Tylor). smooth board, while the left is still checked by the velvet at $\mathrm{C}$; therefore the runner will again be shifted round or refracted as it passes out. You can easily follow the course of the runner through the other lenses for yourself, always noticing that the arrow marks which way the ray of light is coming; and when you have done this you will have a beautiful imitation of the way in which the waves of light are refracted in passing through different mediums.

Double Refraction.-There is still one more remarkable 
fact about light which Huyghens explained; namely, the double refraction of light through a crystal called Iceland spar. A physician of Copenhagen named Erasmus Bartholinus had received from Iceland a crystal in the form of a rhomboid (see Fig. 34), which, when broken, fell into pieces of the

FIG. 34.

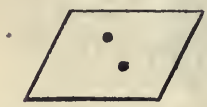

A spot of ink seen through a crystal of Iceland spar. same shape. Bartholinus called this crystal 'Iceland spar,' and while making experiments with it he observed that an inkspot or any small object seen through it appeared to be doubled. He was not able to explain this curious fact, but he published an account of it in 1669 , and Huyghens accounted for it quite correctly by suggesting that the crystal was more elastic in one direction than in the other, so that a wave of light passing into it was divided into two waves moving at different rates through the crystals. This would cause them to be bent differently-one according to Snell's ordinary law of refraction (see p. I07), and the other in an extraordinary way. Thus these two separate rays falling upon the eye would cause there the impression of two objects.

This curious effect is very interesting to study, and it led Huyghens to make a number of remarkable experiments. $\mathrm{He}$ found that the two rays when they passed out at the other side of the crystal remained quite separate the one from the other, and if they were afterwards sent through another crystal in the same direction that they had gone through the first, they went on each their own way. But now came a very extraordinary fact : if the second crystal was turned round a little so that the rays passed in rather a different direction through it, each ray was again split up into two, so that there were now four rays, sometimes all equally bright, sometimes 
of unequal brightness, but the light of all four was never greater than the light of the one ray, out of which they had all come. These four rays continued apart while he turned the second crystal more and more round; till, when he had turned it $90^{\circ}$, or a quarter of a circle, the rays became two again, with this remarkable peculiarity, that they had changed characters! The ray which before had been refracted in the ordinary way now took the extraordinary direction, while the other chose the ordinary one.

This curious effect observed by Huyghens is now known as the 'polarization of light' by crystals. It is very difficult to understand, and you must be content at present to know that he discovered the fact. There is a beautiful explanation of it, but we must wait for that till we consider the science of the nineteenth century, for it is now much better understood. Huyghens' 'Theory of Light' was published in 1690 , under the title 'Traité de la Lumière.' He remained in Paris for some years; but left it and returned to Holland when the persecution of the Protestants began after the revocation of the Edict of Nantes. He died in 1695.

Chicf Works consulted.-- Ierschel's 'Familiar Lectures' - art. 'Light;' Tylor, 'On Refraction'-_Nature,' vol. ix. ; 'Edin. Phil. Journal,' vols. ii. and iii._-'On Double Refraction;' Ganot's 'Phy. sics ;' Encyclopædias -. 'Britannica,' 'Metropolitana,' and Brewster's. 


\section{CHAPTER XXII.}

- SUMMARY OF THE SCIENCE OF THE SEVENTEENTH

\section{CENTURY.}

WE have now arrived at the close of the seventeenth century, and it only remains for us, before going farther, to try and picture to ourselves the great steps in advance which had been made between the years 1600 and 1700 . We saw at p. 82 that the work of the sixteenth century consisted chiefly in making men aware of their own ignorance, and teaching them to inquire into the facts of nature, instead of merely repeating what they had heard from others. In the seventeenth century we find them following out this rule of patient research, and being rewarded by arriving at grand and true laws.

Astronomy.-To begin with Astronomy. Here Galileo led the way with his telescope. The structure of the moon, with its mountains and valleys; the existence of Jupiter's four moons revolving round it and giving it light by night; the myriads of stars of the Milky Way; the spots of the sun coming into view at regular intervals, and thus proving that the sun turns on its axis; all these discoveries forced upon men's minds the truth that our little world is not the centre of everything, but a mere speck among the millions of heavenly bodies. But while they humbled man's false pride in his own importance, they taught him on the other hand the true greatness which God has put in his power by giving 
the intellect to discover and understand these wonderful truths if he will only seek them in an earnest and teachable spirit.

Then came Kepler with a still grander lesson, for he showed that the movements of the planets are governed by regular and fixed laws, which can be traced out so accurately that an astronomer is able to foretell with confidence what will happen many years after he himself has passed away. Thus we see Gassendi and Horrocks, by the use of Kepler's labours, calculating within a few minutes the time of a planet's passage across the face of the sun and watching the exact fulfilment of the prediction. Nor is this all : so exact and true are these movements, and so completely is man able to read them rightly, that by this simple passage of a small black spot across the sun Halley showed that we may actually number the millions of miles between ourselves and the great light around which we move. We might almost think that we had now travelled as far as man's mind could go, but something far greater remained behind. Newton sitting under his apple-tree and pondering on the wonderful mechanism of the heavens, found the one great law which accounts for the movements of all the bodies in the universe - a law which explains equally why a pin falls to the ground and why a comet which has been lost from sight for more than a hundred years will return to a certain fixed spot at a day and an hour which can be accurately foretold. Kepler had pointed out fixed and definite laws by which the universe is governed ; Newton demonstrated that one law explains them all. He showed us how one single thought, as it were, of the Divine mind suffices to govern the most complicated as well as the simplest movements of our system. 
All this advance from Galileo to Newton was the work of the seventeenth century. It began, you see, with certain simple facts; by Galileo seeing that bodies existed in the heavens which were not known to be there before ; it ended in the beautiful law of which we have just spoken. But I want you particularly to notice that this end would never have been reached by men who were content to sit down idly and talk of the greatness of God. It was the result of real work by men who tried first to learn the facts, and from these to prove reverently the way in which it pleases God to bring them about ; and in this labour of love, being brought face to face with the infinite grandeur of nature, they learnt that true humility which led Newton, the greatest of them all, to feel that he was but as a little child gathering pebbles on the shore of the great ocean of truth.

Physics.-If we now turn to Physics, we shall find that the way to knowledge lay still along the same road of patient inquiry. Torricelli's barometer and Guericke's hemispheres of Magdeburg both proved by direct experiment that the atmosphere round our earth is pressing downwards with great weight; and this again brings us round to the force of gravity, which is the cause of this weight; while Boyle's experiment showed that air is elastic, being compressed in exact proportion as the weight upon it is increased, and expanding again directly it is diminished.

Again, in the subject of Light, we begin with hard dry facts, which doubtless you may have thought it wearisome to master, but we end with a theory so wonderful and beautiful that it seems more like a fairy-tale than sober science. The first step here was the invention of the telescope, which, while it opened the road on the one hand to astronomical discoveries, also led to the grinding of lenses, and to a more 
careful study of the laws of light. This it was which caused Snellius to make experiments on the bending of rays with a view to improving telescopes, and so to discover the law of refraction, afterwards more fully stated by Descartes. Then we find this last philosopher trying to explain the rainbow, and studying the colours falling through a prism, and so the subject passed on into the hands of Newton.

Here, by experiment again, the threads of light were disentangled in the prism, and Newton drew out its manycoloured rays, tracing them one by one on their road, till he had shown that refraction explained them, and that to this law, which seemed so uninteresting at first, we owe all the lovely colours which surround us. And now Huyghens takes up the story and leads us fairly into the invisible world. This light, which Roemer had proved to be travelling across space with marvellous speed, Huyghens shows to be no actual substance at all, but most probably a trembling of an invisible and intangible ether-a succession of infinitely tiny waves chasing each other across millions of miles, and striking at last on the minute opening of our eye, bringing to us the wonderful effects of light. As Newton traced colours, so Huyghens traces the invisible waves through many substances, showing us their path and why they take it ; and landing us at last in the bewildering effects of polarization, leaves us there to wait for more knowledge in a future century.

Biology.-And now we come to Biology, or the study of all those sciences which relate to life. Here you must remember that our account of the discoveries made, must be more than usually imperfect, because the subject is more than usually difficult. Yet we can form some idea of the new light thrown upon the nature of the living body, by Harvey's 
theory of the circulation of the blood and the discoveries which followed concerning the way in which nourishment is carried to it. We can see how Mayow's experiments, proving that part of the air is burnt within us, supplying heat to our bodies, would have been a grand step in advance if he had lived to make them more known, and how, indeed, they did influence those who came after, though his name was for a time forgotten. More clearly still we can understand how Malpighi's and Grew's investigations with the microscope, bringing to light hidden parts and vessels of the human frame, gave rise to a totally new branch of science, and enabled men to study the organisation of their own bodies with an accuracy quite impossible before; while the same method applied to Botany gave the first real insight into the structure of plants, tracing out their delicate organs, and even the tiny cells of which their flesh is composed. And lastly, in the field of Natural History, we find that Ray and Willughby performed the immense task of classifying the whole animal and vegetable kingdoms, and laid the foundation of the grand generalizations of Linnæus in the next century. 


\section{SCIENCE OF THE}

\section{EIGHTEENTH CENTURY}


Chief Men of Science in the Eighteenth Century.

\begin{tabular}{|c|c|c|c|c|c|}
\hline Boerhaave & & • & - & . & $\begin{array}{l}\text { A.D. } \\
\text { - } \quad 1668-173^{8}\end{array}$ \\
\hline Hales & - & . & . & . & . $1677-1761$ \\
\hline Haller & - & - & - & . & - $\quad 1708-1777$ \\
\hline Hunter & - & - & - & - & - $\quad 1728-1793$ \\
\hline Bonnet & • & - & - & - & 1 720-1 793 \\
\hline Spallanzani & & - & - & - & . 1729-1799 \\
\hline Buffon & - & - & - & - & - $\quad 1707-1788$ \\
\hline Linnæus & . & - & - & - & . $\quad 1707-1778$ \\
\hline Lazzaro Mo & oro & - & - & - & . $1687-$ \\
\hline Werner & - & - & - & . & - $\quad 1750-1817$ \\
\hline Hutton & - & - & - & - & - $\quad 1726-1797$ \\
\hline William Sn & mith & . & - & . & $1769-1833$ \\
\hline Black & - & • & • & . & $1728-1792$ \\
\hline Bergmann & - & - & - & - & - $\quad 1735^{-1784}$ \\
\hline Cavendish & - & - & . & - & . $1731-1810$ \\
\hline Priestley & . & - & . & - & . $1733-1804$ \\
\hline Scheele & . & - & . & - & . $1742-1786$ \\
\hline Rutherford & . & - & - & - & . 1749-1819 \\
\hline Lavoisier & . & - & - & : & . $1743^{-1794}$ \\
\hline Watt . & - & - & - & - & - $\quad 1736-1819$ \\
\hline Franklin & . & - & . & . & $1706-1790$ \\
\hline Galvani & - & - & - & . & - $\quad 1737-1798$ \\
\hline Volta & - & - & - & • & . $\quad 1745^{-1827}$ \\
\hline Maskelyne & . & - & - & - & $1732-1811$ \\
\hline Lagrange & . & - & - & . & . $\quad 1736-1813$ \\
\hline Laplace & - & - & - & - & - $\quad 1749-1827$ \\
\hline Herschel & - & - & - & . & - $\quad 1738-1822$ \\
\hline
\end{tabular}




\section{CHAPTER XXIII.}

SCIENCE OF THE EIGHTEENTH CENTURY.

Great spread of Science in the Eighteenth Century-Advance of the Sciences relating to Living Beings-Foundation of Leyden University in 1574-Boerhaave, Professor of Medicine at Leyden, I 70IFoundation of Organic Chemistry by Boerhaave-Influence of Boerhave upon the study of Medicine-Belief of the Alchemists in 'Vital Fluids'-Boerhaave's Experiments on the Juices of Plants-Dr. Hales' Experiments on Plants-Boerhaave's Analyses of Milk, Blood, \&c. - Great popularity of his Chemical Lectures.

WE have now arrived at the beginning of the eighteenth century, only 155 years before our own day, when the different sciences which we have been tracing in their rise, like little rills on the mountain sides, were beginning to swell out into mighty streams, widening and spreading so rapidly that it is in vain we strain our eyes to try and watch them all. The time had now come when any man who wished to be a discoverer was obliged to devote his whole life to one branch of science, following it out in all its intricate windings. And so we find that about this time each science begins to have a complete history of its own, with its own eminent men, and its peculiar language growing more and more technical so as scarcely to be understood by ordinary readers.

For this reason most general histories of Science stop at this point and refer their readers to special works on the different sciences. I do not, however, propose to do this ; 
for though I must warn you again more strongly than ever that I can only give you little glimpses of the work that was being done, still I think that if we struggle on through the increasing mass of knowledge and gather up a fragment here and there, you will gain a general idea of the progress of science, and be able to read more advanced scientific books with much greater interest, even though you may have learnt very little of any one science.

Astronomy, Physics, and to a certain extent Chemistry, had made such a start at the end of the seventeenth century that it was a great many years before those men who came after Newton, Halley, Huyghens, and Stahl, had mastered the new discoveries sufficiently to progress any further. Therefore we find that it was not in these sciences that most advance was made in the beginning of the eighteenth century, but in those which relate to living beings, and which are all included under the head of Biology, or the science of life. Medicine, Anatomy, and Physiology were the branches which grew-most rapidly about this time; and the five great men whose names stand out most conspicuously are Boerhaave, Haller, John Hunter, Bonnet, and Spallanzani : Boerhaave, as the founder of the study of organic chemistry, Haller and Hunter as the fathers of comparative anatomy, and Bonnet and Spallanzani as the discoverers of some very remarkable facts in physiology. We will take these subjects in regular order, and try to understand something of the work which was done in them.

Medical School of Leyden.-Foundation of Organic Chemistry by Boerhaave, 1701.-On the coast of Holland, just where the Rhine empties itself by a number of small channels into the German Ocean, stands the city of Leyden, which became famous in the year 1574, on account of a 
siege of four months which the starving inhabitants endured with the utmost heroism, when the Protestant Netherlanders were struggling for life and liberty against Philip II. of Spain. The Dutchmen were successful at last and drove out the Spanish army, by cutting away the dykes and letting the sea swallow up their beautiful pastures, their neat villages, and their fruitful orchards ; and as a reward for their devotion to the cause, William of Orange founded the University of Leyden, which afterwards became very celebrated.

Hermann Boerhaave, of whose work we are now going to speak, was a Professor of Medicine in this University about a hundred years after its commencement. The son of a Dutch clergyman, he was born in 1668 at Vorhout, one of those same small Dutch villages near Leyden which had been for days under the sea in 1574 . His father intended him for the church; but the young student, having been accused of holding false opinions, was only too glad to give up this profession and study medicine, in which he delighted. He was so successful that in $\mathrm{r}$ 70 $\mathrm{r}$ he was made Lecturer of Medicine in the University, and a few years later the Professorships of Chemistry and Botany were also given to him. From that time the Medical School of Leyden became famous all over the world. Students flocked to it from all quarters, and most of the best medical men of Europe were pupils of Boerhaave. This was due chiefly, of course, to his wonderful medical knowledge and his skill as a lecturer; but his popularity was greatly increased by his enthusiasm, kindly temper, and the great interest which he took in the success of his pupils. He was always ready to help others and to give them credit for the work they had done, and it is said that even his enemies could not resist his constant and uniform kind- 
ness and good-temper. He loved his science too well to hinder its progress by angry disputes; and by imparting this spirit to his pupils he did almost as much for the spread of medical science as by the facts which he taught them.

But besides his influence upon medicine in general there was one particular study which Boerhaave may be said to have founded; this was the chemistry of living substances, or organic chemistry. You will remember that the false science of alchemy had always been much mixed up with chemistry, and the alchemists had some strange mystical notions about 'vital fluids,' which they supposed to exist in animals and plants, and to cause their life and growth. Little by little, however, more correct ideas had grown up in the 16 th and 17 th centuries about the nature of life. Vesalius, Harvey, Malpighi, Grew, and many others, had gradually described more and more accurately the working of the different organs of a living being, and now Boerhaave went farther, and tried to discover by means of chemistry of what materials these organs themselves are composed.

In the same way that Geber had decomposed or divided up inorganic substances, such as metals and earths, by distillation and sublimation (see p. 44), so Boerhaave proposed to decompose the organic substances of which plants and animals are made, and to discover the materials contained in them. To accomplish this he took a plant, such as rosemary, and putting fresh moist leaves of it into a furnace, heated them gently and drove out all the moisture, which he collected in a separate vessel. When this moisture had cooled down into a liquid he examined it and found that it was made up of water, and of different kinds of oils and essences, according to the plant he had taken. For instance, from rosemary he got an essence with the peculiar 
scent of rosemary; from the bark of the cinnamon tree, Laurus Camphorum, or Cinnamomum camphorum, he got essence of cinnamon; from its roots, camphor ; and from its leaves an oil with the taste of cloves. Then after he had extracted all the juice from the plant, he burnt the dry remains, to see what would be contained in its ashes after the fire had driven off part of the solid matter as gas, and he found in them a kind of salt, which was also different in different plants. But if he poured hot water on the plant before burning it, he found no salt in the ashes, for it had been dissolved and carried off in the water.

Having now found what substances were in the plant, the next step was to discover where they came from; so he took several specimens of earth in which plants can grow and examined them also; and he found that he could extract from them many of the substances, such as sait, alum, borax, and sulphur, which he had also discovered in the ashes of the plants. It was clear, then, that the plant took these salts out of the earth ; and by a number of experiments he went on to prove that they are dissolved by the rain-water which sinks into the earth, and are then sucked up by the plants through their roots and carried up to the leaves, where they are exposed to the air and sunshine, and altered so as to become food for the plant. The other parts which did not come from the soil he concluded must be taken in from the air. These were splendid facts, and curiously enough a celebrated English chemist, Dr. Hales (born 1677 , died 1761 ), made some of the same experiments almost at the same time, which confirmed those of Boerhaave. Hales even went so far as to measure the quantity of water taken in at the roots and given out at the leaves of plants, and he discovered the way in which 
plants breathe through the little stomata, or mouths, discovered by Grew (see p. 14I).

From the juices of plants Boerhaave next went on to those of animals, and he decomposed in a most beautiful and simple manner milk, blood, bile, and those fluids called chyle and lymph which convey nourishment to the blood. These he compared with the sap, gums, resins, and oils of plants, and showed that animal bodies are made up of altered vegetable matter, just as plants are in their turn composed of matter taken from the soil and the air; and he suggested that by careful experiments it would at last be possible to discover exactly the materials of which all living beings were made.

Boerhaave's analyses of organic substances were very rough and imperfect compared to those which are made now; for you must remember that the four gases, oxygen, hydrogen, nitrogen, and carbonic acid, which we now know are the chief constituents of plants, were not yet discovered. Yet even these rough attempts were so interesting that students crowded round the doors of his lecture-room for hours before the lecture began, to secure admission; and there can be no doubt that his 'Elements of Chemistry,' published in I 732, contained the first steps in the study of the chemistry of living things. Boerhaave was also a celebrated botanist. $\mathrm{He}$ died in $\mathbf{I 7 3 8}$, and deserves always to be remembered as one of the greatest teachers of the eighteenth century.

Chief Works consulted.-Brewster's 'Encyclopædia '- 'Boerhaave ;' Cuvier, 'Hist. des Sciences Naturelles ;' Sprengel, 'Hist. de la Médicine,' 1815 ; Burton's 'Life and Writings of Boerhaave,' 1746; Boerhaave, 'Elements of Chemistry,' Englished by Dallowe, I735; Miller's 'Chemistry ;' Hales' 'Essays concerning Vegetable Staticks,' 1759. 


\section{CHAPTER XXIV.}

SCIENCE OF THE EIGHTEENTH CENTURY (CONTINUED).

Childhood of Haller-Foundation of the University of Göttingen in 1736-Haller made Professor of Anatomy-Haller's Anatomical Plates-He discovers the power of Contraction of the MusclesRise of Comparative Anatomy-John Hunter's industry in Dissecting and comparing the Structures of different Animals - H is Museum and the arrangement of his Collection--Bonnet's Experiments on Plants - Experiments upon Animals by Bonnet and Spallanzani-Kegrowth of different parts when cut off-Bonnet's theory of Gradual Development of Plants and Animals-Anatomical Works of Haller-He discovers the power of the Muscles to contract.

Haller, 1708-1777.-Among the pupils of Boerhaave there was one man who became, if possible, even more famous than his master. This was Albert von Haller, son of the Chancellor of Baden, who was born at Berne in 1708 , and died in 1777. Haller seems to have been a most extraordinary child; at nine years of age it is said that he knew Latin and Greek, had made a Hebrew and Greek dictionary, a Chaldean grammar, and an historical dictionary! We are not told how good these books were; but how very few boys of nine years old would have been able to write them at all! At seventeen Haller went to Leyden to study under Boerhaave, and under Albinus, a famous anatomist; and at nineteen he was already a doctor of medicine. Having been driven out of Paris because the people were horrified 
at his dissecting dead bodies, he went to Berne, where he became professor of anatomy; and in I736, when George II. of England, who was also Elector of Hanover, founded the University of Göttingen, he went there as professor of anatomy, surgery, and botany, and soon made that University as famous as Boerhaave had made Leyden.

One of his first reforms was to turn the work of his pupils to good account. When medical students are going to pass their last examination they are required to write an essay, or thesis, as it is called, before they can receive their degree of doctor. Haller used always at these times to propose to each one of his students some difficult point in anatomy or physiology, in which he thought new discoveries might be made, and he then drew out a plan for them and showed them how to begin. By this means their essays were often full of new and useful information, and it was a great deal owing to the help of his pupils that Haller was able to publish 180 volumes on science, all more or less valuable.

There was also a very good anatomical theatre at Göttingen, and from dissections made there Haller produced a set of most beautiful anatomical drawings, which he published between $\mathrm{I} 743$ and $\mathrm{I} 753$. You will remember that Vesalius published many fine engravings of parts of the human body (see p. ${ }^{67}$ ), and since his time many others had been made, especially by Haller's master, Albinus. But Vesalius' drawings were coarse, because he had no mirroscope to help him, and Albinus had only drawn separate parts, such as a muscle, a nerve, or a vein. Haller's plates were the first which showed the different nerves and vessels attached in their right position, and to each plate he added a complete history of the function, or use of the parts drawn. He made these drawings so accurate, and spent so 
much time upon each minute structure, that in seventeen years, with all the help he had, he was not able to complete the description of the whole human body.

Haller discovers the Power of the Muscles to Contract. - It was while he was at work at these dissections that he made one great discovery, which you must try to understand. If you clasp your right hand round your left arm, just above the elbow, and then bend your left arm, you will feel the part under your hand swell up and grow hard. The reason of this is that the muscle of your arm, called the biceps, has contracted, or grown shorter and thicker, in the process of bending your arm. If you open your arm again, the swelling will go down, because the muscle is stretched out. Now before Haller's time it was thought that the muscles could not contract of themselves, but were drawn up by the nerves. Haller discovered that this is not so, but that a muscle, if irritated, will draw itself together even when it is quite separated from the nerves, and this has since been proved to be true by a great number of experiments. So that though it is true that our nerves are the cause of our moving, because they excite the muscles and so make them contract, yet the real power of contraction is in the muscle itself.

Comparative Anatomy, or the Comparison of Different Structures in Men and Animals.-John Hunter.-Another point in which Haller did good service to science was in comparing the same parts of the body of men and animals, and showing how far they are alike. This study, which is called the study of comparative anatomy, has now become very important, for by examining any organ, such as the heart for example, from the lower animals in which it is very simple, up to man in whom it is complicated, we can 
trace its gradual improvement, and understand it much more perfectly. Aristotle and Vesalius had both of them compared some of the parts of different animals, and so had other and later zoologists; but Haller was the first to make it a regular study, and John Hunter, who lived about the same time, devoted his whole life to it, and raised it to the rank of a separate science.

John Hunter, who was born in the County of Lanark, in 1728 , was the brother of a very eminent London physician, Dr. William Hunter, who was also a great anatomist. John, being delicate, had been allowed to grow up with very little education, and at twenty years of age he came up to London, a mere ignorant lad, to try and help his brother in his anatomical dissections. Here he soon showed that he had plenty of ability, for he learnt dissecting so rapidly that at the end of a year he was able to teach his brother's pupils, and before long he became one of the leading surgeons at St. George's Hospital, and had a large private practice.

But though he made a great deal of money by his profession, he spent it all upon his favourite study of anatomy, to which he devoted every spare moment. His great wish was to compare thoroughly the different parts of men and animals, so as to show how the life of each one of them is carried on. For this purpose he dissected and preserved in different ways the bodies of all the animals he could lay his hands upon. He bought up all the wild beasts that died in the Tower, where they were then kept, and any which he could procure from travelling menageries, and he even kept foreign animals himself in a piece of ground at Earl's Court, Brompton, that he might watch their habits and dissect their dead bodies.

As years went on and his specimens increased he built a 
large museum in Leicester Square, and arranged his collection so as to show which parts in different animals serve for the same use. For example, to illustrate the way in which animals digest their food, he placed first the hydras, polyps, and sea-anemones, which are all stomach, being in themselves nothing but a simple bag surrounded by little feelers, and having a fluid inside which dissolves the food. Then he arranged in order many forms up to the leech, which is a bag with two openings, and has a head and nerves and other parts, besides a stomach. Then came the insects, some of which, as the bees, have a separate receptacle for honey, of which they disgorge a part and then pass on the rest into the real stomach. Then came the snails, in which the stomach is a separate part with a second opening to pass out the food it cannot take up. Then the fishes, some of whom have stomachs strong enough to crush the shells and indigestible parts of their food, while others have the mouth lined with teeth for this purpose; then came the stomachs of reptiles; and afterwards those of birds, with the curious crop where the food lies first, and the gizzard, in which it is rubbed against the little stones which the bird swallows. Then finally came the stomachs of the higher animals, with many curious and interesting peculiarities; as for example, the divided stomach of those animals, such as the calf, which chew the cud, and of the camel, in which one division serves as a water-bag. And side by side with these organs of digestion he placed the teeth of each animal, showing how these were each exactly fitted to prepare the food for the particular kind of stomach of the animal to which they belonged.

In this way Hunter tried to arrange the history of all the different organs of the body, tracing out each as perfectly as 
he could, and showing how it suited the wants of the various animals. His museum cost him an immense amount of labour, and more than $70,000 l$. in money; when he died, in 1793 , it was bought by the English Government for $15,000 \%$. and placed in the London College of Surgeons, and for the last eighty years many a London student of physiology has had occasion to be thankful to the rough and uneducated John Hunter for the laborious and careful work he did, and the magnificent collection he left behind him.

Experiments upon Animals by Bonnet and Spallanzani. -While Haller and Hunter by their dissections were adding greatly to our knowledge of the structure of animals, two famons naturalists in Switzerland and Italy were bringing to light some extremely curious and interesting facts about their groweth.

The first of these, named Charles Bonnet, was born at Geneva in 1720 , and died in 1793 . He had a great love of natural history, and when he was twenty years of age he wrote a paper upon aphides, or plant-lice, which was so remarkable that the French Academy of Sciences at once elected him one of their corresponding members. $\mathrm{He}$ also made some vary interesting experiments upon plants, showing that they have the power of seeking out for themselves what is necessary for their growth. We all know that plants grow towards the light, and if kept in a dark room will seek out even a crack through which the light comes. But Bonnet proved that they will do much more than this, for he found that if he twisted the branch of a tree so as to turn the leaves bottom upwards, in a little time each leaf turned right round on its stalk so as to get back into its natural position; while on the other hand, if he hung a wet sponge over a leaf, the leaf would turn its under side up- 
wards, so as to bring the little mouths, or stomata, close to the sponge, and enable them to drink in the water. In this way a plant will always find out the best way of growing so as to get as much sun and food as it can. Many curious facts of this kind were published in Bonnet's work on the ' Use of the Leaves of Plants,' but what I wish now particularly to relate to you are his experiments upon animals and the regrowth of limbs which had been cut off.

It had long been known that very simple organisms, such as polyps, may be cut in pieces, and each part will live and become a perfect creature; but no one thought it possible that any of the more complicated living beings could be treated in this way. Bonnet, however, and the famous Italian naturalist Spallanzani ( $1729-1799)$ proved by a great number of experiments that tails, legs, and even heads will grow again in some animals after they have been cut off. The garden-worm, for example, is an animal with many organs : it has numerous bristles, which serve as feet, it has arteries and veins, nerves, and organs of digestion, and a mouth ; yet Bonnet found that a worm if cut in pieces would grow a new head or a new tail, and, what was still more curious, in some rare cases it grew the head on the end where the tail had been before!

Spallanzani went even farther than this, for he experimented on snails. Now the common garden snail has a head with four horns, moved by very complicated muscles, and two of these horns have eyes at the end of then ; moreover it has a mouth, with teeth and a tongue. Spallanzani cut off first the horns with eyes, and afterwards the mouth and tongue, and found that the snail had power to re-grow them all. He then tried upon aquatic salamanders, which rescmble our newts, or efts. These creatures have red blood 
like ourselves, they have a heart, lungs, bones, and muscles, and their legs possess muscles and nerves like those of a man; yet Spallanzani cut off the tail and legs of one salamander six times in succession, and in another case, Bonnet cut them off eight times, and they grew again. Bonnet even took out the right eye of a newt, or eft, and in eight months another eye had grown in its place. These experiments were very startling, for they showed that the life of the lower animals does not depend on a particular part of the body so much as it does in ourselves and in the higher animals. If you cut off the head of a man or an ox, they die, or if you cut off a leg, it never grows again; but these experiments proved that the worm and the snail live and grow new heads and limbs, and that the more simple an animal is, the more power it has to live and grow after it is cut in pieces.

These discoveries led Bonnet to make a suggestion which I want you to remember, because we shall have to speak of it by-and-bye. He asked whether it was not likely that there was a gradual development or complication of the parts of the body as you ascend from the lowest plant up to the highest animal, so that the body of a worm, for example, could do all the work necessary to keep it alive and to make it grow, without the help of its head, and a lizard could in the same way make a new leg without much difficulty. But as the machinery grew more and more complicated this would not be so easy, till at last it would become impossible in the higher animals, just as in a complicated machine one broken wheel will upset the whole working. Bonnet wrote a book called 'The Contemplation of Nature,' in which he dwelt upon this subject, and tried to trace out how animal forms had become gradually higher and higher, till they had arrived at man. We shall see by-and-by how this idea occurred also 
to the naturalist Lamarck, and how it has become the foundation of a grand theory of life in the present century. Meanwhile you must bear in mind that Bonnet and Spallanzani added enormously to our knowledge of the lower animals and their powers of life, and together with Boerhaave, Haller, and Hunter did a great deal to advance the sciences of anatomy and physiology in the beginning of the eighteenth century.

Chief Works consulted. - 'Life of Haller'- 'Naturalists' Library ;' Brewster's 'Encyclopædia,' arts. 'Physiology' and 'Haller ;' Lawrence's 'Lectures on Comparative Anatomy,' I816 and 1848; Lawrence's translation of Blumenbach's 'System of Comparative Anatomy,' 1807; ' Life of John Hunter'- 'Naturalists' Library,' vol. x. ; Cuvier, 'Hist. des Sciences Naturelles ;' Carpenter's 'Comparative Physiology ;' Tom Taylor's 'Leicester Square,' Appendix by Professor Owen. 


\section{CHAPTER XXV.}

Birth a.sd Early Life of Buffon and Linneus compared-Buffon's Work on Natural History-Daubenton wrote the Anatomical Part -Buffon's Buoks very interesting, but not always accurate-He first worked out the Distribution of Animals-Struggles of Linnæus with Poverty - Mi: Clifford befriends him-He becomes Professor at Upsala-He was the first to give Specific Names to Animals and Plants-Explanation of his Descriptions of Plants - Use of the Linnæan or Artificial System-Afterwards superseded by the Natural System-Linnæus first used accurate terms in describing Plants and Animals-Character of Linnæus-Sale of his Collection, and Chase by the Swedish Man-of-war.

\section{Advance of Natural History-Buffon and Linnæus.-In} the year 1707 two men were born, the one in France and the other in Sweden, whose names have become almost equally well-known, although they were by no means equally great.

The Frenchman, George-Louis Le Clerc Buffon, the son of a counsellor of the parliament of Dijon, was born on his father's estate in Burgundy. The Swede, Karl Linnæus, the grandson of a peasant and son of a poor Swedish clergyman, was born in a small village called Râshult, in the south of Sweden. Buffon enjoyed the best education which France could afford him, with plenty of opportunity to cultivate his love of natural history. At one-and-twenty he succeeded to a handsome property, and after travelling for some time settled down to a life of ease and literature, partly 
in Paris, and partly on his estate in Burgundy. Linnæus was taught in a small grammar-school, where he showed so little taste for books that his father would have apprenticed him to a shoemaker if a physician named Rothmann, who saw the boy's love of antural history, had not taken him into his own house and taught him botany and physiology. At one-and-twenty, when Buffon came into his fortune, the young Linnæus, with an allowance of eight pounds a year from his father, was a struggling student at the University of Upsala, putting folded paper into the soles of his old shoes to keep out the damp and cold.

Buffon's work on Natural History: he traces the Distribution of Animals.-Buffon's private life is not interesting. He was a vain man, and not a moral one; but he had great talents, and remarkable perseverance and industry. In 1739 he was appointed Superintendent of the Royal Garden and Cabinet at Paris, a position which he held till his death. His great work, of which we must now speak, was his 'Natural History,' which occupied him the greater part of his life. It is one comprehensive history of the living world, containing descriptions of all the animals then known, their structure, their distribution, their habits, and their instincts, and, mingled with these, many curious theories about the world and its inhabitants.

The anatomical part of this work was done by a physician named Daubenton, who came from Buffon's own village, and was appointed keeper of the cabinet of natural history through his influence. Buffon was very fortunate in having the help of this man, for having weak sight himself, and being more fond of general theories than of petty details, this part of his work would have been very poor if it had not been for Daubenton's careful and conscientious dis- 
sections and descriptions. The rest of the work was written chiefly by Buffon himself, who bestowed upon it immense pains and labour. He was a very pleasing writer, and did a great deal for natural history by making it popular. His books were more like romances than works of science, but he collected in them a great deal of very useful information, and put it in a shape which everyone could read with pleasure, and in this way led people to think, and to wish to know more about natural history and the habits and lives of animals. He was also the first to trace out with any care the way in which animals are distributed over different parts of the globe; how they are checked by climate, by mountains, by rivers, and by seas from wandering out of their own regions, and how they are more widely spread over cold countries than over.warm ones, because they are able to cross the seas and rivers upon solid or floating ice, and so get from one region to another.

In this general way Buffon gathered together a great many interesting facts about animals. His works were all the more popular because he disliked anything like classification. He would not attempt to group the animals after any particular method, but liked to describe each one with a little history of its own, and to write on freely without any very great scientific accuracy. Of course the consequence was that he often made great mistakes, and arrived at false conclusions; still he had so much genius and knowledge that a great part of his work will always remain true, and Natural History owes a great deal to Buffon. He died in 1788 , in the eighty-first year of his age, and twenty thousand people assembled to do him honour at his funeral.

Life and Influence of Linnæus, 1707-1778.-We must now turn to Linnæus, whose whole life and labours were as 
different from those of Buffon as his birth and early life had been. Buffon hated to be bound down to exact details; Linnæus found his greatest pleasure in tracing out each minute character in plants and animals so accurately as to be able to build up a complete classification, by which anyone could tell at once to what part of the animal or vegetable kingdom any living being belonged. While Buffon's books were entertaining and readable, Linnæus's were often hard dry science, consisting chiefly of long accurate tables and minute details about the structure of animals and plants. Yet Linnæus's writings are worth infinitely more than those of Buffon's for one simple reason, he had a more earnest love of $t$ ruth.

Linnæus seems to have been born a botanist. He writes in his own diary that when he was four years old he went to a garden party with his father and heard the guests discussing the names and properties of plants; he listened carefully to all he heard, and ' from that time never ceased harassing his father about the name, quality, and nature of every plant he met with,' so that his father was sometimes quite put out of humour by the incessant questioning. However at last, when Dr. Rothmann took him into his house, he had opportunities of learning, and from that time he advanced so rapidly that he was soon beyond all his teachers.

In 1736 , after meeting with many kind friends in his poverty, and making a journey to Lapland, which was paid for by the Stockholm Academy of Science, he went to Holland. Here he called on the celebrated Boerhaave, who with his usual good nature introduced him to a rich banker, named Clifford, who was also a great botanist. This was the turning-point of Linnæus's life. Mr. Clifford invited 
him to live with him, treated him like a son, and allowed him to make free use of his magnificent horticulutral garden. $\mathrm{He}$ also sent him to England to procure rare plants, and gave him a liberal income. This continued for some time till Linnæus's health began to fail, and he found besides that he had learnt all he could in this place, so he resolved to leave his kind friend and wander farther. Mr. Clifford seems to have been much hurt at his leaving, yet he continued his kindness to him through life.

Linnæus went to Leyden and Paris, and from there to Stockholm, where he practised as a physician, and at last he settled down as Professor of Medicine and Natural History at Upsala, where he founded a splendid botanical garden, which served as a model for many such gardens in other countries, such as the Jardin de Trianon in France, and Kew Gardens in England. His struggles with poverty were now over for ever, and his fame as a botanist was spread all over the world. He used to set out in the summer days with more than 200 pupils to collect plants and insects in the surrounding country, and many celebrated people came to Stockholm to attend Linnæus's 'Excursions.' Then as his pupils spread over the world he employed them to collect specimens of plants and animals from distant countries, and he himself worked incessantly to classify them into one great system.

Linnæus gives Specific Names to Plants and Animals. -And now we must try to seize upon the chief points of Linnæus's work, that you may be able to understand something of what he did for science, although it is quite impossible for us to give even a sketch of his divisions of the animal and vegetable kingdoms. The first and greatest point of all was that he gave a second or specific name to every plant and animal. Before his time botanists had 
only given one name to a set of plants ; calling all roses, for example, by the name Rosa, and then adding a description to show which particular kind of rose was meant. Thus, for instance, for the Dog-rose they were obliged to say Rosa, sylvestris vulgaris, fore odorato incarnato, that is, 'common rose of the woods with a flesh-coloured sweetscented flower.' This, you will see, was extremely inconvenient ; it was as if all the children in a family were called only by their father's name, and you were obliged to describe each particular child every time you mentioned him; as 'Smith with the dark hair,' or 'Smith with the long nose and short fingers,' \&c. A botanist named Rivinus had suggested in 1690 that two names should be given to plants, and Linnæus was the first to act upon this idea and to give a second specific, or, as he called it, trivial name to each particular kind of plant, describing the plant at the same time so accurately that anyone who found it could decide at once to what species it belonged. To accomplish this he classified all plants, chiefly according to the number and arrangement of their stamens and pistils (or those parts which produce the seeds), and then he subdivided them by the character and position of their leaves and other parts.

In describing the geranium, for example, he mentions first the 'sepals,' or little green leaves under the flower; he says they are five, and very pointed ; then the 'petals,' or flower-leaves, are five also, growing on the sepals and heart-shaped ; the 'stamens' are ten in number, and grow separate; the little vessels on the top of the stamens, which are called ' anthers,' and hold the yellow dust, are oblong; the 'pistil,' or seed-vessel, is formed of five parts, which are joined together into one long beak which ends in five points; the seeds are covered with a skin and are shaped 
like a kidney, having often a long tip which is rolled round in a spiral (like a corkscrew). Here we have a definition of the genus geranium; but many geraniums will answer to this description, so he goes on to describe some more special characters. The sepals in this particular specimen, he says, are joined together in one piece ; the stem of the plant is woody, the joints are fleshy, the leaves are slightly feathered at the edge. These last characters are peculiar to this kind of geranium, which he calls Geranium gibbosum, and here we have the specific name. Any geranium which has the woody stem, the joined sepals, the fleshy joints, and the feathery-edged leaves, will be the species called by Linnæus gibbosum.

You will see that by this system it is always possible to find out easily to what part of the vegetable kingdom your plant belongs and what its name is ; and if, after you have traced its genus, there is no species which exactly agrees with yours, you then know that you have discovered a new species which has not been described before. Linnæus classified animals after this same plan, quadrupeds chiefly by their teeth, and birds by their beaks, and after his system was complete anyone could discover the scientific name of a plant or animal by exercising a little care and patience. This system is called the Linnæan, or artificial system, because it only selects a few particular parts of a plant, so as to help you to look it out in a kind of dictionary. It tells you very little of the real or natural life of the plant, and often brings some very near together which are really very different. It is as if you classified people by some particular feature, such as those who had long hair, or short hair, dark or light, curly or straight. This might be very useful for recognising them, but it would be quite artificial, 
and would tell you very little about their real relationship. Therefore this classification has now been partly set aside for another or natural classification, which Linnæus also suggested, only he thought it too difficult for ordinary people ; and which was worked out by a French botanist named Jussieu, as we shall see by-and-by. But the Linnæan system is still extremely useful for finding the name of a plant or animal, and many people in the last century were led to study zoology and botany by the simplicity of the classifications of Linnæus.

The other useful point in Linnæus's system was the accurate and precise terms he invented for describing plants. Before his time naturalists used any words which suited them, and as different people have often very different ideas as to what is meant by long or short, round or pointed, \&c., the descriptions were often of very little value. But Linnæus could not work out his system without using very clear terms and explaining beforehand what he meant by them ; and as his nomenclature, or system of names, was soon followed in other countries, botanists in all parts of the world were able to recognise at once what was meant by the description of any particular plant. The same advantage arose out of his classification of animals, and the care with which he traced out their chief characters. I wish I could have given you some idea of this system, which was fully explained in the 'Systema Naturæ,' completed in I768. But when you remember that Linnæus classified minutely the whole of the animals and plants known in the world, you will perceive that I should have to write a separate book to make you understand it. If you can only remember that he did build up this artificial system, and that he was the first to give specific names to plants and animals and to create an 
accurate nomenclature all over the world, you will, I think, have learnt as much as you need at present about the, work of the great Swedish naturalist.

Linnæus was not a vigorous old man. The hard struggles of his youth and the immense work of his afterlife had worn him out, and at fifty-six he was obliged to ask the King of Sweden to let his son lecture sometimes in his place. With this help he continued to work at science till within two years of his death, when his mind became feeble. $\mathrm{He}$ died in 1778 , loaded with honours and beloved and esteemed by the greatest men all over the world. His had been a noble life; enthusiastic and truth-loving, he had worked, even when he was poor, for science and not for wealth, and when he became famous and rich he helped his pupils as others had helped him, and lived simply and frugally till his death. Unlike Buffon, his private life was as pure as his public life was famous. Over the door of his room he placed the words 'Innocue vivito, Numen adest,' ('Live innocently, God is present'), and he lived up to his motto. His study of nature had filled him with deep reverence and love for the Great Creator, and he used often to tell his friends how grateful he was to God for those gifts which had made his life so full of interest and delight.

After the death of Linnæus his mother and sisters sold his collection of plants and insects, and all his books and manuscripts, to Dr. Edward Smith (afterwards Sir E. Smith), for one thousand pounds. The King of Sweden was at this time away from Stockholm, but directly he returned and heard that such a valuable national treasure was on its way to England he sent a man-of-war to try and bring it back. A very amusing chase then took place; Dr. Smith did not mean to lose his prize if he could help it, so he set full sail 
and literally ran away till he reached the Thames, and landed safely in London without being caught. Thus the Linnæan collection came to England, and is now in Burlington House. The Swedes are naturally sorry that it left their country, but on the other hand it has become more known to scientific men in London than it could ever have been in Stockholm. With Linnæus we must end for the present the history of the sciences relating to living beings. Early in the nineteenth century we shall return to them again, but in the next chapter we must learn something of a new science which arose about this time; namely, the science of 'Geology,' or the study of the earth.

Chief Works consulted.-Jardine's 'Naturalists' Library,' vols, ii. and xiii. ; Brewster's 'Encyclopædia'- 'Buffon and Linnæus ;' Cuvier, 'Histoire des Sciences Naturelles ;' Smith, Sir J., 'Introduction to Botany;' Pulteney's 'View of Writings of Linnæus;' Linnæus, 'Systema Nature.' 


\section{CHAPTER XXVI.}

\section{SCIENCE OF THE EIGHTEENTH CENTURY (CONTINUED).}

The Study of the Earth neglected during the Dark Ages-Prejudices concerning the Creation of the World-Attempts to Account for Buried Fossils-- Palissy, the Potter, first asserted that Fossil-shells are real Shells-Scilla's Work on the Shells of Calabria, 1670Woodward's Description of Different Formations, 1695-Lazzaro Moro one of the first to give a true explanation of the facts-Abraham Werner lectures on Mineralogy and Geology, 1775-Disputes between the Neptunists and Vulcanists-Dr. Hutton first teaches that it is by the Study of the Present that we can understand the Past-Theory of Hutton-Sir J. Hall's Experiments upon Melted Rocks-Hutton discovers Granite Veins in Glen Tilt-William Smith, the 'Father of English Geologists'-His Geological Map of England.

Early Prejudices concerning the Formation of the Rocks.-You will no doubt remember that when we were speaking of the science of the Greeks, we learnt (p. II) that Pythagoras made many interesting observations about the crust of the earth, which led him to say that the sea and land must have changed places more than once since the creation of the world. Especially he pointed out that seashells are found inland, deeply buried in the hills; and that the sea eats away land on the coast in some places, while in others earth is washed down by the rivers and laid at the bottom of the ocean.

We have now passed over more than 2,000 years since the time of Pythagoras, and you will notice that we have 
heard nothing more about observations of this kind. The fact is, that during the Dark Ages the study of the earth had been almost entirely neglected, and people had taken up the mistaken notion that they ought to believe, as a matter of faith, that the world was created in the beginning just as we now see it. But knowledge and inquiry were advancing so fast in the eighteenth century, that it was impossible for such ignorance to continue long. People could not go on digging wells and making mines in all parts of the world without being struck by the way in which the different strata, or layers of rock, are arranged in the earth's crust, nor without noticing the fossil shells, plants, and bones of animals which they found buried at great depths.

At first they were very unwilling to believe that these remains had ever belonged to living animals and plants, and they tried to imagine that they were only stones resembling shells, leaves, \&c., which had been in some way mysteriously created in the earth. Then, when this absurd idea was given up, they next enquired whether a universal flood might not have spread them over the land; but though this opinion was upheld for more than a hundred years, yet it was clear to all those who really studied the subject that it could not account for the many layers of fossils deeply buried in the earth.

First Attempts to study the Fossil Remains and the beds containing them.-At last, little by little, there arose men who adopted the more sensible plan of studying the different formations in the crust of the earth before making theories about them. Bernard de Palissy, the maker of the famous French pottery, was the first to assert, in 1580 , that the fossil shells were real sea-shells left by the waters of the ocean; then, in 1669 , we find Steno, a Dane, writing a re- 
markable work on petrifactions in the rocks; and in 1670 Scilla, an Italian painter, published a treatise on the fossil shells and other remains in the rocks of Calabria, and made some beautiful drawings of these remains, which may now be seen in the Woodwardian Museum at Cambridge. Next we find our own scientific men, Hooke, the naturalist Ray, and a famous geologist Dr. Woodward, speculating why the earth's crust is made up of different layers, one above another, with different fossils in each. Woodward (1695) made a careful collection of specimens of chalk, gravel, coal, marble, and other rocks, together with the fossils which he found in them; and these also are in the Cambridge Museum. But all these men, though they did good work, still held very erroneous notions about the way in which the. crust of the earth had been formed.

The first geologist who gave any real explanation of the facts was Lazzaro Moro, an Italian, born at Friuli in Lombardy, in 1687 . Moro pointed out, as Woodward had done before him, that the different strata lie in a certain order one above the other, and that within them are imprisoned fossil fishes, shells, corals, and plants, in all countries, and at all heights above the sea. The rocks, said Moro, writing in 1740, must have been soft when these fossils were buried in them, and some must have been near rivers, because they contain fresh-water animals and plants ; while others contain only marine fossils, and must have been laid down under the sea. It is clear, then, that they must all have been formed in lakes or seas, and have been raised up by earthquakes, or thrown out by volcanoes, such as we see taking place from time to time in the world now. This explanation, though rough, was true, and Moro deserves to be remembered as one of the first men who led the way towards a true study of the earth. 
After him there followed many others, whom we cannot mention here; but the next whose name is famous was the great Werner, professor of mineralogy at Freyberg in Saxony.

Werner calls Attention to Geology, 1775.-Abraham Werner, the son of an inspector of mines in Silesia, was born in 1750 . His first playthings were the bright minerals which his father's workmen gave him, so that he knew them by sight, even before he could tell their names; and as he grew up he seemed to care for nothing but mineralogy and the wonderful facts it revealed about the formation of the earth. Freyberg, when he first began to lecture there, in 1 775, was only a small school for miners; but it was not long before he raised it to the rank of a university, so great was the fame of his lectures. He pointed out to those who came to learn of him, that the study of the rocks was something more than merely searching for minerals; and that the crust of the earth was full of wonderful histories, which might be read by those who cared to take the trouble. He pointed out how some formations were stratified, that is, arranged in layers, and contained fossil shells and other organic remains ; while, on the other hand, some were unstratified, and had no fossils in them. Some rocks were bent, as in Fig. 35 ;

FIG. 35.

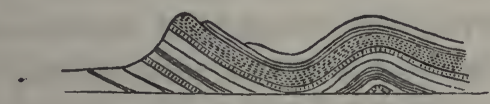

Diagram of Bent Rocks. (Page.)

others had been snapped asunder and forced one up and the other down, as in Fig. $3^{6}$; and he bade them try to seek out the reason of these bendings and breakings of the earth's crust. He reminded them also that mining was one of the 
PT. III.

great roads to wealth, and that even the history of nations often depended upon the kind of ground which they had under their feet. By facts such as these he opened men's eyes to see the wonders of the earth's crust, so that people began to talk everywhere of the geological lectures of Werner, and numbers flocked from distant countries, and even learnt the German language, that they might come and hear him.

In this way he spread the love of geology all over Europe. He was so eager and earnest himself that his pupils could not fail to catch some of his enthusiasm, and to try to follow out his ideas. But, unfortunately, this very enthu-

FIG. 36 .

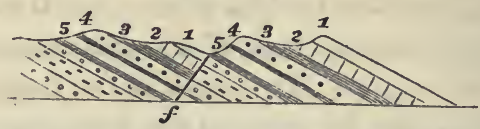

Diagram of rocks which have been rent apart at the poin! $f$, and tilted up. $x, 1,2,2$, \&c., Beds which before the disturbance were continuous."

siasm led him to insist upon a theory which kept back his favourite science for many years.

Neptunists and Vulcanists. - Werner had only studied a small part of Germany, and there were then very few descriptions of other parts of the world which he could read; and so, from want of knowledge, he formed the mistaken idea that in olden times, after the globe had cooled down and become fit for living beings, there were no volcanoes for long ages, but that basalt and other rocks, which we now know were made by volcanic heat, were all laid down by water. There were men living in Werner's time who knew that this was a wrong theory, but he would not listen to their arguments, and the two parties became so violent that many years were lost in angry disputes between the

1 Kindly drawn for me by Professor Ramsay. 
Neptunists, or those who thought all rocks were laid down by water, and the Vulcanists, who contended that many rocks, such as basalt, were made by volcanic heat.

Hutton teaches that it is by the Study of Changes going on now that we can alone learn the History of the Past.-While these discussions were going on upon the Continent, a Scotchman was setting to work in the right way to settle the question. This man was Dr. Hutton, one of the greatest geologists that has ever lived; and the reason of his greatness was the same which we have found at every step in our history of science. Before he made any theory he sought out the facts. He travelled and observed for himself, he collected patiently details about the layers or strata in the formations of all countries through which he passed; and it was only after all these investigations that in I 788, when he was sixty years of age, he wrote his famous ' Theory of the Earth,' in which he showed how the history of the earth's crust might be traced out. This work, although very interesting, was not much read; but one of Hutton's favourite pupils, the celebrated Dr. Playfair, wrote a book called 'Illustrations of the Huttonian Theory,' by means of which Hutton's opinions became well known.

About Hutton himself there is very little to tell. He was born in Edinburgh in 1726 , studied medicine, and took his doctor's degree in Leyden in 1749 , and then returned to F.dinburgh, and devoted all his life to science. Of his teaching I should like to write a great deal, but we must content ourselves with a little which you can understand. His great principle was that it was useless to try and guess how the rocks had been made and fossils buried in them, for this had only led to endless confusion and disputes. Men must go, he said, and see with their own eyes how 
rocks are being made now, how rivers and glaciers are carrying down earth and stones from the mountains into the sea, and how volcanoes are throwing out melted matter which cools down into hard rock; and then they must compare these with the older rocks in the crust of the earth, and see whether they were not formed in the same way.

Aqueous (or water-made) Rocks. - When we find a piece of marble made up almost entirely of oyster and other shells, and of pieces of coral, we cannot doubt that it must once have been a heap of loose shells and corals such as we now see on the shore or under the water, and that it has since been hardened into limestone. When we find that by crushing or scraping sandstone we can turn it into sand like that which we see on the seashore, and which we know has been made by the sea grinding the stones and rocks of the beach against each other, then we cannot doubt that the sandstone has once been loose sand, and before that was part of a rock which has been ground down by the waves.

And so we are led to the conclusion that the rocks of our earth, as we see them now, have been formed out of the materials of still older rocks which existed before them, and are being gradually moulded into other and newer rocks, which will exist when these have been destroyed. Our solid earth is being wasted every day. The sides of the mountains are washed down and their materials are carried through the valleys by the running water. In this way the soil is brought down to the coast, and here it is eaten away by the waves of the sea, and falls to the bottom of the ocean, out of which it will be raised again by earthquakes, volcanoes, and other movements of the earth's crust, such as can be proved to be going on in parts of the world at this day. As far back as investigations and reasoning can go we find 
everywhere signs that these gradual and incessant changes have always been going on, and that the face of our earth, as we now see it, has been moulded out of the ruins of an older world.

Igneous (or fire-made Rocks). - But how are we to decide about those rocks, such as basalt, which Werner thought were made by water? Hutton was convinced they were formed in volcanoes; and yet it was true that they did not contain bubbles of air as lava does, which has poured down the sides of a volcano in the open air. Here his friend and pupil Sir James Hall came to his assistance by melting pieces of rock in his chemical laboratory, and letting them cool down under very heavy pressure. When this was done they could hardly be distinguished from pieces of basalt which he took out of the earth. It is clear, therefore, he said, that these rocks have either cooled down inside the volcano, with a great weight of rocks above them, or have been poured out under the sea, which would press down heavily upon them and shut out the air.

Another question which Hutton cleared up in the same way was that of the formation of granite. Werner believed that all the granite rocks, of which you may see plenty in different parts of he world, were made first, before any other rocks were laid down by water. Hutton did not think this was true, but that, on the contrary, granite might be even now forming deep down within the crust of the earth. But how was he to prove this? He said to himself, 'If melted granite forms under the softer strata which have been laid down by water, it ought occasionally to obtrude itself into them in narrow wedges when it is expanded by heat, and I shall be able somewhere to find veins of granite piercing the rocks above.' 
To prove whether this was so he made a journey to the Grampians, where there are large masses of granite; and there, in Glen Tilt, he found the veins of red granite branching out into the clay-slate and limestone rocks above, as in Fig. 37. It is easy in this diagram to see that the water-made layers, $a, b$, must have been there before the granite was melted, otherwise it could not have sent the straggling veins, $c c$, up into them. And so he convinced himself that some granites are newer than the aqueous rocks which lie above them. It is said that he was so delighted

FIG. 37.

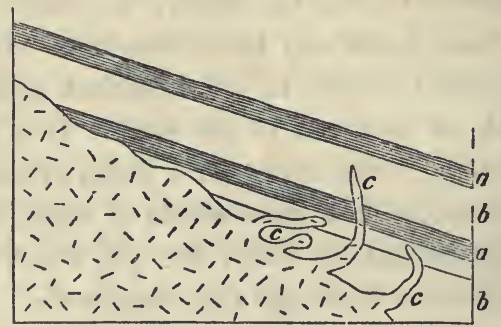

Granite Veins in Glen Tilt.

a. Clay slate. b. Limestone. c. Granite veins.

at finding this proof that the guides who were with hin thought he had discovered a vein of gold.

This is one out of many examples of the way in which Hutton worked and corrected the mistakes which had sprung up in the German school of geology. Werner had taught his pupils that there was really something to be learnt from the study of the rocks; that they could be made to tell real histories of the past and help men to get wealth for the future, and thus he persuaded them to give time and thought to this work. Hutton showed that to carry on this study rightly they must open their eyes to all that is going 
on now, and that the only way to read the history of the past is to compare it with the present.

William Smith surveys the Rocks of England.-Meanwhile another man, whom we must not forget to mention, was working away very quietly without any help, and with very little money; and yet in his way was doing at least as much work as the others. This was William Smith, a plain English surveyor, who was so much struck with the arrangement of the different formations in the hills among which he travelled that he determined to try and map them out so as to show exactly how the strata are placed one above the other, and what counties they pass through.

He began his work in I790, and travelled over the whole country, chiefly on foot, marking as he went all the different positions of the rocks, and collecting the shells and other fossils which he found in them. He had not gone on long before he observed that certain fossils which appeared in the lower beds disappeared when he reached those which lay above them, and that others took their place; so that in this way it was possible to use the fossils to trace out the age of any particular rock, just as the face of a coin helps you to tell the reign in which it was cast; and the story told by the fossils agreed very well with the divisions which he had worked out by the position of the rocks above each other. $\mathrm{He}$ was even so observant that he distinguished between the fossils which had their edges fresh, showing that they had not been disturbed since they were buried in the earth, and those which were rubbed and water-worn. The fresh ones only, he said, are of use to tell the age of a rock, for those which are rubbed may have been washed out of some older formation by rivers.

In this way William Smith, for pure love of science, and 
without any hope of gain, travelled over the whole of England and Wales, mapping out the rocks and noticing all their peculiarities. In 1799 he published a list or tabular view of the formations with their fossils, and the places where they might be seen in the hills; and in 1815 he at last succeeded in completing a geological map of England, which has ever since formed the foundation of our British geology, and which remains a lasting monument of what one man may accomplish by patience and indefatigable industry. William Smith fairly earned the title of the 'Father of English Geologists,' which has ever since been given him, and, with Werner and Hutton, deserves to be remembered as one of the founders of the science of geology.

Chief Works consulted. - Lyell's 'Principles of Geology ;' Lyell's 'Student's Elements of Geology ;' Page's 'Advanced Text-Book of Geology ;' Hutton's 'Theory of the Earth ;' Fitton's 'Notes on Progress of Geology in England;' 'Life of Werner' - 'Naturalists' Library,' vol. xxaix. 


\section{CHAPTER XXVII.}

SCIENCE OF THE EIGHTEENTH CENTURY (CONTINUED).

Birth of Modern Chemistry-Discovery of 'Fixed Air,' or Carbonic Acid, by Black and Bergmann - Working out of 'Chemical Affinity' by Bergmann - He tests Mineral Waters, and proves 'Fixed Air' to be an Acid-Discovery of Hydrogen by Cavendish - He Investigates the Composition of Water-Oxygen discovered by Priestley and Scheele-Priestley's Experiments-He fails to see the true bearing of his Discovery-His Political Troubles and Death - Nitrogen described by Dr. Rutherford - Lavoisier lays the Foundation of Modern Chemistry-He destroys the Theory of 'Phlogiston' by proving that Combustion and Respiration take up a Gas out of the Air-Discovers the Composition of Carbonic Acid and the nature of the Diamond-French School of ChemistryDeath of Lavoisier.

DURING the last half of the eighteenth century, while Hunter and Linnæus were adding to our knowledge of living beings, and Werner and Hutton were reading the history of the crust of the earth, a little group of men in England, France, and Sweden were making discoveries which entirely altered the science of chemistry. These men were Bergmann and Scheele in Sweden; Black, Cavendish, and Priestley in England ; and Lavoisier in France.

In order to understand what their discoveries were, and what they taught us, it is necessary to bear in mind that up to this time chemists had believed fire, air, and water to be simple substances which could not be decomposed or split up irto any other kind of matter. Mayow, indeed, had 
shown that the atmosphere could be separated into two gases, but his experiments had been passed over and forgotten; and though Dr. Hales, at the beginning of the eighteenth century, had collected several gases, he had not distinguished them from air. The fact was that Stahl's imaginary 'phlogiston,' which was supposed to pass out of burning and breathing bodies into the air, was a constant source of confusion, and led men away from the truth.

But the time had now come when these misty ideas were to be dispelled, by the discovery of the four gases-carbonic acid, hydrogen, oxygen, and nitrogen.

Discovery of 'Fixed Air,' or Carbonic Acid, by Black, 1756. - The first step was made by a Scotch physician named Black, who was born in 1728 , and became Professor of Chemistry at Glasgow in 1756 . Here he made many valuable experiments, and among other things he was very anxious to find out why limestone altogether changes its character when it is burnt. If you take a piece of ordinary limestone or chalk, and put it in water, it will remain without any change unless you add a little acid to the water, and then the limestone will effervesce, and bubbles will begin to rise up from it. But if you take a piece of the same limestone and burn it in a fire, it turns into a powder called quick-lime, which will no longer give out bubbles when you pour acid upon it, but directly you mix it with water it will swell up and become intensely hot, as you may see for yourself if you watch bricklayers making mortar by the roadside. This complete change in the limestone, caused by merely heating it, had been a great problem to chemists; and Dr. Black was still more puzzled by finding that the lime was lighter after it had been burnt, although he could not discover that it had lost anything except a little 
water, which was not enough to account for the loss of weight.

At last he remembered that Dr. Hales had driven air out of substances, and collected it in bottles; and he began to consider whether the heat of burning might not have driven some heavy kind of air out of the limestone, and so made it lighter. To prove this he made the experiment which has since been always used for making small quantities of carbonic acid gas. He put some pieces of limestone in the bottle, a, Fig. 38, and poured upon them some water and

FIG. $3^{8}$.

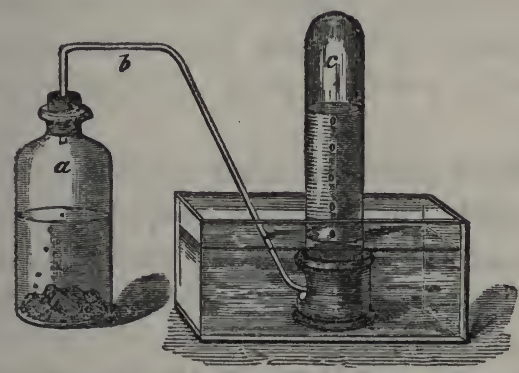

Carbonic Acid rising from Limestone and Acidulated Water (Griffin).

a, Bottle containing pieces of limestone in water and acid. $b$, Connecting tube. $c$, Inverted jar, out of which the rising gas is driving the water.

some acid. He then stopped the bottle with a tight cork, and joined it by the tube $b$ to a large glass jar, $c$, filled with water, and standing with its open end downwards in a vessel of water. In a few moments the bubbles began to rise from the limestone, and passing into the jar, $c$, drove out the water and filled the jar with gas.

This gas Black called 'fixed air,' because it had been fixed in the limestone before it was driven out by the acid. He collected and weighed it, and found that it exactly 
made up the weight which the limestone had lost. He then reversed the experiment, and taking some water which had lime dissolved in it, he passed some 'fixed air' into it, and, as he expected, the gas joined itself to the lime and formed a powdered white chalk at the bottom of the bottle. By these two experiments he proved that limestone is composed of lime and ' fixed air.'

$\mathrm{He}$ then proceeded to examine the gas itself. He found that animals died in it, and that a flame would not burn in it, and also that it was the same gas as that which bubbles out of beer and other liquids when they ferment, and often out of mineral springs. He also proved that there is 'fixed air' in our breath, by breathing into a glass of lime-water, and thus forming powdered chalk, which fell to the bottom of the glass.

All this Black discovered about 'carbonic acid,' which is sometimes called 'fixed air' even now, when people speak of it in effervescing drinks. He did not know that it is an acid; this discovery was made by Bergmann of Sweden, of whom we must now speak.

Bergmann shows that Fixed Air is an Acid-Works out 'Chemical Affinity' of many Substances.-Torbern Bergmann, who was born in 1735 in West Gothland, was the son of a tax-collector, and he had the greatest difficulty in getting permission to study science. His father had intended him for the law or the church, and it was not until his scientific books had been burnt, and he had fallen ill with disappointment, that they saw it was useless to oppose him, and he was allowed to take his own course. From that time he was happy; he put himself under the great Linnæus, and in 1761 became Professor of Natural Philosophy at Upsala, and afterwards of Chemistry at Stockholm. 
Bergmann made a great advance in chemistry by working out the 'chemical affinity' of many substances, and showing how to make use of it to test or try mineral waters.

Nearly a hundred years before Bergmann began to study chemistry, Newton, when writing on attraction, had pointed out that when substances are mixed together some kinds attract each other very strongly and join together, making one compound substance. For instance, he said, if you put copper into nitric acid the copper will dissolve and disappear; but if you plunge a piece of iron into the liquid the copper will re-appear and fall to the bottom of the glass, because the iron attracts the nitric acid more strongly than the copper does, and so it takes it up out of the liquid, setting the copper free.

Chemists had till now neglected this observation of Newton's, but Bergmann followed it out, and by a number of experiments he made out a table of those substances which seemed to have the greatest affinity for each other, and which would unite whenever the conditions would allow them. This he called a table of ' elective affinities.'

It is easy to see how this could be used for testing or trying what substances lie hidden in mineral waters. Iron, for instance, in the case given by Newton, would show when copper was dissolved in a liquid containing nitric acid. Boyle, too, had shown that a blue liquid extracted from the lichen called litmus turns to a bright red directly it touches an acid ; so that blue litmus is a sure test of an acid. Again, common salt put into a clear liquid containing silver, turns it cloudy; while tincture of gall-nuts makes a purple cloud in a solution containing iron. Bergmann worked out a number of these tests, and by means of them analysed or separated out the substances contained in mineral waters: 
he even melted solid minerals in acids and tested them in the same way.

One of the first uses that he made of his tests was to try Black's 'fixed air.' When he heard of this gas he suspected that it must be an acid, because it joined itself to lime, which is an alkali, that is, a substance in all respects unlike an acid; and he had found that unlike substances nearly always attract each other most strongly. So he made some 'fixed air' and tested it with blue litmus, and, as the litmus turned red directly, he knew that he was right in supposing it to be an acid, and he called it 'aërial acid,' or acid air. He then weighed it and proved that it was heavier than common air, and by passing it through water he showed that a large quantity of it would dissolve.

Thus these two men, Black and Bergmann, had arrived at a pretty good knowledge of this gas. They had proved that it is an invisible heavy kind of air ; that it dissolves in water ; that it is acid and joins itself to lime, forming limestone or chalk; that it destroys life when breathed, and puts out a flame; that it is given out by fermenting liquids, and from mineral springs, and is contained in our breath. One thing they had not found out, namely, that it is made up of two elements ; this, as you will see (p. 238), was discovered by Lavoisier in 1779 , when he gave it the name of 'carbonic acid.'

Discovery of Hydrogen by Cavendish, 1766.-The next gas discovered was hydrogen, and its discoverer was Henry Cavendish, grandson of the Duke of Devonshire, who was born in I 731. Cavendish was a very shy and reserved man, who lived much alone and found his greatest pleasure in studying science for its own sake. It is even related of him that he taught all his servants to understand by signs what 
he wanted in order that he might be able to think without interruption.

In the year 1766 he read a paper before the Royal Society upon a gas which he called 'inflammable air,' because it burst into a flame whenever a light was brought near it, and also because he believed it to be the cause of the explosions which so often take place in mines. $\mathrm{He}$ obtained this gas by pouring sulphuric acid and water upon zinc, iron, or tin, and then collecting the bubbles as Black had done (see Fig. 38, p. 227). But when he began to make experiments with this gas he found it very different from Black's 'fixed air.' It is true that a candle would not burn, nor could animals breathe in it ; but when a light was brought near it, it took fire and burnt with a pale blue flame inside the bottle. Then instead of being heavy like 'fixed air,' it was lighter than the atmosphere, and for this reason it was soon used for filling balloons. It had also another remarkable peculiarity, that when mixed with air in a bottle, it exploded with a loud noise directly a light was brought near it, leaving drops of moisture inside the bottle. Cavendish did not understand the cause of this explosion at first, but in 1784 (after Priestley had discovered oxygen) he mixed pure oxygen and hydrogen in a closed vessel, and lighted them by an electric spark, and then he made the great discovery that these two gases, when lighted, rush together and form water, which is therefore a compound substance made of oxygen and hydrogen.

Oxygen discovered by Priestley in 1774, and by Scheele in 1775.- The next gas discovered was oxygen, the most common and the most useful of all the substances in our globe. It was discovered independently by two menPriestley, a dissenting minister at Leeds, and Scheele (born 
1742), a small apothecary at $\mathrm{Kjöping,} \mathrm{a} \mathrm{little} \mathrm{village} \mathrm{in}$ Sweden.

There is no doubt that Scheele deserves as much credit for this discovery as if Priestley had never made it, for he had not heard of his experiments, and he added many useful facts which Priestley did not know. Still, as they both went over much the same ground, we cannot afford space here to give Scheele's experiments. You must not, however, forget his claim, for though the world often forgot him because he remained a poor apothecary all his life, yet Scheele was really one of the first chemists of Europe. We owe to him the discovery of chlorine ; and of manganese, barytes, fluorspar, and many other earths whose names I cannot expect you to know. Indeed, his merit was so great that Bergmann, his friend and patron, once said, 'The greatest discovery he ever made was when he discovered Scheele.'

Joseph Priestley, the discoverer of oxygen, was born in 1733. The greater part of his life was spent in writing upon religious subjects, and it was only in his leisure hours that he studied chemistry. He tells us in his autobiography that he first began to take an interest in such things in consequence of visiting a brewery next door to his house and watching the fixed air which rose from the beer-vats. His first chemical experiment of any value was to force this 'fixed air' into pure water, thus making an effervescing drink much the same as the soda-water we drink now. He next tried what effect growing plants have upon air, and by keeping a pot of mint under a bell-jar in which the air had been spoilt by burning or breathing, he proved that plants take up the bad air and render the remainder fit again to support a flame or life. He did not, however, yet know why this took place. $\mathrm{He}$ also invented a number of troughs and other 
apparatus for collecting and washing gases, and amused himself as Hales had done in driving gas out of different substances.

And thus it happened that one day, August 1, 1774, he made an experiment which led to a great discovery. He took a red pouder called mercuric oxide, which he knew contained mercury and something else besides, and he put it into the bulb, $a$, Fig. 39 ; the rest of the tube he filled

\section{Fig. 39.}

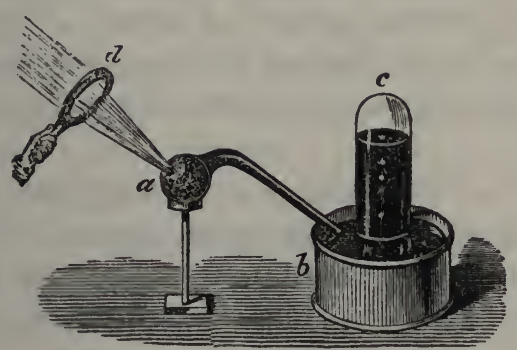

Priestley's Apparatus for procuring Oxygen.

$a$, Bulb containir. red mercuric oxide. $b$, Vessel containing mercury. c, Inverted jar for collecting the gas. $d$, Burning glass.

with mcrcury, and passed it into the basin $b$, and up into the jar $c$, both $b$ and $c$ being also filled with mercury. He next took a powerful burning.glass, $d$, and brought the rays of the sun to a focus upon the red powder. As soon as the powder became very hot a gas rose out of it and passed along the tube into the jar, $c$, driving out the mercury; while the red colour began to disappear in the bulb, $a$, and only pure shining mercury remained behind. So far he had only proved that red mercuric oxide is made up of mercury and a gas.

When he had collected enough gas to experiment upon, 
he passed some of it through water and found that it did not dissolve as 'fixed air' does ; but what surprised him still more was that a candle put into it burnt with a large vigorous flame, and a piece of red-hot charcoal burst into flame in it and burnt furiously. It was clear then that this could not be either 'fixed air' or 'inflammable air', for neither of these would feed a flame. He next put two mice into some of the gas, and he found that they lived much longer than in ordinary air. When he breathed it also into his own chest he felt singularly light and easy for some time afterwards. 'Who can tell,' he writes, 'whether this pure air may not at last become a fashionable luxury? As yet only two mice and myself have had the privilege of breathing it.'

Here, you see, we have come back again to Mayow's fire-air, so long forgotten, which supports life and flame. Priestley had learnt more about it than Mayow had, for he had collected it separately, had burnt it, and breathed it without other air being mixed with it; and he had moreover shown that it could be driven out of metallic compounds, for mercury is a metal. Yet it is disappointing to learn that, in spite of having gone thus far, Priestley was so imbued with Stahl's theory of 'phlogiston,' that he did not really understand the great discovery he had made, but called his gas 'dephlogisticated air,' or air which had lost that imaginary 'phlogiston' which was always confusing men's minds.

There is no doubt that he discovered the gas and showed that it was the chief actor in combustion and respiration, and for this discovery and that of an immense number of other gases, he was elected a member both of the Royal Society and the Académie des Sciences, and his fame was 
great all over Europe; yet still he had not hit upon the entire truth-he had given the facts, and it remained for Lavoisier to read the riddle.

Besides his chemical writings, Priestley published many books on theology, and though he was a singularly gentle quiet man, yet his religious and political essays were often very severe, and they led to his being driven out of Birmingham, and his house burnt by the mob, when they attacked the leading Dissenters during the panic caused by the French Revolution. After living for some time near London he emigrated to America, where he died in 1804 . $\mathrm{He}$ continued his chemical experiments up to the time of his death, and made many important discoveries, but the chief discovery which will always be connected with his name was that of oxygen, in 1774 .

Properties of Nitrogen determined by Dr. Rutherford in 1772. - There now remains to be mentioned only one of the four gases spoken of at page 226 , namely, nitrogen. This gas was first properly described by Dr. Rutherford in 1772 , but there is very little to be said of it except that it has scarcely any of those properties which belong to the other gases. It does not support life or flame like oxygen; it does not make lime-water cloudy as carbonic acid does, nor does it burn like hydrogen. In fact, it is a dull sleepy gas, which remains after oxygen has been taken out of the air, and which can be driven out of many solid bodies, especially nitre or saltpetre.

Lavoisier lays the Foundation of Modern Chemistry, 1778. - The determination of nitrogen completes the history of the discovery of those gases of which fire, air, and water are composed ; but you will have noticed that we have not yet arrived at the new explanation of chemical changes which 
was to take the place of 'phlogiston.' The fact is that Black, Bergmann, Cavendish, Scheele, and Priestley, were all so cramped by the old theory, that though they discovered the facts they could not make the right use of them. The man who did this, and who laid the foundation of modern chemistry, was the celebrated French chemist, Lavoisier.

Antoine Laurent Lavoisier was born in Paris in 1743 . His father, who was a wealthy merchant, gave him a splendid education, and when he was still quite young the new discoveries which were being made in chemistry tempted him to learn that science. At twenty-one years of age he received a gold medal from the Académie des Sciences for a very elaborate and learned essay on the best way of lighting the streets of Paris. At five-and-twenty he was elected a member of the Académie, and from that time he determined to devote his life to chemistry.

As early as 1770 Lavoisier had begun to suspect that the famous theory of phlogiston was false. His chief reason for thinking this was that he found, as Geber had done more than 900 years before (see p. 44), that when metals are heated so that they turn into powder, the powder weighs more than the original metal did before it was heated. Moreover, he also found that the air which remained behind in the vessel in which the metal had been heated had lost exactly as much weight as the metal had gained. So it seemed to him clear that the metal must have taken something from the air instead of giving anything to it.

For eight years Lavoisier worked incessantly at this problem. He heated many metals, such as iron, lead, tin, $\& c$., and other substances such as sulphur and phosphorus, and in every case, if he collected all that remained, he found it heavier than before. But there was one point in which he 
could not succeed; he could not make the metals give back again what they had taken from the air, so that he might

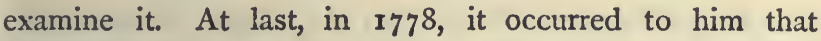
Priestley had separated mercuric oxide into two substances; namely, the metal mercury and a gas. Here, then, was just the step he wanted. If he could first make mercuric oxide by heating mercury in the air, and then afterwards separate it back again into mercury and a gas, he would thus prove what it had taken out of the air. He therefore took some mercury and put it into a tube A, Fig. 40 , which was connected

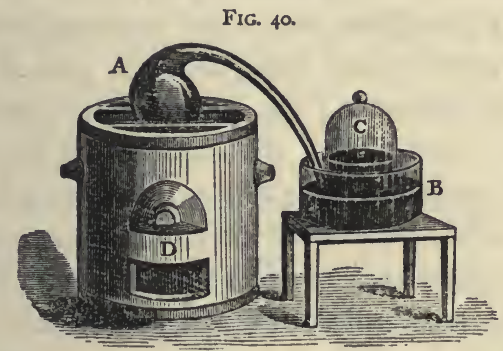

Lavoisier's Apparatus for Heating Mercury and making it take up Oxygen. A, Bulb containing mercury. B, Vessel containing mercury. C, Bell-jar partly full
of air. D, Stove.

with a bell-jar c, containing air and standing over mercury. Then he heated the bulb A over the stove $\mathrm{D}$, and kept the mercury boiling for twelve days.

During the first five days little by little red specks began to appear on the top of the mercury in c, that is, mercuric oxide was formed; but after that time, when about one-fifth of the air in the bell-jar, c, had disappeared and mercury risen in its place, no further change took place. He then lifted off the bell-jar and took 45 grains of this red powder and made Priestley's experiment with it (see p. 233), 
and he obtained, of course, the gas which Priestley had called 'dephlogisticated air.' He afterwards found by more exact experiments that the amount of this gas contained in the mercuric oxide exactly equalled the amount lost by the air in which the mercury had been heated.

Now see what Lavoisier had done : he had proved that the reason why air shrinks when substances are burnt in it, is because the substances take up a gas out of the air, and he had also shown that this gas is the same as that which Priestley discovered. Now, at last, the false theory was destroyed, and the starting-point of a true theory was found. The innaginary phlogiston, which had been supposed to load the air when. anything was burnt in it, was proved never to have had any existence; for it was clear that just the opposite effect takes place. All burning and breathing and the change in metals is caused by a gas being taken up out of the air and joined to other substances. Lavoisier called

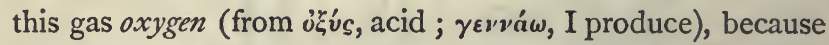
he found that most substances were acid after they had been united with it. This, too, led him to suspect that as 'fixed air' was an acid, and could be made by burning charcoal, it must be composed of oxygen and carbon. So he burnt small quantities of charcoal in pure oxygen, and by analysing the 'fixed air' produced proved that 100 parts by weight of this gas contained 72 parts of oxygen and 28 of carbon. For this reason he called it 'carbonic acid,' a name which it still bears. By burning a diamond in oxygen and producing carbonic acid, he also proved that a diamond is pure carbon.

Lavoisier had very great difficulty in persuading the other leading chemists that they had been labouring under a false idea, and that substances when burning do not put 
something into the atmosphere but take a gas out of it. Dr. Black was one of the first to be convinced, but Priestley died without giving up his old opinions. The younger chemists, however, saw the truth of Lavoisier's explanation, and from this time chemistry advanced very rapidly. Lavoisier invented an entirely new set of terms instead of the old names of the alchemists, and though his terms have been greatly altered by later discoveries, still many of them will always be used. He repeated with a better apparatus Cavendish's experiment of turning hydrogen and oxygen into water, and he gave hydrogen its name from $\hat{v} \delta \omega \rho$, water, and $\gamma_{\varepsilon} v^{\prime} \boldsymbol{u}^{\prime} \omega$, I produce. Lastly, he published his 'Elements of Chemistry,' in which he gave a clear explanation of the different chemical changes, and now students could work them out for themselves.

Lavoisier was now at the height of his fame, full of his new theory, and prepared to devote the rest of his life to making chemistry a grand science; but a very sad fate was awaiting him. In 1793 the great French Revolution broke out in Paris. Lavoisier was a farmer-general, that is a kind of collector of taxes, and all the farmers-general were hated by the people; so he knew that he should most likely lose all his fortune, and was prepared to work for his living; but he had not expected the blow which fell upon him. All the farmers-general were condemned to death, and though a physician named Hallé, who deserves always to be remembered for this act, pleaded that Lavoisier's life should be spared till he had completed his experiments, the ignorant and brutal Government replied, "We do not need learned men,' and on May I8, I 794, at the age of fifty-one, Lavoisier was guillotined.

After his death the French School of Chemistry took the 
lead for many years, until new discoveries in England, which we shall mention by-and-by, made another great advance. When you are able to read larger works upon the history of chemistry you will find how very interesting the period was of which we have been speaking. I have only been able to give you here the very barest outline of it, so that the names of these great chemists may not be quite unfamiliar when you meet with them in other books.

Chief Works consulted.-'Three Papers on Factitious Air,' by Cavendish - 'Phil. Trans.,' I 766 ; Brande's 'Chemistry :' Hoefer's 'Histoire de la Chimie ;' Cuvier, 'Histoire des Sciences Naturelles ;' Huxley, 'On Priestley'_ 'Macmillan's Magazine,' 1874 ; Priestley, 'On Different Kinds of Air,' 1774 ; Thomson's 'Hist. of Koyal Society ;' Scheele's 'Chemical Experiments on Air and Fire,' translated 1780; Miller's 'Elements of Chemistry ;' Lavoisier's 'Elements of Chemistry,' translated by Kerr, I790. 


\section{CHAPTER XXVIII.}

SCIENCE OF THE EIGHTEENTH CENTURY (CONTINUED).

Noctrine of Latent Heat, taught by Dr. Black in $1760-$ Water containing Ice remains always at $0^{\circ} \mathrm{C}$., and Boiling Water at $100^{\circ} \mathrm{C}$., however much Heat is added-Black showed that the lost Heat is absorbed in altering the condition of the Water-Watt's Application of the Theory of Latent Heat to the Steam-engine-Early History of Steam-engines-Newcomen's Engine-Watt invents the Separate Condenser-Diagram of Watt's Engine-Difficulties of Watt and Boulton in introducing Steam-engines.

Discovery of Latent Heat by Dr. Black in 1760.-We must now go back a few years, to the time when Dr. Black was lecturing at Glasgow in $\mathbf{1} 760$; for he then made a remarkable discovery about heat, which belongs to the history of physics rather than of chemistry. This was the discovery of latent heat, or of heat which becomes lost or hidden whenever ice is turned into water, or water into steam.

If you put a lump of ice in a saucepan on a stove, and when it begins to melt stir it gently so as to keep the water well mixed, you will find that so long as the smallest piece of ice is left in the water, a thermometer standing in the saucepan will not rise higher than $0^{\circ}$ Centigrade, or the meltingpoint of ice. Now the heat from the stove must be continually entering the water, otherwise the ice would not melt. What then becomes of this heat? Again, if you keep the water on the stove after the ice is melted, it will grow hotter 
and hotter till it reaches $100^{\circ}$ Centigrade, when it will boil. Here, again, it will remain at the same temperature, and though you go on boiling it till it has all passed away in steam, the last drop of water will never be hotter than $100^{\circ} \mathrm{C}$. So that here again the heat which is added remains hidden and does not become apparent. This last fact about boiling water had been long known to philosophers, but no one found any explanation of it until Black began his experiments on melting ice; and he then came to the conclusion that the heat is employed in altering the condition of the water, hat is, in changing it, in the one case from solid ice into water, and in the other from water into a vapour.

He proved this by some simple experiments which are not difficult to make. He took two glass flasks, and filled one with ice just on the point of melting, and the other with an equal weight of ice-cold water. These he hung in a moderately warm room, which he kept all the time at the same heat $\left(8^{\circ}{ }_{5} \mathrm{C}\right.$.). At the end of half an hour the icecold water had risen four degrees (from $0^{\circ}$ to $4^{\circ}$ ), but the melting ice remained at $0^{\circ}$, and it was ten hours and a half before the ice had disappeared and the water had reached the same temperature as that which the water in the other basin had attained in half an hour. Now the melting ice had been receiving heat for twenty-one half-hours, and therefore had taken in $21 \times 4$, or $84^{\circ}$ of heat, while it only showed a rise of $4^{\circ}$. It was clear, therefore, that the remaining $80^{\circ}$ must have been spent in turning the ice into water.

Black now tried the same thing in another way. $\mathrm{He}$ found that a pound of water at $79^{\circ} \mathrm{C}$. would exactly melt a pound of ice. So he again took two vessels, in one of which he put a pound of ice-cold water at $0^{\circ}$ and a pound of hot 
water at $79^{\circ}$, and when they were properly mixed he found, as he expected, that the heat of the mixture was half-way between the two, that is $39 \frac{1}{2}^{\circ}$. In the other vessel he put a pound of ice at $0^{\circ}$ and a pound of hot water at $79^{\circ}$, and here, when the ice had disappeared, the mixture still remained at $0^{\circ}$, showing that the whole $79^{\circ}$ of heat in the boiling water had been absorbed in melting the ice, and remained hidden or latent in the two pounds of water. The latent heat of water is therefore between $79^{\circ}$ and $80^{\circ}$.

We know now what becomes of this heat, as you will see (chapter xxxiv.) in the history of the science of the nineteenth century ; but the first step was to prove its disappearance into the water, and this we owe to Black; as well as the fact that still more heat is lost in turning water into steam.

This last fact he proved by filling a glass bottle half full of water, corking it very tightly, and then heating the bottle till the water began to boil. He was obliged to do this very gently, because steam expands with great power, and he did not wish to drive out the cork or break his bottle. After a little time the water ceased boiling, because the other half of the bottle was full of steam, and there was no room for more to form. But now the water began to grow hotter and hotter, and rose above $100^{\circ} \mathrm{C}$., showing that when the heat could no longer form steam it did not remain hidden, but increased the temperature of the water. At last, when he was afraid to heat the bottle any more, he loosened the cork, which flew out with great violence, followed by a cloud of steam. And now notice what happened; directly the rush of steam was over, the heat of the water in the bottle fell again to $100^{\circ} \mathrm{C}$., for all the rest of the heat had been used in forming more steam the moment the pressure was removed. 
James Watt, 1736-1819.-Black had now completed his discovery, and from that time he taught in all his lectures that heat becomes iatent or absorbed when a solid is changed into a liquid, or a liquid into vapour. It was about this time that the famous engineer, James Watt, began to study the power of steam, and as Black was his friend, he came to him to help him solve his difficulties. The history of the steam-engine, being the history of an invention, does not strictly belong to our work; but the use which Watt made of the discoveries about steam is a part of science, and we must therefore find room for a slight sketch of it here.

James Watt was born at Greenock in 1736 ; he was the son of a builder and shipwright, and was so delicate as a child that he was kept at home, and learnt reading from his mother, and writing and arithmetic from his father. When at last he was sent to school he found it hard work, for he was slow and thoughtful, and the other children jeered at him for his want of quickness. Everyone knows the story of his being scolded by his aunt for sitting silent a whole hour, holding first a spoon and then a saucer over the steam rising from a kettle, and watching drops of water gathering upon them. It was in this quiet way that little James's mind grew, and it may be an encouragement to slow, plodding boys to know that one of our greatest inventors was considered a dull and backward child.

As he grew older James went up to London, and there, after overcoming many obstacles, which the guilds, or trades' unions of those days, put in the way of all independent workers, he learnt to make mathematical instruments, and then returned to Glasgow, where he began business. Though he was only one-and-twenty he soon became known as a 
man of unusual ability, for the mind of the dull boy had developed, and his thoughtfulness had begun to produce results. Not only the students, but even the professors of the University used to stroll into his little shop to discuss the discoveries of the day. 'Whenever any difficulty arrested us,' writes a student named Robison, 'we used to run to our workman, and he never let go his hold until he had entirely cleared up the proposed question.' One day it was necessary to read a German book on mechanics; Watt immediately set to work and learnt German, and another time, for the same reason, he studied the Italian language. It is scarcely surprising that a man with such talent and perseverance as this, who was also gentle and loving to everybody, should be sought after both by masters and students.

Among those who came to Watt's shop was one Anderson, professor of physics, who, finding that a little model of a steam-engine in the University museum was out of order, brought it to Watt to be repaired, and thus led the way to his invention. And here it is necessary to point out two things : First, you must not suppose that by a steam-engine is meant a railway engine; all contrivances which move by the power of steam are steam-engines, and locomotive engines which draw carriages were not made till 1804 , long after Watt's time. Secondly, you must get rid of the idea, which many people have, that Watt was the first man to make an engine which moved by steam. This was done long before his time. The thing which Watt really did was to make an engine such as we now use, working entirely by steam, without the help of air, and doing an enormously greater amount of work with the same quantity of fuel than any others had done before.

The Newcomen Engine, 1705.-Steam, had been used to turn a globe by Hero of Alexandria, a Greek who lived 
120 years before Christ ; and Baptiste Porta in 1580, Solomon de Caus in 1615, and the Marquis of Worcester in I663, all tried to make use of steam to do work. Again, in 1690 and 1698, a Frenchman named Papin and an Englishman, Captain Savery, tried to make steam-engines to raise water out of mines. But the only one of all these engines which we need describe here was that which fell into the hands of Watt, and which was made by a man named Newcomen in 1705. A plan of Newcomen's engine is given in Fig. 4I. Its working depended on the pressure of the atmosphere (explained p. 123) on the piston at one end of the beam, and the weight of the lump of iron, $e$, at the other end.

The lever-beam of this engine is balanced in such a way that when it is not at work the weight $e$ pulls it down on the side away from the engine, and the piston, $p, p$, is drawn up to the top of the cylinder, as in the figure. To set the engine going a fire is lighted under the boiler, and the tap or stopcock, $a$, is opened, so that the steam rises into the cylinder, driving out the air through the air-vent, $c$. As soon as the cylinder is full of steam, $a$ is turned off, and the stopcock, $b$, turned on. Immediately a small jet of cold water from the tank $\mathrm{T}$ rushes through $b$ into the cylinder, turning the steam back into a few drops of water, which flow out with the cold water down the pipe $d$. Now notice, the cylinder is quite emply; for the steam drove out the air, and the cold water carried the steam away with it, while no air can come in at $c$ or $d$, because the little valves in them are kept shut by the weight of the atmosphere outside. So there is nothing to hold up the piston, which is being heavily pressed down by the air above it. The consequence is, down it comes to the bottom of the cylinder, dragging with it the 
end of the lever-beam. Directly it reaches the bottom the stopcock $b$ has to be shut, and $a$ opened again. Up rises the steam directly from the boiler, driving up the piston, and the whole thing begins again. In this way the leverbeam is kept moving up and down by simply turning the

Fig. 41.

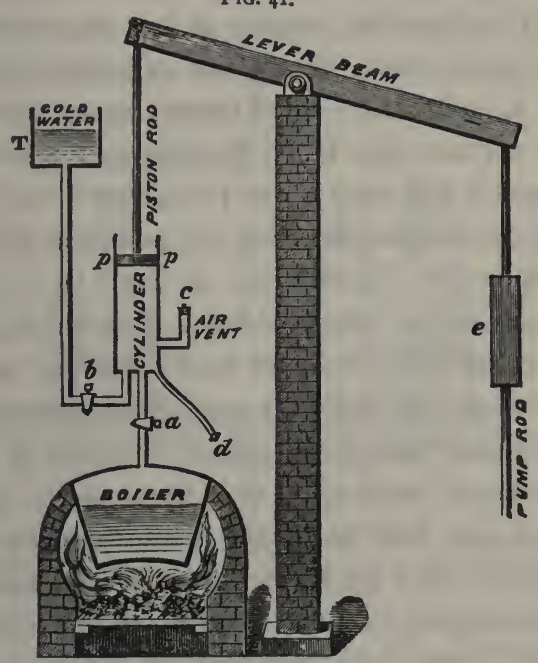

Newcomen Engine (Black).

$a$, Stopcock between boiler and cylinder. $\boldsymbol{\delta}$, Stopcock between cold-water tank and cylinder. $c$, Valve closing air-vent. $d$, Valve closing the outlet for condensed steam. $e$, Weight which drags down the beam. $p, p$, Piston which is pressed down by the atmosphere when the cylinder is empty. ${ }^{1}$

two stopcocks one after the other. These were at first opened and shut by boys; but one day an ingenious lad named Humphrey Potter, who wanted to save himself the trouble of turning the cocks, found that by tying strings from

1 The boiler and cold-water tank both in this figure and in fig. 43 are drawn much too small in proportion, in order to bring them into the figure. 
the handles to the different ends of the beam he could make the engine open its own cocks as the beam went up and down. This rough arrangement was soon improved, and the machine worked by itself.

Watt's Separate Condenser.-Such was the engine as Watt found it. When he began to examine it he saw at once what an immense quantity of heat was wasted. Every time the piston came down, the cylinder, as well as the steam in it, had to be cooled down; every time the piston rose, the cylinder had to be heated again; and the thing which puzzled him most about it was, that it took six pounds of cold water to condense only one pound of steam.

It was in this difficulty that he came to Dr. Black, and learnt from him the theory of latent heat, which showed that there is an immense store of heat hidden in steam, which has to be drawn out before it can become water. This was an entirely new light to Watt, and it led him to make many experiments still more exact than those of Dr. Black, which convinced him that no engine would ever work well or economically, while so much power was wasted in cooling and re-heating the cylinder at every stroke. But how was he to cool down the steam without cooling the cylinder which held it?

For months he pondered over this without finding any answer. At last, one Sunday afternoon, when he was walking on the Green of Glasgow, the way to do it flashed upon his mind. If he could draw the steam off into a separate vessel and condense it there, the cylinder might still be kept hot, and the thing would be done. Fig. 42 will help you to understand how this could be effected. Here the two flasks, $A$ and $B$, are first quite emptied of air, and $B$ is half filled with water. Under B is placed a lamp, D; under A, a basin of 
ice, E. Now as long as the tap, c, is kept open, the steam which is constantly rising from the water in $\mathrm{B}$ will rush along the tube into the empty flask, A, and will there be turned into drops of water by the cold of the ice underneath, and this will go on as long as there is any water left in B, because there will always be an empty space or vacuum in A to receive the steam as it rises. When the tap, $\mathrm{c}$, is shut, the steam in B will become very dense, and when it is opened

FIG. 42.

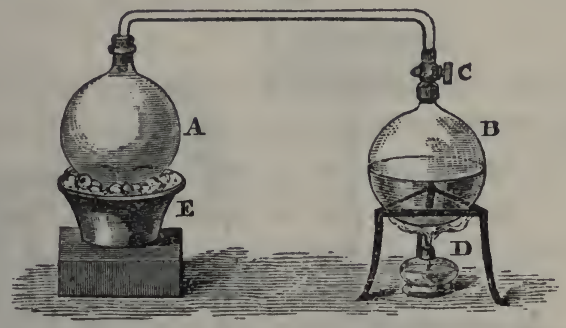

Steam condensed in a separate Vessel.

A, Flask empty of air. B, Flask half-full of water and empty of air. C, Tap connecting the two bottles. D, Spirit lamp keeping the water in B boiling. E, Basin of ice cooling down the steam which passes into $\mathrm{A}$.

again the greater part of the steam will rush out and be cooled down in A, while B remains hot as before.

Watt's Engine.-This was exactly the plan Watt adopted in his steam-engine; B answers to his cylinder (Fig. 43), which could be kept always hot, and $\mathrm{A}$ to his condenser, in which his steam was turned back into water. We carnot. follow out all the different steps of his invention, and must content ourselves with a rough description of his engine after he had completed it, as shown in Fig. 43.

In the first place you must notice that cold water is kept flowing down from the $\operatorname{tank} \mathrm{A}$ into $\mathrm{B}$, and out through the pipe C, so that the condenser standing inside $\mathrm{B}$ is kept quite cold : 
and, secondly, I must tell you that the rods, $\mathbf{I}$ and 2, are so placed that when the engine-end of the lever-beam is raised, as in the figure, the stopcocks $a$ and $c$ are open, and $b$ and $d$ are shut; and when that end of the beam falls, $b$ and $d$ will be open, and $a$ and $c$ will be shut.

Let us now begin with the machine as we see it in the figure. In this position of the bean the cocks $a$ and $c$ are open; therefore, the steam below the piston will rush out at

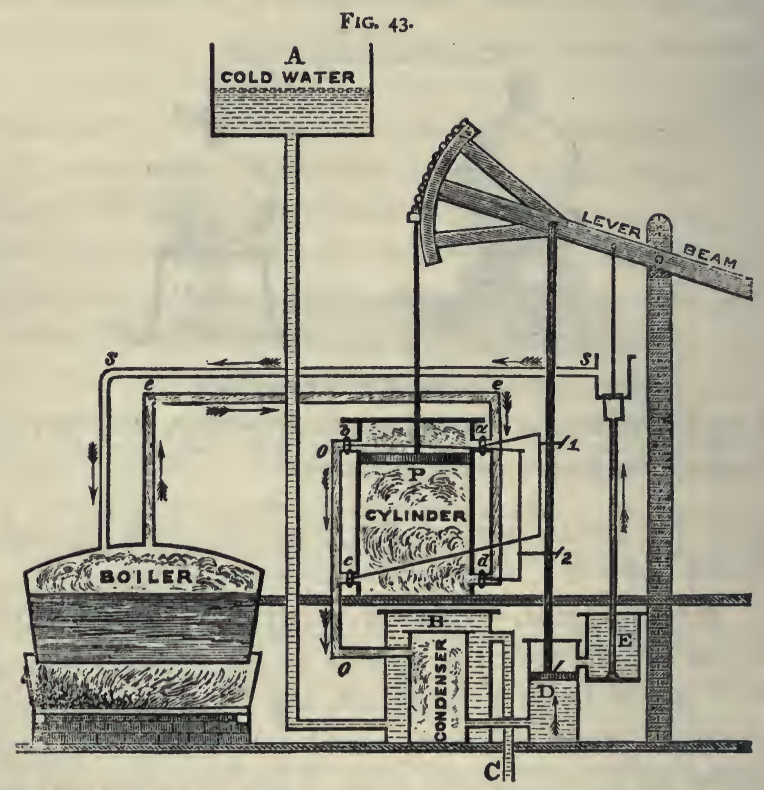

A, B, Cold water tanks. C, Outlet for cold water. D, E, Pumps for drawing off hot water and sending it along $s, s$, back to the boiler. $P$, Tight-fitting piston. $a, d$, Cocks for letting steam into the cylinder. $b, c$, Cocks for letting steam out of the cylinder. e, e, Pipe which carries steam from boiler to cylinder. 0,0 , Pipe which carries steam from cylinder to condenser. I, 2, Rods connecting the cocks with the lever-beam.

$c$ into the condenser, there to be turned into drops of water, while the steam from the boiler, entering at $a$, will force the 
piston down. But now, the piston having pulled down the beam, $a$ and $c$ will be closed and the other two cocks, $b$ and $d$, will be opened. So the steam above the piston will rush out at $b$ into the condenser, while the steam from the boiler will pass directly from $e$ down to $d$, and coming in belowe the piston, will drive it $u p$ again. In this way, although the cylinder is never cooled, the piston moves steadily up and down; because the steam is driven off into the condenser standing in $\mathrm{B}$, where it is turned into water, and is drawn up by the two pumps $\mathrm{D}$ and $\mathrm{E}$, and sent along the pipe, $s, s$, back to the boiler.

This was the principle of Watt's double-acting steamengine, and if you understand the difference between Figs. 4I and 43 you will see that, though Watt was not the first to make engines move by steam, he was the first to make a pure stcam-engine, where the piston moves up and down without any help from the outside air, or of the counterbalancing weight $e$, Fig. $4 \mathrm{I}$, and without the enormous waste of heat and fuel which made all the earlier engines comparatively useless.

I have only told you here of the way in which he applied steam to his engines; all the numberless other improvements which he made you must read about in books on engineering. For twenty long years he went on improving and inventing without reaping any reward for his labour. Other men tried to steal his ideas and to make a profit out of his genius, and he had to fight against prejudice and injustice, and against constant depression caused by his own ill-health. Yet he found many kind friends upon his road, and amongst the most famous of these was Boulton, the Birmingham manufacturer, who became his partner in 1769 , and stood by him manfully in all his difficulties and troubles. It was from 
Boulton's manufactory at Soho (a suburb of Birmingham) that Watt's engines went forth to the world, and worked that great change in the manufactures of England which has made us one of the first nations of the world.

The names of Boulton and Watt deserve to be classed together as benefactors of mankind. Watt was the inventor, the man who loved science, and who could not live without creating. Boulton was the large-minded, enterprising man of business; he gave Watt men, money, courage, and support to carry out his inventions; and by his sympathy with, and command over the workmen, he led the army which conquered indifference, persecution, and difficulties, and established steam machinery in all the workshops of the world. Watt died in 1819 , in the eighty-third year of his age, and was buried in Handsworth Church, near his friend and partner Boulton, who had died ten years before.

Chief Works consulted.-Black's 'Elements of Chemistry,' 1803 ; 'Edinburgh Review,' vol. xiii. 'History of Steam-engines;' Arago, 'Biographies of Scientific Men,' 1857 ; Smiles's 'Lives of Boulton and Watt ;' Everett Deschanel's 'Natural Philosophy ;' Tyndall's 'Natural Philosophy ;' Balfour Stewart's 'Treatise on Heat ;' Beckman's 'History of Inventions.' 


\section{CHAPTER XXIX.}

SCIENCE OF THE EIGHTEENTH CENTURY (CONTINUED).

Benjamin Franklin, born 1706-His Early Life-Du Faye discovers two kinds of Electricity-Franklin proves that Electricity exists in all bodies, and is only developed by Friction-Positive and Negative Electricity-Franklin draws down Electricity from the Sky -Invents Lightning-conductors-Discovery of Animal Electricity by Galvani - Controversy between Galvani and Volta - Volta proves that Electricity can be produced by the Contact of two Metals-Electrical Batteries-The Crown of Cups-The Voltaic Pile.

Benjamin Franklin, born 1706.-He Investigates the Nature of Electricity, 1746.-Benjamin Franklin, the printer and man of science, was born at Boston, in America, in the year I 706. He was the son of a tallow-chandler, and had so many hard struggles in his early life that he does not seem to have turned his thoughts to science till he was nearly forty years of age. His father intended him for the Church, but there was not enough money to pay for his education, so he was apprenticed to his brother, who was a printer. Here he worked very hard, yet he used to snatch every spare moment to read any books which came within his reach; but his brother being unkind and harsh to him. a quarrel sprang up between them, and Benjamin at last ran away to New York, and from there to Philadelphia. In this last place he got a little work, but hoping to do better in England he came to London, where he learnt many of the 
newest improvements in printing. After a time he went back to Philadelphia, and from that time he began to succeed as a printer and became a well-known and respected man.

It was in the year 1746 that he first began to pay attention to the experiments in electricity which were being made in England and France. A great deal had been learnt about this science since the time when Otto Guericke made the first electrical machine in 1600 , and a Frenchman named Du Faye had shown that two different kinds of electricity could be produced by rubbing different substances. You will remember that a pith-ball, when filled with electricity from a stick of electrified sealing-wax, draws back, and will not approach the sealing-wax again (see p. I24). But Du Faye discovered that if you rub the end of a glass rod with silk, and bring it near to this ball, it will draw the ball towards itself, showing that the electricity in the glass rod has exactly the opposite effect to that in the sealing-wax. In other words, while Guericke had shown that substances filled with the same kind of electricity repel each other, Du Faye showed that substances filled with different kinds of electricity attract each other. Both these men thought that electricity was a fluid which was created by the rubbing, and which was not in bodies at other times; when Franklin, however, began to make his experiments he saw clearly that this was not as they had supposed, but that all bodies have more or less electricity in them, which the rubbing only brings out.

The way in which he proved this is very interesting; but to understand it you must first know that any body which is to be filled with electricity requires to be so placed that the electricity cannot pass away from it into the earth. The best way to do this is to stand it upon a stool with glass legs, because electricity does not pass easily along glass. 
You must also. know that when any substance is full of electricity, if you bring your finger or a piece of metal near to it, a spark will pass between the electrified substance and your finger or the metal.

You will now, I think, be able to follow Franklin's experiments. He put a person, whom we will call $\mathrm{A}$, upon a glass stool, and made him rub the metal cylinder of an electrical machine with one hand and place his other hand upon it to receive the electricity. Now, he said, if electricity is created by the rubbing, this person must be filled with it, for he will be constantly taking it from the machine, and it cannot pass away, because of the glass legs under the stool. But he found that $\mathrm{A}$ had no more electricity in him after rubbing the cylinder than he had before, neither could any sparks be drawn out of him. He then took two people, $\mathrm{A}$ and $\mathrm{B}$, and placing each of them on a glass stool, made A rub the cylinder, and B touch it, so as to receive the electricity. Now notice carefully what happened. B was soon so full of electricity that when Franklin touched him, sparks came out at all points ; but what was still more curious, when Franklin went to $\mathrm{A}$ and touched him, sparks came out between them just as they had done between him and $\mathrm{B}$.

This he explained as follows : 'A, B, and myself,' he said, ' have all our natural quantity of electricity. Now when A rubbed the tube, he gave up some of his electricity to it, and this B took, so that A had lost half his electricity and B had more than his share. I then touched $B$, and his extra charge of electricity passed into me and ran away into the earth. I now went to A, and I had more electricity in me than he had, because he had lost half his natural quantity, and so part of my electricity passed into him, producing. the sparks as before.' 
This Franklin believed to be the case with all electricity, namely, that every body contains its own amount of it, but that when for any reason it is distributed unequally, those which have no more than they can well carry, give some up to those which have less, till they have each their right quantity. And this explained at once why a man cannot electrify himself, for so long as he has no one else from whom he can procure electricity, he is only taking back with one hand what he gives out with the other. Those who had too much electricity were called by Franklin positively electrified, and those who had too little, negatively electrified, and from this come the terms positive and negative electricity, which are now used.

I should tell you here that it is now believed that electricity is composed of two different kinds existing together in all substances. These two kinds are supposed to remain at rest as long as they are equally balanced, but when a body contains too much of one kind, it is always trying either to give it up or to get some of the other kind to balance it. This theory explains some facts which Franklin's theory does not; but it is not yet really known what electricity is, only it is certain that Franklin was right in saying that it is not created when we see its effects, but only drazen out of bodies which contain it.

Franklin draws down lightning from the Sky.-It was in 1749 , when he had already made most of his experiments upon electricity, that Dr. Franklin began to consider how many of the effects of thunder and lightning were the same as those which he could produce with his electrical machines. Lightning travels in a zigzag line, said he, and so does an electric spark; electricity sets things on fire, so does lightning; electricity melts metals, so does lightning. 
Animals can be killed by both, and both cause blindness; electricity always finds its way along the best conductor, or the substance which carries it most easily, so does lightning ; pointed bodies attract the electric spark, and in the same way lightning strikes spires, and trees, and mountain tops. Is it not most likely that lightning is nothing more than electricity passing from one cloud to another just as an electric spark passes from one substance to another?

Franklin communicated these ideas to the Royal Society in London, suggesting at the same time that, if he was right, it would be possible to prevent a great deal of the harm done by lightning by fixing upright rods of iron near high buildings so that the electricity might run down from the clouds into the earth without doing any harm. But this notion seemed so absurd, even to clever men, that they could not help laughing when his papers were read, and did not even think them worth printing. You will easily understand that after this Franklin was ashamed to speak of an experiment he meant to make by which he hoped to bring down electricity from the sky. So we find that he told no one but his son, whom he took with him upon this strange expedition.

Franklin's idea was that if he could send an iron rod up into the clouds to meet the lightning, it would become charged with the electricity, which he believed was there, and would send it down a thread attached to it, so that he might be able to feel it. He took, therefore, two light strips of cedar fastened crossways, upon which he stretched a silk handkerchief tied by the corners to the end of the cross, and to the top of this kite he fixed a sharp-pointed iron wire more than a foot long. He then put a tail and a string to his kite, and at the end of the string near his hand he tied 
some silk (which is a bad conductor), to prevent the electricity from escaping into his body. Between the string and the silk he tied a key, in which the electricity might be collected.

When his kite was ready he waited eagerly for a heavy thunderstorm, and, as soon as it came, he went out with his son to the commons near Philadelphia and let his kite fly. It mounted up among the dark clouds, but at first no electricity came down, for the string was too dry to conduct it. But by-and-by the heavy rain fell, the kite and string both became thoroughly wet, and the fibres of the string stood out as threads do when electricity passes along them. Directly Franklin saw this he knew that his experiment had succeeded; he put his finger to the key and drew out a strong bright spark, and before long he had a rapid current of electricity passing from the key to his finger. The wise men of London might now laugh if they pleased, for the discovery was made; he had drawn lightning from the sky, and proved that it was electricity! Soon after this he made an apparatus in his own house for collecting electricity from the clouds, which rang a peal of bells when it was sufficiently charged for him to make experiments with it. $\mathrm{He}$ also introduced iron rods as lightning conductors, which were for the future placed near all high buildings to attract the lightning and carry it away into the ground.

Franklin had now earned a great name; he was made a Fellow of the Royal Society, and many honours were paid to him by all the countries of Europe. He made many other very valuable experiments, and was besides an active citizen and politician. He died in 1790 , in his eighty-fifth year, after a life of hard labour and toil, for which, however, he was well repaid by success. 
Discovery of Animal Electricity by Galvani, and of Chemical or Voltaic Electricity by Volta, 1789-1800. Only a few months before Franklin died a new fact had been discovered about electricity, which would have given the old man great delight if he could have lived to see the results. This discovery was made by Galvani, Professor of Anatomy at Bologna, or perhaps we ought to say by Madame Galvani, for it was her observation which first led her husband to study the subject.

Aloysius Galvani was born at Bologna in 1737 , and we know little of his early life except that, instead of becoming a monk as he first intended, he married a professor's daughter, and became the Lecturer on Anatomy in the University of Bologna. He had in his house an electrical machine which he used for experiments, and one day in I 789, as Madame Galvani was skinning frogs for a soup, one of Galvani's assistants was working the machine near her. Just as the flow of electricity was going on rapidly, this young man happened to touch a nerve of the leg of a dead frog with a dissecting knife, and to his great surprise the leg began to move and struggle as if it were alive. Madame Galvani was so much struck by this that she told her husband of it directly he returned, and he repeated the experiment many times, and found that whenever the flow of electricity from the machine was brought near the nerve of the frog's leg it produced convulsions. He next tried whether lightning brought down upon the nerves of the leg would have the same effect, and the experiment succeeded perfectly.

Meanwhile another accident showed him that the convulsions could be produced without either lightning or an electrical machine. He had prepared the hind legs of 
several frogs and hung them by copper hooks upon an iron balcony outside his house. As they hung there the wind swayed them to and fro, so that the ends of the legs touched the iron of the balcony; and every time they did so he noticed that the legs were convulsed just as they had been by the electrical machine and the lightning. But this time he could not see that any electricity had come near them from outside, so he supposed that there must be an electric fluid in the leg itself, which passed round every time the two ends of the leg were joined by the metal. These discoveries of Galvani soon became spoken of far and wide under the name of galvanism, and the supposed fluid was called the galvanic fluid.

Among the celebrated men who were attracted by this new discovery was Alessandro Volta, Professor of Natural Philosophy at the University of Pavia, who was born at Como in 1745 , and was at this time a well-known naturalist. Not satisfied with merely reading about Galvani's experiments, Volta tried them himself, and he began to suspect that the electricity was not, as Galvani imagined, in the frog's leg, but was produced by the two metals, copper and iron, upon which the legs had been hung, and which were acted upon by the moisture in the flesh.

Then began a very famous controversy. Volta insisted that the electricity came from the metals, Galvani that it came from the animal. In each new experiment which Galvani brought forward to prove his point, Volta still showed that the electricity could be produced without the animal, until at last Galvani succeeded in finding a test which he thought must silence Volta for ever. He found that by laying bare a nerve of the leg of a frog, called the 'crural nerve,' and bringing the end of it to the outside of the muscles of the leg, he could produce the convulsions 
without any metal at all. But Volta was not so easily convinced; he still insisted that it was the different fluids and tissues being brought together which caused the electricity, and that there was not a current running through the animal. At this point, just when the truth would probably have been worked out, Galvani died (in 1798), leaving Volta in possession of the field; and for twenty-eight years no more was heard of animal electricity. We know now that both the professors were right. Volta was right in saying that the convulsion of the frog's legs on the balcony was produced by the contact of the two metals in connection with a fluid; while Galvani was right in saying that there is an electricity in animals which acts without any other help. In 1826 an Italian named Nobili repeated Galvani's experiment, and having then an instrument called a galvanometer (see p. 35I), by which the passage of the faintest electric current can be detected, he proved that such a current does exist in the frog, and it has since been found to be common to all animals.

Meanwhile, however, Volta had also made a very remarkable discovery, namely, that two different metals when joined together in contact with moisture, and separated from other substances, produce a current of electricity. This may easily be tried in its very simplest form. If you take a piece of copper and a piece of zinc and put one above your tongue and one below it, you will feel nothing remarkable so long as the two metals are kept separate, but directly you let them touch each other at the ends, a tingling sensation will pass through your tongue, proving to you that an electrical current is passing between the metals. If you put the zinc under your upper lip, so that the copper may remain outside, you may, perhaps, even see a slight flash when the two metals meet. 
Volta found not only that it was necessary to have moisture between the two metals, but that some acid put in the water greatly increased the strength of the electricity. Fig. 44 shows the first electric battery which he made, and which is the one now commonly used for simple experiments. In this battery each piece of zinc is joined to one of copper, and where the two are not united they are in the same cup, so that the liquid acts as a link to them. We know now what Volta did not know, that a chemical change is going on between the zinc and the acid water, which sets the action going, but we do not yet know exactly what the electricity itself is. The movement in Fig. 44 begins on the

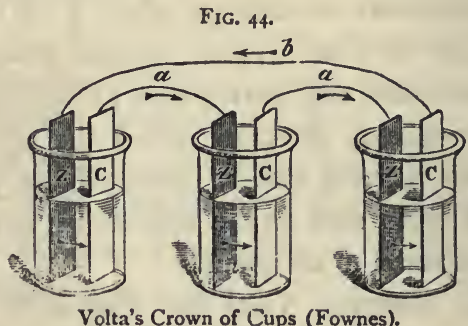

z, Zinc. c, Copper. $a a, b$, Connecting wires. The arrows show the course of the positive currents.

left-hand side at $z$. Here the current' ${ }^{\prime}$ is set up by the action of the acid and water upon the zinc, and is passed on to the copper, $\mathrm{c}$; then along the wire $a$, to the next $z$, and.so on till it reaches the last cup, when it is carried by the wire $b$ back to the first piece of zinc, and so the round is completed.

1 There are always two currents passing along the wire-the positive current, starting from the copper to the zinc, and the negative current, going the opposite way from the zinc to the copper; but to avoid confusion, the positive current is always called the current, and no notice is taken of the other. 
This battery is called the 'Crown of Cups,' but though it is so simple, it has not become as famous as the second battery made by Volta, which is still called the 'Voltaic Pile' (see Fig. 45). In this battery the metals are laid one above the other, and have small pieces of card or flannel between them which are wetted with salt and water. The battery ends with a plate of zinc at the bottom, and of copper at the top, and these are connected by the wire, $a a$. The action passes round this battery just as it did through the cups, and if the wire, $a a$, is cut in the centre and tipped with charcoal (which, being a rad conductor, causes the electricity to pass with difficulty), a bright stream of fire will be zept up between the points as long as the battery is at work. Such was Volta's discovery, and we owe to it all the powerful galvanic batteries with which our most valuable experiments are now made. $\mathrm{He}$ completed his Voltaic pile in 1800 , just at the close of the

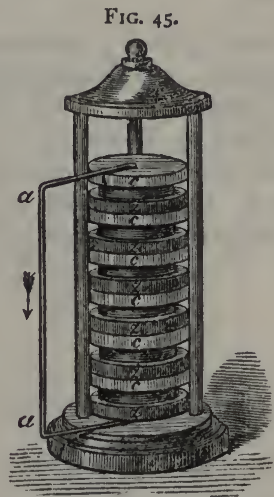

The Voltaic Pile (Fownes).

$z$, Zinc. $c$, Copper. $a, a$, Rod connecting the top layer of copper with the bottom layer of zinc. century, and even from this slight sketch you may see what grand strides had been made in electricity during the past fifty years.

Franklin had proved the real action of electricity, had shown it to be the same as lightning, and had brought it down from the sky. Galvani had proved its existence in animals, and led the way to Volta's discoveries; and Volta had produced it in enormous quantities by two metals and 
acidulated water, so as to keep up a constant flow, which would travel any distance so long as the circuit was not broken. Here, you will see, was the first step towards the electric telegraph. It was but a commencement, and for nearly forty years no further advance was made; but the seed was sown, and when we reap the benefits we must always remember the names of Franklin, Galvani, and Volta, as the great pioneers in the science of electricity.

Chief Works consulted. - Lardner's Cyclopedia, 'Electricity, Magnetism, and Meteorology ;' 'Encyclopædias Britannica,' and 'Metropolitana,' art. 'Electricity ;' Frauklin's 'Experiments and Observations on Electricity' I749; Priestley, 'On Electricity,' 1785 ; Thomson's 'Hist. of Royal Society,' rS12 ; 'Life of Franklin,' by himself, 1833; Bennett's 'Text-liook of Physiology ;' Fownes's 'Chemistry ;' Wilkinson's 'Galvanis:n.' 


\section{CHAPTER XXX.}

SCIENCE OF THE EIGHTEENTH CENTURY (CONTINUED).

Bradley and Delisle, Astronomers-Aberration of the Fixed StarsNutation of the Axis of the Earth-Delisle's Method of Measuring the Transit of Venus-Lagrange and Laplace-Libration of the Moon accounted for by Lagrange-Laplace works out the Long Inequality of Jupiter and Saturn-Lagrange proves the Stability of the Orbits of the Planets-Sir William Herschel constructs his own Telescopes-Discovery of a New Planet-Discovery of Binary Stars - Herschel studies Star-clusters and Nebulæ-Theory of Nebulæ being matter out of which Stars are made-The Motion of our Solar System through Space-Weight of the Earth determined by the Schehallien Experiment-Summary of the Science of the Eighteenth Century.

Astronomical Labours of Bradley and Delisle.-And now, as we approach the end of the eighteenth century, we must take up once more the history of Astronomy, which we have neglected since Newton died in 1727 . Since that time many good astronomers had been occupied in making different observations, but the only two who need be mentioned were Bradley, the Astronomer-Royal (born I692, died I 762 ), and Delisle (born 1688 , died 1768 ).

Bradley explained two difficult astronomical problems; the first of these is called the 'aberration of the fixed stars,' which is an apparent movement of each fixed star in a small circle in the heavens, but which is really the combined effect of the yearly motion of our own earth, and of the time which light occupies in coming down from the stars to us. 
This question is very difficult, as is also his second discovery of the mutation, or slight oscillation, of the earth's axis ; but it is necessary to bear in mind that he made these observations, for they are very important in astronomy.

Delisle will interest you because he proposed a second method of measuring the transit of Venus, which is now used at stations where Halley's rule (see p. 160) cannot be applied. Delisle's method consists in marking the time at which the transit is seen to begin in one part of the world, and to end in another; instead of measuring, as Halley did, the duration or length of time occupied by the whole transit as seen at each place. It requires that the clocks of all the different stations from which the transit is observed should be set exactly to the same time, and then it answers as well. as Halley's.

These discoveries are all that need be mentioned during the first half of the eighteenth century, but during that time there had been born within a few years of each other three men, Lagrange, Laplace, and Herschel, who were to light up the close of the century with the most brilliant discoveries. The two first of these were Frenchmen, the last we may fairly claim as an Englishman; for though he was born at Hanover in 1738 , of German parents, still Sir William Herschel came over to England at the age of twenty-one, and all his discoveries were made here. It was our King George III. who gave him the pension which enabled him to devote himself to science; and his son Sir John Herschel was, like his father, one of our greatest astronomers, and made England his home and country.

Lagrange and Laplace.-Louis de Lagrange was born at Turin in 1736 . His father, who had been Treasurer of War, lost all his fortune when his son was quite a child, and 
Lagrange often said that it was partly owing to this mischance that he became a mathematician. His talent showed itself so early that before he was twenty he was appointed Professor of Mathematics in the Military College of Turin, where nearly all his pupils were older than himself. From there he went to the Academy of Sciences at Berlin, and remained twenty years, during which time he worked out most of his celebrated problems. In 1787 he settled in Paris, where he died in 1813 , at the age of seventy-seven.

Pierre Simon Laplace was the son of a farmer, and was born at Beaumont-en-Auge, near Honfleur, in 1749 . He, too, began work very early in life, for in 1769 the famous geometer D'Alembert was so struck with his talents that he procured for him the chair of Mathematics in the Military School of Paris, and from that time for more than fifty years Laplace devoted himself to the pursuit of science, never letting his active life as a politician interfere with his scientific studies. He died in 1827 .

The work which was done both by Lagrange and Laplace in astronomy was purely mathematical, and dealing as it did with some of the most complicated movements of the heavenly bodies, it cannot be rightly understood by any but mathematicians. But some general idea may be formed of the problems they solved, and we will take these in the order of time, for they treated so much of the same questions, one taking up the subject where the other left it, that it is difficult to separate their work.

Libration of the Moon accounted for by Lagrange, 1764-1780.-Long before the time of Lagrange it had been known from observation that the moon always turns the same side of her globe towards our earth as she goes round it, so that we never see, and never can see, more than one 
side of her surface, so long as she has the same movement as at present.

In 1764 the Académie des Sciences offered a prize for a complete explanation of this curious fact, and Lagrange was thus led to study the question, which he solved quite satisfactorily in $\mathrm{I} 780$.

Many people find it very difficult to understand how the moon can be always turning round upon her own axis, as a top spins, and yet always keep the same side towards us; therefore, it will be as well to make a simple experiment which explains it quite clearly. Take a round ball and stick a pin in one side of it, then turn the ball slowly round like a teetotum, and notice as it goes round that the pin points successively to each of the sides of the room one after the

FIG. 46.

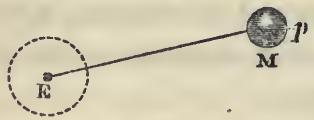

Diagrain showing why one side of the Moon is always turned towards the Earth.

M, Ball representing the moon. $\mathrm{z}$, Point representing the centre of the earth. $p$, Pin to mark the side of the moon which is never turned towards the earth. other; then sew a piece of cotton to the side of the ball opposite the pin, and fasten the other end down to the table (as at E, Fig. 46). If you now roll the ball round the table, you will observe that the pin points to each side of the room in succession, as it did before, showing that it has been turning slowly once upon its own axis while going once round the point $\mathrm{E}$, and that, for this reason, the same side has been facing $\mathrm{E}$ all the time.

This is the case with the moon as she travels round our earth, and Lagrange proved mathematically that it must be so, as Newton had already suggested, on account of the attraction of the earth upon the bulge at the moon's equator. But Iagrange also showed that as the moon moves in an 
ellipse round the earth, and therefore goes at one time a little faster, and at another a little slower, while her rotation on her own axis does not vary, she does not keep always exactly the same face towards us, but we catch little glimpses farther round her globe, sometimes on one side and sometimes on the other. This balancing movement is called the libration of the moon.

Laplace works out the Long Inequality of Jupiter and Saturn, 1774-1783.-The next calculation about the planets was made by Laplace, and is more difficult to understand. You will remember that Newton showed that every planet attracts every other planet, and has some effect upon its path round the sun. Now it had been found by comparing old astronomical tables with later ones that these different attractions had altered some of the ellipses in which the planets move ; and both Lagrange and a celebrated mathematician named Euler had tried to calculate these changes and find out whether the planets would ever come back into their old places. Laplace, however, carried the calculation farther than either Lagrange or Euler had done, and he showed that the whole machinery does work round in the course of a long period. Only two planets, Jupiter and Saturn, did not seem to follow this general law, but behaved in a very eccentric manner; for it appeared that during the seventeenth century Jupiter had been moving more quickly every year and Saturn more slowly. If this went on it was clear that Jupiter would draw nearer to the sun, and at last fall into it, while Saturn would go farther off, and disappear entirely from our system, and this would upset the balance of our planets, and might lead eventually to our being all drawn into the sun.

This was a very serious question, and it was a grand step 
when Laplace answered it, and showed that there was nothing to fear, for that, odd as their movements appeared, these two planets really obeyed the law of gravitation, and would return to their old places like the other planets after an immensely long period. He showed that their irregularity arises from the fact that Jupiter travels two-and-a-half times round the sun while Saturn travels once, and on this account Jupiter is always catching Saturn up, so that the two planets are often near together, or in conjunction, as it is called. When this happens, they pull each other so strongly that they are drawn each out of its proper path. If they always met in the same places, and so were pulled in exactly the same direction, they would nèver right themselves again; but as Jupiter does not quite make three rounds while Saturn makes one, their points of meeting vary a little each time, and this brings them round at last to their old positions. Laplace's calculation of this movement is called the long inequality of Jupiter and Saturn.

Laplace also discovered the reason why the moon goes on for a long time moving more and more quickly round our earth, and then gradually more and more slowly. This problem, which is too long to examine here, was the last which remained to complete the proof that Newton's theory of gravitation would account for all the movements of the heavenly bodies.

Iagrange proves the Stability of the Orbits of the Planets, 1776.-And now, in the year 1776 , came Lagrange's great conclusion. He and Laplace had worked hand in hand, proving more and more at every step how beautifully all the heavenly bodies move in order, so that an equal balance is preserved between them all. At last Lagrange, taking up all the known facts and uniting them in one grand mathe- 
matical problem, proved that whatever might be the changes, and they are almost infinite, caused by all the attractions of the different planets on each other, yet in the course of long ages every part of the solar system remains stable. Each planet has its appointed road, along which it travels, through many twists and turnings, but from which it cannot escape, for the grand force of gravitation holds them all in one eternal round about their sun.

These are some of the problems solved by Lagrange and Laplace. You cannot expect to understand their full significance, nor must you imagine that these few pages contain more than a very small fraction of the work which these two mathematicians accomplished. Laplace made some beautiful calculations explaining the theory of the tides, and you will also often hear him mentioned as the author of the 'Nebular Hypothesis,' by which he taught that our earth and all the planets were in the beginning formed by the condensation of gases and fluid matter. All this, which is too difficult to enter upon here, is discussed in his famous work, the 'Mécanique Céleste,' published in 1799. But the main points to be remembered are that Lagrange and Laplace proved the regular order of the movements of the planets, and explained all those anomalies which had seemed to be out of harmony with Newton's theory of gravitation.

Sir William Herschel constructs his own Telescopes, and discovers Uranus, 1781.-William Herschel, who was born in 1738 , was one of ten children. His father, who was an eminent musician, brought him up to follow his own profession, and when William came over to England with his regiment he started in life as a teacher of music. The first three years in this country were years of hard struggle 
and privation, but at last he was appointed organist at Halifax in Yorkshire, and from there he went in 1766 to Bath, where he soon became known as a talented musician, playing in the Octagon Chapel and at concerts and parties with immense success, and procuring a large number of private pupils.

It was at this time, in the midst of active work which kept him fully occupied all the day, that Herschel began those nightly observations which have made his name famous. His interest was at first excited by seeing the stars through a small telescope only two feet in length; and his desire was so great to be able to penetrate farther into the starry depths, that he sent to London to order a large telescope. When the answer came, however, he found that the price of the instrument was quite beyond his means; and so determined was he to carry out his project, that he set to work to construct a telescope with his own hands. The first one answered so well that he made several others, and at last succeeded in completing one forty feet long.

From that time he spent the greater part of every night in observing the stars, and on March $13,178 \mathrm{r}$, when he was examining some near the constellation Gemini, or the 'Twins,' he caught sight of one star more conspicuous than those around it. Struck by its size, he put a stronger magnifying power on to his telescope, and found to his surprise that this star became larger, while those round it remained as small as before. The fixed stars, as you know, are so far off that no magnifying power makes any difference in their apparent size; so Herschel began to suspect that this must be a body very much nearer to our earth than the stars which surrounded it. This led him to watch it, and he soon found that instead of being fixed it moved onwards steadily. He 
thought at first that he had discovered a comet, but it was not long before his wandering star was proved to be a new planet, moving round the sun outside Saturn. This planet is about half the size of Saturn, and takes more than eightyfour years to go once round the sun. It was first called the 'Georgian star,' after George III. ; then it was called 'Herschel,' after its discoverer; and lastly it received the name Uranus, which it still retains. It was through this discovery that Herschel became known, and George III. gave him a pension of 300 guineas a year, and a house near Windsor, in order that he might devote himself entirely to astronomy.

Star-gauging and Discovery of Binary Stars, 17811802. - One of the first tasks which Herschel undertook, was to divide the stars into groups, according to their brightness. Thus he classed the most brilliant as stars of the first magnitude, those a little less brilliant as of the second magnitude, and so on. While he was thus gauging, or measuring the distance of the stars by the intensity of their light, his attention was arrested by some which appear single when seen through a small telescope, but which prove to be two stars when they are greatly magnified. A few of these double stars were known already when Herschel began to observe them, but he soon detected no less than 500 scattered about in different parts of the sky.

Now it had always been believed that these stars appeared close together because one was almost directly behind the other a long way off, just as two posts standing one at some distance behind the other will appear to touch if they are nearly on a line with your eye. But this explanation did not satisfy Herschel, for he observed that many of these stars, instead of merely passing to and fro in a straight line across each other, as they would appear to do in consequence of 
the movement of our earth. in its orbit, had another peculiar curved motion, as if they were both moving round some point half-way between them. This movement was so slow that it was twenty-five years before he could be sure about it ; but at the end of this time he was able to tell the Royal Society that these double or binary stars, as they are called, are not one behind the other, but are actual pairs of stars moving round and round each other, as if they were connected by a rod suspended by its centre, and then set revolving!

To understand how great a discovery this was, it is necessary to bear in mind that Newton had only been able to prove that gravitation acts between the sun and the planets; but here was a reason for believing that even in the far-off stars, millions of miles away from our system, the same force is holding distant suns together, and keeping them in their orbits. This great discovery has been still more clearly proved by later investigations, and groups of two, three, and even more stars are now known, in which these bodies revolve round a common centre, held together by the force of gravitation.

Herschel studies Star-clusters and Nebulæ, 1786.-The next discovery which Herschel made was quite as remarkable as that of the binary stars. As long ago as the time of Ptolemy (I00 B.C.) five curious stars had been observed, which he called 'cloudy stars,' because they looked as if they were covered by a mist; and the number of these cloudy masses had been increased by different astronomers as time went on. When Herschel turned his attention to them he discovered so many that, in 1786 , he published a catalogue of no less than a thousand, and added fifteen hundred more a few years later! Some of these bodies, such as the bright spot called the 'beehive,' in the constellation 
Cancer, were simply clusters of stars which might be seen distinctly through a telescope. In others the separate stars could not be seen even with the strongest magnifying power, but the group looked so much more distinct through a powerful telescope than through a feeble one, that it seemed most likely the stars were there, if only they could be distinguished. But a third set of cloudy bodies did not appear in the least more separated, even with the largest telescopes, and these Herschel called nebula, or clouds, because he believed they were made up of mere masses of matter which had not yet formed themselves into stars.

It was at this point that the grand thought forced itself upon his mind that in these nebulæ we might be looking at the actual beginning of new worlds : and that the creation of the different bodies of the universe was not begun and finished long ages ago, but is even now going on under our eyes. The nebulæ he believed to be composed of starmatter, out of which stars might be slowly forming, so as to be first seen scattered like minute points in some of the more hazy star-clusters, and then clearly visible, as in the 'beehive' in the constellation Cancer. In those days Herschel could get very few astronomers to believe in this idea, but you will see in the history of the nineteenth century how the discoverers of the spectroscope (see p. 327) have proved that some of the nebulæ are made of gaseous matter; so that it becomes extremely probable that Herschel was right, and that, in far distant space, star-mist is forming into stars, and creating new suns to illuminate the universe.

The Motion of our Solar System through Space, 1783. - The third and last theory which we can mention as coming from Sir William Herschel is that of the motion of our sun through space. In 1783 he showed from a study of the 
astronomical catalogues of past centuries that the stars do not stand in exactly the same places with regard to us as they did in ages gone by, and that, therefore, either we or they must be moving through space. Now, when everything around you appears to be moving backwards, it is most likely, to say the least, that it is you who are moving forwards, and not that all other things are in motion; therefore Herschel concluded that the reason of the apparent change in the place of the stars was the real movement of our sun and its planets among them.

But, if such were the case, then there ought to be one point straight in front of our path which would not appear to move; for if you walk into a forest you will observe that the trees on either side appear to spread farther and farther apart as you approach, but that those exactly in front of you will not seem to change their places. Now Sir W. Herschel found one point in the sky, in the constellation Hercules, where the greater number of the stars do not appear to move, while those to the right and the left seem to be gliding off each in their own direction. $\mathrm{He}$ therefore concluded that our sun is carrying the earth and the other planets straight towards this point in the constellation Hercules. The rate at which this movement goes on is not accurately known, but it must be very great, probably at least as much as $150,000,000$ miles every year.

And here we must leave the discoveries of this great astronomer, although we have only glanced at them very superficially. The immense strides in astronomy made by Laplace, Lagrange, and Herschel cannot be understood in a moment; and I wish you always to remember that you can only gather crumbs of knowledge from this book, which 
may, I hope, lead you to long and seek for more solid food. Before, however, we take leave of Sir W. Herschel, we must not forget to mention the faithful assistant who was so great a help to him in his labours.

When George III. gave Herschel his home and pension, the astronomer sent to Hanover for his sister Caroline, and she lived with him and received a small salary as his assistant. She shared his night-watches and mapped down the stars, star-clusters, and nebulæ, as he came across them with his slowly-moving telescope; she helped to draw up his catalogues, to write his papers, and to make his calculations. In a word, she fulfilled one of the highest duties of a woman, in becoming the patient helpmate of a great and noble mind; and for this reason although she never sought fame for herself, the name of Caroline Herschel will always be associated with the labours of our great astronomer. Sir William died in 1822 , in his eighty-fourth year, leaving behind him a son, the late Sir John Herschel, who will be mentioned in the next chapter.

\section{Determination of the Density of the Earth by the Sche-} hallien Experiment, 1774.-After speaking of the wonders of the vast universe, and of suns so distant that we cannot even guess at the space which lies between them and us, we must now come back to our little planet and mention a remarkable experiment which was made in 1774 by Maskelyne, who was then Astronomer-Royal of England. This was the finding out of the weight of the earth compared to its size, or in other words, the density of the earth.

If our globe were made of one material, it would be easy to weigh a small piece and multiply that by the size, which we know pretty accurately, and so to get at the weight of the whole. But as the rocks of the earth's crust differ very much 
PT. III.

in weight, and we do rot know what the middle of the globe is made of, this plan is not possible. We know, however, that every atom of matter has the power of attraction, so that if we could find out how much attraction our earth possesses, by comparing it with the attraction of some other body which we can weigh, then we could arrive at the weight of the earth.

Now Newton, in his 'Principia,' had pointed out that a plumb-line, that is, a piece of string with a weight of lead at the end of it, will not point straight to the centre of the earth when it is held near a mountain, because the mountain attracts the lead and draws it slightly towards itself. Therefore, if the size and weight of the mountain were known, and it were also known how great its pull is compared to the pull of the whole earth, this would enable a mathematician to calculate the weight of our entire globe.

A man named Bougier was the first to make this experiment near a high mountain in Peru in 1738 , but he succeeded very imperfectly, and in 1772 Maskelyne proposed to the Royal Society to repeat the observation. Accordingly, he went in 1774 to a very high mountain called Schehallien, near Loch Tay, in Perthshire, and there he measured the inclination or slope of the plumb-line on each side of the mountain. You will remember that, according to the theory of gravitation, the lead at the end of the line would point straight to the centre of the earth $\mathrm{c}$ if the mountain did not disturb it $;^{1}$ and if the plumb-line is taken to two places a certain distance apart and its inclination measured by means of one of the stars overhead, it is easy to find out

1 This is not strictly true, on account of bulge at the equator and flattening of the poles; but the discrepancy is of no importance to the argument. 
exactly how much the lines $\mathrm{D} F$ will slope towards each other when no mountain is between them. This measurement being known, Maskelyne then made two observations, one on each side of Schehallien, and found that in this case the inclination, instead of being from $\mathrm{D}$ to $\mathrm{F}$ on each side, was from $\mathrm{E}$ to $\mathrm{F}$, because the mountain drew the lead towards itself on either side. So the deflection E F D through which the plumb-line was drawn from the perpendicular showed the difference between the pull of the whole earth and the pull of the mountain.

Then Dr. Hutton, the celebrated geologist, set to work to find out the size and weight of Schehallien. This he did by surveying it and measuring it in every direction, and then taking pieces of the different rocks it contained and weighing them carefully. When this was done it was found that the mountain pulled half as strongly in comparison to its size as the earth did for its

FIG. 47.

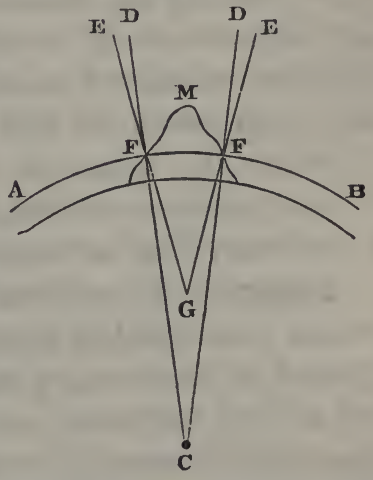

Schehallien Experiment for estimating the Density of the Earth (Herschel).

A B, Surface of the earth. D, C, D, Angle formed by the two plumb-lines pointing to the centre of the earth. E, G, E, Angle formed by the two plumb-lines when drawn aside by the mountain $\mathrm{M}$.

size. This showed that the materials in the mountain were half as heavy as the average of those in the earth generally, and as they were also about $2 \frac{1}{2}$ times as heavy bulk for bulk as water it was proved that the whole globe is about five times heavier than it would be if it was made entirely of that fluid.

This calculation must be very near the truth, for the 
chemist Cavendish obtained nearly the same result from quite a different experiment made with a pendulum. This, which is called the 'Cavendish experiment,' is too difficult to explain here. In our own times, Sir Henry James, Sir Edward Sabine, and others, have repeated these observations and found them to be correct.

\section{Summary of the Science of the Eighteenth Century.-}

This sketch of the advance of astronomy brings us to the end of the science of the eighteenth century ; for although the greater number of the eminent scientific men of our day were born before the year 1800 , yet their works belong chiefly to the nineteenth century. Before going farther therefore we must now look back and see how far science has travelled since our summary of the seventeenth century.

Biology, or the science of life, had made great progress. It had been enriched by the study of organic chemistry, founded by Boerhaave, by which we learn the elements of which living bodies are composed; by a more complete knowledge of anatomy, or the structure of the bociy in all its most minute parts, as Haller studied and represented them in his anatomical works; and by a knowledge of comparative anatomy, as taught by John Hunter; or the Comparison of each organ as it appears in different beings, from the lowest animal up to man. But even now the chief point remains to be mentioned, for all these are of little use without the study of physiology, or the science of living beings, in which we must not only learn the great facts of the working of our own bodies and those of animals, but must take into account the strange freaks of nature taught us by the experiments of Bonnet and Spallanzani. In the history of the nineteenth century we shall have to consider some of 
these facts, and see how Cuvier, Lamarck, and Darwin have carried out the study of physiology to great results in our own day. But we have still more to include under Biology. After learning the nature of living beings, we must have some order of arrangement by which we can distinguish them. Here we come to the work of Linnæus, one of the grandest men of the eighteenth century. While Buffon was popularizing natural history, we find the great Swede patiently working out all the minute characters and general features of animals and plants, and reducing the whole kingdom of life into such beautiful order, that after his time it could be studied accurately and usefully by all who cared to take time and trouble.

Thus, even without mentioning the science of medicine, which has grown far beyond our power of following it up, or the wonderful work with the microscope, which had increased rapidly since the days of Grew and Malpighi, biology grew during the eighteenth century into a group of sciences, the works upon which would fill a library, and each branch of which requires the study of a lifetime to master it.

Geology. - Side by side with biology arose about this time the modest and almost unnoticed science of the earth, then generally called physical geography, but now known as Geology. This was a small seed sown in the eighteenth century, to grow into a large tree only in our time; yet it was a great step when Scilla insisted that fossils were the remains of living beings, and that the rocks containing them were formed gradually under lakes or seas. And when Werner taught men to study the earth's crust, and Hutton forced them to see that Nature is, and has always been, building up our present world out of the ruins of the past, the foundations were laid for the real study of the earth and 
its formation. Meanwhile William Smith toiled over England, mapping out the position of each rock as he saw it, and thus he led the way to a long series of careful observations, by which the whole geology of England has been worked out.

Chemistry.-But the science which before all stands forth in the eighteenth century is chemistry; for here the discovery of the different gases led to certainty where all had been guess-work before, showing the actual chemical changes which are taking place on all sides in the world around us, and teaching men to weigh and test invisible substances, and not to rest satisfied with their knowledge of any substance till they had traced it home to its first and simplest elements. We need not recapitulate here the different discoveries of Scheele, Bergmann, Black, Cavendish, Priestley, and Lavoisier. You will remember how they all helped to overthrow the imaginary theory of Phlogiston, and to prove that combustion and respiration are merely chemical changes taking place between different substances and the oxygen of our atmosphere; and this truth is the starting-point of modern chemistry.

Physics.-Of Physics I have told you but little in this century, but the two points we have considered have caused greater changes throughout the world than any previous discoveries. When Black proved the amount of heat which is lying hid in water and in steam, and when Watt applied it to the steam-engine, a giant power was born into the world which has worked marvels. Visit any of the little towns all over England and see the machines of all kinds moved by the simple power of steam; then go to the great manufacturing towns and see the huge engines doing the work of thousands of horses, with no other help than 
that of a man feeding the furnace with coals. Look at any one of your own clothes, at the ironwork in all parts of your house, from the rough heavy iron of fireplaces and fenders to the delicate steel spring which moves the hands of your watch; look at the planks on your floors, and the carpets which cover them! All these have been woven, and forged, tempered, sawn, and worked by steam machinery. Then think of the way in which people are carried from one place to another of the world; so that in one month a man may be in India, and the next in London ; while food, clothing, and goods of all kinds are spread over different countries in a few weeks whenever they are wanted. And then remember that all this has sprung out of the latent heat of steam, and its application by Watt to the steam-engine.

The next discovery is perhaps even more wonderful. Franklin tries experiments upon the peculiar power known by the name of electricity, and he suspects that it is everywhere and in everything. He proves its passage from one body to another, and finds out many of its properties. In spite of the derision of his friends, he seeks to bring it down from the sky, and succeeds in making a prisoner of the lightning and working with it in his own laboratory. Galvani next finds this wonderful power hidden in the nerves of a frog ; while Volta crowns the whole by showing how powerful electricity can be produced by two metals placed in a little acid and water, and how this can be carried along a wire of any length which touches the battery at both its ends. Here lies hid the germ of the electric telegraph ; but the grand secret of carrying messages from one end of the world to another in a few moments was not to come yet. That remained for the nineteenth century to accomplish.

Astronomy.-Lastly we come to astronomy, and to some 
of the most tremendous problems in the working of our universe. Here we find Lagrange proving that the system of our sun and planets is self-regulating, so that in spite of all its infinite changes, there is no real irregularity or changeableness in its machinery, but all moves in one perfect and constant round. Laplace shows the reason of those irregularities which seemed to contradict Newton's law of gravitation, and proves that they are all explained by that law, thus completing the work of the great astronomer. Then Herschel takes up the story, and after discovering a new planet, he studies the cloudy nebulæ, and points out the probable formations of new suns going on now in far-distant regions; he pictures our own sun rushing through space at the rate of $150,000,000$ miles a year, carrying with it our earth and all the other planets; and above all he traces the law of gravitation into the distant star-world, and shows it there holding suns together and causing them to revolve round each other. And so, out into space as far as the mind can reach, we find everlasting order reigning through out the visible universe.

List of Works consulted.-Werschel's 'Astronomy ;' Arago, 'Vie et travaux de Herschel,' I\&43 ; Proctor's 'Essays on Astronomy,' 'The Universe,' 'Other Worlds than Ours'; Grant's 'History of Physical Astronomy ;' Arago, 'Eloge of Laplace;' Airy's 'Astronomy ;' 'Encyclopæedia Britannica' - 'Astronomy ;' 'Orbs of Heaven,' Mitchell. 


\section{SCIENCE OF THE}

\section{NINETEENTH CENTURY}


Some of the Chief Men of Science of the I9th Century who are mentioned in the following pages.

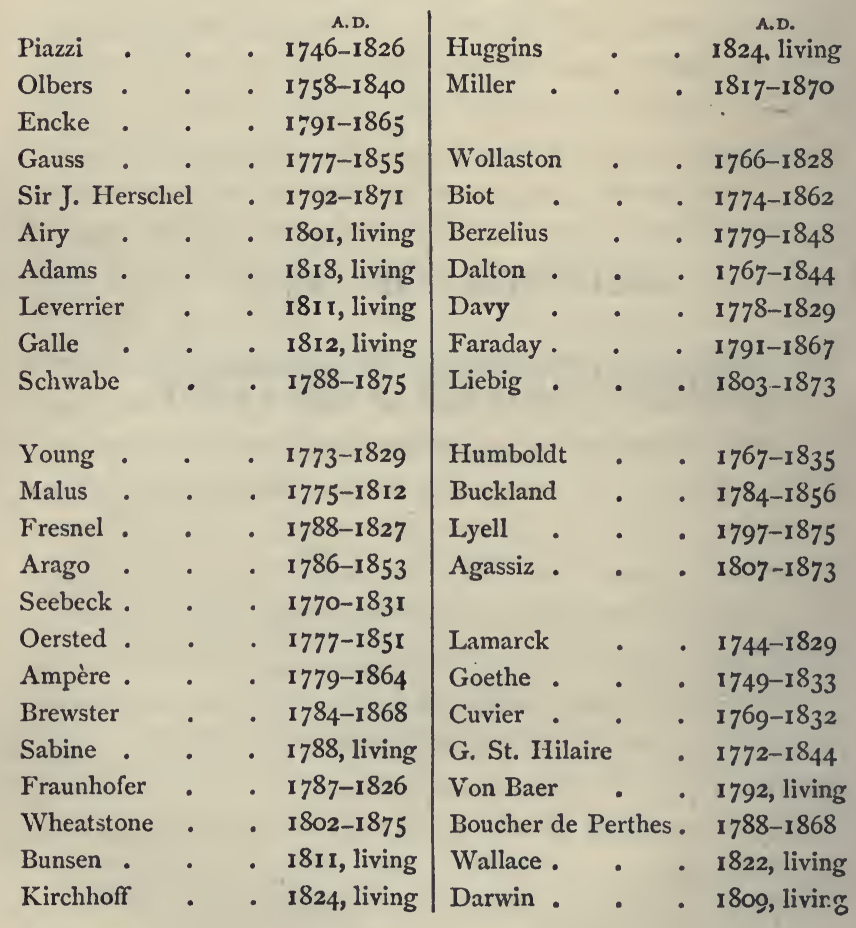




\section{CHAPTER XXXI.}

SCIENCE OF THE NINETEENTH CENTURY.

Difficulties of Contemporary History - Discovery of Asteroids or Minor Planets between Mars and Jupiter-Dr. Olbers suggests they may be fragments of a larger Planet-Encke's Comet, and the correction of the size of Jupiter and Mercury-Biela's Comet noticed in 1826 -It divides into two Comets in 1845-Irregular movements of Uranus-Adams and Leverrier calculate the position of an unknown Planet-Neptune found by these calculations in 1846-A Survey of the whole Heavens made by Sir John Herschel-His work in Astronomy-Comets and Meteor-systems.

WE have now arrived fairly at the beginning of our own century, and shall have to speak of events which happened as it were but yesterday, and of men whom our grandfathers, or even perhaps our fathers, have seen and known. How are we to find our way through the mass of discoveries which have been made in every science during the last seventy years, or to make our choice among the number of famous men whose names we meet with every day? We must begin at once by recognising that it is impossible to mention all, even of the leading points, of the science of our time, and then we may try to learn a few of them, if we do so with a clear understanding that we are leaving important gaps unfilled.

There are two special difficulties which we must encounter in the history of this century; first, we cannot avoid mentioning the work of some living men, while at the 
same time we omit others who are equally eminent; and secondly, we must speak of many subjects which are still, as it were, on their trial, and which will not be finally settled till they can be judged dispassionately by future generations. I have tried, however, to follow as far as possible the plan I adopted in the earlier centuries, of mentioning only a few great men whose work you can understand and follow; and stating on doubtful subjects what is the opinion of those who are best able to judge from the evidence. Therefore you must constantly bear in mind that this last portion of the book cannot be said to contain a history of the science of the nineteenth century, but only an account of a few of the leading discoveries and theories of our times and of the men who made them.

Advance in Astronomy. - The science of Astronomy, in particular, has spread far beyond our power to follow it. We have seen that astronomers up to the end of the eighteenth century were always striving to work out the laws which govern the movements of the heavenly bodies. The key to this problem was found by Newton, and the work was completed when Laplace and Lagrange showed that even those planets which seem to have the most irregular orbits are really governed by the force of gravitation. From that time astronomy became really an exact science, and men had only to make their calculations with perfect accuracy in order to be able to foretell what was going to happen; or if they failed, then they knew there must be some other unknown heavenly body (such as Neptune, p. 294) causing the irregularity. Therefore, the science of astronomy in our century has been chiefly occupied in discovering new planets, stars, and star-clusters; at every step giving us new proof that gravitation rules throughout the visible universe. And 
side by side with this has grown up a new study, namely that of the nature of the sun, planets, stars, comets, meteors, \&c., telling us what they are like in themselves, whether they have an atmosphere like our own, and of what materials they are made. This study has been carried on partly by powerful telescopes, but chiefly by the wonderful method called spectrum analysis, of which we shall speak presently. Meanwhile we must first begin by naming a few new bodies lately observed in the heavens.

Discovery of the Asteroids and Minor Planets between Mars and Jupiter, 1801-1807.-Not long after the discovery of Uranus, a well-known astronomer named Bode pointed out that the distances of the planets from the sun seemed to follow a remarkable arithmetical law. The only exception to this law was between Jupiter and Mars; and here the gap was twice as large as it ought to be according to the calculation. Therefore astronomers suspected that there must be a planet between these two which had not yet been seen; and in the year 1800 , at a meeting at Lilienthal, in Saxony, they agreed to search diligently for this supposed missing body.

Signor Piazzi, the Astronomer of the Observatory at Palermo, in Sicily, was one of these planet-searchers, and on the first night of the year $180 \mathrm{r}$ he caught sight of a small star in the constellation Taurus, which had not yet been noticed in any catalogue. The next night he looked for it again, and found that it had moved its position. He did this for twelve nights, and the movement seemed to show that it was the planet he was seeking. Just at this point, however, he was taken ill, and although he had told other astronomers of what he had seen, no one could find the planet again. Months passed, and people began to doubt 
whether he had not made a mistake; but at last a young German astronomer named Gauss set to work to calculate, from the facts which Piazzi had given, whereabouts in the heavens the planet ought then to be, and turning his telescope to the point, there he found it! This planet was called Ceres; it was very small compared to the other planets, but the astronomers were satisfied at having filled up the supposed gap.

Before two years had passed away, however, in the year 1802, another astronomer, Dr. Olbers, of Bremen, suddenly announced that he had found another little planet near Ceres, which he called Pallas, and in 1804 a third was found by another astronomer named Harding, who called it Juno. It seemed very strange that so many bodies should be moving round the sun at nearly the same distance from it, and Dr. Olbers suggested that they might perhaps be parts of one large planet which had broken up into fragments. If this was so he expected to find more, and truly enough in I 807 a fourth was discovered, which he called Vesta. In 1845 and 1847 two more were added to the number. Since then some have been found every year, till now no less than 153 of these small planets, or asteroids as they are called, are known to be moving round the sun between Mars and Jupiter. Pallas, the largest of these, only measures about 600 miles across, and when it comes nearest to the earth does not look larger than a star of the eighth magnitude. Whether they are really fragments of a planet is not proved, and we have still a great deal to learn about them.

Encke's Comet, 1819. - The next bodies of interest which were discovered were two returning comets, each of them remarkable for different reasons. The first of these was observed in 1819 , through the telescope at Marseilles, by a Frenchman named Pons. It was very small, and is mainly 
of importance because after Professor Encke, of Berlin, had calculated that it returned regularly every three years and a quarter, he found that it arrived two hours and a quarter earlier each time. Why it should come earlier is a question which is still very perplexing to astronomers, though several explanations have been suggested. In order to find out how fast this comet moved, Fncke was obliged to calculate very accurately how much the different planets attract it ; and this led him to discover that Jupiter is larger than the earlier astronomers had supposed, while Mercury is much smaller.

Biela's Comet, 1826. - In r 826 another remarkable comet was observed by an Austrian officer named Biela, and on that account called 'Biela's comet.' M. Clausen, a German astronomer, computed that it revolved in an elliptic orbit in a period of six years and eight months, and it was then shown to be the same comet which had been observed in 1772,1805 , and 1818 . This comet has had a very curious history. In the year $183^{2}$ great alarm was excited because the astronomers calculated that it would cross the orbit of our earth on October 29. People who did not understand the question thought this meant that it would run into us and perhaps destroy our earth; and many even sold their houses and land because they thought the end of the world was at hand. The people in Paris especially were so frightened about it that the Academy of Sciences were obliged to ask Arago, the French astronomer, to quiet their fears, and he wrote a popular essay showing that though the comet crossed the path of our earth, yet on that day we should be fifty-five millions of miles away from the spot.

But it was in 1845 that Biela's comet proved most interesting. On November 26 in that year it came at the 
time it was expected, and was seen each night afterwards as usual till January 12. On that night, however, when Lieutenant Maury looked at it from the observatory at Washington, in the United States, he saw, not one comet, but two distirit and separate comets moving along together. This seemed so strange that it would scarcely have been believed if several astronomers had not watched the comet for more than a month, and satisfied themselves that it had really split uf into two parts, each part being a perfect comet, with a bright head and a glowing tail! These two comets returned in $185^{2}$, still keeping each other company at the same distance apart as in 1846 , but since then they have never been seen again. Many other comets have been discovered besides these, and we know that many thousands or even millions must be wandering through space, but of these we cannot speak here.

Adams and Leverrier determine the Position of an Unknown Planet by its Influence on the Orbit of Uranus, 1843-1846. - The next discovery which we must consider is one of the most remarkable in the history of astronomy, because it was not made with the telescope but was worked out independently by two men entirely by means of Newton's theory of gravitation. You will remember that in $178 \mathrm{r}$ Sir William Herschel discovered the planet Uranus moving outside all the other planets (see p. 272). Now many astronomers had noticed this body in earlier ages, and supposing it to be a star, had marked its position from time to time in the. heavens, and from these observations it was now possible to calculate its path round the sun. When this was done it was found, however, that the planet did not move ais it ought to do according to the theory of gravitation. The pull of the sun and the known planets did not account for 
its orbit, for it roamed farther out into space than it should do if they were the only bodies which attracted it. Either, therefore, the early astronomers had marked the position of the planet wrongly, or some unknown and unseen body must be pulling it out of its course. This last seemed the most likely explanation, but no such planet could be seen, and the problem remained unsolved.

It was at this point that a young student of St. John's College, Cambridge, named John Couch Adams, then only twenty-three years of age, made a memorandum in his notebook to work out the movements of Uranus, and see if by this means he could discover whether there was another planet farther away from the sun. As soon as he had taken his degree as Senior Wrangler in 1843 , he set to work to carry out his intention, and two years afterwards he sent a paper to Mr. Airy, the Astronomer-Royal at Greenwich, stating in what part of the heavens astronomers ought to look for the unknown planet which would explain the capricious movements of Uranus.

It is not easy for any but mathematicians to understand what a wonderful thing it was to calculate accurately, in this way, where a planet would be found which had never been seen. When Pallas was discovered between Mars and Jupiter, Piazzi saw it through the telescope for some days, and it was only found again by following out the movement which he had recorded. But in Adams's case nothing had ever been seen, and the only reason for suspecting anything to be there, was that astronomers could not make their very difficult calculations of the attraction of the different planets come out right. Adams, therefore, had first to calculate all the attractions of the sun and the planets, in their different positions, and then to find out how they would affect Uranus 
in his path ; and wherever the planet did not follow their pulling he had to calculate where another body must be to draw it away from them. This he accomplished, and it is very remarkable that the great living French astronomer named Leverrier also worked out the same problem, without having heard that Adams had done it.

In the year 1839 Leverrier had begun a long series, of calculations (which were only completed last year, 1874 ), to find out the varying attractions, and by that means the size and weight, of the different planets, and while he was at work at this he became convinced that there must be some unseen body pulling at Uranus. Now it so happened that just at the time when Adams and Leverrier began to feel after this supposed planet, Uranus had lately been very much disturbed, and so they knew that the disturbing cause must have approached near to him, and this showed them in which part of the heavens the attracting planet ought to be.

Leverrier published his calculations in the Journal of the Académie des Sciences at Paris for June 1846, and when the Astronomer-Royal read the paper he was astonished to find that the French astronomer had fixed the place of the unknown planet within one degree of the spot which Adams had named. This led him to read Adams's paper again more carefully, and to put the two astronomers into communication with each other; and the consequence was that Leverrier wrote another paper in August $\mathbf{3} 846$, stating still more accurately where the planet ought to be found. This paper he sent to his friend M. Galle, of the Berlin Observatory, on September 23, 1846, asking him to look for the planet in that part of the sky which he pointed out. M. Galle did so, and on that same night, by following the instructions of the two astronomers, he found the unknown planet. 
So true is the law of gravitation that two men sitting at home in their studies were enabled, from slight irregularities in the motion of Uranus to predict the existence and place of a disturbing body, rolling on through space! This new planet is called Neptune, and is a little larger than Uranus; it has certainly one moon, discovered by M. Lassell, and Herr Struve thinks he has seen a second.

Sir John Herschel's work in Astronomy.-While these different discoveries were being made in the observatories of Europe, Sir John Herschel was carrying on the work his father had begun of gauging or measuring the brilliancy of the stars. Born at Slough, close to his father's observatory, in 1792 , the young John Herschel spent his early life with his father and aunt, and saw them always busy night and day studying the heavens. In $\mathrm{I}_{8} \mathrm{I}_{3}$ he was Senior Wrangler at Cambridge, and after that he turned his attention to double stars, and in 1828 completed a list of no less than 2,000 of these wonderful double and sometimes treble suns which revolve round each other. When he had completed the survey of the whole of our northern skies, he went in I $\delta_{33}$ to the Cape of Good Hope, where an observatory had been built in 1820 , and there he spent four years gauging the stars of the southern hemisphere and classing them according to their brilliancy, as his father had classed those of the northern hemisphere. He was thus the first astronomer who swept his telescope over the whole of the heavens which are visible from our planet, and who saw with his own eyes every star, planet, and nebula then visible in the sky. Among the remarkable appearances which he examined were those cloudy masses of light called the Magellanic Clouds, which are the Milky Way of the southern hemisphere, and he found them to be made up of 
stars, star-clusters, and nebulæ, mingled together in wonderful complexity.

When he returned to England in 1838 , you can imagine what a wonderful picture he must have had in his mind of the whole universe as far as we can see it. It was then that he wrote his famous 'Outlines of Astronomy,' which was a new edition of a little book he had written years before. In this great work Sir John Herschel first taught ordinary people what a grand science astronomy is. Before his time the different discoveries and theories had been scattered about in various scientific papers, too difficult and too tedious for the public to read. But Sir John wrote simply and plainly about the great truths which had been worked out from the days when Aristarchus first asserted that the earth moved round the sun to the time when Sir William Herschel pictured our whole solar system travelling onwards through endless space; and through his book many who would never otherwise have studied the science learnt to know something of the wonders of the heavens and the lessons they teach. Sir. John was a true lover of the works of nature, and he taught all his readers to love them too, and to feel a true reverence for the Infinite Mind of the Creator of them all. He died in $187 \mathrm{I}$, and was buried in Westminster Abbey, but never will those who knew him forget the beautiful truth-loving spirit which breathed in every word he wrote or spoke.

Sir John Herschel is the last of our great astronomers who is no longer living, and here we should close the history of physical astronomy, if it were not that a wonderful discovery has been made within the last ten years which must at least be mentioned.

Discovery of the Paths along which Meteors travel, 
and the Agreement of two of these with the Orbits of Returning Comets, 1862.-Everyone has heard of falling or shooting-stars, and most people have probably seen one or more of these bright meteors rush across the sky on a calm summer evening, and then vanish as suddenly as it appeared. The rude Lithuanian peasants have a touching legend about these falling stars. 'To every new-born child,' they say, 'there is attached an invisible thread, and this thread ends in a star; when that child dies the thread breaks, and the light of the star is quenched as it falls to the earth.' Science has taught us a different, but a not less wonderful history. It is now known that these meteors are solid stones, 'pocket planets' as Humboldt called them, which travel round the sun in the opposite direction to that in which we are going. When we meet them they rush through our atmosphere so fast that they become heated, and give out light for a short time till they are burst into fine dust and vanish. When they are too large to be consumed before they reach the earth, they fall, often with great violence, and are split into countless fragments. A large collection of these meteoric stones is to be seen in the British Museum, some weighing hundreds of pounds, others only a few grains. They have been analysed, and are found to be composed chiefly of iron, tin, sulphur, olivine, and oxygen.

Before the present century all that was known about these bodies was very vague and unsatisfactory. From time to time accounts of stone-falls came from different parts of the world, but they were not much attended to, and people found it difficult to believe that stones and mineral masses actually fell from the sky on to the earth. But in 1803 a fiery globe was seen to rush over the town of Aigle, in Normandy, and a stony mass was dashed to the ground and shattered into 
thousands of fragment3, some of which weighed as much as I $7 \frac{1}{2} \mathrm{lbs}$. This created so much astonishment that the French Government sent M. Biot, a celebrated French chemist, to examine into the matter, and he reported that there could be no doubt that a shower of hot stones had fallen upon the earth.

From this time more interest was taken in meteors and meteoric stones. People had remarked for a long time that shooting-stars were more abundant from the gth to the IIth of August than at other times, and more lately it was also noticed that a shower of the same kind happens about the I $3^{\text {th }}$ of November. Astronomers began, therefore, to think that these meteors must move in regular orbits, crossing the orbit of our earth in certain places, so that we pass through them. There were also reasons for thinking that the November meteors travelled in an enormous ellipse, passing at one end even outside the planet Uranus.

It was not, however, till thirteen years ago that anything was really known. In the year 1862 an Italian astronomer named Schiaparelli made a very remarkable suggestion. $\mathrm{He}$ noticed that a comet which was seen in that year crossed the earth's path just at the point where we are always in the middle of the meteor-shower on August 10, and it occurred to him whether it might not be possible that the August meteors were travelling in the same orbit as the comet. His guess turned out perfectly right, and by a calculation which we cannot follow here he proved that the comet and the August meteors travel along precisely the same path in the shape of a long ellipse passing at one end outside the planet Neptune, the most distant of the known planets. This was the first time that the orbit of any set of meteors had been traced out:

The next was that of the November meteors, which was 
determined by Adams, and also independently by Leverrier. It had been shown by searching out all the past accounts of November showers that in times gone by, the earth passed through these meteors a little earlier in the year than she does now, and this could not be accounted for by any irregularity in the movement of the earth. It looked therefore as if the orbit of the November meteors must be slowly shifting, just as the orbits of the planets do, within certain limits. It was upon this shifting that Adams founded his calculations, and he worked out the meteor path with great accuracy, showing that those astronomers had been right who thought it extended beyond Uranus. This time the problem was solved by pure astronomical reasoning and not by a happy guess. But perhaps the most remarkable part of the story is that in 1866 , long after Adams had determined the orbit, a new comet was seen which was found to move exactly along the path of the November meteors, in the same way that the comet of 1812 agrees with those which fall in August.

Although these two meteor-showers are the most important, they are by no means the only ones crossed by our earth. Any clear night, if you watch carefully, you may see (according to the astronomer Proctor) about six shooting-stars in one hour; and Professor Newton, of America, has calculated that $7,500,000$ meteors large enough to be seen without a telescope pass through our atmosphere in one single day and night. At least a hundred sets of meteors, or meteor-systems as they are called, are known to astronomers, and each one of these is composed of millions of bodies; and you must bear in mind that these systems do not move round us, but round the sun, so that it is only because we happen to cross their path that we know anything of them. It would be idle to 
suppose that these hundred meteor-systems which we come across are the only ones existing. On the contrary, we have every reason to think that they are only a few out of thousands of meteor-systems which we never meet, and which must grow more numerous the nearer they approach the sun.

And so we arrive at the wonderful thought that the whole of our solar system is swarming with meteors rushing along with immense speed! What their use is we do not know. Some astronomers imagine that the heat of the sun is kept up by these meteoric stones falling in countless myriads on his face, but this is disputed by others; and for the present it is enough if we can picture to ourselves these rings of meteors whirling round and round in space, and flashing into light as they rush through our atmosphere whenever we happen to cross their path.

I have chosen out these new facts about meteors because, of all modern discoveries, they give the best idea of the wide fields of knowledge which are opening out before us. Within the last fifty years a number of most interesting observations have been made about the nature of the sun itself; but they would require long explanations, and being all the work of living men they scarcely belong to our history.

In the chapter on Spectrum Analysis we shall learn something of the atmosphere of the sun and stars, and in the chapter on Magnetism something of the spots on the sun and their effects on our earth. But for the history of the discovery of the photosphere, corona, red prominences, and other wonderful appearances upon the face of the sun, you must read special works on the subject. 
Chief Works consulted.-Airy's 'Report on Astronomy,' British Association, 1833; J. D. Forbes's 'Progress of Mathematical and Physical Science'-Sixth Dissertation; 'Encyclopædin Britannica,' new edition; Guillemin, 'The Heavens ; 'Herschel's 'Astronomy ;' Grant's 'Physical Astronomy ;' 'Reports of the Astronomical Society;' 'The Orbs of Heaven,' Mitchell ; Proctor, 'On ShootingStars and Meteors.' 
PT. 111.

\section{CHAPTER XXXII.}

SCienCE OF THE Nineteenth Century (CONTINUED).

Discoveries concerning Light made in the Nineteenth Century-Birth and History of Dr. Young-He explains the Interference of Light -Cause of Prismatic Colours in a Shadow-And in a Soap-bubble - Malus discovers the Polarization of Light caused by ReflectionBirth and History of Fresnel-Polarization of Light explained by Young and Fresnel-Complex Vibrations of a Ray of Light-How these Waves are reduced to two separate Planes in passing through Iceland Spar-Sir David Brewster and M. Biot explain the colours produced by Polarization.

WE must now go back to the history of Light, which we left, as you will remember, at the end of the seventeenth century, at the point which Newton and Huyghens had reached. During the whole of the eighteenth century very little was learnt about this science, and it remained for the men of our own time to make the next step and to discover the grand laws of light which we must now consider. It will be best to divide our subject into two parts- 1 st. The discoveries which have led to a true Theory of Light. These are very difficult to understand, and you must not expect to gain more than a slight notion of them; 2nd. The new facts lately discovered about the Chemistry of Light, and called Spectrum Analysis, and of these I hope you may understand enough to fill you with delight at the beautiful histories they reveal.

Discovery of the Interference of Light by Young, 1801.You will remember that Newton and Huyghens had proposed 
two different theories of light (see page 174). Newton's, called the Corpuscular or Emission Theory, supposed light to be made up of minute particles darting out from the sun and every light-giving body. Huyghens, on the contrary, taught that light is produced by the vibrations or waves of an invisible ether which is supposed to fill all space. This was called the Undulatory or Wave Theory.

Newton's authority was so great, and the experiments he made to prove his theory were so striking, that the 'Corpuscular theory' was generally received as the true one, especially as Huyghens had only made a few simple experiments in support of his idea; and it was more than a hundred years after Huyghens first published his 'Treatise on Light' before a man arose to defend the Undulatory theory and to bring it again into notice. This man was Dr. Thomas Young, the first Professor of Natural Philsophy at the Royal Institution of London.

Thomas Young, who was the son of a Quaker, was born at Milverton, in Somersetshire, in 1773 , and died in 1829. He was brought up at home, and seems to have been a very clever lad, for he knew seven languages at the age of fourteen, besides having studied Natural Science as an amusement. He then went to the Edinburgh University, where he worked under dear old Dr. Black, whose enthusiasm, no doubt, helped much to increase his love of science. When he was only twenty he sent a paper on 'Vision' to the Royal Society, and was elected a member the following year. $\mathrm{He}$ then went to Cambridge in order to be able to satisfy the College of Physicians, and practised as a medical man in London, where, in 1801, he was also made Professor of Natural Philosophy at the Royal Institution, which had just been founded, and Editor of the Nautical Almanack. He is 
very famous as one of the first men who deciphered the Egyptian hieroglyphical writings, and you will often hear him mentioned as an Egyptian scholar; but what we have now to consider are his discoveries about Light.

Young tells us himself that it was in May I80I that he first made an experiment which seemed to him to prove that light must be a succession of tiny waves moving across space as Huyghens had supposed. His experiment was the following. He made a hole in the window-shutter of a dark room, and covered it with a piece of thick paper, in which he had pricked a small hole with a needle. He then put a small looking-glass outside the shutter, so as to throw the sunlight very fully upon the hole and send a cone of spreading light through it. In this cone of light he held a very narrow strip of card and watched the shadow which it threw on the wall, or on another piece of card behind it. On each side of the shadow there were some faint fringes of colour, but besides these he saw in the shadow itself dark and light upright bands, which finished off in a faint white band in the middle of the shadow. It was from these faint bands, which many men would have thought not worth noticing, that Young worked out the truth of the Wave Theory of Light.

The first question he asked himself was- 'Why should there be any light at all in the shadow?' This was not difficult to answer, for as light travels in all directions, a part of it, passing on each side of the strip of card, will spread out behind it. But why should this light arrange itself in stripes and not fall equally all over the shadow? It seemed at first impossible to explain this; but when Young placed his hand so as to prevent the light passing along one of the edges of the card he found that the fringes or bands dis- 
appeared entircly, and when he took away his hand they returned. It was clear, then, that so long as the light passed in one direction only behind the card it spreads itself out equally, but directly the two sets of rays from the two sides met each other, dark and light bands appeared.

Now Newton's emission theory would give no explanation of this curious fact, for if light were made of tiny particles there is no reason why these particles in crossing each other should make dark bands. On the contrary, the more of them there were the more light there ought to be. The Undulatory or Wave Theory, however, explained the bands perfectly, and this we must now try to understand.

You will remember that Huyghens supposed an ether filling all space to be set in motion by the sun, or any other luminous body, and to heave up and down in tiny waves just as the sea heaves, or the water of a pond when you agitate it.

Suppose, therefore, that a number of waves of water, all of the same size, are moving along one side of a lake as at $\mathrm{A}$, Fig. 48, p. 306 , and flowing out through a narrow channel at the end, and suppose another set of waves to be moving along the other side, B, so that the two sets meet at the mouth of the channel. Then, if the two waves $c$ and $d$ are both rising up when they meet, they will join together into one large wave, and will continue to flow in large waves down the channel. But if they meet, as in Fig. 49, when $c$ is falling and $d$ is rising, then $c$ will flow into the hollow of $d$ and fill it up, and instead of a large wave being made, the surface of the water will become smooth.

Now Young pointed out that this is exactly what happens to the undulations of light. After passing through the hole in the shutter, they move on till they come to the card, and here they wheel round each edge of the card and meet 
behind it. Those which meet in the middle of the shadow have each travelled exactly the same distance with the same number of waves, so they meet as in Fig. 48, and a strong undulation is produced, causing a band of light. But on either side of the exact middle the rays will not have travelled exactly the same distance, but one will have made half a wave more than the other, so they will meet as in Fig. 49, and destroy each other, causing a band of darkness. Outside these again the ray which has come the longer dis-

FIG. 48.

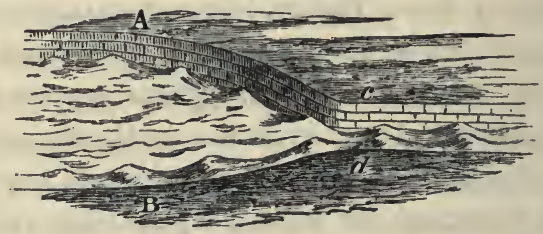

Fig. 49.

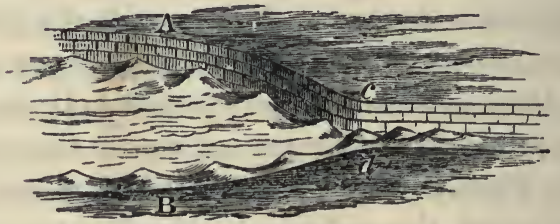

Diagrams illustrating the Interference of Waves.

In Fig. 48 the waves, $c d$, meet in the same phase, and produce strong undulations. In Fig. 49 the waves, $c d$, meet in the opposite phase, and interfere with each other.

tance has had time to make up another half-wave, so it meets the other ray as a friend again, and both of them rising together, a strong wave and a light band is the result. In this way they go on, first helping and then interfering with each other, and thus making alternate bands of light and darkness across the shadow. For this reason Young called his discovery the 'Interference of light.' 
If this experiment is made with light of one colour only, as, for example, with light which has been passed through red glass, and so is composed only of red rays, then the bands are simply dark and light. But if sunlight is used another curious effect is seen, namely, the bands are faintly tinged with the colours of the rainbow; and this too Young showed to be beautifully explained by the Undulatory Theory. It was stated at p. 177 that the colour of the light which reaches our eye depends upon the rapidity of the vibrations of the ether, just as the sound of a note upon our ear depends upon the rapidity of the vibrations of the air. Consequently the waves of the prismatic colours are of different lengths, so that when the two rays of light meet behind the card the waves of the various colours do not all arrive together. For example, those waves which cause us to see the colour violet are much shorter and more rapid than those which cause us to see red. Therefore, when the red waves meet each other as friends (as in Fig. 48), and make a strong vibration, the violet ones will meet each other as foes (as in Fig. 49), and interfere with each other; and so we shall see a bright red stripe made by the strong red wave, while the violet waves will be destroyed A little farther on the violet waves will meet as friends, and then we see a violet streak, while the red ones will in their turn be destroyed.

Colours on the Soap-bubble. - The beautiful colours of the soap-bubble are caused in this way, and an explanation of them will help you to picture to yourself this effect of the interference of light. If you have ever blown a well-shaped soap-bubble, and watched it settle down quietly where there is no wind to disturb it, you cannot fail to have noticed the colours which appear upon it. If the bubble is very perfect 
these colours arrange themselves in rings, beginning with a dark spot at the top of the bubble and forming alternate bands of blue, yellow, orange, and red, which grow fainter and fainter down the sides of the bubble till they disappear. The reason of these colours is that, when the sunlight falls on the thin film of the bubble, a little of the light is reflected straight back to the eye from the surface $a$, Fig. 50 ; but most of it passes on to the second surface $b$, and there again some is reflected, so that two sets of waves are constantly reaching the eye, one from $a$ and one from $b$. These two sets meet before they come to our eye, and we have just seen (p. 306) that it depends entirely how they meet whether we see light or darkness.

Suppose the film is just thick enough for the two rays to

Fig. $5 a$

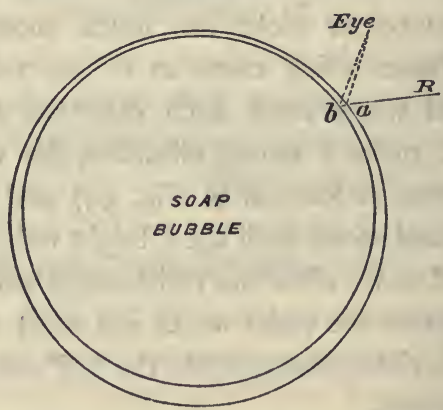

Reflection of Light from the two surfaces of a Soap-bubble.

R, Ray of light, part of which is reflected from the surface $a$, and part from the inner surface, $b$, to the eye.

meet when the red waves of each are rising; we shall then have a full red wave upon our eye. But in that case, as the

1 The film of a soap-bubble is really only the thickness of a fine line even in the thickest part; but it was necessary to exaggerate the two surfaces in the diagram to show the passage of the ray of light. 
violet waves are a different length, they will not have met as friends, but as foes, one $u p$ and the other down, and will destroy each other; and so will the waves of all the other colours, because they are not of the same length as the red waves. Therefore the only impression on our eye will be that of red. But the bubble is always growing gradually thicker down its sides because the soapy liquid is creeping downwards. So a little lower down the red waves from the two surfaces $a$ and $b$ will no longer fit each other, but will meet unevenly and the red colour will be destroyed. It will now be the turn of the violet rays to combine and make a strong wave to our eye ; a little lower down it will be the turn of the green waves, then of the yellow, and then the film will be thick enough for the red waves to come together again, and so it will go on ; each colour in its turn will produce a strong wave, while all the others are quenched, until the film is too thick for the effect to be produced.

This is a very rough idea of the way in which the Undulatory Theory explains the colours which we see in shadows and in the soap-bubble. When you study the subject of light you will see how very complicated these wave movements really are; but without special knowledge you cannot understand more than I have given you here. The colours on mother-of-pearl, on a duck's neck, on the transparent wings of insects, and even on the scum floating on a pond, are all produced by the interference of light, and we owe the discovery of this simple and beautiful explanation to Dr. Thomas Young.

Malus discovers the Polarization of Light by Reflection, 1808. - The next step in the science of light was made by Etienne Louis Malus, a young French engineer officer, who was born in 1775 , and died in 1812 , when he was only 
thirty-seven years of age. $\mathrm{He}$ was a most accomplished mathematician, and if he had lived longer would probably have been one of the most celebrated men of our century.

You will remember that in 1669 a Danish physician named Bartholinus discovered that a ray of light is split into two rays in passing through Iceland spar in any direction except along the axis of the crystal ; and that Huyghens explained this by saying that the crystal was more elastic in one direction than in another, so that the waves moved at different rates through it (see p. 180). To understand Malus's discovery you must also remember that one of these divided rays, if it falls upon a second crystal in the same manner as the first, goes on its way as a single ray, but if the second crystal is turned round a little the ray splits up again into two rays, one much bxighter than the other.

In the year $1808, M$. Malus was standing at his study window in the Rue d'Enfer, in Paris, looking through a prism of Iceland spar at the sunlight reflected from the windows of the Luxembourg Palace, which stood opposite. All at once he observed to his surprise that he saw only one image through the prism instead of two. Turning his prism a little, he got the two images again, but one was much brighter than the other, and when he turned the crystal a little farther the other image disappeared, and he had only one again. In fact, the light which was reflected from the window at one particular angle $\left(5^{\circ} 45^{\prime}\right)$ behaved just like one of the divided rays which has come out of a crystal, and not like an ordinary ray which comes from the sun.

This remarkable peculiarity puzzled Malus greatly, and led him to make a great many experiments, by which he discovered that, whenever light is reflected from glass at this particular angle of $56^{\circ} 45^{\prime}$, it has the peculiar characters of a 
divided ray which has passed through Iceland spar. Light reflected from other substances is also divided up in this way, only the angle at which this change takes place is different for each different substance. Malus was the first to call this peculiar effect polarization, and light which behaves in this way has since been always called 'polarized light.'

His discovery led to a completely new study, for people had almost forgotten the experiments which had been made by Huyghens more than 100 years before; but this novel and curious fact attracted attention, and the subject was taken up again. Malus did not live to explain the matter; he found out many remarkable facts about it, but it was Young and the French philosopher Fresnel who really worked out the theory of the polarization of light.

Polarization of Light explained by Young and Fresnel. 1816.-Augustin Fresnel, the contemporary and friend of Thomas Young, was born at Broglie, in France, in 1788. He was a delicate backward boy, who disliked books, but loved practical experiments, and he followed his tastes by becoming an engineer. Being a Royalist, however, he was harshly treated by the Emperor Napoleon I., and he retired to Normandy to derote himself to science. He died of consumption in 1827 .

It is very difficult to decide whether Young or Fresnel was the first to point out how certain peculiar vibrations of the ether explain the polarization of light. But fortunately this need not trouble us, for the men themselves were not anxious to dispute about their claims. Young's discoveries were very coldly received in England, for very few men understood them; and unfortunately Lord Brougham wrote many severe articles against them in the 'Edinburgh Review,' which made people think they were only foolish specula- 
tions. But in France two men, Fresnel and his friend M. Arago, understood and valued Young's labours as soon as they heard of them, and from that time the three men helped each other in every way without the least jealousy as to who should have the credit of the work.

Fresnel had puzzled out the question of the 'Interference of Light' before he heard that Young had done so too; and it happened that while Fresnel and Arago were one day making experiments upon the way in which waves of light interfere with each other, they found that the ordinary and extraordinary rays coming out of crystal and Iceland spar would not interfere with or quench each other, as two ordinary rays do. (See p. 306.) This led Fresnel to suspect that the waves in the two rays must move in a different manner. He wrote this to Dr. Young, and found that he also had the same idea, and this led to a number of experiments, by which they proved at last that the waves in a natural ray of light do not move merely up and down like waves in a pond, but also from side to side; and that when light is polarised this complex vibration is destroyed and the waves of each separate ray move only in one direction.

To understand this, take a piece of string, and, fastening one end to the wall, hold the other end in your hand. If you now move your hand up and down, you will make waves in the string which will point up to the ceiling and down to the ground, making what are called vertical vibrations (A, Fig. 5 I). Stop this movement, and then move your hand from side to side ; the waves will now point from wall to wall in horizontal vibrations (B, Fig. $5 \mathrm{I}$ ). If you then move your hand so that it points to the ceiling to your right, and the floor to your left, you get waves between the two others, and so you can go on varying the position of the waves in all directions ; 
or, in scientific language, you cause the string to vibrate in a different plane.

Now Young and Fresnel proved that a natural ray of light is composed of all these different waves moving at the same time, some up and down, some from side to side, and some between the two. But when the light passes through a piece of Iceland spar, there are two and only two ways in which the waves can move : one up and down-and along this path one ray of light goes; the other from side to side-and along this the other ray goes, and so they become divided.

You can imitate this by passing your string through a card with a straight slit in it. Place the card upright, as at $\mathrm{A}$, Fig. $5 \mathrm{I}$, and it is clear that the waves will be up

Fig. 5 I.
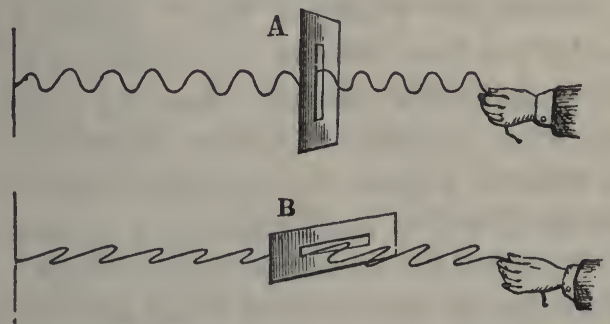

Diagram illustrating the passage of Waves of Light through a Crystal.

A, Waves moving in a vertical plane. B, Waves moving in a horizontal plane.

and down; place it sideways, as at $\mathrm{B}$, and the waves will be from side to side. These two positions of the card imitate the two paths of a ray of light through a crystal, and they show how the difference in the peculiarities of the divided rays is caused by their moving in a different plane.

We cannot follow this out more completely in a history, 
for the polarization of light is a very difficult subject ; but this was the first step made in it. Fresnel afterwards worked out accurately why, when light is reflected at a certain angle, the vibrations are all made to move in one plane, and so the light is polarized, as Malus had found it to be from the surface of the Luxembourg windows. He also showed how in some crystals, as in quartz crystals, the waves are made to act upon each other, so that, instead of moving to and fro, they wind round and round like the wire of a corkscrew. These and many other experiments, as for example, those upon the beautiful colours caused by polarization, were carried much farther by the eminent French chemist, M. Biot (born 1774 , died 1862), and by Sir David Brewster (born 1784 , died 1868), but they are too long and difficult to be explained here. As I said at the beginning of this chapter, the 'Theory of Light' requires a special study, and if you have understood something of the movement of the supposed ether waves-how they can interfere with each other and produce light or darkness, how they produce coloured rings in the soap-bubble, and how their vibrations are altered in passing through a crystal or in reflection at certain angles-you have learnt as much as can be easily grasped of the discoveries of Young and Fresnel.

Chief Works consulled. - Young's 'Lectures on Natural Philosophy,' 1845 ; Peacock's 'Life and Works of Young ;' Arago's 'Éloge of Fresnel ;' Herschel's 'Lectures on Familiar Subjects ;' Tyndall, 'On Iight ;' Spottiswoode's 'Polarization of Light ;' Whewell's 'Inductive Sciences;' 'Encyclopædia Britannica '-Sixth Dissertation. 


\section{CHAP'TER XXXIII.}

SCIENCE OF THE NINETEENTH CENTURY (CONTINUED).

History of Spectrum Analysis-Discovery of Heat-rays by Sir W. Herschel-And of Chemical Rays by Ritter of Jena-Photography first suggested by Davy and Wedgwood-Carried out by Daguerre and Talbot-Dark Lines in the Spectrum first observed by Wollaston - Mapped by Fraunhofer-Life of Fraunhofer-He discovers that the Dark Lines are different in Sun-light and Star-light-Experiments on the Spectrum of different Flames-Four new Metals discovered by Spectrum Analysis-Bunsen and Kirchhoff explain the Dark Lines in the Solar Spectrum-Metals in the Atmosphere of the Sun-Huggins and Miller examine the Stars and Nebulæ by Spectrum Analysis.

History of Spectrum Analysis, 1800-1861.-We now come to the history of Spectrum analysis, or the study of the various coloured bands produced by different kinds of light when seen through a prism. This is certainly one of the most wonderful discoveries of our century, and though its history is difficult, partly because it belongs to our own time and is going on even now, yet we may learn something about it. The first step was made, as you will remember, when Newton discovered that white light is composed of different coloured rays, but even he little suspected what histories those rays could be made to tell.

Discovery of Heat-rays by Sir William Herschel, 1800. -One of the first facts which was learnt in this century about the spectrum was, that the coloured band which is seen when a ray of white light is passed through a prism does not 
give us the whole of the dispersed ray; for there are many invisible rays at both ends of the coloured part which are very active, though we cannot see them.

It had always been thought that the hottest rays must be those, such as the yellow ones, which give the most light, and in the year $1800 \mathrm{Sir}$ William Herschel, wishing to try this, took a thermometer and passed it gradually from one end to the other of the coloured band. The result was curious. He began at the violet end of the spectrum (Plate I. No. I, p. 320), and, as he expected, the thermometer rose higher and higher as he approached the yellow part; but to his surprise it did not stop here. When he passed on through the yellow into the red, the heat still increased, and even became more intense as he passed out of the coloured band altogether into the darkness beyond. By this experiment he found that the heat-rays extend for some distance beyond the red colour, and that they are strongest in that part where no light is to be seen.

\section{Discovery of Chemical Rays by Ritter, 1801.-Soon} after Sir William Herschel had discovered the dark heatrays, a still more remarkable fact was brought to light about the violet end of the spectrum. The Danish chemist Scheele, who you will remember as one of the discoverers of oxygen (see p. 232), had once remarked that nitrate of silver will turn black if the violet rays of a spectrum are thrown upon it. In r8or, Professor Ritter, of Jena, was repeating this experiment, and he found that the black patches appeared slightly on those parts of the paper where the violet rays fell, but very strongly indeed beyond those rays where the spectrum was quite dark. So that at this end also there are invisible rays, and these have the extraordinary power of decomposing or breaking up nitrate of silver, and some other 
substances, so as to leave distinct marks upon anything touched by them.

Photography.-You will see at once that this is the secret of Photography. In 1802 , Sir Humphry Davy and Dr. Thomas Wedgwood suggested that pictures might be taken in this way by the rays of the sun acting upon chloride of silver, and they even succeeded in making some. But they could not prevent them from fading away again, and it was not until 1839 that a Frenchman named Daguerre learnt how to fix the pictures so that they would remain, and Mr. Fox Talbot afterwards improved the process. We cannot enter here into a complete account of photography, but you may form some idea of how the rays of light produce a picture.

When you go to have your photograph taken, the glass plate which is to receive your picture has been bathed in nitrate of silver, with some other chemicals. When you stand in front of it and it is uncovered, a luminous image of your face or body, which has been brought to a focus on the lens of the camera, falls upon the plate, and the chemical rays (which are chiefly those beyond the violet end of the spectrum) decompose the nitrate of silver. You can see nothing when the plate is taken out of the box in which it was placed, but by pouring some more chemicals called protosulphite of iron and pyrogallic acid upon it, the parts which the light has touched all start out in different shades, exactly in proportion as the chemical waves of light have fallen upon it strongly or feebly. It will be exactly the opposite to your real appearance, because where most light has fallen, there the chemicals will be most decomposed and will leave the blackest tints.

Another fluid called hyposulphite of sodium is now 
poured upon the plate to melt away any nitrate of silver which remains, so that when the sun next falls upon it it may not blacken the rest of the plate and destroy the picture. Then the glass plate is again placed in the sun with properly prepared paper under it ; and now the shades are reversed. Under the dark parts of the plate the sun will act feebly on the paper, and produce light patches, while through the light parts it will act strongly and produce shadows. And in this way the lights and shades of your image will appear in their right places on the paper. All this work is done by the chemical rays which are chiefly at and beyond the violet end of the spectrum, and this explains why bright red and yellow objects come out dark in a photograph, because these colours contain so few chemical rays, while the darkest blue and violet come out nearly white, because they act strongly upon the nitrate of silver.

Wollaston first observes the Dark Lines in the Spectrum, 1802. - In the same year that Ritter discovered the chernical rays at the dark end of the spectrum which have given us the whole art of photography, Dr. Wollaston, one of our most celebrated chemists (born 1766, died 1828), first saw the dark lines in the spectrum which have enabled us to discover the actual materials which exist in the sun and stars. Dr. Wollaston, who made many good experiments on light, was one day examining ordinary daylight through a prism, and instead of letting in the light by a round hole in the shutter as Newton had done, he made only a very thin slit, so that the colours of the spectrum were prevented from overlapping each other, as they had done in Newton's experiment. The result was that seven dark upright lines or spaces appeared in the band of colour, which seemed to show that no light fell on those parts. Wollaston did nothing more 
than point out the existence of these lines; but in 1814 Fraunhofer, a German optician, who had heard nothing of Wollaston's experiment, discovered them over again independently, and learnt more about them.

Fraunhofer, 1787-1826.-Joseph Fraunhofer, the son of a glazier, was born in 1787 , at Straubing, in Bavaria. Being left an orphan when quite young, he was apprenticed to a glass manufacturer, who kept him hard at work all day. But he longed so much for knowledge that he borrowed some old books and spent his nights in learning. In the year I 801 the house in which he lived fell down one night and killed all the people in it except young Fraunhofer, and his cries being heard by the people outside, they set to work to try and release him. It happened that Maximiliar Joseph, Elector of Bavaria, came to see the accident, and he encouraged the workmen so much, that in four hours the young man was dug out, wounded, but alive. The Elector was so much interested in this narrow escape, that he gave Fraunhofer eighteen ducats, and the lad used the money to buy himself off from his apprenticeship in order to have some free time for study. After this he lived by polishing lenses, and he worked so well that he soon became the master of a business, and was able to spend his spare time in the study of Physics and Astronomy, which he loved passionately. Finally he became manager of the physical laboratory of an academy in the town of Benedictbaiern, near Munich.

Fraunhofer's Discoveries about the Spectrum, 1814From having been constantly at work as an optician, Fraunhofer had been led to study the subject of light, and among other experiments he repeated those of Newton; and it happened that he too used a narrow slit, as Wollaston had done. 
Thus he also noticed the black lines which divided the colours, and by making his slit very narrow and using prisms of very pure glass he discovered in a ray of sunlight no less than 576 of these black lines. Plate I., No. 2, gives a few of the principal of these, to which he put letters, and which have ever since been called 'Fraunhofer's lines.' As none of these lines appear when the light of a candle or lamp is passed through a prism, Fraunhofer concluded that sunlight must be defective, and some of its coloured rays must be missing. For, as numberless waves of coloured light are passing through the slit and the prism spreads them out so that each set of waves makes an upright image of the slit on the spectrum, if any waves were missing there would be a dark image of the slit instead of a coloured one.

By far the best way of understanding this is to see it for yourself. Sir John Herschel says that a little inexpensive instrument may be easily made with a hollow tube of metal, blackened inside, a prism fixed in it, and a metal plate with a narrow slit fastened across the end of the tube. I have not been able to find so simple an instrument as this; the cheapest sold by Mr. Browning, the famous spectroscope maker, in the Strand, costs twenty-two shillings, and with this you may see the black lines clearly when you turn it to the sun. But if this is not to be had, you may gain some idea of the principle of the dark lines by the following illustration. Colour a strip of paper exactly like the continuous spectrum, No. $x$, Plate I., and then cut it across into very narrowe strips and place them in order side by side on a dark ground ; each strip will represent an image of the slit, and the whole will be a continuous spectrum as before. But now suppose one set of waves to be wanting; take out one of your strips and you will have a dark space. This repre- 
sents one of the black lines in the spectrum where a dark image of the slit is thrown, and if you take out those which correspond to the lines in the sun spectrum No. 2, you will have an illustration of 'Fraunhofer's lines.'

Fraunhofer measured these black lines with the greatest care, and he found that in every ray of sunlight they came exactly in the same places. Then he tried the light of the moon and Venus; still the black lines were the same, for these planets, as you know, only shine by the light of the sun. But, when he turned his telescope to the stars and caught their light, he found a difference. There were dark lines in the star-spectrum, but they were not all in the same place as those in the sun-spectrum, as you will see if you compare No. 2, Plate I., with the star-spectrum, No. 5 , in which the lines seen on the right-hand side of the solar spectrum are entirely wanting.

Fraunhofer, therefore, argued in this way: If the black spaces were caused by some of the waves being stopped in coming through our own atmosphere, they would be the same in any spectrum wherever the light came from. But as these dark spaces are different in the starlight from what they are in the sunlight, there must be some real difference between the light of the sun and the light of the stars before it comes to us. This was the first step in the study of the heavenly bodies by means of spectrum analysis.

Experiments on the Spectra of different Flames, 1822.For more than forty-five years these black lines remained a complete puzzle to all who studied the spectrum, but in the meantime Sir John Herschel, Mr. Fox Talbot, Sir David Brewster, and others, had made many valuable experiments upon the colours produced by different burning lights. You know already that it is possible to make coloured flames by 
burning certain substances. For instance, if you put common salt in a spirit-flame, it will burn with a yellow colour, while a substance called nitrate of strontium will give a brilliant red flame, and is used in making red fire for the theatres. Many other metals and earths, however, tinge the flame so slightly that you cannot see the colour, and it is only by passing the light through a prism that you can detect it.

It had long been known that light from white-hot solids when thrown on a prism produces a continuous spectrum, that is, a coloured band unbroken by any dark lines. A white-hot poker, for example, will give the spectrum No. I, Plate I., and so will burning paraffin, because it contains solid atoms of carbon. But burning gases or vapours do not give a continuous band of colour, they only produce a few bright lines, such as those in Nos. 3 and 4 . You can see this by looking at an ordinary gas flame through Browning's little spectroscope.

Now there is a remarkable peculiarity about these bright lines formed by gases or vapours, namely that they are different for the gas or vapour of cvery different substance. Thus, if you burn any substance containing sodium, a bright yellow stripe will appear as in No. 3 ; while hydrogen will give one red, one blue, and one violet stripe, as in No. 4 . This test is so true and delicate that the eighteen-millionth part of a grain of sodium will give the yellow line; nor does it matter if you burn many substances together, for the vapour of each one will give its own lines without interfering with the others.

It was Sir John Herschel in 1822 who first suggested that by burning substances in a flame, and marking the bright lines which they produced, it would be possible to detect the 
most minute quantities of any metal or earth which they contained, and Mr. Fox Talbot carried out this suggestion in 1834. By this means in the course of time spectroscopists, or men who made the spectrum their study, were able to map out accurately the coloured lines of every known substance ; and what is still more wonderful, new metals were actually discovered by the new lines they threw on the dark band. The first of these two new metals, called Casium and Rubidium, were discovered by Bunsen and Kirchhoff; the third, called Thallium, which throws a beautiful green line, was found by Mr. Croskes; and the fourth, called Iridium, by Richter and Reich. Thus you see spectrum analysis gives us an entirely new and sure way of analysing, or discovering the different elements in any substance.

Bunsen and Kirchhoff explain the Dark Lines in the Sun Spectrum, 1861.-But all this time no one could solve the question of the black lines in the solar spectrum. Sir David Brewster came very near to it once, but just failed to hit upon the truth. ${ }^{1}$ At last, in $186 \mathrm{r}$, only fourteen years ago, Bunsen and Kirchhoff, two celebrated professors of chemistry and physics at Heidelberg, discovered the secret.

These two men had been making a long set of careful experiments upon all the different substances of our globe, burning them and examining their gases one by one, and marking the bright lines of each upon the spectrum. In doing this they did not use one prism only as Fraunhofer had done, but four (see Fig. 52, p. 324), so arranged that the light coming in through a slit at the beginning of the

1 Sir William Thomson states in his address to the British Association in 1871 , that Professor Stokes gave the true explanation of these lines in his lectures at Cambridge in 1851 , although he did not publish anything about it, and his idea was not generally known. 
tube $A$, was spread out more and more through each prism as it passed, and fell in a spectrum on the object glass, c, of the telescope B, through which they examined it. They soon found that in order to mark the exact position of the bright lines of each gas upon the spectrum, they wanted some fixed measure, and it occurred to them that the black lines of the solar spectrum, which never change, would make a good scale with which to compare all the others. So they arranged their spectroscope in such a manner that one-half of the slit was lighted by the sun and the other half by the

FIG. 52.

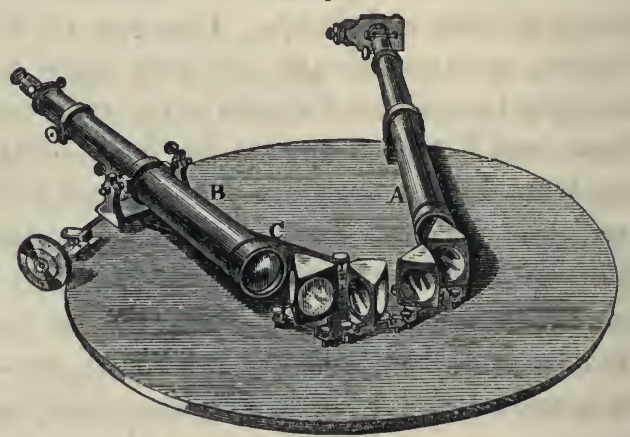

Kirchhoff's Spectroscope (Roscoe).

flame of a gas. In this way No. 2, Plate I., would appear above, and No. 3 , for example, immediately below it.

While doing this they could $n$ t t help remarking that the bright yellow line of the sodium spectrum, No. 3 , was exactly in the same position as the black line, D, in the solar spectrum $;^{1}$ and Kirchhoff found that when he passed a faint ray of sunlight through a flame of sodium (so as to make

1 These lines are really double when seen in a powerful spectroscope, but they appear single in a small instrument. 
the two spectra, 2 and 3, cover each other), the yellow line exactly filled up the black line with its light. He now wished to see how bright he could make the solar spectrum without overpowering the light of the sodium, so he let the full sunshine pass through the sodium flame. To his great astonishment he saw the black line at D start out more strongly than ever. The sodium flame had revenged itself for being overpowered by absorbing some of the yellowe light of the sun!

This suggested to him the idea that the black line $\mathrm{D}$ must be caused by the white light from the sun passing through sodium vapour before it reaches us. There was a very simple way of proving whether this were so ; for burning solids, you remember, give a continuous spectrum ( $\mathrm{I}$, Plate $\mathrm{I}$.), therefore, if he could produce a dark line by passing the light of a burning solid through sodium vapour, he would imitate one of the defects in sunlight. So he burned a lime-light, and when he had the continuous coloured band in his spectroscope, he burned a sodium flame between the limelight and the prism. The experiment was quite successful ; the dark space, $D$, started out upon the spectrum, and thus he proved beyond doubt that burning sodium vapour absorbs in white light exactly those rays which it gives out itself when burning.

He repeated the experiment with other burning metals, such as potassium and strontium, and always with the same result. Each burning gas absorbed in the white light exactly those rays which it gave out itself when burning.

The black lines on the solar spectrum were now explained, for each one of them must imply that some particular ray of sunlight has been absorbed by a gas between the sun and us, and it must have been absorbed near the sun, as Fraun- 
PT. III.

hofer had pointed out, because the lines are different in light which comes from the stars, showing that in that case it has passed through other kinds of gases. Therefore Kirchhoff concluded that round the solid or liquid body of the sun, which gives out white light, and would of itself produce a continuous spectrum, there must be an atmosphere of gases of different kinds, which absorb or destroy particular rays of light, and prevent them reaching us.

If this is the case, it is clear that we can tell from the lines in the spectrum what gases and vapours there are in this solar atmosphere. For example, there must be sodium which cuts off the rays which ought to come to $\mathrm{D}$, and there must be also iron, magnesium, calcium, chromium, potassium, rubidium, nickel, barium, lead, copper, zinc, strontium, cadmium, cobalt, uranium, cerium, vanadium, palladium, aluminium, titanium, and hydrogen, for the bright lines of all these metals are replaced by dark lines in the solar spectrum, showing that the white light from the body of the sun must have passed through their gases.

Dr. Huggins and Dr. Miller examine the Stars by Spectrum Analysis, 1862.-Only a few months after Kirchhoff had proved that the black lines in the solar spectrum reveal to us what elements exist as gases around the sun, two English chemists, Dr. Miller, who died a few years ago, and Dr. Huggins, who is still living, began to try the same experiments with the other heavenly bodies, and the study has since been carried still farther by Mr. Lockyer.

Their instruments were now much more perfect than those which Fraunhofer had used, and they were able to see the effects of our own atmosphere upon sunlight, for when the sun is setting and its light has to pass through a long layer of air bef ore it reaches us, faint lines appear on the 
spectrum, because some light is absorbed by the vapours in our atmosphere. Now, when Miller and Huggins examined the light which comes from Jupiter, they found three or four lines like those caused by our atmosphere, showing that Jupiter must have an atmosphere partly, but not entirely like ours. Mars and Saturn also both showed these atmospheric lines, and so did Saturn's rings, proving that a similar atmosphere must spread over them also. But our moon gave none of them, and this agreed with other evidence in showing that the moon has no atmosphere.

They next passed on to examine the light of the stars, and this was by no means an easy task, because the stars are so far off that their light is very faint and difficult to catch. Nevertheless they proved that round one star, called Aldebaran (No. 5, Plate I.), there must be an atmosphere of hydrogen, sodium, magnesium, calcium, iron, tellurium, antimony, bismuth, and mercury, and you will notice that the last four of these are not found in the sun. In the light of the star Betelgeux, in the constellation Orion, and in another star, called $\beta$ Pegasi, no hydrogen is found, but it is found in all the other stars, together with many other substances. In some of the stars there are besides, lines which are not found by the burning gas of any known substances on our earth.

Dr. Huggins proves that some Nebulæ are Gaseous, 1864.-And now we come to a very interesting experiment. You will remember that astronomers doubted Sir W. Herschel when he suggested (p. 275) that some of the nebulæ are not made of tiny stars, but of gas which is forming into stars. In 1864 Dr. Huggins began to examine these nebulæ with the spectroscope, and he found that they did not give a band of colour with dark lines upon it as the stars do, but a feco faint lines on a dark ground, exactly as 
gases do which we burn here on earth. If you compare the spectrum of sodium (No. 3), or of hydrogen (No. 4), with the nebula spectrum (No.6), you will see at once that the nebula spectrum is made by a gas, and so the truth of Sir W. Herschel's idea was proved, and there can be now no doubt that some of the nebulæ are composed of gaseous matter; chiefly, so far as we can learn, of nitrogen and hydrogen.

Mr. Alexander Herschel examines the Spectrum of Falling Stars. - I have said that it was difficult to examine the spectrum of the stars and nebulæ, but something which to an ordinary observer seems still more wonderful has been lately done. Mr. Alexander Herschel has actually caught the light of falling stars in the spectroscope, and in this way has discovered that some of them give a continuous spectrum, showing that they are solid bodies, while others give a gas spectrum, on which are the bright lines of potassium, sulphur, and phosphorus, but chiefly of sodium.

Such wonderful facts as these about far-distant suns and sun-matter, we have learnt, and are still learning by means of spectrum analysis. The whole study was only begun fifty years ago, and it is in the works of living men that you must look for the details of its history. But though many eminent names are connected with it, those of Fraunhofer and Kirchhoff should always be remembered as the chief founders of the science.

Chief Works consulted.-Roscoe's 'Spectrum Analysis;' 'Edinburgh Review,' vol. cxvi. ; 'Philosophical Magazine,' 1860; Proctor, 'The Sun ;' Tyndall's 'Lectures on Light ;' 'Half-hours with Modern Scientists ;' Kirchhoff's 'Researches on the Solar Spectrum,' 1862; 'Encyclopædia Britannica,' art. 'Optics ;' Ganot's 'Physics ;' Wollaston, 'On Dispersion '- 'Phil. Trans.' 1802 ; Lockyer, 'The Spectroscope.' 


\section{CHAPTER XXXIV.}

SCIENCE OF THE NINETEENH CENTURY (CONTINUED).

Early Theories about Heat-Count Rumford shows that Heat can be produced by Friction-He makes Water boil by boring a CannonDavy makes two pieces of Ice melt by Friction-His conclusion about Heat-How 'Latent Heat' is explained on the theory that Heat is a kind of Motion-Dr. Mayer suggests the Determination of the Mechanical Equivalent of Heat-Dr. Joule's Experiments on the conversion of Motion into Heat-Dr. Hirn's Experiments on the conversion of Heat into Motion--Proof of the Indestructibility of Force, and Conservation of Energy.

Early Theories about Heat.-From Light we will now pass on to Heat, and in this chapter I hope to show you how the philosophers of this century have discovered what heat is. The subject in itself is so vast that a mere sketch of all the men who have worked at it and their chief experiments would fill a volume of this size, and you must clearly understand that we can only select those examples which will best enable you to comprehend the nature of heat, and how it has been determined.

Have you ever asked yourself what heat is, or why the mercury in a thermometer rises when it is put into hot water? The old philosophers considered heat to be a fluid, which passed out of substances when they were too full of it, and which, entering the mercury of the thermometer, swelled it out and made it rise. This was the general idea about heat up to the end of the eighteenth 
century, although Lord Bacon, more than two hundred years before, had suggested that it was not a fluid but a movement, and the philosopher Locke, in the seventeenth century, and Laplace in $\mathbf{1 7 8 0}$, gave the same explanation.

Still most scientific men looked upon heat as a fluid, which they called caloric, until, in the year 1798 , Count Rumford first showed by experiment that it is probably a kind of motion. In following strict chronological order, this discovery ought to have been mentioned at the end of the eighteenth century, but it belongs so intimately to the modern theory that it comes more naturally in this place.

Count Rumford shows that Heat can be produced by Friction, 1798.-Benjamin Thompson, afterwards Count Rumford, was born in the United States in 1753. He spent his early life fighting in the English army against the Americans, in the War of Independence, and afterwards settled at Munich, and became aide-de-camp to the Elector of Bavaria. In 1798 he came over to England, where he was one of the founders of our Royal Institution, and finally he died in Paris in 1844 .

Rumford's inquiries into the nature of heat began in rather a curious way. He was very anxious to make the poorer people in Bavaria happier and more prosperous, and to accomplish this he persuaded the Elector of Bavaria in I790, to forbid anyone to beg in the streets. Those who could not find work for themselves were taken up and kept in a kind of workhouse, where they were given good food and clothing, but were forced to work to pay for their own support. When this law was first passed, there were no less than 2,500 beggars to be provided for, and Rumford was obliged to calculate very closely how he could find food and clothing, heat and light, for the least money. 
Accordingly he studied how fire-places could best be built to prevent coal being wasted, and invented a lamp which gave a brilliant light, without burning so much oil as other lamps did. He even went so far as to make a complete set of experiments on different clothing materials, in order to see which kept in the most heat. It was in this way, and especially in using steam for warming and cooking, that he first began to study the properties of heat, and he became much interested in the different ways in which it may be produced.

It happened one day, when he was boring a cannon in one of the military workshops of Munich, that he noticed with surprise the great heat produced by the grinding of the borer against the gun. You can easily make a similar experiment by boring a hole quickly with a gimlet in a piece of hard wood, and on withdrawing the gimlet you will find that it is hot enough to burn your hand. Rumford examined carefully the gun and the chips which fell from it, and found that they were both hotter than boiling water.

This led him to consider how it could possibly happen, if heat were a fluid, that the mere rubbing of two metals together should produce it; and he tried many experiments to find out whether the gun, the chips, or the borer had lost anything in consequence of having given out heat. But he could not discover that they were changed in any way; and moreover, he found that by going on boring he could make them give out heat as long as he liked, whereas if he had been drawing a fluid out of the metals it seemed to him that it ought to come to an end sooner or later. Then he considered whether the heat could come out of the air, and to avoid this he repeated the experiment under water, but still the metals grew hot, and even made 
the water warm, so it was clear they had not drawn any heat from that fluid.

He now began to suspect that Bacon and Locke might be right, and that the rubbing together of the two metals might set their particles vibrating in some peculiar way so as to cause what we call heat. If this were so, then by great friction he ought to be able to produce any amount of heat, and to prove this he tried the following experiment.

He took a large piece of solid brass the shape of a cannon, and partly scooped out at one end. Into this he fitted a blunt steel borer, which pressed down upon the brass with a weight of ten thousand pounds. Then he plunged the whole into a box holding about a gallon of water, into which he put a thermometer, and fastening two horses by proper machinery to the brass cylinder he made them turn it round and round thirty-two times in a minute, so that the borer worked its way violently into the brass. Now notice what happened: When he began the water was at $60^{\circ} \mathrm{F}$., but it soon grew warm with the heat caused by the friction of the borer against the brass. In one hour it had risen $47^{\circ}$ up to $107^{\circ} \mathrm{Fahr}$; in two hours it was at $178^{\circ}$, and at the end of two hours and a half it actually boiled.

'It would be difficult,' writes Rumford, 'to describe the surprise and astonishment of the bystanders on seeing so large a quantity of water heated and actually made to boil without any fire,' and he adds that he himself was as delighted as a child at the success of the experiment; and we can scarcely wonder, for he had proved the grand fact that motion can be turned into heat.

Rumford afterwards calculated that the friction caused by one horse pulling round the cylinder against the borer 
was sufficient to raise $26 \mathrm{lbs}$. of ice-cold water up to the boiling-point in two hours and a half.

Davy makes Two Pieces of Ice melt by Friction in a Vacuum, 1799.-Only a few months after Rumford had made the discovery that heat can be produced by friction, Sir Humphry Davy, whose history as a chemist you will read in chapter xxxvi., proved the same thing by a different experiment. He took two pieces of ice, and by rubbing them together made them melt without any warmth being brought near them. In this case, as he said, no one could think that the heat came out of the ice, for ice holds less heat than water ; and in order to be quite sure that it did not come out of the air, he made a second experiment. He took a small piece of ice and put it in a machine under an air-pump, by means of which he drew out all the air; then he set his machine to work so that it rubbed against the ice, and in this way he melted the whole lump, without any air being present.

Heat a Vibration. - From these experiments Davy came to the conclusion 'that heat is a peculiar motion, probably a vibration of the corpuscles (that is the little particles) of bodies, tending to separate them.' Thus for example, when you put a saucepan full of water on the fire, the quivering motion which is going on in coals as they burn passes into the iron of the saucepan, and through it to the water. Immediately all the little particles of which the water is composed are pushed asunder as if they were trying to get away from each other; but as they are still held together by the force of attraction, they vibrate to and fro, struggling more and more to get free, and it is this motion which causes in us the feeling of heat when we come in contact with it. Then, if a thermometer be placed in the water, the vibration 
passes on through the glass of the tube into the mercury, and the particles of mercury are also set in motion, and so the mercury swells and rises in the tube.

The cause of Latent Heat explained.-And now, if you will look back for a moment to chapter xxviii., and read again about the 'latent heat' which puzzled Dr. Black so much, you will see how beautifully it can be explained by this theory that heat is a kind of motion. You will remember that, however much heat he put under a piece of ice he found that the temperature of the water would not increase above $0^{\circ}$ Cent. so long as a morsel of ice remained unmelted; and again, that boiling water never grew hotter than $100^{\circ}$ Cent., while it was being turned into steam. Now if we look upon heat as a vibration, we can understand that the motion which is sent into ice from the fire below, will all be employed in overcoming the force of attraction and separating the particles of ice so as to turn the solid into a fluid, and it will only be when the last particles are free that there will be any movement to spare so as to produce the quivering motion of heat. Then if you go on heating the water still more, the struggling movement will continue between the force of attraction and the force of motion, and so the water will grow hotter and hotter, till at last at $100^{\circ}$ Cent. the force of motion wins the battle, and the little particles fly asunder and float away as steam; and from that moment all the extra movement is employed in forcing asunder particle from particle, till all the water has passed away in vapour.

It was for this reason that Watt had to use so much more cold water to cool down steam of $100^{\circ}$ Cent. than to cool down water of $100^{\circ}$ Cent.; for in cooling down steam he had not only to get rid of the quivering motion 
of heat, but of all the extra force which was holding the particles asunder.

Dr. Joule's Experiments on the Conversion of Motion into Heat, 1849.-It had now been shown that motion could be turned into heat, and Rumford had even calculated roughly how much heat was caused by a certain amount of motion. But when a horse walks round and round you cannot measure how much strength he gives out, and in order to prove that motion by itself can produce heat we must measure exactly how much motion produces a definite quantity-say $\mathrm{I}^{\circ} \mathrm{Fahr}$. of heat, and then see if that amount of heat can be turned back again into motion. This was done by Dr. Joule, of Manchester, a celebrated physicist, who is still living.

In 1839 a Frenchman named M. Séguin, and in 1842 a German physician, Dr. Mayer, of Heilbronn, both suggested that by careful experiments it might be found out how much work must be done to produce a certain quantity of heat, and Dr. Mayer made many calculations about it. In I 843, without having heard of Dr. Mayer's suggestion, Dr. Joule began those famous experiments which have formed the foundation of the dynamical theory of heat, or the theory of heat produced by motion, and he completed them in 1849 . A description of one of his experiments will explain the results he obtained. He took a weight, A, Fig. 53, which weighed I lb. and fastened it by strings to the roller, $f f$. On to the wheel, B, of this roller he wound another string which passed round the roller $r$, and this roller was attached to a paddle which was shut into the box of water, c. He next wound up the string on the roller $f$, so as to draw up the weight $\mathrm{A}$, and then set it free. Immediately the force of gravity drew the weight down to the ground, and in doing so 
PT. JII.

pulled round the wheel $\mathrm{B}$, and consequently the roller which turned the paddle in the water. When the weight reached the ground he took out the little pin, $p$, which fastened the paddle to the roller, so that he could wind up his apparatus without disturbing the water and begin again.

Now observe how this measured the motion and the heat. Every time the weight fell, it turned the paddle, and so, by agitating the water, added to its heat. The scale, D, told him exactly how far the weight fell, while the thermometer, $t$, in the box told him how much hotter the water grew. At the end of an hour, therefore, he had only to see how many feet his pound-weight had fallen, and how many degrees of Fahr. the heat of his water had risen; and after allowing for the friction of his machinery and for the heat lost in the cooling of his vessel, both of which he ascertained by careful experiments, he could tell how much motion had been used up in producing the heat. In this way he found that a weight of $\mathrm{I} l b$. would have to fall 772 feet in order to make $\mathrm{I}$ lb. of water warmer by $\mathrm{I}^{\circ}$ Fahr.

$\mathrm{He}$ next tried the same experiment with oil and with mercury instead of water, and also measured the heat produced by rubbing together two plates of iron ; and in every case he found that a certain amount of work gave a certain amount of heat and no more. For example, if the weight in Fig. 53 fell double the distance, the heat of the water was raised two degrees instead of one, while if it fell only half the distance, or 386 feet, the water was only raised half a degree.

In this way Dr. Joule established what is called the mechanical equivalent of heat, namely that the fal! of a pound weight through 772 feet equals the heating of a pound of water $\mathrm{I}^{\circ} \mathrm{Fahr}$. And now you must try to for $\mathrm{m}$ a clear idea what this means, and how it proves that heat is altered 
motion. Looking at the diagram, try to picture to yourself what would be taking place if the weight was able to fall the whole 772 feet without stopping. First, a man must wind up the weight, and in doing this he uses force to overcome the force of gravitation which is pulling the weight down to the earth ; so that the machine starts with a certain stock of force stored up in the weight, and its amount is called 772 foot-pounds because it has raised a weight of

Fig. 53.

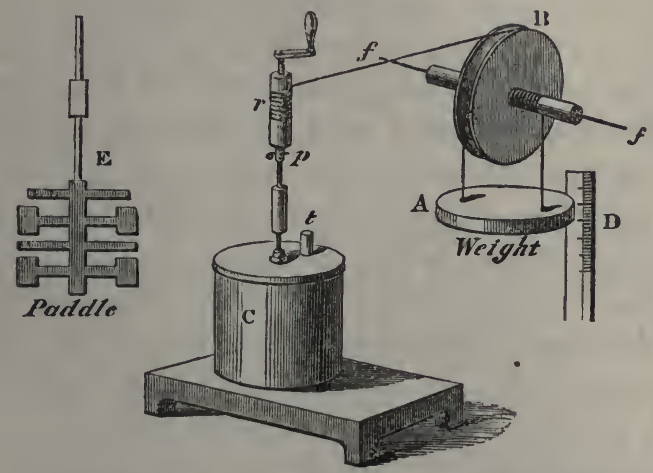

Joule's Experiment on the Conversion of Motion into Heat (Phil. Trans).

A. Weight. $\quad$, Wheel of the roller, $f f$. c, Vessel containing water and the paddle. $\mathrm{D}$, Scale to measure the distance that the weight falls. E, Paddle contained in the vessel, c. $f f$. Roller turned by the falling weight. $r$. Roller turning the paddle. $p$, Pin which joins the roller and the paddle. $t$, Thermometer plunged in the vessel, $c$.

I lb. to a height of 772 feet. This stock of force philosophers call potential energy, or possible energy which may be called into use at any time. When the man sets the weight free, it begins to fall, drawn down by the force of gravity, and the stock of energy is set free. What becomes of it? It passes by the wheel $\mathrm{B}$ into the roller $r$, and, turning the paddle in the box, enters the water. If the water were free, 
it would pass on into the air and we should lose sight of it ; but the water is shut in and the force cannot escape, so now it employs itself in dashing to and fro all the little particles which make up the water, and producing the effect we call heat; and as it produces exactly $\mathrm{I}^{\circ} \mathrm{Fahr}$. of heat by the time the $\mathrm{I} \mathrm{lb}$. weight has fallen 772 feet, we say that $77^{2}$ foot-pounds of force equals $\mathrm{I}^{\circ}$ Fahr. of heat. You might easily prove to yourself in a somewhat unpleasant way that the force is there; for if you were to go on turning the paddle violently for many hours, and there were no means for the heat to escape, the motion of the particles would be so violent against the sides of the boiler that it would burst.

Hirn's Experiments on Heat converted into Motion. -If you have understood this explanation, you will have some idea of the theory that heat is altered motion; but to complete the history we require not only to turn work into heat, but also to turn heat into work. This had already been done many years before by a French engineer, $M$. Carnot, though he did not understand its real significance, but it has now been most beautifully proved by a long series of experiments made by M. Hirn, of Colmar, in Alsace. What M. Hirn practically did was to find out how much heat can be obtained from a ton of coals, and then to find out how much work was performed in an engine by that amount of heat. This was by no means a simple task, for much heat is lost in various ways in passing through the engine; and even when he thought he had allowed for all this, it was found that some of the steam had turned back into water on its way, and thus used up some of the heat. At last, however, when all was carefully measured and calculated, he found that for every pound of water heated $1^{\circ}$ Fahr., enough reork had been done to raise a weight of I lb. to a 
height of 772 feet. This, you will notice, was exactly the converse of Joule's experiment, and proved that exactly as much motion is produced by means of confined heat as there is heat produced by means of checked motion.

Conservation of Energy.-And thus we arrive at one of the grandest discoveries of modern science, namely, that the whole amount of energy, or power of doing work, possessed by any set of bodies, remains unaltered whatever transformations it may undergo. - It may exist in onẹ of two forms-either as potential or stored-up energy, which is unseen by us, or as visible energy, when it is actually performing work ; but while it changes from one form to another its amount never alters. Thus in Joule's experiment the energy stored up in the weight which had been pulled up 772 feet was gradually transformed, as soon as the weight was released, into an amount of heat capable of raising the temperature of a pound of water $\mathrm{I}^{\circ}$ Fahr. ; while Hirn showed, on the other hand, that exactly this amount of heat can be turned back into enough energy to raise a weight to the height of 772 feet at which it stood before.

The potential energy, or power of doing work, remained, therefore, exactly the same whether it was stored up in the weight or in the hot water, and reproduced exactly the same amount of visible energy or actual work. And even though we know that practically some energy disappears at every part of a machine when it is at work, yet this is not lost ; for it turns into heat wherever it disappears as motion. If you grease the wheels of a machine, you will detect this heat beginning to do work again by turning the solid grease into a liquid.

By whatever means, therefore, heat is turned into motion, or motion into heat, the energy which causes them both 
remains the same, and this is one out of many proofs that force cannot be destroyed, but is only lost in one form to reappear in another.

Other Experiments on Heat--Although the experiments and calculations which have proved heat to be a kind of motion are some of the most interesting which have been made of late years, yet they are by no means the only ones. In 1811 Sir John Leslie carried on a most interesting series of observations on the reflection of heat; and the Italian physicist Melloni has traced the whole passage of heatrays through different solid bodies. All these discoveries are clearly and simply described in Professor Tyndall's work on 'Heat,' where you may also find the great additions that he has himself made to the work of these men.

We must content ourselves here with remembering that the physicists of the nineteenth century have shown that heat is 'a mode of motion,' and have traced it through all its many wanderings both in earth, air, and sky. They have even followed it from the sun down to our earth, through the plant-world into the beds of coal which are stored up in our rocks, and back again, when this coal is burnt, to the motion which carries our steam-engines and steam-ships across the world. All this lies before you to study in books of science, but now we must pass on to new discoveries in two remarkable sciences, namely, electricity and magnetism, which, we shall find, are closely bound up with heat and motion.

Chief Works consulted. - Rumford's 'Essays,' vol, ii._ 'Friction a Source of Heat,' 1798 ; Davy's 'Works,' vol. ii._- Essay on Heat and Light ;' Joule's 'Mechanical Equivalent of Heat '- 'Phil. Trans.,' 1850; Mayer's 'Forces of Inorganic Nature'-'Phil. Mag.,' 1843; Tyndall's 'Heat a Mode of Motion;' Watts's 'Dict. of Chemistry,' art. 'Heat ;' Clerk-Maxwell's 'Theory of Heat.' 


\section{CHAPTER XXXV.}

SCIENCE OF THE NINETEENTH CENTURY (CONTINUED).

Oersted discovers the effect of Electricity upon a Magnet-Electromagnetism-Experiments by Ampère on Magnetic and Electric Currents-Ampère's Early Life-Direction of the North Pole of the Magnet depends on the course of the Electric Currents-Magnetic Currents set up between two Electric Wires - Electro-magnets made by means of an Electric Current-Arago magnetises a Steel Bar with an ordinary Electrical Machine-Faraday discovers the Rotatory Movement of Magnets and Electrified Wires-Produces an Electric Current by means of a Magnet-Seebeck discovers Thermo-electricity, or the production of Electricity by HeatSchwabe discovers Periodicity of the Spots on the Sun-Sabine suggests a connection between Sun-spots and Magnetic Currents-This proved in 1859 by observations of Carrington and HodgsonElectric Telegraph - Wheatstone - Cooke - Steinheil - Morse-Bain.

Oersted discovers the Effect of Fl ctricity upon a Magnet, 1820. - We left the history of electricity at p. 264 , at the point where Volta had shown in 1800 that two different metals joined by a wire and placed in acid and water will set up two currents of electricity flowing in opposite directions from one metal to the other along the wire, and back through the water. Every galvanic battery, that is, an apparatus for producing electricity by chemical action, is made on this principle. You will hear of Grove's battery, Bunsen's battery, Daniell's battery, and many others, all of which have been invented in the present century; but all 
these are only different and more perfect methods of carrying out Volta's discovery. The next great step in the study of electricity was made by Oersted, Professor of Physics at Copenhagen, in 1820 , twenty years after the invention of the voltaic pile.

Hans Christian Oersted was born in 1777 , and died in $185 \mathrm{I}$; he was a very eminent man, and wrote many works in Latin upon chemistry and magnetism, but the one discovery which has made him famous was that of electro-magnetism. We have seen (p. 53) that the invention of the mariner's compass in the fifteenth century arose from Flavio Gioja noting that a needle which has been rubbed along a piece of loadstone always points north and south. But why should the needle lie in this direction? What force makes it turn round when you leave it free after placing it another way? Ever since the fifteenth century people had asked this question, and when Volta and Franklin showed that electrical currents are constantly passing to and fro in our atmosphere, scientific men began to consider whether it might not be some force like electricity which acted upon the magnet ; especially as it had been observed that when a ship was struck by lightning, the needle of the mariner's compass was sometimes thrown quite uut of its right position.

Still nothing was really known until the year 1819 . In that year, when Professor Oersted was one day making some galvanic experiments at a lecture, it happened that a magnetic needle poised upon a point (as in Fig. 54) was standing near the wire along which an electric current was passing. All at once, when the current was very strong, the needle became excited and began to turn round upon the point. Oersted and his assistants were much surprised at this, and the consequence was that for several months Oersted made 
a series of experiments by which he proved that an electric current passing near a magnetic necdle will aiway's make it turn round so as to lie ACROSS the path of the current.

For example, if the bar of copper wire $a b$, supported on the glass rods $e, e$, be so placed that the end $b$ points to the north and $a$ to the south, then the magnetic needle $c$ will lie exactly in a line with the bar, because a magnet always points north and south. But if the two ends of the copper $\operatorname{rod} a, b$, are fixed to the wires of a voltaic battery $d$, Fig. 54 , so that an electric current runs along the $\operatorname{rod}$ from $a$ to $b$, then the north end of the needle will begin to move away from the north towards the west, that is towards the left sidc

Fig. 54.

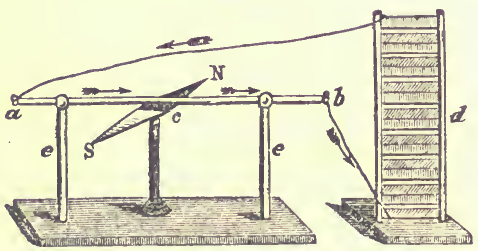

Magnet turned by an-Electric Current.

$a b$, Rod of copper wire. c, Magnetic needle. $d$, Voltaic pile (explained p. ${ }^{2} \sigma_{3}$ ). $e$, Glass supports to prevent the current runining down to the ground.

of the current ; and it will turn more and more as the current grows stronger, till it lies right across it, pointing direct east and west.

This was a very grand fact, and it has become the beginning of a new science called electro-magnetism, for it shows that electricity and magnetism act upon each other in some peculiar way. Oersted did not publish an account of his experiments until 1820, and then the whole of Europe rang with the news of the discovery.

Ampère, 1775-1864.-One of the first men who heard 
of it was Ampère, one of the professors at the Ecole Polytechnique in Paris. We must pause a moment to learn something of the early history of this man, for it is very interesting. André Ampère was born at Lyons in 1775 . When he was quite a little boy he delighted in arithmetic, and used to do long sums for his amusement by means of little pebbles which he arranged in groups. Once when he had a severe illness his mother took the stones away, but, having left him alone one day for a little time, she found on her return that he had broken his biscuit into little bits and was using them to work with instead of his lost pebbles. As he grew older his father began to teach him Latin, but the boy disliked it so much that it was given up, and he devoted all his time to Algebra and Euclid.

One day he persuaded his father to take him to his friend, the Abbé Daburon, to borrow the writings of Euler and Bernouilli, two great mathematicians. The Abbé stared at this little boy, only twelve years old, asking for books which very few men could understand. 'Do you know, my little fellow,' said he, 'that these works are written in Latin, and that the differential calculus is used in them?' André's countenance fell for a moment, for he knew neither of these things. But he soon brightened up again. 'Never mind,' he replied, 'I can learn them,' and he set to work that very day to learn Latin with his father, and the differential calculus with the Abbé, and in a few months was able to come back for the books he coveted.

Before he was eighteen he had not only read the whole of Laplace's 'Mécanique Céleste,' but had even worked out all the complicated problems in it. He had, however, overtaxed his brain, and when his father was killed in the terrible French Revolution of $\mathrm{I} 793$, the grief broke down his 
intellect. For a whole year he was almost an idiot, and it was a long time before he could take up his mathematical studies again. When he did, it was with his old love of work, and he became a teacher first at Lyons, and afterwards in Paris.

\section{Ampère's Experiments upon Magnetic and Electric} Currents, 1820. - This was the man who heard of Oersted's discovery in 1820 . You can imagine the delight with which he seized upon the new idea. He worked at it incessantly, as he had done with his pebbles when a boy, and before a week was over he had proved several new facts about electromagnetism. He found that it was quite true as Oersted had said, that the magnet always lies across the electric current; but he showed that the north pole of the magnet turns different ways, according to the direction in which the

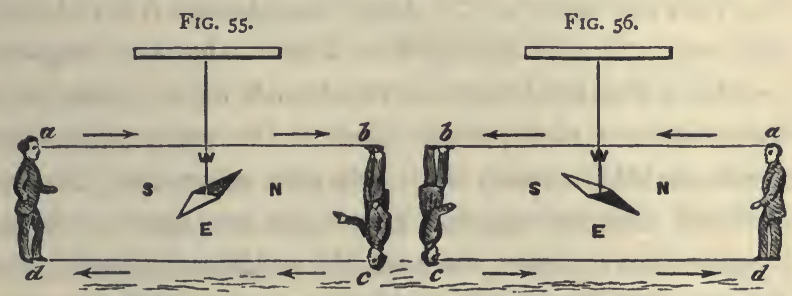

Diagrams showing the direction of a Magnet acted upon by Electric Currents. $a, b, c, d$, Direction of current.

current flows. Thus, if the current ${ }^{1}$ flows from south to north above the magnet, in the direction $a b$, Fig. 55, then the north pole of the magnet turns towards the west; but if it runs from north to south above the magnet, in the direction

1 You must bear in mind that there are always two currents, one from the negative and the other from the positive pole of the battery; but to avoid confusion the positive current is always spoken of as the current. 
$a b$, Fig. 56 , then the north pole turns towards the east. Again, if it runs from north to south below the magnet, in the direction $c d$, Fig. 55, the magnet will again turn to the west ; while lastly, if it runs from south to north below the magnet, $c d$, Fig. 56 , the north pole turns again to the east. In order to remember these different directions easily, Ampère gave something like the following rule. If a man will imagine himself to be standing so that the positive current would come out of his mouth and return by his feet, the north pole of the magnet will always be on his left-hand side. If you are fond of standing on your head, and will try the positions in Figs. 55 and 56 , you will see that this is so-the north pole of the magnet will always be towards your left hand.

\section{Magnetic Currents set up between two Electric Wires.-} The next discovery which Ampère made was a very important one. It was already well known that two magnetic needles will either attract or repel each other according to the position of their poles. Thus, if the north pole of one needle is held towards the south pole of another, they are attracted strongly together, but if the two north poles are brought near together, the movable needle is repelled. Now Ampère argued that if an electric current always causes a magnetic current across itself, then two electric wires side by side will have magnetic currents running across them, and they ought to attract or repel each other as if real magnets were lying between them. And this he proved to be true. $\mathrm{He}$ put two wires side by side in such a position that they could move freely, and when he sent an electric current in the same direction through each of them they moved towards each other; while, if he sent the currents one way through one wire and the other way through the other, they drew 
apart; exactly in the same way as magnets attract or repel each other, according to the direction in which they lie.

This may be difficult to understand without more explanation, but you can remember that Ampère proved that electric currents produce magnetic currents at right angles to themselves in the air, without needing any bar of steel to help them.

Electro-magnets made by means of an Electric Current. -It now occurred to Ampere that if electric currents give rise to magnetic currents he ought to be able to magnetise a steel bar by passing an electric current round it. So he wound a copper wire (covered with silk to prevent the electricity running into the iron) round a steel bar, and, fastening the two ends of wire to a voltaic battery, he passed a current through it (see Fig. 57). After a short time he took

FIG. 57 .

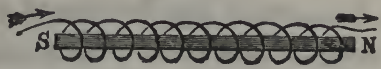

Coil of Electrified Copper Wire turning a Steel Bar into a Magnet.

the bar out and found it was a porfect bar magnet, which would attract iron. The current of electricity, in passing along, had magnetised the steel just as if it had been rubbed on a loadstone.

Steel is very close and hard, and when he used a steel bar the magnetism remained after it was taken out of the electric wire, but if he used a piece of ordinary soft iron the magnetism passed away when the current ceased. He called these magnetised bars electro-magnets, because they are made by electricity. You can easily make them for yourself, and you will find that an iron rod will hold up needles, nails, or even keys as long as the current is passing, but they will all fall off as soon as it stops, showing that it is the electric current which causes the iron to act as a magnet. 
Professor Arago, whom we mentioned before (p. $3 \mathrm{II}$ ) as making experiments on light, succeeded in magnetising a steel bar with currents from an ordinary electrical machine, that is, a glass cylinder rubbed against silk, instead of using a battery.

Michael Faraday, 1791-1867.-We must now travel back to England, where one of our greatest philosophers was watching these new discoveries with intense interest. Michael Faraday, the son of a poor journeyman blacksmith, was born at Newington Butts in 179r. When he was thirteen years old he went as errand boy to a bookseller named $\mathrm{Mr}$. Rieban, in Blandford Street, Manchester Square, and it was there that the books fell into his hands which first awoke his love of science. Mrs. Marcet's 'Conversations on Chemistry,' Lyons's 'Experiments on Electricity,' and other books of a like kind made the lad long for more knowledge about these wonderful sciences. He constructed an electrical machine, and spent his evenings in making experiments, and he persuaded his brother Robert to pay a few shillings for him to attend some lectures given by a Mr. Tatum on Natural Philosophy.

But one of the first great pleasures of his life was when a customer at the bookshop, a Mr. Dance, took him to four lectures at the Royal Institution, given by Sir Humphry Davy. These lectures filled him with an intense longing to learn more, and he took the bold step of writing a letter to Davy, enclosing the notes which he had made of the lectures, and asking for some employment connected with science. It will always be remembered to Davy's honour that he did not throw this letter aside, but wrote a kind reply, telling the young man to come and see him, and in the end made him his assistant at the Royal Institution 
in Albemarle Street, where Faraday afterwards became Professor of Chemistry.

It is impossible in a short sketch to give you any idea of the simple and noble nature of the man who from that time for more than fifty years laboured at science in the Royal Institution. It is not yet eight years since he died, and you may talk with many who have known and loved him, and if you wish to learn the story of his life you must read it in the book called 'Michael Faraday,' written by Dr. Gladstone. Even of his experiments we can only mention a few, for these subjects are becoming almost too deep for us; but those which we must now consider were some which have helped to make his name famous.

Faraday discovers the Mutual Rotation of Magnets and Electrified Wires, 1821.-It was in $\mathrm{I} 82 \mathrm{r}$ that Faraday began to repeat for himself Ampère's experiments on electricity and magnetism, and he soon saw that if an electric current going round a wire gave rise to magnetic currents at right angles to it, he ought to be able to make an electric wire revolve round a magnet, and a magnet round an electric wire. Accordingly, he took two cups of mercury, A B, Fig. 58 , p. $35^{\circ}$, and drilling a hole in the bottom of each, he passed the wires $e, e^{\prime}$, of a battery up into them; then he took two magnets $d, d^{\prime \prime}$; $d$ he fastened by a thin thread to the battery wire in the cup $\mathrm{A}$, so that it floated upright in the mercury, and the top of it could move round easily ; the other magnet, $d$, he fixed firmly upright in the cup B. $\mathrm{He}$ then hung the copper rod $\mathrm{C}$ above the cups, so that the end $f$, which was fixed, dipped into the cup A, and the other end, which was made of a loose moveable wire, $f^{\prime}$, dipped into the cup B. Thus in A the magnet was free to move and the wire was fixed, while in $\mathrm{B}$ the wire was free to move 
and the magnet was fixed. He now sent a current through the wires $e, e^{\prime}$, and immediately in the cup A the magnet $d$ began to move round the fixed wire $f$, while in B the wire $f^{\prime}$ moved round the fixed magnet, $d^{\prime}$. In this way he proved that magnetic and electric currents move round and round in circ'es at right angles to each other. He made the magnet go

Fig. 58.

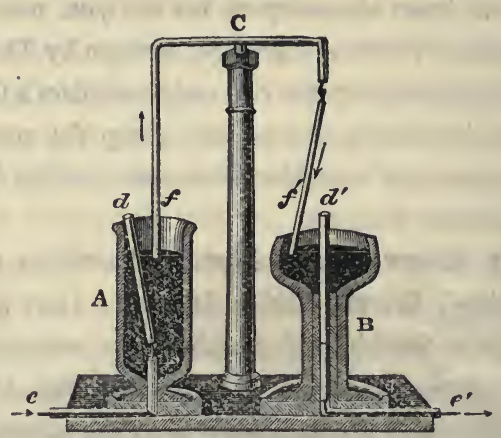

Faraday's Experiments on the Rotation of a Magnet and of an Electric Wire (Brande).

A B, Section of cups of mercury. C, Copper rod. The current coming in at e passes up through the mercury in $\mathrm{A}$, and along the rod $\mathrm{C}$ down into the mercury in $\mathrm{B}$, and back by $d^{\prime}$ to the battery. On its way it causes the floating magnet, $d$, to revolve round the rod, $f$, and the loose wire, $f$, to revolve round the fixed magnet, $d$.

a great way round the circle, but not spin quite round as the wire had done. Ampère, however, who repeated the experiment, succeeded in making the magnet spin round and round like the hands of a clock.

Electric Current produced by means of a Magnet.Faraday's mind was now full of the wonderful effect which. electricity and magnetism produce on each other, and he began to consider whether it might not be possible to reverse Ampère's second experiment (p. 347), and instead of making a magnet by means of an electric current, whether he might not set up an electric current by means of a magnet. 
To try this he wound from 200 to 300 yards of wire round a hollow cylinder $a$, Fig. 59, and carried the two ends of the wire to a little instrument $b$, called a galvanometer, which was invented by Ampere, and the needle of which moves directly the slightest current passes through it. He then took a powerful bar magnet, $c$, and held it within the cylinder. The moment he put it in, the needle of the galvanometer showed that an electric current had passed through

FIG. 59.

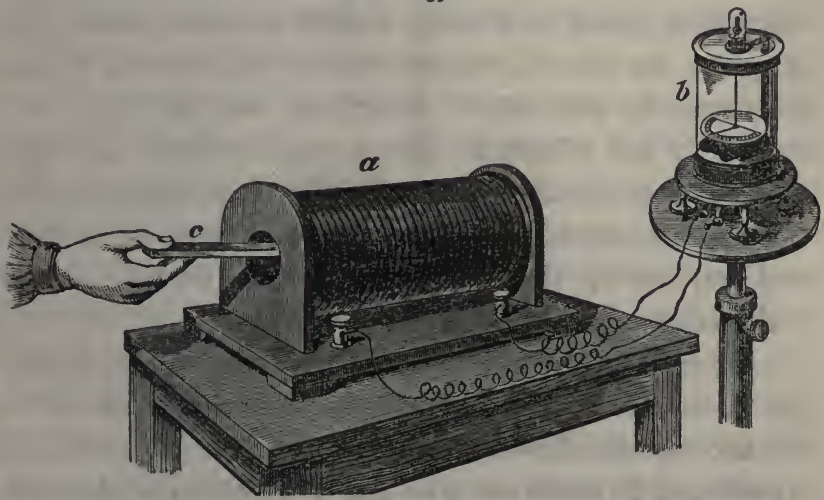

Faraday's Experiment on creating an Electric Current by means of a Magnet (Ganot).

a, Coil of wire round a wooden cylinder connected at the two ends with $b$, a galvanometer, the needle of which shows directly a current passes through the wirc; $c$, a powerful magnet.

the wire in one direction, and the moment he drew it out another rush of electricity occurred in the other direction, showing that the magnet had set up an electric current in a coil of wire. While the magnet remained in the cylinder there was no current ; it was only at the moment of going in and coming out that it produced the effect. By a more complicated apparatus Faraday succeeded in making these currents strong enough to produce electric sparks; and it is 
on this principle that the induction-coil is made which is now used to increase the power of the electricity coming from an electric battery.

Professor Seebeck discovers Thermo-electricity, or the Production of Electricity by Heat.-The fact was now clearly established that electric and magnetic currents move at right angles to each other, and this gives to a certain extent the answer to our question. Why does a magnet turn to the north? Ampère suggested quite early in the discussion, that if an electric current will turn metals into magnets, the electric currents which we know are flowing from east to west round our globe, may turn the earth (which is full of metals) into a great magnet. But it is also true that exactly the opposite effect is possible, and that the magnetic currents may be started by some other cause and may set up the electric currents, so that we do not really know which gives rise to the other.

An interesting discovery was, however, made in 1822 by Professor Seebeck, showing a possible cause of the electric currents flowing from east to west. He wished to try whether he could not give rise to a current of electricity in two metals by merely using heat instead of acid and water. For this purpose he took a half ring of copper and fastened to it a bar of a metal called antimony, so that the two metals had the form of a stirrup, and inside this stirrup he hung a magnetic needle, which would show if any current passed along the metals. Then he heated one of the corners where the metals joined, and immediately the magnet began to turn, showing that an electric current was passing through the copper, and back through the antimony. He tried this with many other metals, and in every case when one of the parts where they joined was made hotter 
than the rest, a current of electricity was caused. This he called thermo-electricity, or electricity caused by heat, and it gives us another beautiful instance of the transformation of energy. We saw in chapter xxxiv. that heat is altered motion and motion altered heat; since then we have learnt that electricity produces magnetism and magnetism electricity, and now we have heat in its turn causing electricity, while we know from the electric spark that electricity produces both light and heat. In all these changes we see additional proof that force or energy cannot be destroyed, but only exhibits itself in different ways.

But to return to the magnet. Seebeck's experiment suggests a possible answer to the direction of the magnetic needle to the north. Our globe is composed of different metals and earths, and is always turning round from west to east, so that one part after another comes under the heat of the sun, and is made hotter than the rest. Therefore, since heat produces electricity, it has been suggested that this may cause the electric currents to flow round from east to west, as they did through the metals in Seebeck's stirrup, thus inducing magnetic currents to flow round from north to south. Our knowledge on this subject is, however, very imperfect, and the observations of which we shall next speak seem to point to some closer connection between the sun itself and magnetic currents.

Periodicity of the Spots on the Sun, and their Effect on the Earth's Magnetism, discovered by Schwabe and Sabine, 1825-1859.-It was mentioned at p. 92 that Galileo and other astronomers of the seventeenth century first observed that from time to time dark spots appear on the face of the sun. These spots were much studied by the astronomers who came after Galileo; but Sir William Herschel was the 
first to suggest in 1793 that they are caused by the opening of bright luminous clouds which float round the sun, and break away sometimes in one place and sometimes in another, allowing us to see down through the gap into the body of the sun itself, which thus has the appearance of a dark spot. This is the explanation now received by astronomers as most probable, and it accounts for the constant appearance and disappearance of the spots.

In the year i826, a well-known German astronomer, Herr Schwabe, of Dessau (who died in 1874 ), determined to take regular notes of the periods when there were most spots to be seen on the face of the sun. Every day during twelve years, when the sky was clear enough for him to observe the sun, he examined it through his telescope, and noted how many spots he could see.

In this way he discovered that there was a regular decrease in the number of spots for about five years and a half, and then during the next five and a half years a gradual increase, till they were very numerous indeed. This led him to think that the spots went through a complete round or cycle of changes in about eleven years ; but as he found it difficult to persuade other astronomers of the fact, he actually carried on his daily observations for twenty years longer, and then, at the end of thirty-four years of daily observation, he was able to assert boldly that he had established the truth of his theory.

He had now kept an account of three periods of eleven years. At the beginning of each of these periods the sun was for some time smooth and almost free from spots ; then from year to year they increased, till, at the end of five and a half years, as many as fifty or sixty could be seen at one time. Then they decreased again till, at the end of another 
five and a half years, the sun's face was comparatively smooth and spotless. During the time that Schwabe was studying these changes, other men in the different observatories of Europe had noticed some remarkable peculiarities about the magnetic needle. As long ago as 1722 , a famous astronomer named Graham pointed out that the magnetic needle shifts from side to side a little every day as the sun passes from one side to the other of the globe. The movement is so small that it cannot be seen without very accurate instruments, but it shows that the sun's course does affect the magnet; and when very careful notes began to be made in different observatories, it was noticed that this daily shifting was greater some years than others. In $185^{\circ}$ an astronomer named Lamont, of Munich, pointed out that the movement became greater each year for about five and a half years, and then grew less during the same period; this led Sir Edward Sabine to suggest that perhaps the spots on the sun had something to do with the magnetic currents, since they both went through a regular cycle of changes in about eleven years.

And now comes a curious proof of the truth of this theory. In September 1859, when a famous sun-gazer, Mr. Carrington, was observing and measuring the spots on the sun, he suddenly noticed a bright spot break out on the sun's face ; and fortunately another observer, Mr. Hodgson, who was in another part of England, saw this same spot at the same moment. The whole time from the appearance till the disappearance did not exceed five minutes, but when inquiry was made, it was found that the three magnetic needles at Kew, which keep a register of their own movements, had all been jerked strongly exactly at this time. Nor was this all : the magnetic currents passing through our 
atmosphere at that moment set up such strong electric currents in the wires of the telegraphs all over the world, that the signalmen at Washington and Philadelphia received severe electric shocks; a telegraphic apparatus in Norway was set on fire, and a stream of electric light followed the pen of Bain's electric telegraph, which writes down the message on chemically prepared paper. Moreover, beautiful auroras were seen in both hemispheres, and these brilliant lights are believed to be caused by magnetic currents. The magnetic storms on this occasion lasted for several days, and there could no longer be any doubt that the sun at a distance of nearly 92,000,000 miles can produce a complete hurricane of magnetic disturbance on our earth. This connection of the storms with the sun-spots seems indeed, as I have said, p. 353, to suggest that the sun must have the power of producing magnetic currents in some more direct way than merely through the action of electric currents set up by the varying heat on different parts of the earth:

\section{Invention of the Electric Telegraph by Wheatstone and} Cooke, 1837. - We have spoken in the last paragraph of the electric telegraph, and though this is more strictly an invention than a step in science, yet we can hardly close an account of electricity and magnetism without showing how the discovery of these two forces has made it possible for our thoughts to be carried in a few moments of time across land and sea to the most distant parts of the world.

Ever since Volta showed, in 1800 , that an electric current can be sent for any distance along a wire the two ends of which are joined to the poles of a battery, scientific men had speculated whether it might not be possible to use this current for making signals at a distance. But there was always the difficulty of how to make the signs at the other 
end. In 1816, Mr. Ronalds, of Hammersmith, hung pithballs on to a wire, which stood out while the current was flowing, and fell down again when it ceased; and many other such plans were tried, but none succeeded well.

When Oersted, however, showed in 1819 that an electric current will cause a magnetic needle to turn from side to side, it was clear that here was a means by which signs could be made at any distance; and accordingly we find that Ampère, in $183^{\circ}$, proposed to work signals by a magnet, and different attempts were made in Europe and America to carry out his idea. The first electric telegraph of any value was patented by Professor Wheatstone and Mr. Cooke in June 1837; and during the same year Dr. Steinheil, of Munich, and Professor Morse, of America, both invented telegraphs of rather different kinds. I shall not attempt to describe all of these, but will only explain the simplest principle of an electric telegraph as it is used in England, and to show how it depends upon electricity and magnetism.

You will see, if you turn back to Figs. 55 and 56, p. 345, that when the electric current flowed round one way, $a b c$ $d$, Fig. 55 , the north pole of the needle turned to the west ; when it flowed round the other way, $a b c d$, Fig. 56 , the north pole turned to the east. Now the signals of the electric telegraph depend upon this fact, that the direction of the current alters the direction of the magnet. When one man wants to send a message to another, he does it by sending an electric current from a battery along a telegraph wire, so that it passes a magnetic needle either from right to left or from left to right. When it flows round one way, the needle, even if it is a hundred miles off, turns to the right, when it flows round the other way the needle turns to the left ; and it is agreed that so many strokes to the right mean one 
letter, and so many to the left another letter, and in this way a message can be spelt out, however far off the two men may be.

This is the whole secret of the electric telegraph; but to understand how it works you must follow the explanation of the two diagrams (Figs. 60 and 6r), very carefully. Suppose that a message is going between London and York, four things are wanted to convey it:- $-\mathrm{I}$. A battery to produce an electric current. 2. A wire to carry the current. 3. A galvanometer, that is a box, $\mathrm{A}, \mathrm{A}^{\prime}$, holding a magnetic needle to make the signs. 4. A little box called a commutator, B, B', in which the position of the wires can be changed so as to send the current first one way and then another.

I. The battery is an ordinary chemical battery such as has already been explained.

2. The wire is stretched from station to station, resting on little earthenware cups to prevent the electricity running down the poles into the earth, and is arranged in a coil round the magnetic needle at each station in such a way that when the current flows from left to right the needle will turn to the right, when it flows from right to left the needle will turn to the left. You will observe that there is only one wire in the diagram, although we know that no current will pass unless there is a complete circuit from the battery, going out at one pole and coming back to the other. At first telegraphs were made with a second wire to return the current, but Steinheil discovered that this is not needed, for that, if the ends of the wires are sunk in the ground, with plates of copper, $f g$, fastened to them, the earth itself will act as the second wire, and carry back the return current to the battery. It is not known precisely how the current returns; it has been suggested that the earth is 
a great reservoir, as it were, of electricity, so that when the current runs into it at one place an equal amount must run out at another; but all that is really known is that the whole globe acts practically as a return wire.

3. The magnetic needle is made of two or more parts, for since it would be very inconvenient if the pointer were always trying to turn to the north, this is avoided by fastening two needles side by side, with the north pole of the one lying

Fig. 60.

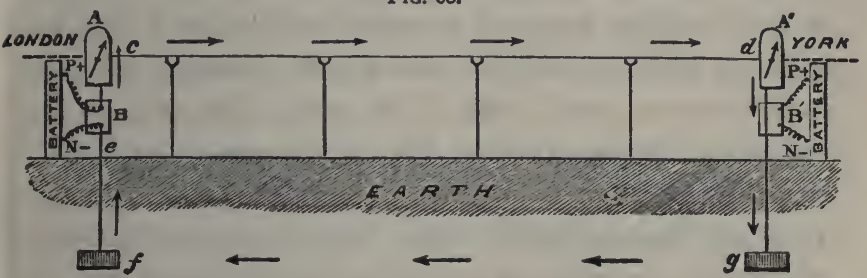

Fig. 6r.

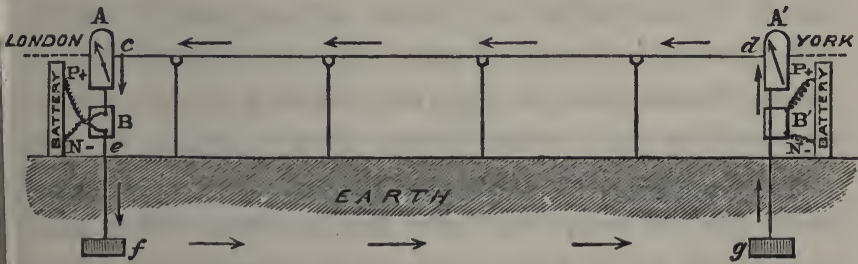

Diagrams showing the general principle of the Electric Telegraph.

$\mathrm{A}, \mathrm{A}^{\prime}$, Galvanometer, or box containing the magnetic needle. $\bullet \mathrm{B}, \mathrm{B}^{\prime}$, Commutator, or box in which the telegraph wire and earth wire are joined to each other as in $B^{\prime}$, or to the battery, as in B. $c, d$, Telegraph wire. $e$, Earth wire. $f, g$, Copper plates at the end of the earth wire. The arrows show the direction of the positive current.

against the south pole of the other, and thus, as the earth attracts each needle in a different way, the pull is neutralized. This double needle is called an astatic needle, and it is so placed in the box $\mathrm{A}$ in the form of telegraph we are describing, that one needle is inside surrounded by the wire, while the other is outside on the face of the box. 
4. The commutator, $\mathrm{B}$, is a box with an apparatus inside which is so arranged that by turning a handle (not shown in the diagram) different ways the earth wire and telegraph wire can be joined together, or either of them can be joined to one of the poles of the battery.

The commutator and galvanometer are really made in one instrument, but I have drawn them separate to make it more clear.

Now, when the man in London wants to send his message to York, he first sends off a current which rings a little bell at all the stations along the line to call attention, and then spells out the word York. This warns the man at that station to turn the handle of his commutator, $B^{\prime}$, so that the telegraph-wire, $d$, and the earth-wire, $g$, are joined together. Then the message can be sent. The man in London turns his handle according as he wishes the current to go. In Fig. 60 he has turned it so that the telegraph wire, $c$, is joined to the positive pole of the battery, and the current will pass above ground along $c d$ to the galvanometer $\mathrm{A}^{\prime}$, turning the needle to the right, and will then go back through the earth by $g f e$ to the battery. But in Fig. 6r the man has altered the handle, and now the earth wire, $e$, is joined to the positive pole, and so the current passes underground at $e f$, and out at $g$, and entering the galvanometer on the left side, turns the needle to the left, and goes back by the telegraph wire, $d c$, to the battery. In this way he turns it from right to left as he will, and spells out the message thus : Left, right $/ /=A$; left, right, left, left, $/{ }_{\|}=\mathrm{L}$; left, right,

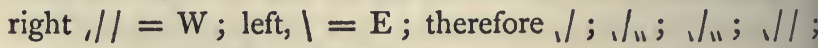
, ; $/ 11 ; 1 / 1$; spells ' all well.'

It is not necessary to have a separate wire for every telegraphic station : one wire will do all the work so long as it is 
only used by one man at a time. Therefore at every station there is a galvanometer to point out the message, a battery to provide the current, and a commutator to change the current; but these are not joined to the general wire unless they are being used. In Morse's American telegraph, which is generally used on the Continent, the needle pricks holes in a strip of paper, so that the message can be kept, and Bain's electro chemical telegraph writes down the marks on chemical paper. But all these are only improvements of the same principle by which an electric current going first one way and then another acts on a magnetic needle.

Chief Works consulted. - Lardner's 'Cyclopædia' - 'Electricity, Magnetism, and Meteorology ;' 'Annals of Philosophy,' New Series, I822, vols, ii. and iii. ; 'History of Magnetism ;' 'Encyclopæedia Metropolitana,' art. 'Electro-Magnetism ;' Faraday's 'Experimental Researches in Electricity,' 1859; Tyndall's 'Faraday as a Discoverer;' Gladstone's 'Michael Faraday ;' 'Nouvelle Biog. Universelle'- ' Ampère,' 'Oersted '; Ampère, 'Observations Electro-dynamiques,' I822 ; Faraday, 'Various Forces of Nature;' Proctor, 'The Sun ;' Herschel's 'Familiar Lectures ;' Brande's 'Manual of Chemistry.' 


\section{CHAPTER XXXVI.}

SCIENCE OF THE NINETEENTH CÉNTURY (CONTINUEN).

Davy discovers that Nitrous Oxide produces Insensibility-Laughinggas-Safety-lamp, 1815-Nicholson and Carlisle discover Decom. position of Water, 1800-Davy discovers the effect of Electricity upon Chemical Affinity-Faraday's Discoveries in ElectrolysisIndestructibility of Force-Various modes discovered of Decomposing Substances-John Dalton, Chemist-Law of Definite Proportions-Law of Multiple Proportions-Dalton's Atomic TheoryThe study of Organic Chemistry-Liebig the great Teacher in Organic Chemistry.

Sir Humphry Davy, 1778-1829.-We saw in the last chapter how Oersted, Davy, Ampère, Faraday, and Seebeck, by their various discoveries, showed the connection between Electricity, Magnetism, and Heat. We must now learn how the connection between electricity and chemical change was also worked out. This was done by Sir Humphry Davy and Faraday, who thus put England once more at the head of chemical discovery, in which the French school of Lavoisier had so long taken the lead.

Sir Humphry Davy, whom we have mentioned before as making experiments upon heat, was born in 1778 , at Penzance, in Cornwall, and died at Geneva in 1829 . His mother being a widow, he was apprenticed when quite young to an apothecary, and there with wine glasses, old medicine bottles, tobacco pipes, and a syringe, he made his first chemical experiments. When he was scarcely twenty years 
of age, Dr. Beddoes, a physician, who had opened a hospital for curing patients by the use of different gases, heard so much of the young man's abilities that he invited him to come to Bristol, where he employed him in making experiments.

In this way Davy's attention was drawn to nitrous oxide, a gas which had been declared by a celebrated physician, Dr. Mitchell, to be very poisonous. Our young chemist wanted to try this for himself, and actually began breathing it in small quantities to see whether it would affect him. He proved that it certainly was not so poisonous as Mitchell had thought, and, growing gradually bolder and bolder in the use of it, he succeeded at last in breathing the gas for several minutes, at the end of which time he lost all consciousness, and found himself in a land of delicious dreams, out of which he awoke gradually without being injured in any way. Enchanted at having discovered such a delightful sensation, he carried on his experiments for more than ten months, and when he published the results, and told the world that the mere breathing of a gas could make a man sleep, and dream, and laugh without any cause, it created a great sensation, and Davy's name soon became well known.

At this time (rסor) the Royal Institution had just been founded, and Count Rumford, seeing that Davy was a young man of great talent, offered him the appointment of Assistantchemist. Davy accepted it, and from that time devoted himself entirely to science. He was young, bright, and enthusiastic, and his lectures were so clear and eloquent, that the Royal Institution soon became famous under his influence, while every new appliance for making chemical experiments was given him in his laboratory. It was here that he made his observations on flame in 1815 , and constructed his Safety- 
lamp, which has saved so many lives, and for the invention of which he received the title of baronet. It was here also that he made his first experiments in electro-chemistry, which is the only one of his many discoveries of which we can speak.

Discovery of Electrolysis, or the Decomposition of Water by an Electric Current, 1800-1806.-In the year 1800, two men named Nicholson and Carlisle discovered by chance that when the two wires of a voltaic battery were dipped in water, bubbles of gas rose up from them. They also found by experiment that the gas from one wire was oxygen, and from the other hydrogen; but where these gases came from, whether they were produced by the electricity, or came from the battery, or from the water, they could not tell. Moreover, besides the oxygen and hydrogen which came off, there also appeared an acid of some kind at the positive pole, as was shown by damp litmus paper turning red (see p. 22.9), and an alkali appeared at the negative pole which turned this red litmus paper blue again. This looked as if the electric current had produced something in the water, for Cavendish, as you will remember, had shown that pure water is made of oxygen and hydrogen only (see p. 231). Many chemists, therefore, set themselves to try to discover what effect the electric current had on the water, and Davy in 1806 succeeded in solving the question.

The history of his experiments is especially interesting because it shows, as we have noticed so often before, that a patient and careful inquiry into nature always gains a true answer in the end. Davy did not believe that the electric current produced anything in the water; he thought that both the acid and the alkali came from the vessels that were used. So he set to work steadily to clear away all possibility of impurities. He took distilled water, and used cups first 
made of agate, and afterwards of pure gold, because he found that the clay of the china cups was acted upon by the current. Yet, in spite of these and many ether precautions, the acid and the alkali still continued to appear. Then he used water which he had evaporated very slowly, instead of distilling it, because he found that distilled water carried away some salt with it. When he had done this the acid was weaker, but the alkali was as strong as ever. At this point it occurred to him that the alkali might perhaps come out of the air, so he put his gold cups of water under an airpump, and completely exhausted the air, filling the pump with hydrogen to make quite sure that no other gas could be left in. When he had tried this several times and made it perfect in every way, he succeeded at last in getting nearly pure oxygen at one pole and hydrogen at the other.

By this experiment Davy not only confirmed Cavendish's discovery that pure water is made of hydrogen and oxygen, but he also established a totally new method of analysing substances, and finding out the materials of which they are composed. This method was in some ways more certain than Bergmann's method of tests, for when you drive one element out by putting another in its place, you have some difficulty in finding out exactly what has happened; but when a substance is decomposed by electricity you literally take it to pieces, and see the elements of which it consists.

Discovery of Potassium and Sodium.-Having succeeded in the case of water, Davy now went on to try the effect of the electric current on other bodies, and the first which he took were common potash and soda, which had always been supposed to be simple substances, which could not be decomposed. For several reasons, however, Davy believed that it would be possible to reduce them 
PI. III.

into more than one substance. So he heated some pure potash in a spoon until it was quite liquid, and fastening the two ends of the spoon to the wires of a battery, he sent an electric current through it. After a little while the potash began to be agitated, and to rise up in bubbles, and then there came to the surface beautiful silver-like globules, some of which burst into flame, while others renuained covered by a sort of white film.

'Davy's delight,' writes his brother, 'when he saw the minute shining globules like mercury burst through the crust of potash and take fire as they reached the air, was so great that he could not contain his joy-he actually bounded about the room in ecstatic delight.' It must indeed have been a beautiful sight in itself; but probably Davy's excitement arose chiefly from the new truth he saw in it. He had proved that potash was not a simple substance, but contained something which had never before been discovered.

At first he had great difficulty in collecting the globules, for they not only burst into flame when they met the air, but even in water they took fire, joining themselves to the oxygen and setting the hydrogen free. At last, however, he succeeded in collecting them in rock oil, or naphtha, which contains no - oxygen. He was then able to examine them, and he found they were composed of a metal hitherto quite unknown, to which he gave the name of potassium. A few days later he procured the metal sodium out of common soda by the same process.

This method of decomposing substances is called electrolysis, which means 'setting free by electricity.' Davy made use of it to decompose many earths, such as lime, magnesia, \&c., and the great Swedish chemist, Berzelius (born 
1778, died $18+8$ ), discovered several new chemical substances by means of it.

Faraday's Experiments on the Connection between Electricity and Chemical Affinity.-This was the practical use of the discovery; but it had another great interest for chemists, because it proved that electricity can overcome that power called 'chemical affinity', which holds two or more elements together in one compound substance. You will remember that Bergmann, and indeed Newton before him, pointed out that there is some force which causes certain bodies to choose each other out when they meet, and to unite firmly so as to become a new substance which has its own peculiar characters. Chlorine and sodium, for example, when heated, unite to form common salt, which is not the least like either chlorine or sodium when they are separate; and in the same way hydrogen and oxygen unite to form water. In these new states they are held together by a power which for want of a better name we call ' chemical attraction,' or 'chemical affinity' (see p. 229).

Now Davy showed that an electric current conquers this power and sets the different elements free, so that they can each go their own way. Thus the electric current passing through the water overcomes the force which holds the oxygen and hydrogen together, so that, at the point where the battery wires touch the water, hydrogen bubbles come off on one side and oxygen on the other.

It is to Faraday, however, that we owe most of our knowledge about the intimate connection between electricity and chemical change. He followed up Davy's experiments, and traced out very clearly the cause and effect of the chemical current. He showed in the first place that a substance cannot be decomposed by electricity unless it is a 
good conductor, so that the current passes readily along it. Thus, ice being a bad conductor, the slightest film of ice interposed between the water and the electric wires will prevent the current from setting free the oxygen and hydrogen; and ether and alcohol cannot be decomposed at all by electricity, because they will not conduct the current.

He also showed that the electric current itself does not depend upon any effect which the two metals have directly upon each other, as Volta thought, but is caused by the chemical action going on between the zinc and the water. Thus, if you put some zinc in sulphuric acid and water, the zinc pulls the water to pieces, and hydrogen gas comes bubbling off, but if you coat the zinc with mercury, hydrogen will no longer come off, and no action will take place till you put another metal in the water, as for example a piece of copper and connect the two metals by a wire. Then the hydrogen bubbles off again, but this time it does not come off the zinc, but off the copper. The force which overcomes the chemical attraction in the water has been made to travel across the vessel from one metal to the other, and this journey may be made as long a one as you choose, and may even be continued for hundreds of miles if only the current has some means of finding its way home to the first metal at last.

Now all this is a modified result of the chemical action of the zinc and acid water upon each other; as Faraday proved in a most beautiful way by showing that the power of the electric current to decompose water in another vessel depends entirely upon the violence of the action going on between these two elements of the battery. If the battery is weak, the water in which the ends of the wires are dipped is decomposed slowly; if the battery is strong, the bubbles 
of oxygen and hydrogen come off rapidly and vehemently. This led him to invent a useful little instrument called a voltameter, which measures the quantity of water decomposed, and so tells exactly what is the strength of the electric current. 'Thus we see,' says Faraday in one of his lectures, 'that the power which decomposes water, or produces the heat and light of the electric spark, is neither more nor less than the chemical force of the zincits very force carried along the wires and conveyed to another place.'

And here again we find ourselves brought face to face with the truth that all the various physical forces are only different forms of one and the same force. We learnt before that motion can be turned into heat and heat into motion, while heat, magnetism, and electricity all in the same way give rise to each other; and now we learn that chemical change gives rise to electricity, and electricity in its turn to chemical change. So that the whole set of physical forces, heat, motion, electricity, magnetism, and chemical change, are all different phases of one indestructible force which we lose sight of in one shape, only to find it in another.

Methods of Studying Chemistry.-We have now learnt how most of the chief methods of producing chemical change have been worked out. The science of chemistry consists in using these methods to test and decompose all the substances in our earth and atmosphere, and so learning their nature.

We have seen that there are four ways of thus analysing compound bodies. First, by testing them with other substances which attract some of their elements, and draw them out of the compound, as when by plunging a piece of iron into nitrate of copper the iron attracts the nitric acid and 
draws it out, leaving the copper to fall down as a metal. This was the method chiefly worked out by Bergmann in 1761, and which has since then been brought to much greater perfection by other chemists.

Secondly, by heating substances gently and examining the vapours which rise from them, and afterwards analysing what remains by burning. This method was fairly understood by Geber, and was first applied to organic substances by Boerhaave.

Thirdly, by passing an electric current through a compound substance in a fluid state, and so overcoming the force which holds the different elements together and setting them free. This method, called electrolysis, was discovered by Davy in 1806 , and afterwards thoroughly worked out by Faraday.

Fourthly, there is the method of spectrum analysis suggested by Herschel in 1822, which was carried on with great success by Bunsen and Kirchhoff. In this method the substance is turned into gas either by ordinary heat or by the electric spark, and is then examined by the spectroscope; the elements being determined by the position of the bright lines they throw on the spectrum.

There is still a fifth method, about which we have said nothing as yet, and which was chiefly brought into use by the chemist Berzelius (mentioned p. 366), namely the fusing of substances by means of the blowpipe. This instrument is merely a little tube with a mouthpiece at one end and a very minute hole at the other. By placing the minute hole in the middle of a flame and blowing through the mouthpiece, the centre of the flame is made to burn furiously, and many substances can be melted and decomposed by it which do not yield to ordinary heat. 
By these different methods a very large number of substances have been analysed since the time of Davy and Faraday, and sixty-four elements or simple substances have been discovered. It is possible that some of these may even at some future time be decomposed and shown to be made up of two elements; we can only affirm that now they appear to us to be simple substances. Some of these elements have been brought together and made to unite into compound substances by artificial means; as when, for instance, oxygen and hydrogen mixed and lighted by a spark rush together and form water, or when hydrogen and chlorine mixed together and placed in the sunlight unite to form hydrochloric acid. ${ }^{1}$ This method of bringing elements together to form a compound substance is called synthesis, and is exactly the opposite of analysis, or the splitting up of a compound substance into its elementary parts.

To follow out the gradual development of synthesis and analysis, and to see how all the different elements and compounds were in this way determined, would be to write a work upon chemistry. There is only one other general principle which we ought to try and understand here; namely, the proportions in which the elements combine to form substances. This principle, which lies at the root of all our modern chemistry, was first worked out by a poor schoolmaster named Dalton.

Dalton shows that the Different Chemical Elements always Combine in Definite Proportions.-John Dalton was born of Quaker parents in I766, near Cockermouth, in

1 Sir H. Davy was the first to discover, in 1807 , that hydrochloric acid is made merely of hydrogen and chlorine; before then it was believed that every acid must have oxygen in it. 
Cumberland. He received the ordinary education of a village school, and after being master of a small academy at Kendal, he went to Manchester, where he supported himself all the rest of his life by teaching mathematics.

Fortunately for science, a blind gentleman named Gough became interested in him, and gave him the use of his library and chemical laboratory, which enabled Dalton to work out many useful facts, and to establish the laws which are now the guide of all chemists, though they differ about some of his conclusions.

You will remember that it was only in the time of Lavoisier that chemists began to weigh carefully the gases into which substances can be decomposed. Before then it had been thought sufficient to say that a substance contained sulphur, mercury, carbon, \&c., without saying how much of it there was. But after the discovery of oxygen, when the real nature of chemical change began to be understood, chemists saw the importance of weighing accurately the different elements into which a substance can be broken up; and when this had been done for some time, and a great number of analyses had been made, it was seen that any given chemical compound always contains the same elements combined in the same proportion.

Thus, for example, all water, whether it comes from rain, snow, dew, steam, or exploded oxygen and hydrogen, will always be found to contain two parts by weight of hydrogen to sixteen parts by weight of oxygen; so that if you decompose $\mathrm{I} 8$ ounces of water you will collect

2 volumes of hydrogen weighing $1 \mathrm{oz}$. each . . 2 ozs.

I volume of oxygen weighing 16 ozs. . . . 16 ozs. 
And this never varies. Again, if you take some ammonia and decompose $\mathbf{I} 7$ ounces of it you will collect

3 volumes of hydrogen weighing $\mathbf{I} \mathrm{oz}$. each . . 3 ozs.

I volume of nitrogen weighing $14 \mathrm{oz}$. . . 14 ozs.

I7 ozs.

And this again never varies. Wherever you get ammonia it will always be made up of these proportionate weights of hydrogen and nitrogen.

This combination of the different elements in fixed quantities is called the law of definite proportions. It was hinted at by four chemists before Dalton; namely Proust, Wenzel, Higgins, and Richter, but it was very little understood, and some eminent chemists, such as Berthelot, even doubted whether it was true. Dalton, however, made a remarkable discovery which both proved the truth of the law itself and showed that it meant a great deal more than had been imagined.

He found that not only are the elements in any one substance always in a fixed proportion, but that each element, such as oxygen, has a weight of its ozon, and will only combine with other elements in proportions of this fixed weight. For example, oxygen will join itself to nitrogen in five different proportions, making five different substances, and in each case the same fixed weight of oxygen is added. Thus, if you decompose 22.4 litres of

$$
\begin{gathered}
\text { Volumes of Weighing } \\
\text { Nitrogen Oxygen Nitrogen Oxygen }
\end{gathered}
$$

Nitrous oxide, you will get 2 . I . 28 grammes 16 grammes

Nitric oxide

Nitrous acid

Nitric peroxide

Nitric acid

\begin{tabular}{|c|c|c|}
\hline 2 & . . 2 & . \\
\hline 2 & - $\cdot 3$ & \\
\hline 2 & . 4 & - \\
\hline & . 5 & . \\
\hline
\end{tabular}

$32 \quad "$,
$48 \quad "$
$64 \quad "$
80

So that each substance contains one more volume of oxygen 
compared to the nitrogen than the one before it ; and this volume always weighs 16 grammes, while each volume of nitrogen weighs 14 grammes.

Oxygen behaves in this way in all compounds, only joining itself to other elements in weights of 16 or multiples of 16 . Thus, if you heat mercury as Lavoisier did, so that it takes up oxygen out of the air, 200 parts by weight of mercury will combine with 16 of oxygen and no more. If you heat carbon with oxygen, 12 parts by weight of carbon will take up 16 of oxygen to make carbonic oxide, or twice I $6=32$ to make carbonic acid, but it will not take up anything between these weights. This same law holds true of all the elements, each one having its own peculiar weight. Nitrogen, for example, combines in weights of 14 , or twice $14=28$, or three times $14=42, \&$ c. ; sodium in weights of 23,46 , and $69,8 \mathrm{c}$. This is called the law of multiple proportions, which we owe entirely to Dalton, and it is a fact about which all chemists agree. Dalton went on to try and explain it by a theory which is still a matter of speculation, and which some chemists do not receive.

Dalton's Atomic Theory, 1808-In order to explain why each element should have its fixed weight in which it always combines, Dalton imagined, as Democritus, Epicurus, Bacon, and Newton had done before him, that all matter is composed of tiny parts, or atoms, which are too small to be seen and which cannot be divided. These atoms, which he pictured to himself as round grains like very small shot, would be of the same size in every substance, but not of the same weight. Hydrogen atoms would be the lightest of all, for hydrogen is the lightest substance known; oxygen atoms would be $\mathrm{I} 6$ times, and nitrogen 14 times, as heavy as those of hydrogen. 
Now when two elements combine together they cannot take up less, according to Dalton, than one atom of each, or two atoms of one to one of the other, and so on, and therefore exactly the weight of an atom of any substance will always be added. For example, to turn back to our table on p. 373 , Dalton would say that a molecule, or the smallest portion which can be imagined, of nitrous oxide will contain 2 atoms of nitrogen weighing 14 each to $I$ atom of oxygen weighing 16 ; while nitric acid will contain 2 atoms of nitrogen $=28$, and 5 atoms of oxygen, $5 \times 16=80$. If half an atom of oxygen could be added, then it might be possible to take up $16+8$, or 24 parts of oxygen; but as the atoms are supposed to be indivisible, this cannot be done, but a whole aton weighing 16 must be added each time. There-. fore you will see that by an atom Dalton meant the smallest quantity of any element which can combine with other substances.

Thus, water is made up of molecules, each containing two atoms of hydrogen and one of oxygen. But as these atoms cannot be seen, how can it be known how many there are in any substance, and when we have arrived at the smallest weight of any element? Dalton knew it in something like the following way :-

If you decompose water by electricity, you know that you will collect two bottles of hydrogen for one of oxygen. But you can also decompose it another way: if you take a small piece of the metal sodium and float it on water, it will roll round and round fizzing violently. This is because sodium joins very readily to oxygen, and the sodium is turning out some of the hydrogen from the water and taking its place. When the piece of sodium has disappeared, if you evaporate off the rest of the water, you will have a white 
powder, which is caustic soda; and if you decompose this soda, you will get out of it one measure of hydrogen, one of oxygen, and one of sodium. The sodium, you observe, has turned exactly half the hydrogen out of the water and taken its place; and this shows there must have been two atoms of hydrogen in the water, because a single atom could not have been divided.

In the soda we have now got the smallest quantity of each element-sodium, oxygen, and hydrogen-whicì will combine with any other. You can turn either of these three out of the soda, but you cannot turn out a part of any one of them. Therefore, a molecule of soda is said to be made of one atom of hydrogen weighing $\mathbf{r}$, one atom of oxygen weighing 16 , one atom of sodium weighing 23 , and these numbers are called the atomic weights of hydrogen, oxygen, and sodium.

This will give you a rough idea of Dalton's theory of atoms. There is always this difficulty in it that we cannot be quite sure when we have arrived at the smallest quantity of any substance; for suppose that one day we were to find that oxygen could be split up into two substances, then it would no longer be true that an atom of oxygen could not be divided. It would then be made up of two elements, the smallest quantities of which, when joined together, would weigh 16. But if we bear this possibility in mind, then the theory is of great use in giving us the symbols which are now used in chemical language. For when it was once agreed that the weight of an atom of hydrogen should be reckoned as 1 , then an atom of oxygen will weigh 16 , and the letters HHO express a great deal. They tell us that two atoms of hydrogen weighing 2 are joined to one atom of oxygen weighing 16 , to fcrm a molecule of water. In the same way 
$\mathrm{HO}, \mathrm{Na}^{1}$ tells us that one atom of each of these substances, weighing respectively, $1,16,23$, form a molecule of soda. And thus a complete chemical language has sprung up, by which chemists in all parts of the world can understand at once what is the composition of any substance; and by means of these simple letters the most complicated chemical problems can be worked out clearly and intelligibly.

Dalton's theory was received very quickly by chemists, considering how entirely new the ideas were which it taught. His friend Dr. Thomson, an eminent chemist (born 1773 , died $\mathrm{r}_{52}$ ), gave a very clear account of it in his 'System of Chemistry,' and brought it under the notice of Davy and Faraday; and a great French chemist, GayLussac (born 1778 , died $185^{\circ}$ ), adopted it at once, and added another discovery in favour of it in 1809-namely, that when substances are reduced to gas, and the gas is collected, it is found that the different elements combine in equal or multiple volumes.

You will understand this by turning back to the compounds of nitrogen and oxygen (p. 373), where you will see that there was always either $\mathrm{I}, 2,3,4$, or 5 volumes of oxygen collected for one of nitrogen, and never a part of a volume. This was really a different fact from the one Dalton pointed out, that the elements combine in definite weights, and it was necessary to complete the law of multiple proportions.

Liebig the Great Teacher in Organic Chemistry.-And now, before closing the history of chemistry, we must mention, in passing, one great division of the science of which we cannot attempt to give any real account-namely, the science

$1 \mathrm{Na}$ stands for Natrium, the Latin name for soda, now used for the metal sodium. 
of organic chemistry, or the chemistry of living bodies. This study began, as you will remember, when Boerhaave first examined the juices of plants and the fluids in animal bodies. But it can scarcely be said to have made any great advance till the year 1828 , when a German chemist named Wöhler first showed that urea, a substance in the bodies of animals, can be made artificially. Since then Berthelot and other eminent chemists have discovered how to make many compounds in the laboratory which were before only found in living beings.

But the great master of organic chemistry whose name you must remember, though we can speak but little about him, was Baron Liebig, of Darmstadt, who was born in 1803 , and died only a few years ago. He was the first to analyse organic substances satisfactorily, by heating them in vessels with metallic oxides, and so reducing them to carbon and their other elements; and he also brought agricultural chemistry to great perfection. This subject, which was first treated by Sir H. Davy, teaches how the growth of plants depends upon the chemical state of the soil in which they are sown, how different crops should be sown in succession in any field so as not to exhaust the soil ; and what nanure will best give back to the ground the elements which the plants have taken out of it. Liebig also traced out the changes which food undergoes in our bodies, and studied which kinds turn to fat, muscle, blood, or sugar in our system. In $183^{2}$ he also discovered chloroform and chlorale, though these were not used for producing unconsciousness till more than fifteen years later by Dr. Simpson.

The whole history of organic chemistry, however, is far beyond us at present ; the science has only existed for the last fifty years, and the cliemical substances which are 
created in a living body are extremely complicated, making the whole subject very difficult to understand. Moreover, we do not pretend to follow out the particulars of any science; if you can remember the names of some of the great pioneers of chemistry from the time of Geber in the ninth century up to the days of Davy, Faraday, and Liebig, and have some slight understanding of the nature of the work they did, it is all we can attempt in a book of this kind.

Chief Works consulted.-Davy's 'Works,' 1840; Whewell's 'Inductive Sciences;' Dalton's 'Chemical Philosophy,' 1808; Dr. Henry's 'Memoir of Dalton,' 1854 ; Fownes's 'Chemistry ;' Brande's 'Chemistry;' Faraday's 'Various Forces of Nature;' 'Edinburgh Review,' vol. xciv. 'Modern Chemistry ;' Hoffmann, 'On Liebig and Faraday.' 


\section{CHAPTER XXXVII.}

SCIENCE OF THE NINETEENTH CENTURY (CONTINUED).

The Organic Sciences are too difficult to follow out in detail-Jussieu's

Natural System of Plants-Goethe proves the Metamorphosis of Plants-Humboldt studies the Lines of average Temperature on the Globe-Extends our knowledge of Physical Geography-Writes the 'Cosmos'-Death of Humboldt in 1858 .

THE short sketch of advances in modern chemistry given in the last chapter brings us to the end of the physical sciences, or those which deal more particularly with the properties of bodies, and the laws of their action upon each other. We must now pass on to those sciences which treat of the past and present history of the globe and the living beings which inhabit it. I shall not attempt to speak of these sciences separately, for it is clearly impossible without a great deal of special knowledge to follow the modern discoveries in physiology, anatomy, medicine, zoology, botany, and geology.

All these sciences had advanced rapidly since the time of Haller and Hunter, Linnæus and Buffon. Famous arıatomists and physiologists such as the two Monros, father and son, in England, Bichat $(1771-1802)$ in France, Camper (1722-I789) and Blumenbach (1752-1840) in Germany, had been carrying on the study of the comparative structure of men and animals, and training up students to understand, far more completely than before, the functions 
of living beings. And the followers of Linnæus all over the world had been collecting and sending home for comparison rare plants and animals formerly unknown, which were eagerly studied for the new light they threw upon those which had been already dissected and described.

And so it came to pass that towards the end of the eighteenth century men became eager not merely to examine separate specimens or structures, but to form theories about the living beings on the globe. They began to inquire why animals should all be so much alike in their general plan, and yet so different in their special characters; why the same part of the body should be made to serve for different purposes in different animals, instead of a special organ being provided ; as, for example, the wing of the bat, which answers exactly to the front leg of a mouse, but is altered so as to be used for flying instead of walking. Then again, as the distribution of animals became better known, the question arose why certain kinds, such as kangaroos, should be found only in Australia, while they are wanting in all other parts of the world. Such general questions as these began to occupy the minds of naturalists, and we cannot close a history of science without trying to understand something of the attempts made to answer them, although they are so difficult that it will require all your attention and thought to understand them.

The Poet Goethe proves the Metamorphosis or Transformation of Plants, 1790.- One of the first men who threw any light upon the history of the growth of plants was the poet Goethe. Goethe had a deep love of Nature, as may be seen in many of his beautiful minor poems, and this love led him in the year 1780 to devote himself to the study of the anatomy of plants and animals. 
PT. III.

Since the time of Linnæus botany had become very popular, and the two celebrated French botanists, Antoine de Jussieu and his son Bernard de Jussieu, had established the Natural System of plants, which obliges men to observe every part of a plant before placing it in a class or order. You will remember that Linnæus suggested this method (see p. 2 I I), but thought it too difficult for ordinary students, and even to this day the Artificial System of Linnæus is used side by side with Jussieu's.

The study of the Natural System, however, led botanists to observe more carefully the nature of plants and the manner in which they grow; and when Goethe turned his attention to botany he was very much struck with the power which plants have of transforming or changing the growth of their parts. For example, the common wild rose in the hedges has a crown of pink petals, with stamens and pistils in the centre; but the garden rose, which is nothing more than the wild rose grown in a better soil, has lost the stamens and pistils, or rather has changed them into flower-leaves, so that the whole flower is one mass of petals, and rarely forms any seeds.

- It is clear, therefore, said Goethe, that the stamens and pistil of a plant are nothing more nor less than flower-leaves transformed into a peculiar shape, so that they serve to form seeds, and to carry on the life of the plant. And this is true of all the different parts of the plants. Wherever you look in the vegetable kingdom, you will find that every part of a plant is nothing more than stem or leaves altered in various ways to suit the work they have to do. Thus the stem of a geranium, the trunk of a tree, the twining stalk of the vine, the straw of wheat, the thorns of a rose-bush, 
CH. xxxvil. THE METAMORPHOSIS OF PLANTS. 383

the runners of a strawberry, the roots of plants, and the fleshy potato, are all only different forms of stems and branches. Again, the two cotyledons of a seed which are well seen in the halves of a bean are but the first pair of leaves. Out of them grows the stem, and out of this, leaves of different forms according to the peculiar species of plant.

Then, as the plant developes, come the buds of the flower, but these again are only stems and leaves growing more thickly together. We find in different plants every variety of flower from mere green leaf-like blossoms to the most gorgeous colours. The green leaves called sepals, which lie under the yellow petals in the buttercup, are transformed into brilliantly coloured petals in the tulip, while in some cases, such as occasionally in white clover, the whole flower, sepals, petals, pistil and stamens, has been known to be changed into little leaflets growing as if upon a branch.

For this reason gardeners find it possible to cultivate a plant so that it shall be all leaves and no flower, or, on the other hand, shall have a gorgeous flower while the leaves remain small and insignificant; or, as in the potato or the turnip, they can increase the size of the root at the expense of the leaves and flowers. And thus we are led to see that all the different parts of a plant are only peculiar transformations of simple stems and leaves, such as we find in mosses and the lowest forms of plants.

This beautiful truth of the transformation or metamorphosis of plants we owe to the poet Goethe; for though Linnæus suggested it rather vaguely in some of his writings, and a botanist named Wolff seems also to have taught it, yet it was Goethe's essay on the 'Metamorphosis of Plants,' 
published in $179^{\circ}$, which first led naturalists to consider the question. Goethe's work was very little read at first, and he had great difficulty in finding a publisher for it, for it was thought that a poet could not know much of science; but the great Swiss botanist, Auguste de Candolle (born I 778, died I84I) seeing what a new light it threw upon the study of plants, taught it in his works, and then it became gradually known as one of the greatest discoveries in modern botany.

Alexander von Humboldt studies the Lines of Equal Heat over the Globe-Founds the Study of Physical Geography-Writes the 'Cosmos,' 1793-1859. - While Goethe was studying plants at Weimar, and learning the secrets of Nature in the quiet of his own home, another man of whom we must now speak, was planning to travel in distant countries, and to write a history, as far as he was able, of the work which Nature is doing all over the world.

Alexander von Humboldt, who forms a link between the science of the eighteenth and the nineteenth centuries, was born at Berlin in 1769 , and was educated (together with his brother William, the great politician) at the University of Göttingen. At the age of one-and-twenty he went to Freyberg, where he was a pupil of Werner. It was at this time, when he was only just of age, that he formed the plan in his mind of spending his life in studying the works of Nature, and writing a 'grand and general view of the Universe.'

The first sketch of his book, which he called 'Cosmos,'

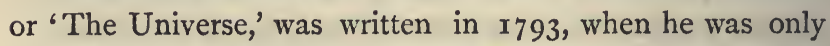
twenty-four; and the last sheets were printed in 1859 , when he was ninety years of age. In the sixty-six years between these two dates he collected and published in popular 
language an immense number of facts about nature in all parts of the world.

His chief voyage was to America in I 799, when he spent six years in Mexico, and along the shores of the Orinoco. Here he began one of his greatest undertakings, namely finding out the climate of different parts of the world, and tracing out isothermal lines, or lines of equal heat over the globe, showing what countries have the same average temperature, and explaining why some enjoy an almost equable climate all the year round, while others are very hot in summer and cold in winter. For example, he pointed out that Greenland is much colder than Lapland, even in places which are on the same line of latitude, because a cold current from the North Pole flows past Greenland, while the warm Gulf Stream crosses over from the Gulf of Mexico and washes the shores of Lapland. The importance of this study of variations of temperature was first pointed out by Humboldt, and it should be remembered as one of his most original investigations.

Again, in his long journeys through South America, he traced everywhere the different species of plants which grew at various heights, even up to 20,000 feet on the slopes of the Andes. This led him to try and find the reasons why certain plants are only to be found in certain areas, in the same way that Buffon had worked out the distribution of animals. When he returned to Paris in $\mathrm{I}^{804}$ he had collected an immense number of facts as to the heights of mountains, the climate of countries, the minerals and metals found in them, the active and extinct volcanoes, the nature of the rocks and soils, the vegetation and the animals; and with the help of the best scientific men in Paris (each 
I'T. III.

undertaking his own special science) he published twentyeight large volumes, which contained the conclusions based upon the facts he had learnt in his travels.

In 1827 he returned to Berlin, and was then invited by the Emperor of Russia to go on a journey into the Russian provinces of Asia, where he spent nine months making the same kind of observations that he had made in America. In 1830 he was sent to Paris as Prussian ambassador, and it was not till he returned to Berlin some years after, that he began to publish the 'Cosmos' he had been preparing for so long.

In this grand work he gives a complete history of astronomy, and all the discoveries in it made up till his time; and then taking our own world as part of the universe, he describes the changes which are going on now, or have been going on in past time, on the face of the earth. It is to Humboldt that we owe much which makes geography interesting. The study of the surface of the globe, of mountain-chains, table-lands, and rivers, the climates of countries, the different winds which blow, and the currents which cross the ocean; the way in which plants and animals are distributed over the world; the different races of men, and how they have spread over the globe-all these and other facts which make geography something more than a mere list of names, Humboldt studied during his various journeys, and related them with a freshness which had a peculiar charm.

It was not so much that he advanced any one branch of science as that he led men to look upon the earth and the universe as one vast whole, and to find a living interest in every part of it. In 1858 the last sheets of the 'Cosmos' were put into the publisher's hands, but Humboldt did not 
live to see them finished. He had done his part: the work he had proposed to himself was completed, and he fell peacefully asleep on the 6th of May, 1859 .

Chief Works consulted.-Goethe's ' CEuvres Scientifiques;' Faivre ; Asa Gray's 'Botany ;' L. Agassiz's 'Centenary Address on A. von IIumboldt ;' Humboldt's 'Cosmos.' 


\section{CHAPTER XXXVIII.}

SCIENCE OF THE NINETEENTH CENTURY (CONTINUED).

The three Naturalists, Lamarck, Cuvier, and Geoffroy St.-HilaireCuvier begins the Museum of Comparative Anatomy-Lamarck's History of Invertebrate Animals-Geoffroy St.-Hilaire brings Natural History Collections from Egypt-Lamarck on the Development of Animals-Geoffroy St.-Hilaire on 'Homology,' or the similarity in the parts of different Animals-Cuvier's 'Rène Animal,' and his Classification of Animals - Cuvier on the perfect agreement between the different parts of an Animal-He studies and restores the remains of Fossil Animals-His 'Ossemens Fossiles'-Death of Cuvier-Von Baer on the study of Embryology-His History of the Development of Animals, 1828 .

Lamarck-Cuvier-St.-Hilaire.-When Humboldt visited Paris in 1804 there were three men holding professorships in the Museum of Natural History in that city, who had afterwards a great influence upon the study of the science of living beings. These three men were Lamarck, professor of zoology ; Geoffroy St.-Hilaire, his fellow-professor ; and Cuvier, assistant-professor of comparative anatomy.

The early part of the nineteenth century was, as you will remember, a very troubled time for France. The first Napoleon was carrying war and desolation all over Europe, and Paris was kept in a constant state of turmoil for many years. During all this time it is interesting to see how steadily and quietly the three men I have mentioned pursued their search after knowledge. Geoffroy St.-Hilaire 
twice risked his life in saving friends from the terrors of the Revolution; and Cuvier held political appointments both under Napoleon and under Louis Philippe; but in spite of these duties and interruptions their scientific work was never neglected; and a great part of the knowledge about plants and animals which we now possess was accumulated during the troublous times of the French revolutions.

Jean Baptiste de Monet, Chevalier de Lamarck, the elder of these three men, was born in 1744 at Bezantin, in Picardy, and a somewhat curious circumstance led him to devote his life to science. His father intended him for the church, but the lad had a passion for the army, and on his father's death, in 1760 , set off to Germany, where the French were then fighting, and soon distinguished himself as a volunteer. Some time afterwards, however, one of his comrades lifted him up by his head in joke, and so strained the glands of the neck that after a very severe illness he was obliged to give up his profession and become a banker's clerk in Paris. He had thus time and opportunity to study natural science, for which he had always had a great liking, and in 1778 he published a small book on botany. Buffon, who was then at the height of his fame, was pleased with this work, and procured for Lamarck an appointment in the botanical department of the Académie des Sciences. From there he went to the Jardin des Plantes, and eventually became professor of geology in the Musée d'Histoire Naturelle.

George Leopold Cuvier, afterwards made Baron Cuvier by Louis XVIII., was born of Swiss parents at Montbéliard, near Bésançon, in 1769 . He, too, was intended for the church, because his parents were not rich and he had an uncle who could help him in that profession; but Prince Charles of Wurtemberg having heard of his abilities, sent for him and 
gave him a free education in the Académie Caroline at the University of Stuttgard. Here he already began in his spare moments to read books of natural history and make drawings of plants and animals. When he left Stuttgard he went as tutor in a nobleman's family at Caen, in Normandy, and found a new and delightful study in the examination of the marine animals on the sea-shore. After living there six years, he happened to meet the celebrated Abbe Tessier, who had fled from the Revolution in Paris, and through his means the young Cuvier was introduced to Geoffroy St.-Hilaire and other scientific men in Paris, and became assistant-professor of comparative anatomy in the Jardin des Plantes. From this post he rose to very great honours both as a politician and man of science, holding the posts of President of the Institute, Inspector-General of Education, Councillor of the Imperial University, and many others of equal importance.

Geoffroy St.-Hilaire, the third and youngest of the three friends, was born at Etampes in 1772 . It is curious that he also began his education as a priest, and that all these three men should have given up the church for science. In St.-Hilaire's case it was a passionate love for zoology which led him to persuade his father to let him stop in Paris to study at the Jardin des Plantes, where he was soon offered a post which gave him an excuse for following his own tastes. He afterwards joined Lamarck at the Musée d'Histoire Naturelle in I793; and in I795 it was chiefly through his influence that Cuvier was invited to Paris and became their fellow-worker.

It now remains for us to see what was done by these three remarkable men. For three years they all remained at work in the museum. Cuvier had found in a lumber-room four or five old skeletons collected by Daubenton (p. 205), 
and he determined to make them the beginning of a museum of comparative anatomy, which afterwards became very famous. St.-Hilaire worked with Cuvier, while Lamarck began the study of those animals-such as insects, snails, worms, shell-fish, sea-anemones, and sponges-which have no backbone, and to which he first gave the name of 'invertebrate animals.' Lamarck's work on these animals is one of the most famous he ever wrote.

In 1798 Cuvier and St.-Hiliare were both invited by Napoleon I. to go with the French army to Egypt and study the curiosities of natural history which were to be found there. Cuvier declined, but St.-Hilaire went, and spent three years examining the embalmed animals of the Egyptians. He succeeded in $180 \mathrm{r}$ in bringing away the beautiful collections of these and other relics from Alexandria, when the French were forced to give up the town to the English. These collections were conveyed safely to the Museum in Paris in $\mathbf{1} 802$.

Lamarck on the Development of Animals, 1801.-Meanwhile Lamarck published in 180 r a little work on the 'Organization of Living Bodies,' and in it he first suggested that the different animals were not created separately, but had been gradually altered from a few simple living forms, so that, in the course of long ages, there had sprung up an immense variety of species of animals in the world. It must be remembered that Lamarck had chiefly studied plants and the lower animals. We have seen how Goethe showed that all plants are only altered stems and leaves; and the lower animals, such as jelly-fish, snails, and worms, differ much less from each other than the higher animals do. Therefore Lamarck was very much struck with the difficulty there was in settling which wcre distinct forms or species, and 
which might have come from the same parent, and he concluded that the only difference was that some had branched off from the common stock earlier than others, and so had become more unlike-just as brothers and sisters are very like each other while distant cousins are much less liable to have the same features and expression.

The more we know of animals and plants, said Lamarck, the more difficult we find it to settle which are related to each other and which are not. Linnæus had long ago pointed out that among plants which are well known, such as the willows in Europe, the cactuses in South America, and the heaths and everlastings at the Cape, there are so many kinds differing very little from each other that it is impossible to say which ought to be considered as separate species and which as the descendants of one kind of plant.

Moreover, we know how much plants and animals are sometimes altered even in a few years. For example, by growing in a drier soil or up a high mountain, plants become stunted and altered in many ways, while birds when shut up lose the power of using their wings, as has been the case with our domestic poultry. Man can make a number of different varieties both of plants and animals by merely keeping those which have the peculiarities he admires. The different kinds of pigeon, for example--the pouters, fan-tails, tumblers, and others, which are so unlike each other-are said by naturalists to be all descendants of the common rock-pigeon ; and all the varieties of rabbit have come from one wild species. You cannot find a wild pigeon with a fan-tail, or a wild rabbit with lop-ears.

If man, then, in a few hundred years can make such changes, 'is it not possible,' said Lamarck, 'that nature in all the long ages during which the world has existed, may 
have produced the different kinds of plants and animals by gradually enlarging one part and diminishing another to suit the wants of each?' These and many other arguments Lamarck brought forward in his work in r $80 \mathrm{r}$, and again in his 'Philosophie Zoologique' in 1809 , to prove that the way in winich the Creator has formed different plants and animals has been by altering them gradually out of simple forms.

There was, however, one very weak point in all his arguments ; he did not show sufficiently what should cause living beings to go on altering, and becoming more and more different. For if you turn plants and animals, which man has altered, out into the fields again, in a very few generations they return very nearly to their old forms; nor can we see any reason why the differences between animals should go on increasing unless they were picked out and kept apart, as men keep them when they want to get new varieties.

Lamarck did, indeed, point out that climate and difference of food would help to alter the nature of an animal, but the chief reason he gave for changes taking place in them, was that the animal itself might cause the alteration in its form ; as for instance, a giraffe constantly wishing to eat the boughs off high trees might stretch his neck, and so by degrees each generation might have longer necks than the last one. This reason was so weak and ridiculous that it prevented naturalists from paying much attention to Lamarck's theory.

Geoffroy St.-Hilaire points out that the Parts or Organs are the same in all Animals, only Modified to suit their Wants.-Nevertheless Geoffroy St.-Hilaire was inclined to think there was some truth in this theory, although Cuvier was strongly against it. Cuvier, you remember, had given his time chiefly to the restoration of the skeletons of the higher animals, and he was as much struck with the im- 
mense difference between them, as Lamarck had been with the likeness of the lower animals. Cuvier thought that each animal was at first created separately, and all its parts were arranged expressly to meet its wants. He looked upon the creation of each kind of animal as the making of a machine, where we put a wheel here and a valve there expressly to make it do the work required.

Geoffroy St.-Hilaire, on the contrary, insisted that we never find any part of an animal which we can say was made expressly for it. Whenever we examine it closely enough we find it is exactly the same as exists in other beings, only its growth is altered so as to make it useful to that particular animal. The pouch of the Kangaroo, he said, is only a fold of the skin which is looser than in other animals; the trunk of the elephant is a nose which has become extremely long; the hand of a man, the leg of a horse, and the wing of a bat, are the same organ and have the same bones, although they serve such different purposes. 'Nature,' he said, 'has formed all living beings on one plan, essentially the same in principle, but varied in a thousand ways in all the minor parts; all the differences are only a complication and modification of the same organs.'

This similarity of structure, or homology as it is called, which runs through all animals, was thus first clearly stated by St.-Hilaire, and it has now been most carefully worked out and confirmed by our living anatomists. Yet Cuvier opposed it to the last, for his mind was full, as we shall see presently, of another idea which is equally true ; namely, how perfectly each part of an animal is made to fit all the other parts of his body ; and it seemed to him impossible that this could be, unless each part was created expressly for the work it had to do. 
The discussion between the two friends became so animated that all Europe was excited by it. It is said that Goethe, then an old man of seventy-one, meeting a friend, exclaimed, 'Well what do you think of this great event? the volcano has burst forth, all is in flames.' His friend thought he spoke of the French Revolution, and answered accordingly. 'You do not understand me,' said Goethe, 'I speak of the discussion between Cuvier and St.-Hilaire: the matter is of the highest importance. The method of looking at nature which St.-Hilaire has introduced can never now be lost sight of again.' And he was right, for the doctrine of homology, as taught by St.-Hilaire, is one of the strongest arguments for the theory of the development of living beings, now held by all the most able naturalists, and of which we shall speak in Chapter XL.

Cuvier proves that the Parts of an Animal agree so exactly that from seeing one Fragment the Whole can be known.-We have seen that Cuvier did not agree with many of the views of Lamarck and St.-Filaire. We must now consider what work he did himself; for though all the three friends laboured well, Cuvier accomplished the most of all. He had a most remarkable capacity for work ; we find him at the same time restoring skeletons and studying each bone with minute care, lecturing to large bodies of students, writing the history of all the sciences, and examining fossils from the rocks ; besides presiding over councils and superintending national education. And whatever he touched was done thoroughly and with a master-hand.

His first great work was to collect all the different facts of comparative anatomy established since the time of Hunter, and, adding a great mass of his own observations, to build them up into one complete science of anatomy. In 
his 'Règne Animal,' published in 1817 , he made a new classification of the whole animal kingdom, dividing them into four great branches. The vertebrata, or animals with back-bones; the mollusca, or soft-bodied animals, such as snails; the articulata, or animals, such as crabs, spiders, bees, and ants, whose bodies are composed of movable parts, hardest outside, and jointed or articulated together; and the radiata, or animals whose parts are arranged round an axis, such as star-fish and polyps. These four branches he divided again into classes, orders, families, genera, and species, making a much more complete classification than Linnæus had done, because it was founded more upon the internal structure of animals.

In this work he pointed out that the parts of an animal are made to fit to each in such a wonderful manner, that if only a few bones are placed in the hands of an anatomist he ought to be able to tell you exactly what all the other bones must be. You will remember that Hunter had hinted at this when he showed how the teeth of each species of animal are fitted to the kind of stomach into which the food is to pass. But Cuvier proved that this is true not only of the teeth but of every bone in the skeleton of an animal.

'Every organized being,' he says, 'forms a whole and entire system . . none of its parts can change without a change of the others álso. Thus, if the stomach of an animal is made so as only to digest fresh flesh, his jaws must be formed to devour the prey, his claws to seize and tear it, his teeth to divide the flesh, and the whole system of his organs of motion to follow and overtake it. Nature must even have planted in his brain the necessary instinct to hide himself and lay snares for his victim. These are the 
general conditions of a carnivorous life, and all animals who are to live this life must fulfil them, otherwise they cannot exist. And besides these general conditions there are special ones, according to the particular kind of life the animal has to live, and each of these require modifications in the form of the organs; so that not only the class, but the order, the genus, and even the species of an animal are revealed by each part of it.'

And now you will understand why Cuvier could not believe St.-Hilaire's theory that all the parts of one class of animals-such as the vertebrate animals, for example-are made on one model, and that when some organ has to play a different part it is altered, and not created for the purpose. Cuvier was strongly impressed with the beautiful agreement in every part of each particular animal, which enables it to provide for all its wants ; while St.-Hilaire was equally impressed with the general agreement between the structure of all animals in any one great class. Both these views were true, but in the state of knowledge at that time it was very difficult to reconcile them. You must bear this in mind, because it is one of the difficulties upon which light is thrown by Mr. Darwin's observations, which we shall examine by-and-by.

Cuvier Studies and Restores the Remains of Fossil Animals, 1812.-We have seen that Cuvier's knowledge of the agreement between the different parts of an animal was so great that from even one bone he could tell what the other parts of the body must be. The use which he made of this knowledge enabled him to reveal a wonderful history about the fossils buried in the crust of our earth.

When he first came to Paris, and for many years afterwards, a number of skeletons and parts of skeletons of ani- 
mals, were being dug up round about Paris. These were a great puzzle to anatomists, for the bones were many of them immensely large, and none of them seemed to agree exactly with those of any known animals. Cuvier no sooner heard of these fossils than he set to work to study them, making use of his great knowledge of anatomy to sort out the confused mass. His practised eye could detect from among the heap of bones those which belonged to each other, and out of a mere handful of fragments he could restore in imagination the animal from which they must have come. It was like the work of an enchanter's wand.

'At the voice of comparative anatomy,' he writes, 'each bone, each fragment, regained its place. I cannot describe the pleasure I felt in finding that, as I discovered one character, all its consequences were gradually brought to light; the feet agreed with the history told by the teeth; the bones of the legs and thighs, and those parts which ought to unite them, agreed with each other. In a word, each one of the species sprang from its own fragments.'

And so month after month he worked on, and then to the great astonishment of naturalists he told them that all these animals were of species which are found nowhere upon the earth now. They were all extinct animals. The greater part belonged to hoofed quadrupeds, something like our elephant, rhinoceros, and pig; then there was an elegant deer-like animal resembling a gazelie, some birds, some fish, and a kind of opossum, but all these were in some way different from any which live now.

Here was a history so strange that at first no one would believe it; for it meant that at the time when the land on which Paris now stands was being laid down by the rivers, there must have existed a whole group of animals, all of them 
more or less different from our present species of animals, which had not then begun to exist. It had long been known that strange shells were found buried in the earth's crust, but then naturalists could never be sure that some like them might not be living in other parts of the world without our knowing it, and they had always believed that at least the larger animals had been created quite recently at the same time as man. But here were animals which no one had ever seen upon the earth, and it was impossible to suppose that fifty different kinds of creatures of all sizes, some bigger than an elephant, could be roaming about the world unseen by anyone. Therefore there could be no doubt that long before the time of history or tradition strange animals must have lived and died, and have been buried in the deposits now forming part of the earth's crust.

And when this was once recognised, and attention was called to these buried animals, little by little other forms were found in older rocks in different parts of the world, which appeared to be less and less like living animals the older the rocks were in which they were found. All these Cuvier described in his famous work called 'Les Ossemens Fossiles,' which he published in 1812 , and in which he laid before the world a startling history of the long succession of different animals which must have lived in past ages upon the earth.

And here we must close this very imperfect sketch of the work done by the three French naturalists. You ought chiefly to remember about them that Lamarck suggested that animals have been developed out of a few simple forms; that St.-Hilaire proved that animals of one class are formed on the same general plan, similar parts being altered 
to serve different purposes in different animals; and that Cuvier showed that each part of an animal agrees with the rest so perfectly that from a few bones it is possible to tell exactly what animals had lived and died in past ages.

Geoffroy St-.Hilaire outlived both his friends, and died in 1840. Lamarck had died in 1829 , in his eighty-fifth year, having been blind for many years. Cuvier died on May I3, 1832. On the Tuesday previous he had begun his third course of lectures on Natural Science at the College de France, and had promised to give in that course his idea of creation, and how the Divine Intelligence is to be traced through all the operations of nature ; but the promise remained unfulfilled; that same evening paralysis set in, and on the next Sunday he died in his arm-chair as if he had fallen asleep. He had begged to be buried privately, but that was impossible; on hearing of his death men of science flocked from all parts to do him the last honour, and his pupils bore him to the grave.

Von Baer, the Founder of the Study of Embryology. 1828. - We must not leave this question of the structure of animals without noticing in passing a new and important study which began about this time. This was the study of embryology, or of animals in the earliest stages of their life, as in the case of the chicken before it leaves the egg. You know that if you take a bird's egg when it is newly laid, you will see inside it a yellow yolk floating in a white fluid. But if you take the egg after the mother-bird has sat upon it for some days, the yolk will begin to have the form of a bird, and if you were to take' a dozen 'eggs of one brood of chickens and crack one every few days while the mother was sitting upon them, each one would be more like a chicken than the last, until the twelfth, if you opened it just about the time when it ought to be hatched, would be a perfect chicken, only that its 
feathers would not be yet grown. Now the study of the different stages of the develorment of the chicken in the egg, and of all living beings going through the same stages, is called Embryology, and has become of immense importance in the history of animals.

You will remember that Harvey, Malpighi, and many other physiologists, occupied themselves with this study; but no discoveries of very great importance were made in it before the time of Karl von Baer, a Russian anatomist, who was born in $\mathbf{1 7 9 2}$. Von Baer was the pupil of a very famous anatomist, Professor Döllinger, and while he was working under him at Würzburg he made for him a number of observations upon the growth of the chicken in the egg, which led him to study the embryology of animals, and to discover the remarkable law of which we must now-speak.

Before Von Baer's time it had always been supposed that the many kinds of animals, so different from each other, must be quite unlike from the very first moment that they began to grow, but Von Baer discovered that this is not so, but that the embryos or beginnings of an ox, a bird, a lizard, or a fish, are so like each other that they can only be-distinguished by their size ; and, what is still more remarkable, they remain alike till they have-been growing for some time. For example, if you could watch the beginning of these four animals, there would be a certain time during which you could see no difference in their form. Then after a while the fish would start off on a road of its own, but still the other three would go on all alike. Then, when they had grown a little bigger, the lizard would branch off, and only the bird and the ox would continue to have the same 
form, until lastly the bird would take on its own peculiar shape, and the ox would go on alone, having passed through the same stages as the fish, the reptile, and the bird, before it began to shape itself like a mammal. You must notice carefully that this does not mean that the beginning of an $o x$ is at any time like a full-grown fish, which is a mistake that people often make; but only that there is a time when the embryos of these animals follow exactly the same plan.

You will see, if you consider for a moment, that the discovery of this curious fact gave naturalists a new and much more perfect way of classifying animals; for they could actually read the history of an animal by watching it in the earlier stages of -its growth and seeing at what point it branched off and put on special peculiarities of its own ; and in some of the lower and more obscure animals several mistakes of classification were corrected by this means. There was also another very important question settled by Von Baer's law. It proved that St.-Hilaire was certainly right in saying that animals are formed on one plan, having special parts altered to suit their wants, for here in the embryo those parts can be seen actually developing differently in different animals out of the same beginnings. The study of embryology has been carried to great perfection since Von Baer published his 'History of the Development of Animals' in 1828 ; but though many names are better known than his in connection with it, still it should always be remembered that he was the discoverer of the law of embryological development.

Chief Works consulted.-Goethe's 'CEuvres Scientifiques,' Faivre, 1862 ; Asa Gray's 'Botany,' 1858 ; L. Agassiz's 'Centenary Address on A. von Humboldt,' 1869 ; Humboldt's 'Cosmos ;' 'Biog. Univer- 
selle'-Cuvier, Geoffroy St.-Hilaire, and Lamarck ; Lamarck's 'Philo. sophie Zoologique ;' Cuvier's 'Ossemens Fossiles ;' Geoffroy St.Hilaire's 'Zoologie Générale Suites à Buffon ;' 'Vie et 'Travaux de G. St.-Hilaire;' Flourens' 'Éloge de Cuvier;' 'Miscellany of Nat. Hist.'-Lauder's 'Memoir of Cuvier ;' Jardine's 'Naturalist's Library Memoir of Lamarck;' Huxley on Von Baer-Appendix to Baden Powell's 'Unity of Worlds ;' Agassiz's 'Systems of Classification.' 


\section{CHAPTER XXXIX.}

SCIENCE OF THE NINETEENTH CENTURY (CONTINUED).

Prejudices which retarded the Study of Geology-Sir Charles Lyell traces out the Changes now going on-Mud carried down by the Ganges-Eating away of Sea-coasts--Eruption of Skaptar JokulEarthquake of Calabria-Rise and fall of Land-'Principles of Geology' published in 1830-Louis Agassiz: his Early LifeDe Saussure's Study of Glaciurs-Agassiz on Europe and North America being once covered with Ice-Boucher de Perthes on ancient Flint Implements-- MacEnery on Flint Implements in Kent's Cavern, with Bones of Extinct Animals - Swiss Lake-dwellings'Antiquity of Man.'

IN I8I I, when Cuvier published his work on 'Fossil Remains,' William Smith, who, as you remember (p. 233), first studied the rocks of England, had nearly completed his geological map, and scientific men were beginning, both in England and Germany, to understand something of the different ages of the formations which have been laid down from time to time on the surface of the globe; yet still they were prevented from reading the past history of the world rightly, by several false notions which continued to prevail.

People had so long held the belief that our earth had only existed a few thousand years, that when geologists began to find great numbers of strange plants and animals buried in the earth's crust, immense thicknesses of rock laid down by water, and whole mountain-masses which must 
have been poured out by volcanoes, they could not believe that this had been done gradually and only in parts of the world at a time, as the Nile and the Ganges are now carrying down earth to the sea, and Vesuvius, Etna, and Hecla are pouring out lava a few feet thick every year. They still imagined that in past ages there must have been mighty convulsions from time to time, vast floods swallowing up plants and animals several times since the world was made, violent earthquakes and outbursts from volcanoes shaking the whole of Europe, forcing up mountains, and breaking open valleys. It seemed to them that in those times when the face of the earth was carved out into mountains and valleys, table lands and deserts, and when the rocks were broken, tilted up, and bent, things must have been very different from what they are now. And so they made imaginary pictures of how Nature had worked, instead of reasoning from what they could see happening around them.

Sir Charles Iyell teaches that the Rocks of our Earth have been formed by Natural Causes, such as are still going on, 1830.-The man who first broke through these prejudices was our great geologist, Sir Charles Lyell, who has only just now passed away from among us. Charles Lyell was born in Forfarshire, in 1797 , the same year that Hutton died. From his earliest childhood he had a great love of Natural History and Science, but as his father wished him to become a barrister, he went to Oxford to follow the usual course. Here he attended the lectures of Dr. Buckland, the great geologist of that day, and this decided him to devote his life to the study of geology. He began first by examining the formations round about his own home in Forfarshire, and he soon became convinced, 
as Hutton had been before him (see p. 219), that we can only learn the past history of the earth by observing the causes now at work.

What Hutton had suggested Lyell worked out. He collected with great care all that is known of changes going on now all over the world, and the causes which produce them. Among these were-

rstly. The fall of rain, and how it wears away the earth and carries it off in little rills to the river.

2ndly. The amount of mud carried by mighty streams, such as the Ganges, the Nile, and the Mississippi, and laid down in the sea at their mouths.

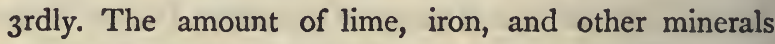
brought up by springs from the inside of the earth, and thrown down on the surface.

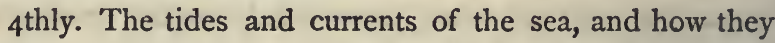
wash up fresh land on some coasts and eat away the land on others.

5 thly. The growth of corals in the sea, and how remains of their skeletons become cemented into limestone.

6thly. The volcanoes which are throwing out lava, and how much they have thrown out in historical times.

7thly. The different earthquakes which man has witnessed, how they have broken and dislocated the land, raising it in some places, as in New Zealand, and causing it to sink in others, as at New Madrid, in America.

8thly. The way in which plants and animals are buried in the mud of lakes, or at the mouths of rivers, or in peat and sand.

All these, and many other changes which are taking place all over the world in the present day, Lyell studied with great accuracy, and then began a book to show that 
what we find in the rocks might all have been produced by such causes as these, without imagining any extraordinary violence of nature.

While writing this book he went with another celebrated geologist, Murchison, to Italy and Sicily, and there he studied not only the rocks which the volcanoes of Vesuvius and Etna have been building up for ages, but he also saw at Syracuse and other places enormous beds of limestone filled with shells of kinds which may still be found living. The immense thickness of these limestone beds, amounting in some places to 700 and 800 feet, astonished him greatly. He knew they must all have been formed slowly beneath the sea, out of the remains of corals and other animals, whose skeletons or shells are composed of lime, and that they must afterwards have been raised up to the height of 3,000 feet above the sea, at which he found thern; and when he thought of the time which this must have taken, and remembered that it had all happened since the other great masses of rocks below, containing extinct shells, had been formed, he felt more than ever convinced that the world must be very old, to have allowed time for all the wonderful changes that have taken place.

In 1830 his book was published, and though it met with great opposition because men's minds were prejudiced the other way, yet his facts could not be denied. He showed, for example, on the one hand that the river Ganges in India carries down every year, and deposits in the sea, as much mud as would make sixty of the great pyramids of Egypt, and which if it was brought in ships would require 2,000 full-sized merchant vessels laden with mud to sail down the Ganges every day. Here, then, was an example of rocks being now laid down in the sea, not by violent floods and 
sudden catastrophes, but so quietly that no one even notices that nature is at work.

Then, on the other hand, he pointed out how in our own little island, on the coasts of Yorkshire and Norfolk, the sea eats away the cliffs, so that towns such as Auburn, Hartburn, and Hyde in Yorkshire, which are marked upon old maps, have been entirely washed away, and the ground on which they stood has been spread out on the bottom of the ocean; and yet this is done so gradually, year by year, that new towns of the same name are built up farther inland, and no one disturbs themselves about the loss.

Then to account for the huge masses of basalt and lava which are found in the earth's crust, he reminded his readers of the great eruption of the volcano called Skaptar Jokul in Iceland, which took place in 1783 . In this eruption the torrent of lava was ninety miles in length, from seven to fifteen miles in breadth, and in some places 600 feet deep, and the whole mass poured out would have made a mountain as big as Mont Blanc.

He then went on to give accounts of the remarkable earthquakes which have taken place in times of history: the earthquakes in India, in Java, and especially in Calabria, in 1783 , when new lakes were formed by the sinking in of the ground, and the rivers were made to run in new channels. He showed also how the height of land is sometimes changed in volcanic countries; as on the coast of Italy, near Naples, where the ground on which the famous Temple of Serapis stands can be proved to have been raised and depressed twice even in historical times.

And besides all these obvious changes which men cannot help noticing, he proved that other quiet and unnoticed risings and fallings of land are taking place ; as, for example, in Norway and Sweden, where the land is rising out of the sea in 
some places at the rate of about two or three feet in a century ; and in Greenland, where it is sinking, so that huts built near the shore have to be moved inland because they are becoming submerged in the sea.

These are a very few of the facts which you can understand, by which Lyell demonstrated that the surface of our earth is always undergoing changes in our own day, and that by similar changes going on in past times the whole of the crust of our earth may have been built up and carved out. In addition to this he showed how plants and animals are now being buried in mud and earth, and how their remains are washed into cares, or preserved in peat-mosses ; thus affording us examples of the way in which the remains of ancient animals have become entombed in the earth's crust.

Thus Sir Charles Lyell taught men to read the true history of the earth. It is difficult in the present day to understand rightly how great a work he accomplished, for though his ideas were ridiculed in the beginning, yet he lived long enough to see all men agree with him, and his doctrines received as self-evident truths. Like all other great men, he was humble and reverent in his study of nature. His one great desire was to arrive at truth, and by his conscientious and dispassionate writings he did much to persuade people to study geology calmly and wisely, instead of mixing it up with angry disputes, like those which, in the time of Galileo, disfigured astronomy. He travelled a great deal, especially in America, and worked out a great many facts in geology. But in future ages his name will stand out among those of other geologists chiefly as having shown that the changes in the crust of our earth have bcen brought about in the course of long ages by causes like those which are still in action.

After the year 1830, when his 'Principles of Geo'ogy' 
was first published, the study of this science went on very rapidly indeed. As with all the other sciences of the nineteenth century, you must read the details in special works; but there are two great discoveries which we must mention very shortly here. These are-rst. The fact that much of temperate Europe, Asia, and America was at one time covered with ice, as Greenland is now ; and 2nd, that man has lived upon the earth much longer than was once supposed.

Louis Agassiz, 1807-1874.-The man whose name will always be remembered as having first traced out the wonderful history of the great ice-period is Agassiz, the famous Swiss naturalist, who was born in 1807 at Mottier, near Neuchatel, and died in 1874 in America.

Louis Agassiz was the son of a Swiss pastor, and he forms one among many bright examples in the history of science, of men who cared neither for wealth, advancement, nor ease, but for the study of nature alone, and the grand truths to be obtained by it. After receiving a good education in the Swiss and German Universities, living frugally and economically, as students can on the Continent, he took his degree of Doctor of Medicine at Munich in 1829, having already written several important papers on zoology. In $183^{2}$ he was made Professor of Natural History at the University of Neuchatel ; and in 5833 he published his work on 'Fossil Fishes,' the expenses of the book being liberally paid by Humboldt. In 1839 he published his grand work on the 'Fresh-water Fishes of Europe,' which cost him so much that he was very poor for years afterwards.

There are very touching passages in some of Agassiz's private letters at this early period, when he had a hard 
struggle with life. His enthusiasm breathes out so naturally, and he speaks so regretfully of want of money, not for himself, but the work he longed to complete; while his gratitude is so sensible and heartfelt towards those who helped him to bring out these splendid additions to the science of zoology. His was a warm-hearted, earnest, and active nature, and he was beloved by all who knew him. It is pleasant to think that the Americans, among whom he spent the latter half of his life, from 1846 to 1874 , appreciated him fully; so much so that Mr. Anderson, a rich trbacco merchant of New York, presented him in 1873 with the island of Penikese, one of the Elizabcth islands, north of New York, and with funds to establish there a marine naturalist's school. The last year of Agassiz's life was spent chiefly on this island, training up a group of young naturalists.

Agassiz proves that parts of northern Europe and North America must once have been covered with Great Fields of Ice, 1840.-It is, however, of the early part of Agassiz's life, while he was still in Switzerland, that we must now speak. Although his chief study was zoology, yet he could not live at Neuchatel, and travel about the Alps without being struck with those mighty rivers of ice, called glaciers, which creep slowly down the valley of the Alps in Switzerland, carrying with them stones and rubbish. (See Fig. 62, p. 4r 2.)

These glaciers are formed by the snow, which collects on the tops of high mountains, and sliding down, becomes pressed more and more firmly together as it descends into the valleys, until it is moulced into solid ice, creeping slowly onwards between the mountains. and carrying with it sand, stones, and often huge pieces of rock which fall upon it. At last one end of this ice-river reaches a point where 
the air is warm enough to melt it, and here it flows gradually away as water, leaving the stones and rubbish it has brought down lying in a confused heap, which is called a moraine.

Towards the end of the eighteenth century a famous geologist, named De Saussure, spent much time in examining

Fig. 62.

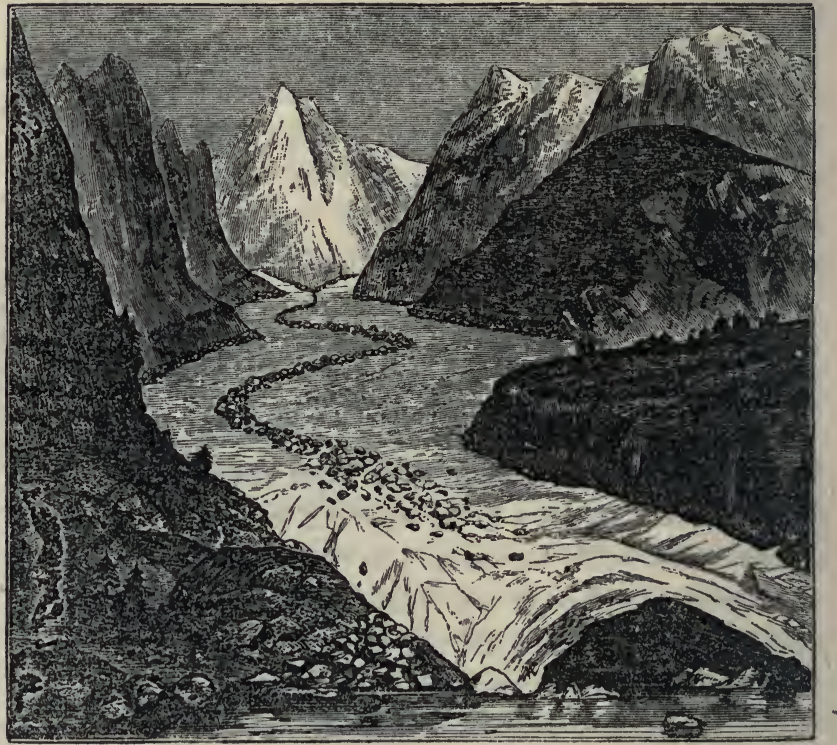

Glacier carrying down Stones and Rubbish (Lyell).

the glaciers of the Alps, and pointed out how they are now forming large deposits in the valleys, out of these heaps of rubbish which they bring down from the mountains. Since his time many geologists had taken up the study, but it was Professor Agassiz who first spelled out the wonderful history we can learn from it, about the former climate of our hemisphere. He noticed that rocks over which a glacier has 
moved, are polished and grooved by the rough stones and sand frozen into the bottom of the ice, just in the same way as a piece of wood is scraped by the sharp iron at the bottom of a plane; and by these glacial scratches, or strice, as they are called, he could tell where glaciers had been, even though there was nothing else to show that ice had ever existed in the country.

Now, when he began to examine the slopes of the Alps many hundred feet above the present glaciers, and also in places where it is now too hot for ice to remain, he found to his surprise numbers of these glacial strix and also remains of huge moraines, showing that the glaciers of olden time must once have been much larger and have stretched farther down the valley than they do now. And what was still more strange, these same marks were to be seen on the Jura Mountains, on the other side of Switzerland, where there are never any glaciers at present ; moreover, on the Jura there were found huge blocks, some of them as big as cottages, which were not made of the same materials as the hills on which they rested, but were broken pieces of rock such as are now only found on the Alps.

It was clear, then, that these enormous pieces of stone must have been carried right across Switzerland from the Alps near Mont Blanc, and across the lake of Geneva, which is $\mathrm{I}, 000$ feet deep, and then deposited on the Jura range near Neuchatel, where one block of Alpine gneiss, called the Pierre-à-Bot, as large as a good-sized cottage, sits perched on a mountain 600 feet above the top of the lake. How had these blocks travelled across the Swiss plains? No flood could have carried them, for they were too heavy, and besides they were not smooth as stones are which have been rolled in water, but were rough with sharp edges. Agassiz 
was convinced, therefore, that they must have been carried by ice, and that huge glaciers must once have come down from the high Alps right across Switzerland, filling the lake of Geneva with ice, and carrying these blocks with them, as modern glaciers do now in the Swiss valleys.

This was a marvellous history, for it showed that all the lower land of.Switzerland must once have been buried in ice, but other facts afterwards came to light which were more wonderful still. In 1840 Professor Agassiz came over to visit Great Britain, and when he went to Scotland with Dr. Buckland his practised eye discovered at once in the Highlands glacial scratchings, remains of moraines, and blocks which had been carried by ice; and soon it became evident that these were not confined to Scotland, for Dr. Buckland recognised them again in Wales and the North of England, where moraines and erratic blocks are to be seen in all parts of the country. So that here, too, in our little island, there must have been at one time huge glaciers as large as those now found in the Alps.

Nor was this all ; for when once geologists knew where to look for these signs of glaciers, it began to be discovered little by little that parts of all the northern countries of Europe, Norway, Sweden, Russia, Germany, Switzerland, Northern Italy, England, and even on the other side of the Atlantic, Canada and North America, have been smoothed and scratched ; and huge erratic (or wandering) blocks have been scattered over them, showing that in very remote ages (yet still while very nearly the same kinds of plants and animals as now were living upon the globe), the temperate parts of our northern hemisphere must have been intensely cold, causing a large part of these countries to be covered with great fields of ice, as Greenland is in the present day. 
And just as we see now that icebergs break off from the Greenland glaciers, carrying with them stones and mud, and dropping them at the bottom of the sea; so in those times icebergs floated over many of the valleys of Europe, which were then submerged beneath the ocean. You may see in the railway-cuttings of Wales and in the sea-cliffs in the coast of Yorkshire and Norfolk huge masses of glacial drift, as it is called, made of mud and stones confusedly mixed together, which were dropped from icebergs travelling southwards from the ice-fields.

This period of cold is called by geologists the 'Glacial Period ;' and when you read works on geology you will see that it explains in a wonderful manner many curious facts in the later history of our earth, and the distribution of plants and animals upon it. For the present it is enough for you to remember that Agassiz first pointed out the signs of this cold period, and that this discovery was one of the earliest rewards of a patient study of causes which are going on now ; for it is from the ice-action in Switzerland and Greenland in the present day, that we are able to understand how these huge ice-fields carried down erratic blocks and the mud of moraines during the Glacial Period.

Geological Proofs that Man lived upon the Earth in Ages long gone by, with Animals which are now extinct, $184 \%$. - The second remarkable discovery which has been made in geology in this century is that of the antiquity of man; or the fact that man must have existed upon our earth long before the very earliest times of history or tradition; in an age when an elephant and a hyæna, of extinct species, roamed about England and France, together with some other strange animals which are not now to be found upon the globe. 
This discovery, which was not believed for a long time, was first announced by a French geologist, M. Boucher de Perthes, in the year 1847. It happened that near this gentleman's house, at Abbeville in Picardy, gravel-pits had been dug from time to time for repairing the fortifications of the town, or mending the roads. During these excavations, in the beginning of the century, a great many bones of animals had been dug up and sent to Cuvier at Paris; and he stated that some of them belonged to animals slightly different from any now living, though not so ancient as those which came from under Paris (see p. 397). This showed that these beds of sandstone must have been formed long before the times of history or the earliest ages in which man was supposed to have been upon the earth. People, therefore, were much astonished when M. Boucher de Perthes stated in 1847 that he had found very rough stone weapons in these beds, such as savages might use, seeming to prove that men must have been living at the same time as these extinct animals.

This seemed so incredible that scientific men would not even listen to Boucher de Perthes' arguments in his work called 'Antiquites Celtiques,' and it was not till 1858, when one of our best living geologists, Mr. Prestwich, went to Abbeville and tonk a well-shaped flint hatchet out of the undisturbed gravel with his own hands, that people began to believe that human beings must have been living in the world much longer than had hitherto been believed. When, however, this was once acknowledged to be true, several new facts sprang up to confirm the theory. Many years before, in 1825 , a Roman Catholic priest, the Rev. J. Mac Enery, had found flint tools, with the bones of the extinct elephant, hyæna, and bear, in a cave called Kent's Hole, 
near Torquay, but very little notice had been taken of this discovery. Now, however, they were thoroughly studied, and they showed clearly that men who made rough flint tools (such as are still made by savages in many, parts of the world) must have lived in England, together with a bear, an elephant, a lion, and a hyæna, all of species which have now ceased to exist.

Discovery of the Swiss Lake-dwellings, 1853.-Again, in Switzerland, most curious discoveries have been made, giving us proofs of three distinct periods in the life of mankind. In the year 1853 , when the Swiss lakes were very low in consequence of a long drought, wooden piles were observed to rise above the water; and when these were examined by the Swiss antiquarians it was found that they were foundations of wooden villages, which had been built by the inhabitants of Switzerland in past ages. They stood some way out in the lake, and must have been joined to the shore by wooden bridges which the villagers could lift up when enemies came to attack them, and thus become protected by the water surrounding them. Habitations of this kind are built in the present day by the natives of Papua or New Guinea.

Down below the piles in the mud of the Swiss lakes a great number of tools, cooking utensils, bones of animals, and even burnt bread and corn, were found ; and the remarkable thing was, that the different kinds of tools showed that the villages did not all belong to one age. In a few, on the lakes of Bienne and Neuchatel, iron tools were buried, showing that when these villages were inhabited men knew how to melt iron out of the rocks and make it into tools. These villages must have been about the time of the Romans.

In others, however, only bronze tools were found, and 
these were much older, because bronze was used long before iron was discovered. And lastly in some, tools of stone only have been found, some beautifully polished, but others rough and rude, showing that the men who used them must have been mere savages like the Australians now ; and yet the oldest of these lake-villages have no bones of extinct animals in them, and therefore cannot be so ancient as those men whose tools were found in the cavern at Torquay and the sandpits of Abbeville, or as have since been found in England, Denmark, Germany, America, and indeed in almost all countries.

It is impossible, without a knowledge of geology, to realise how very long ago these last-mentioned men must have lived. But when I tell you that since their tools were buried in the rocks, there has been time for beds of inmense thickness to be laid down little by little, as the Ganges is laying them down now ; for parts of the French valleys to be gradually washed away, and their shape altered; for rivers to change their courses, and vast beds of peat to grow over the bottoms of the valleys ; and, more than all, for whole races of animals which once lived to have died quite away from the face of the earth, you may perhaps form some idea of the long ages that man must have been upon our globe. This history, however, is so new and as yet so little understood, that it cannot be explained in a few pages. You will find all the proofs of it given in Sir Charles Lyell's work on the 'Antiquity of Man,' in which they were first collected in 1863 ; and you must remember the fact, that man is very ancient, as one of the great discoveries of the nineteenth century.

Chief Works consulted.-Lyell's ' Principles of Geology,' 'Elements of Geology,' 'Antiquity of Man;' Lubbock's 'Prehistoric Times ;' 'Quarterly Geological Journal,' vol. xxx. : Obituary of Agassiz. 


\section{CHAPTER XL。}

SCIENCE OF THE NINETEENTH CENTURY (CONTINUED).

Facts which led Naturalists to believe that the Different Kinds of Animals are descended from Common Ancestors - All Animals of each Class formed on one Plan-Embryological StructureLiving and Fossil Animals of a Country resemble each other Gradual Succession of Animals on the Globe-Links between Different Species-Darwin's Theory of Natural Selection-Wallace worked out the same Theory independently-Sketch of the Theory of Natural Selection-Selection of Animals by Man-Selection by Natural Causes-Difficulties in Natural History which are explained by this Theory-Foolish Prejudices against it-Concluding Remarks on the History of Science.

Facts which have led Naturalists to believe that the different kinds of Animals are descended from common Ancestors.-We now come to the first attempt of any value which has ever been made, to explain how the different kinds of animals and plants have been produced. This question is so very difficult, and seems so much beyond our grasp, that we find very few people throughout the history of science who even tried to answer it. Aristotle, it is true, remarked that we can trace such a close resemblance between the different species, from the lowest plant up to the highest animal, as would seem to show they are related to each other (p. r6). Bonnet, too, thought that animals were developed from lower into higher forms (p. 202); and Lamarck, as we have seen, boldly suggested the same explanation (p. 391). 
But people in general treated these as mere wild speculations, and were content to say that God had created animals, just in the same way as they said that the stars were created by Him, without pausing to consider how $\mathrm{He}$ has created them.

Since the time of Buffon and Linnæus, however, many new facts had gradually been brought to light about living animals; and fossil species had been dug out of the earth, showing that many different forms had lived upon our globe, one after the other; and these new discoveries led naturalists to speculate whether some clue might not be found to explain this long succession of living beings.

Then again, as naturalists spread all over the world and many new forms of animals and plants became known, it was found to be more and more difficult to separate the different species and to say which are and which are not descendants of one parent. Linnæus, as we have seen (p. 392), pointed this out in the case of plants, and wild roses are a very good example of it ; for the different kinds run so much into each other that while one of our best botanists has divided them into seventeen species, another thinks that many of these must have come from the same parent, and that only five species can be distinguished. Again, among insects, the well-known naturalist, Mr. Bates, has shown that on the Amazons in South America it is often impossible to tell, among some families of butterflies, which are the same species and which keep apart from each other. Facts like these, of the relationship of living beings, had long been forcing themselves upon naturalists, and this was one of the reasons given by Lamarck for supposing animals to be all descended from a few simple forms.

\section{All the Animals of each Class formed on the same}


Plan.-Another reason was that curious agreement in the bones of different animals which had become more and more noticed ever since the time of John Hunter, and which Geoffroy St.-Hilaire insisted upon so strongly. Why should the animals of one class (such as the vertebrate or backboned class) be formed all on one plan even to the most minute bones; so that the wing of a bat, the front leg of a horse, the hand of a man, and the flapper of a porpoise, are all made of the same bones, which have either grown together, or lengthened and spread apart, according to the purpose they serve? And, more curious still, why should some animals have parts which are of no use to them, but only seem to be there because other animals of the same class also have them. Thus the whale has teeth like the other mammalia, but they never pierce through the gum; and the boa-constrictor has the beginnings of hind legs hidden under its skin, though they never grow out. Here again it seemed extraordinary, if a boa-constrictor and a whale were created separately, that they should be made with organs which are quite useless; while, on the other hand, if they were descended from the same ancestor as other reptiles and mammalia who have teeth and hind legs, they might be supposed to have inherited these organs ; just as, for example, a child sometimes has a mole or other mark upon its body in exactly the same place as its great grandfather had before it.

Embryos of Animals alike in Structure.-Another still more remarkable fact was that pointed out by Von Baer, that the higher animals, such as quadrupeds, before they are perfectly formed, cannot be distinguished from the embryos of other and lower animals, such as fish and reptiles. If animals were created separately why should a dog begin 
like a fish, a lizard, and a bird, and have at first parts which it loses as it grows into its own peculiar form?

Living Animals of a Country agree with the Fossil ones.-These were facts entirely belonging to living creatures, but now others sprang up about fossil species which were equally puzzling. We know that certain animals are only found in particular countries ; kangaroos and pouched animals, for example, in Australia ; and sloths and armadillos in South America. Now it is remarkable that all the fossil quadrupeds in Australia are also pouched. animals, though they are of different kinds and larger in size than those now living; and in the same way different species of sloths and armadillos are found fossil in South America; while in the rocks of Europe fossil mammalia are found, only slightly different in form from those which are living there now. Naturalists therefore asked themselves again - 'Would it not seem likely that the living pouched animals of Australia and the sloths and armadillos of America are the descendants of the dead ones in the rocks, although they have in the course of long ages become rather different from them; while oxen, bears, wolves, \&c., are also the descendants of those which are found buried in the rocks of Europe?

Gradual succession of Animals which have appeared upon the Globe.-This seemed still more likely as the study of geology advanced, and it became clear that a gradual succession of higher and higher animals had appeared upon the globe. Thus, in the oldest rocks containing fossils, we find no monkeys, no quadrupeds, no reptiles, no amphibians such as our frogs, but only shells of marine animals, and a few bones of fishes, of kinds quite different from those now living.

Then in rocks above these we find the fish becoming very abundant and varied, and higher still we meet with 
footprints of some animal with feet; and the bones of an amphibian, somewhat like a frog, are next found. In these times the fish began to cease to be monarchs of the water, for a little higher up huge swimming reptiles, like our crocodiles and lizards, but much larger, have left their bones in the rocks. Next come reptiles with wings, which measure sixteen feet across from tip to tip, and we must picture these huge flying lizards, with wings like bats, roaming over the globe with no higher animals to persecute them.

But they were only to have their turn, for in rocks formed a little later there appear two skeletons, one of a small creature half reptile half bird, about the size of a pigeon, and the other of a real bird with some of its feathers still remaining; and in beds of about the same age there occurs the jaw of a small insect-eating animal something like an ant-eater. Birds and quadrupeds therefore had now begun to exist, and soon the bones of pouched animals are found, and then of mammalia, like our moles and shrews; and from this time the reptiles become smaller, as if they were kept down and gradually destroyed by the higher animals, and the quadrupeds become larger and more powerful ; till, in those beds which Cuvier studied near Paris, we find the gigantic elephant and rhinoceros-like animals we spoke of before; while in beds of about the same age occur the first bones of monkeys.

This is a very rough sketch of the order in which animals are found in the earth's crust. The lower kinds first, and then gradually higher and higher forms as they come near to our own time; and if we could study them more closely you would see that in rocks nearly of the same age the forms are always very like each other, while the farther apart the formations are, the inore different are the animals. It is true 
that there are very few close links to be found between fossil animals ; but when we remember that nearly all the rocks in the earth's crust are made out of others which have been destroyed, it is scarcely wonderful that so few skeletons should be found of those that were once buried, and it is not likely that many of these would be just the intermediate forms we want. Still some have come to light, for a birdreptile has been found in the rocks of Kansas, in America, which has a skeleton like a bird, but teeth and jaws like a reptile; and a reptile has been dug out of the Stonesfield slate in England, which Mr. Huxley says must have hopped like a bird, having legs, neck, and a bird-like head, while it had nevertheless teeth like a reptile. Again, horses have been found in the rocks of America, which have sepa. rate toes, and others in which the toes are beginning to grow together, showing how they may have been gradually altered into our one-toed horse.

And here again, those who studied fossil animals asked why these forms should succeed each other, gradually passing on into the living forms of our own day, which are all slightly altered copies of these fossils of the rocks?

How can Plants and Animals have become altered?It was questions such as these which seemed to call for answers, and to find none except the one proposed by Lamarck; namely, that the different kinds of animals are all descended from a few simple forms. If this were so, then it would be quite natural that higher and higher forms should appear gradually upon the earth, and that the kinds most alike should follow directly upon each other, those which are now living being very like their ancestors in the newest formation in the earth's crust. It would also help us to understand why animals of the same class should have the 
same bones, and why some should have parts remaining in their body which are no longer of any use; and lastly, it would explain why naturalists have so much difficulty in distinguishing nearly related species.

But though these reasons made it seem very likely that all animals are only different branches from one stem, yet this could only be a mere speculation unless some one could point out what has made them differ so much from each other. Lamarck, as we have seen, could not do this, and therefore his suggestion was passed by; and it was not till about sixteen years ago that two naturalists, Mr. Darwin and Mr. Wallace, discovered a law which is certainly true in itself, and which accounts for many of the facts. Their theory, which we must now consider, is so new that it has been opposed on all sides, just as the Copernican theory was opposed in the sixteenth century, the circulation of the blood in the seventeenth century, and the theory of combustion, which overturned phlogiston, in the eighteenth century. We live in the midst of the discussion about the origin of species, and it will only be our great-grandchildren who will be able to talk of the Darwinian theory in the way in which we talk of the discoveries of past centuries; but you ought at least to understand what this theory is, for it forms an era in the history of science.

Darwin's Theory that Natural Selection has caused the various kinds of Plants and Animals to differ widely and permanently from each other.-The theory of Natural Selection, or the Darwinian theory as it is often called, has been chiefly worked out by a great living naturalist, Mr. Charles Darwin, who was born in 1809 . When he was only two-andtwenty, Mr. Darwin went in her Majesty's ship 'Beagle' to survey the coast of South America and sail round the globe ; 
and on his return he wrote an account of the geology and natural history of the countries he had visited. He tells us himself that even so early as this he noticed many facts which seemed to him to throw light on the difficult question of the origin of the different species of plants and animals ; and he spent twenty years carefully collecting in England all the knowledge he could upon the subject. But he did not publish it, for he wanted more and more evidence ; and as Newton waited sixteen years for more convincing proof before he announced his theory of gravitation, so Mr. Darwin would have delayed much longer than he did if a remarkable circumstance had not obliged him to speak.

It happened that while Mr. Darwin was working in England, another great naturalist, Mr. Alfred R. Wallace, who was then in the Malay Archipelago, also thought that he had discovered the way in which animals are made to vary in the course of long ages. He sent home a paper on the subject, and, though he had never heard of Mr. Darwin's theory, it was found that he had worked out the same result, sometimes almost in the same words.

Sir C. Lyell and Dr. Hooker of Kew were so much struck with the fact that these two men had solved the problem almost precisely in the same way, that they begged Mr. Darwin to allow one of his papers, written many years before, to be published with Mr. Wallace's, and the two essays were read the same evening, July $r ; 1858$, at the Linnæan Society. A year later, in November 1859 , Mr. Darwin's famous work, 'The Origin of Species,' was published.

'The Theory of Natural Selection,' or the choosing out by natural causes of those plants and animals which are best fitted to live and multiply, rests upon a few simple facts which you can understand. 
Firstly, all living beings multiply so rapidly that there would be neither room nor food enough upon the earth for them if they were all to live ; therefore immense numbers must die young, and those will live the longest and have children to follow them who are best fitted for the kind of life they have to lead.

Secondly, no two living beings are ever exactly alike; but children always inherit some of the characters of their parents, so that if any being has a peculiarity which makes it better fitted for its life, and consequently lives long and has a large family, some of its descendants will most likely inherit that peculiarity.

Now it is not difficult to understand that if useful peculiarities of different kinds are handed down in this way from parent to child, those who inherit them will in time begin to be remarkable for different qualities. For example, suppose that in a nest of young birds, one with strong wings lives and has young because it can fly far and get food, while another also lives and has young because its feathers are dark, and the hawks cannot see it in the grass. Then those descendants of the strong-winged bird which also have strong wings, will be most likely to live on in each generation, and will pass on this peculiarity to their children; while the descendants of the dark-coloured bird will also survive in each generation exactly in proportion as their plumage is adapted to hide them; and thus the strong-winged birds and the dark-winged birds will in time become very different from each other. This is roughly the theory of 'Natural Selection;' that nature allows only those animals to live which in some way escape the dangers which threaten their neighbours, and thus in time the race becomes altered to suit the life it has to lead. 
There is only one difficulty. It is clear that the strongwinged birds must not pair with the dark-winged birds, or otherwise both peculiarities would come out in the young birds, and the two kinds would no longer remain distinct. And this is the one stumbling-block in the theory; we have never yet been able to trace out two varieties of an animal which have become so different that they do not pair together. You should fix this difficulty firmly in your mind, because it is almost the only real one we shall meet with. Mr. Darwin's answer to it is, that we have only watched plants and animals for such a short time, and even then not with this idea in our minds, so that we are not likely to have found a case to help us. It has indeed been observed that animals, if left free to choose, do often pair with those which resemble themselves, and do in some cases show a dislike to those that differ; still this is not proved to be always the case, and it must be acknowledged to be a difficulty.

Selection of Animals by Man.-But now setting this aside, let us see what proof there is that animals vary, and that they can be picked out, so that any peculiarity may become stronger in each succeeding generation. The best instance is in pigeons. All our pigeons come from the common wild rock-pigeon; and the way in which all our pouters, fan-tails, barbs, and other pigeons have been produced, is by merely picking out from the young ones those which had either large crops, or wider tails, or longer beaks, and pairing them together, so that the young birds had these peculiarities still more strongly. The same thing is true of our different kinds of oxen, sheep, horses, and fowls; so we see clearly that different varieties can be produced by choosing out particular animals. Man does this quickly, because he only 
attends to one peculiarity, which interests him; but nature does it very slowly, because no animal can live unless every part of it is fitted for its life better than in those which are killed off.

Selection by Natural Causes.-Now Mr. Wallace has calculated that one pair of birds having four young ones a year, would, if all their children, grandchildren, and greatgrandchildren, lived and paired, produce about two thousand million descendants in fifteen years. And Mr. Huxley tells us that a single plant producing fifty seeds a year would if unchecked cover the whole globe in nine years, and leave no room for other plants.

It is clear, therefore, that out of these numbers millions must die young, and it is only the most fitted in every way that can live and multiply. One example from Mr. Darwin's book will show you how complicated the causes are, which determine what particular kinds shall flourish. $\mathrm{He}$ tells us that the heartsease and the Dutch clover, two common plants, can only form their seeds when the pollen is carried from flower to flower by insects. Humble-bees are the only insects which visit these flowers, therefore if the humble-bees were destroyed in England there would be no heartsease or Dutch clover.

Now the common field-mouse destroys the nests of the humble-bee, so that if there are many field-mice the bees will be rare, and therefore the heartsease and clover will not flourish. But again, near the villages there are very few fieldmice, and this is because the cats come out into the fields and eat them; so that where there are many cats there are few mice and many bees, and plenty of heartsease and Dutch clover. Where there are few cats, on the contrary, the mice flourish, the bees are destroyed, and the plants cease to bear 
seed and to multiply. And so you see that it actually depends upon the number of cats in the neighbourhood how many of these flowers there are growing in our fields.

But now let us suppose for a moment that among the field-mice there are some whose skin has a slightly peculiar smell, so that the cats do not eat them when they can find others. Clearly these mice would live longest and have most offspring; and of these again, those with strong-smelling skins would live; and so after a time a new race of mice would arise which would be independent of the cats, and the bees would have a poor chance of living, and consequently the flowers of bearing seeds.

But this might in the end give rise to quite a new race of plants, for it is believed that some moths would visit the clovers, on!y as Mr. Darwin points out, they are not heavy enough to weigh down the petals of the flowers so as to creep inside them. But as no two flowers are ever exactly alike, it is very likely that the petals of some blossoms will droop a little more than in the others, and so if the bees became scarce, these blossoms with drooping petals might live on, because the moths could creep into them and carry their pollen from flower to flower; and thus a new race of clover with drooping petals might spring up independent of the cats, the mice, and the bees, and would become a new species.

You must especially notice in this imaginary example that it is only useful variations which can be passed on from generation to generation. If the smell of the mice (which would probably come from some peculiarity in the pores of the skin) did not preserve them from the cats, the strong-smelling mice would not live, and a peculiar race would not arise; in the same way, if the drooping leaves of 
the clover did not enable the moths to enter, those plants would die out like the others. And this is one of the most striking facts which Mr. Darwin has pointed out; namely, that no variation will continue and increase from generation to generation unless it is useful to the plant or animal which possesses it; so that if this theory be true, every beautiful colour which we aỏmire in animals and plants, every minute detail in their form and structure, is not only to be admired for its beauty, but because it is an evidence of that wonderful harmony of nature which keeps every part, however insignificant, exactly fitted to do its work in the one great scheme of creation.

Difficulties in Natural History explained by Natural Selection.-And now, if we adopt Mr. Darwin's explanation, you will see how St.-Hilaire and Cuvier could both be right when the one said that all animals are formed on one plan, and the other that each part of an animal is exactly fitted to work harmoniously with the rest of its body. For if animals have been gradually altered the one from the other, it is natural "they should all be made on one plan; as, for instance, if the ancestor of the bat, millions of years ago, was also the ancestor of those animals out of which the horse has come, then the bones of the bat's wing may well be similar to those of the horse; while, on the other hand, if no variation can become fixed, and develope into important parts or organs unless it is useful, it is clear that all the parts of an animal must have been gradually modified so as to fit each other and to work in the best possible way for its well-being. Again, it explains why the living animals in a country should be of the same class, though slightly different from those found fossil in the earth. For if in Australia the ancestors were pouched animals, it must 
take a very long time before their descendants could be anything else, although they might begin to differ in many points.

Lastly, it enables us to understand why we find the lower forms of life in the oldest rocks, and why gradually, as animals multiplied and the struggle for life became greater, more and more complicated forms should arise, from the improvement and inheritance of specially useful parts; so that the higher animals have a greater number of different parts to perform different actions, just as a civilized country with a great number of skilled people in it, has men of different trades and professions, one to brew and one to bake, one to dig the ground, and to grow cotton and flax, and another to weave them into garments.

This will give you a very small glimpse of some of the difficulties which are explained by the theory of natural selection. The subject is so difficult to understand thoroughly, that you must not expect to have more than a slight notion of it, and must be content for the present with knowing that our greatest living naturalists, who have made a careful study of living and fossil animals and plants, all believe it to be true.

And as this is so, it is extremely foolish to te prejudiced against it, as some people are, by the idea that animals formed in this way can be less God's creation than if they were made in any other way. The whole history of science teaches us that men, in all ages, have constantly taken false alarm when it has been shown that God's ways are not our ways, and that the universe is governed by far wider and more constant laws than we had imagined in our little minds. But in the same way as the planets are none the less held in God's hand because we now know that it is by 
the law of gravitation that He governs their movements, so every plant and animal must be equally His creation, in whatever way they have been developed. Above and beyond all these laws which we can trace, there remains ever the One Great and Supreme Creator whom Anaxagoras worshipped instead of the heathen gods of Greece (see p. 14), when his fellow-countrymen condemned him as an unbeliever because he believed not in many, but in One God.

A humble, earnest spirit seeking knowledge must indeed find in modern science a deep revelation of the Unity and Unchangeableness of the Creator. Instead of many widely different sciences standing each alone, which the great men of earlier centuries worked out, we are beginning to be able to discern one constant power working through them all; while still new fields of discovery, such as that which spectrum analysis has only lately opened out to us, help us to bear in mind how little we know, and how much more vast than anything that we can imagine, must be the great scheme of Creation which is being worked out around and within us.

Concluding Remarks. -We have now arrived at the end of our history, for a summary of the science of the nineteenth century is manifestly impossible. The subject has become too vast to be dealt with in a short sketch, even if the limits of this little volume were not already reached. Besides, as we have not mentioned the work of living men, except in cases such as those of Kirchhoff and Darwin, where it was impossible to be avoided, we have not really examined the science of this century, but only very small portions of it. We can therefore, in conclusion, only try to understand the tendency of the science of our day as compared with that of earlier centuries. 
The work of the sixteenth century, as we saw (p. 82), was to overcome that blind worship of authority which had sprung up during the Dark Ages, and which is the greatest enemy to true knowledge.

In the seventeenth century the march of scientific discovery began with Galileo, and advanced slowly but triumphantly through many dangers and difficulties, till it ended in the grand generalizations of Newton. This was the first great era of modern science, especially of astronomy and physics, though biology also made a great stride when Harvey demonstrated the circulation of the blood.

The eighteenth century continued the same work of patient enquiry, completing the harmony of astronomy by bringing the observed movements of the planets under Newton's law of gravitation; founding chemistry upon a firm basis of careful experiment; creating the sciences of zoology and botany, by establishing true systems of classification; discovering the hitherto almost unknown force of electricity; and reading in the crust of the earth the history of the past ages of our planet.

And so when the nineteenth century opened, men found themselves with an immense mass of known facts and careful experiments, which had been accumulated during the last two centuries, and which were very difficult to deal with, because it had become almost impossible for any single mind to grasp them all. The scientific men of our century have therefore become divided into two great classes. On the one hand men have devoted themselves to special sciences, and even to special branches of a science, so that a man will often spend his whole life in the study of one department of chemistry or pinysics, or in investigating one little group of 
insects; and in this way discoveries of great value have been made.

On the other hand great minds among us have taken up the separate facts collected by specialists, and have woven the whole of physical science into one grand scheme. Such men as Faraday, Helmholtz, Sir W. Thomson, and Grove, together with many others, have done their part in this work, so that now all the various physical forces have been shown to be probably phases of one great force, appearing under many forms. For the future no one physical force can be studied as if it existed by itself alone, for each is shown to arise out of and to pass into others. Heat, electricity, magnetism, chemical affinity, motion-all are related to each other, and we cannot call any one of them the ruler over the rest. Like the colours on the soap-bubble, they each take their turn in appearing and disappearing, according to the conditions under which they arise. Their relations are almost infinitely complex, and we have still much to learn about them; but the grand fact that they pass the one into the other without loss of energy has been demonstrated in our century ; and, under the names of 'the conservation of energy,' and 'the correlation of the physical forces,' is one of the greatest results of modern science.

The same tendency may be seen in the study of those sciences which relate to life. Here again modern investigation links together the scattered observations of ages, and unites them all in the theory of 'evolution,' or the gradual unfolding of nature; a theory which has been worked out in all its details by Herbert Spencer, one of our greatest living thinkers. In astronomy, indeed, we already catch a glimpse of this law in the probable formation of the heavenly bodies out of gaseous star-matter; and in the or- 
ganic world we find it even more firmly held by scientific men in the belief that all the many forms of plant and animal life have been unfolded out of a few simple forms, just as the stem, the leaf, and the flower are evolved out of a simple seed.

Whether this theory is true or not, it must be the work of many generations to prove, for the history of science teaches us that nothing but truth can stand the test of long investigation, while no power or authority can resist in the end that which is true. The mistaken theory of phlogiston did its work in gathering together many scattered facts in chemistry, and then died a natural death when the discovery of oxygen threw more light upon the subject; while no authority or persecution could suppress the true theory that the earth moves round the sun.

It is of great importance that we should all learn this lesson, to have faith in the invincible power of truth; for it would almost seem as if all the experience of past centuries had hardly yet convinced us. We still, like the Aristotelians and the judges of the Inquisition, often make hasty and ignorant assertions, and try rather to prop up by authority that which we believe, than to enquire earnestly whether it is true. Yet every page in the History of Science teaches the contrary lesson. So much as is true in any belief will stand because it is true; while that which is mistaken will fade away before carnest and impartial examination. Our part is to endeavour, like the great men of whom we have been reading, to open our eyes to the laws which surround us, and which are only hidden from us by our ignorance. And from whatever source we derive our knowledge we must remember that it is very little after all, and be ready at all times to examine new facts, even though they may seem 
to upset some of our favourite opinions; for unless we know everything, it is certain that we must at times find that we have been mistaken.

Those who will labour in this spirit of seeking the truth for itself will find their reward in the ever-increasing delight they will feel in studying God's works, and in the assurance which they will meet with at every step, that nothing can happen except under the guidance of His laws. True science, like true religion, leads to an entire and childlike dependence upon the Invisible Ruler of the universe. It makes us eager to study God's laws, that we may live in accordance with them, and diminish some of the gross ignorance which now prevails; while at the same time it leads even the most instructed to feel how extremely limited our knowledge is, and that we are after all like inexperienced children, dependent upon the love and power of our Maker to bring us safely out of darkness into light.

Chief Works consulted. -Darwin's 'Origin of Species;' Wallace's 'Natural Selection;' Huxley's 'Lectures to Working Men;' Lyell's 'Principles of Geology.' 



\section{CHRONOLOGICAL TABLES}

$$
\text { OF THE }
$$

RISE AND PROGRESS OF THE VARIOUS

\section{BRANCHES OF SCIENCE}




\section{SCIENCE OF THE GREEKS.}

FROM B.C. 639 TO A.D. 200.

The dates of this table refer to the years in which each particular step in advance was ruate; but up to the end of the Middle Ages they must be regarded as merely appraximative.

\begin{tabular}{|c|c|c|c|c|}
\hline Astronomy. & $\begin{array}{l}\text { Physics and } \\
\text { Mechanics. }\end{array}$ & Chemistry. & $\begin{array}{l}\text { Physical } \\
\text { Geography and } \\
\text { Geology. }\end{array}$ & Biology. \\
\hline 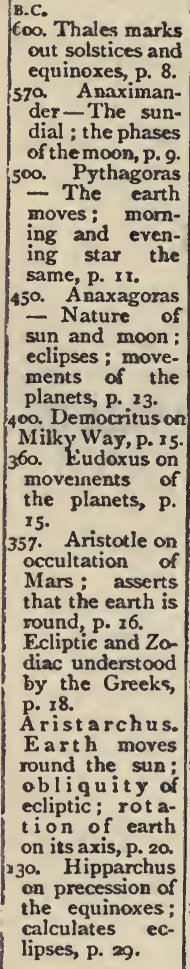 & $\begin{array}{l}\text { 26a Euclid on } \\
\text { light travelling } \\
\text { in straight lines, } \\
\text { p. } 21 . \\
250 \text {. Archimedes } \\
\text { on the lever; } \\
\text { Hiero's crown } \\
\text { and specific gra- } \\
\text { vity screw of } \\
\text { Archimedes, pp. } \\
22-25 . \\
120 \text { Hero's en- } \\
\text { gine, p. } 245 \text {. }\end{array}$ & $\begin{array}{l}\text { Greeks knew how } \\
\text { to extract iron, } \\
\text { mercury, and } \\
\text { other metals } \\
\text { from the ore : } \\
\text { and make co } \\
\text { lours out of } \\
\text { earths, p. } 40 \text {. }\end{array}$ & $\begin{array}{l}\text { w7a Anaximan- } \\
\text { der makes a } \\
\text { map of the } \\
\text { known world, } p \text {. } \\
\text { ro. } \\
500 \text { Pythagoras } \\
\text { on changes of } \\
\text { land and sea : } \\
\text { on earthquakes, } \\
\text { volcanos, and } \\
\text { pe } t r \text { if y ing } \\
\text { springs, pp. Ix- } \\
\text { I2. }\end{array}$ & 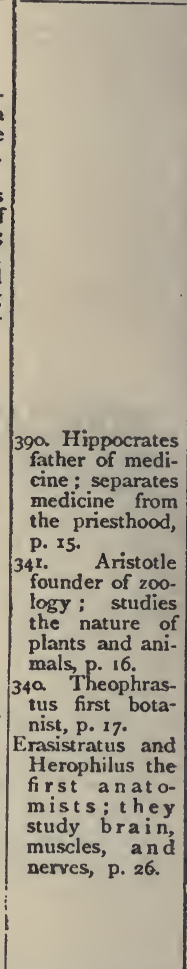 \\
\hline $\begin{array}{l}\text { A.D. roo. Ptole- } \\
\text { my founds the } \\
\text { Ptolemaic sys- } \\
\text { tem, p. } 32 \text {. }\end{array}$ & & & $\begin{array}{l}\text { A.D. 100. Ptole- } \\
\text { my on geo- } \\
\text { graphy, p. } 23 \text { - } \\
\text { Strabo on earth- } \\
\text { quakes and vol- } \\
\text { canoes, p. } 33 \text {. }\end{array}$ & $\begin{array}{l}\text { A. D. I60. Galen, } \\
\text { p hy s ic i an, } \\
\text { studies nerves } \\
\text { and arteries; } \\
\text { works out a } \\
\text { theary of medi- } \\
\text { cine, p. } 33 \text {. }\end{array}$ \\
\hline
\end{tabular}




\section{SCIENCE OF THE MIDDLE OR DARK AGES.}

\section{FROM A.D. 700 TO 1500 .}

\begin{tabular}{|c|c|c|c|c|}
\hline Astronomy. & $\begin{array}{l}\text { Physics and } \\
\text { Mechanics. }\end{array}$ & Chemistry. & $\begin{array}{l}\text { Physical } \\
\text { Geography and } \\
\text { Geology. }\end{array}$ & Biology. \\
\hline $\begin{array}{l}\text { The Arabs great } \\
\text { astronomers, but } \\
\text { mix up astrono- } \\
\text { my with astro- } \\
\text { logy, p. } 45 . \\
\\
\text { coo. Albategnius } \\
\text { calculates the } \\
\text { length of the } \\
\text { year, p. 45. } \\
\text { roo8. Ebn Junis } \\
\text { draws up astro- } \\
\text { nomical tables, } \\
\text { p. } 46 .\end{array}$ & 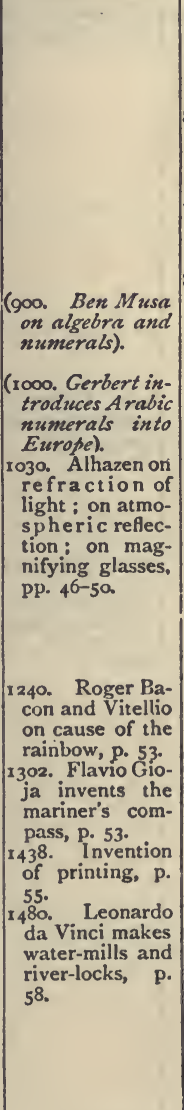 & 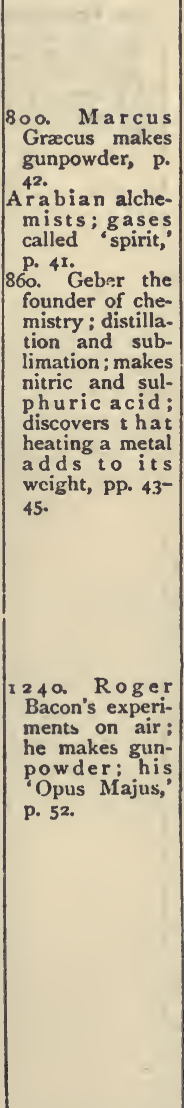 & $\begin{array}{l}\text {. } \\
\text { 980. Avicenna, a } \\
\text { famous writer } \\
\text { on minerals, p. } \\
\text { 50. }\end{array}$ & 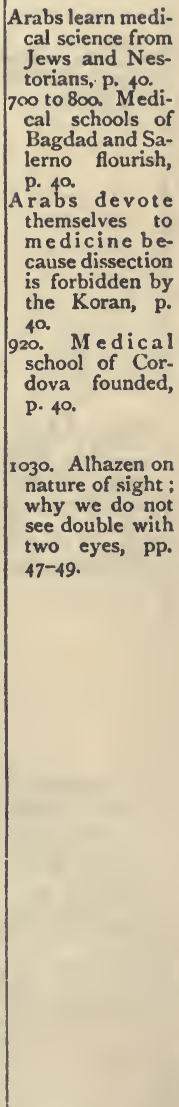 \\
\hline
\end{tabular}




\section{RISE OF MODERN SCIENCE.}

FROM A.D. 1519 TO 1604.

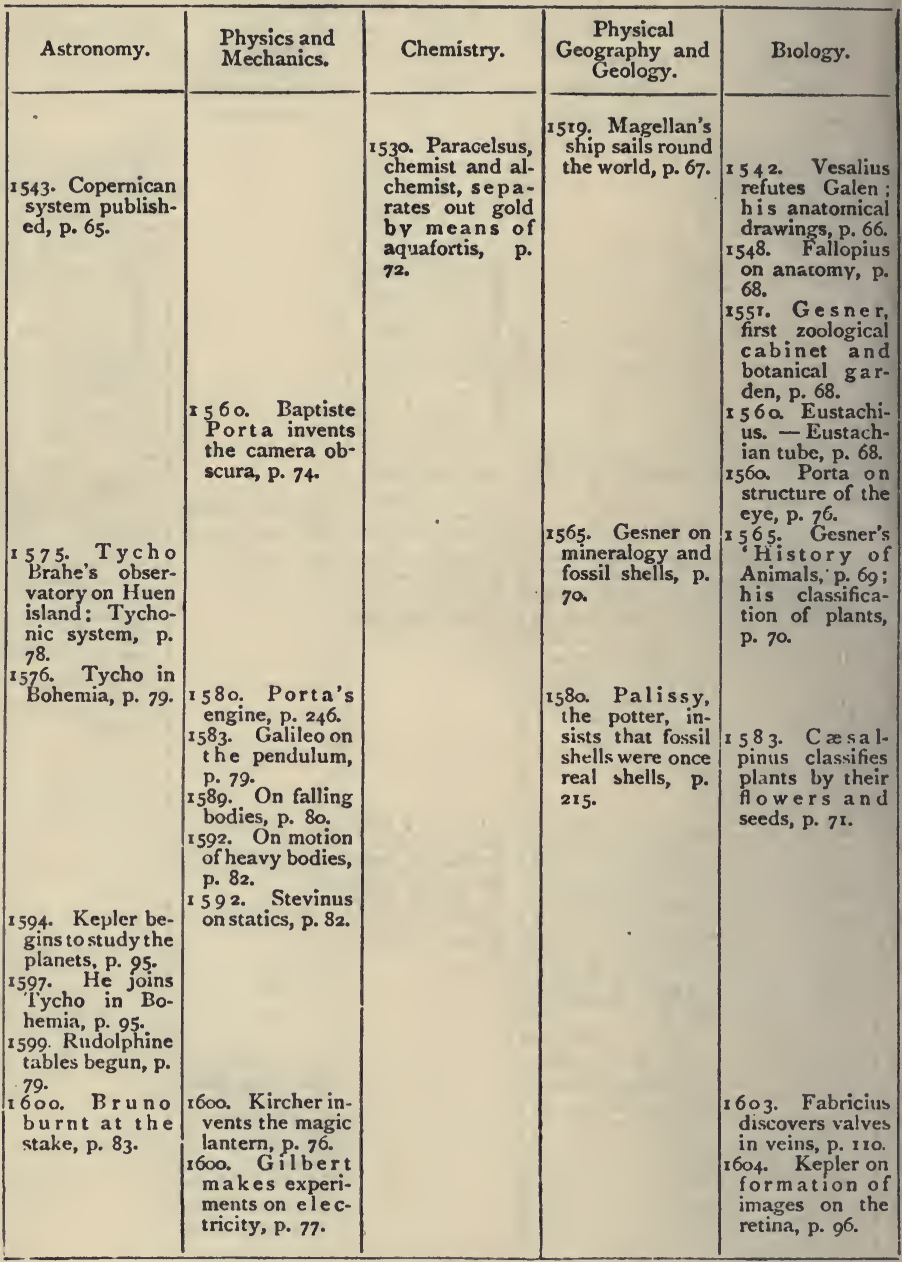




\section{PROGRESS OF MODERN SCIENCE. \\ FROM A.D 1609 TO 1642.}

\begin{tabular}{|c|c|c|c|c|}
\hline Astronomy. & $\begin{array}{l}\text { Physics and } \\
\text { Mechanics. }\end{array}$ & Chemistry. & $\begin{array}{l}\text { Physical } \\
\text { Geography and } \\
\text { Geology. }\end{array}$ & Biology. \\
\hline 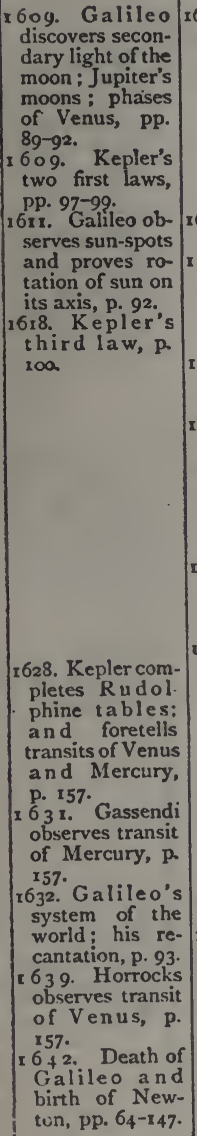 & 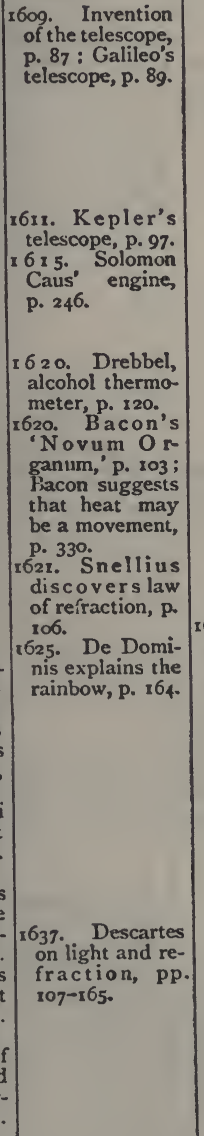 & $\begin{array}{l}\text { | Van Hel- } \\
\text { r624. } \\
\text { mont introduces } \\
\text { the term gas, p. } \\
72 .\end{array}$ & & $\begin{array}{l}\text { x6rg. Harvey } \\
\text { discovers circu- } \\
\text { Iation of the } \\
\text { blood, pp. } 210- \\
\text { x14. } \\
\\
\text { 622. As ellius } \\
\text { disco vers lac- } \\
\text { teals, xt4. }\end{array}$ \\
\hline
\end{tabular}




\section{PROGRESS OF MODERN SCIENCE.}

FROM A.D. 1644 TO 1670.

\begin{tabular}{|c|c|c|c|c|}
\hline Astronomy. & $\begin{array}{l}\text { Physics and } \\
\text { Mechanics. }\end{array}$ & Chemistry. & $\begin{array}{l}\text { Physical } \\
\text { Geography and } \\
\text { Geology. }\end{array}$ & Biology. \\
\hline 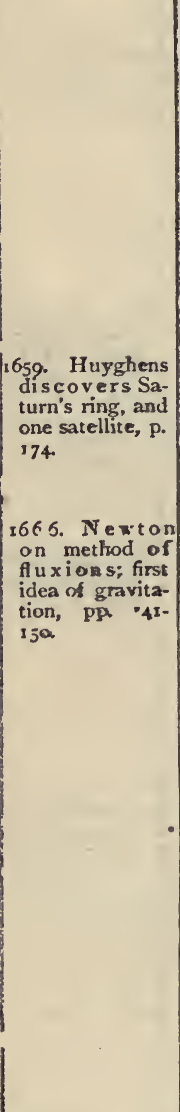 & 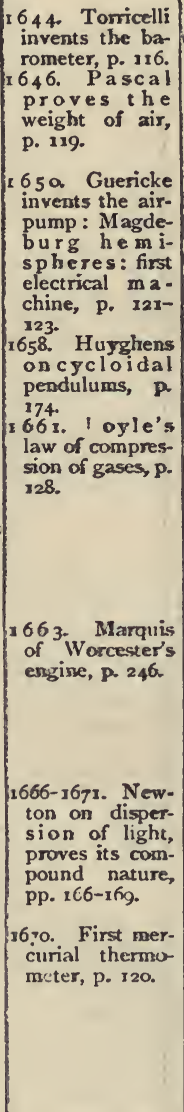 & 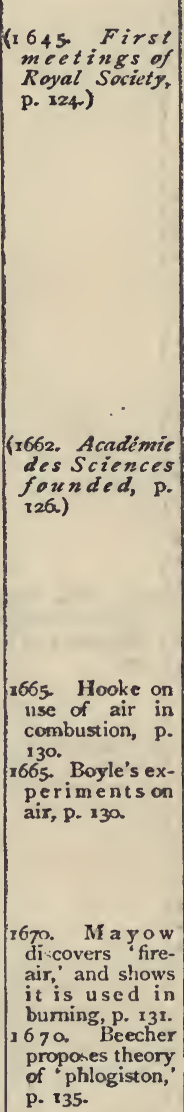 & $\begin{array}{l}\text { I } 669 \text {. Steno on } \\
\text { fossils and petri- } \\
\text { factions, p. } 2 \times 5 \text {. } \\
1670 \text { Scilla on } \\
\text { fossils of Cala- } \\
\text { bria, p. } 216 .\end{array}$ & 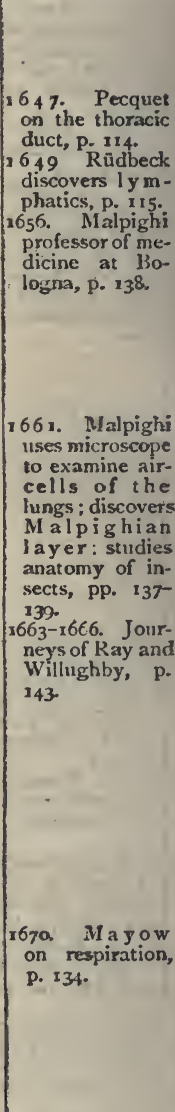 \\
\hline
\end{tabular}




\section{PROGRESS OF MODERN SCIENCE.}

FROM A.D. 1674 TO 1732.

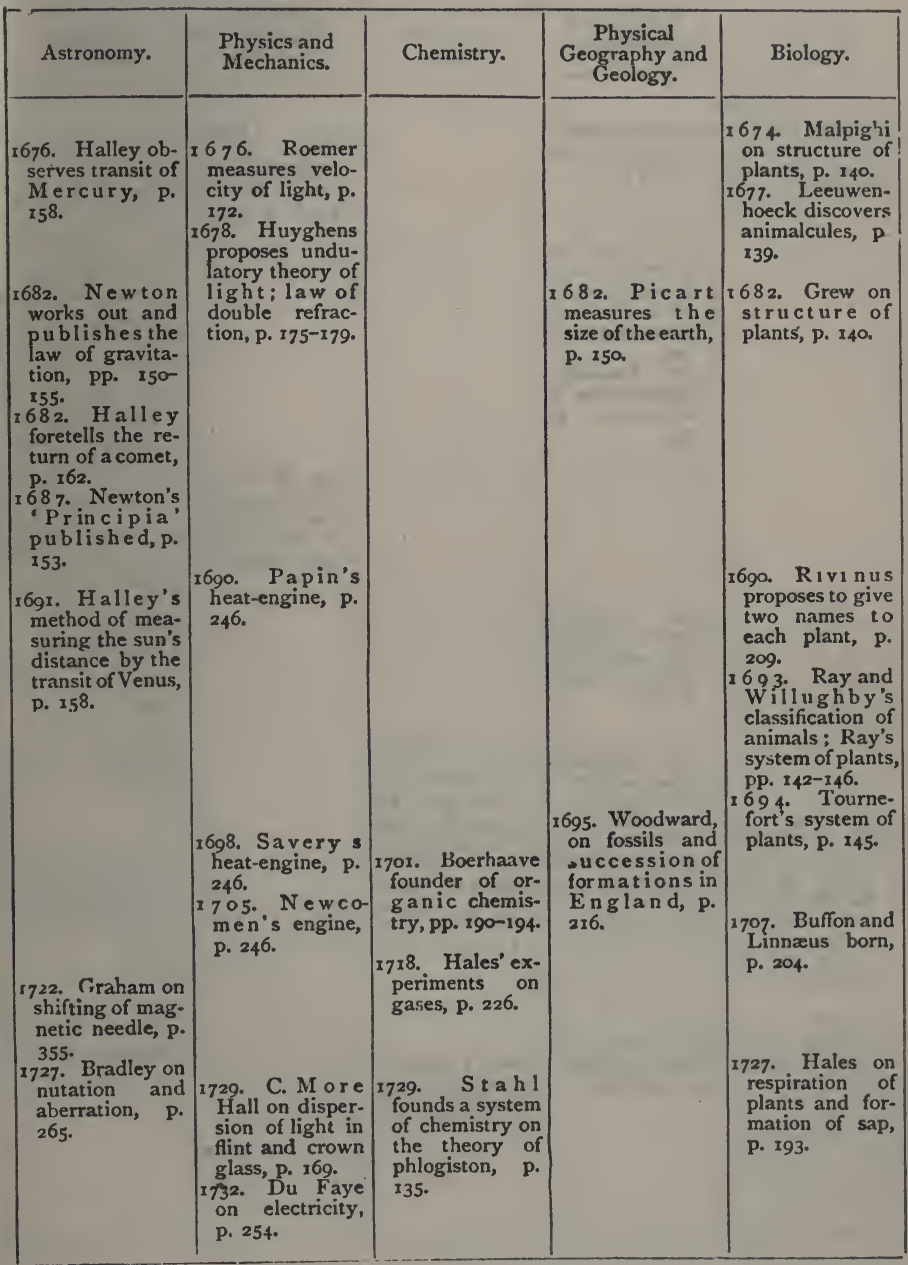




\section{PROGRESS OF MODERN SCIENCE.}

FROM A.D. 1738 TO 1766.

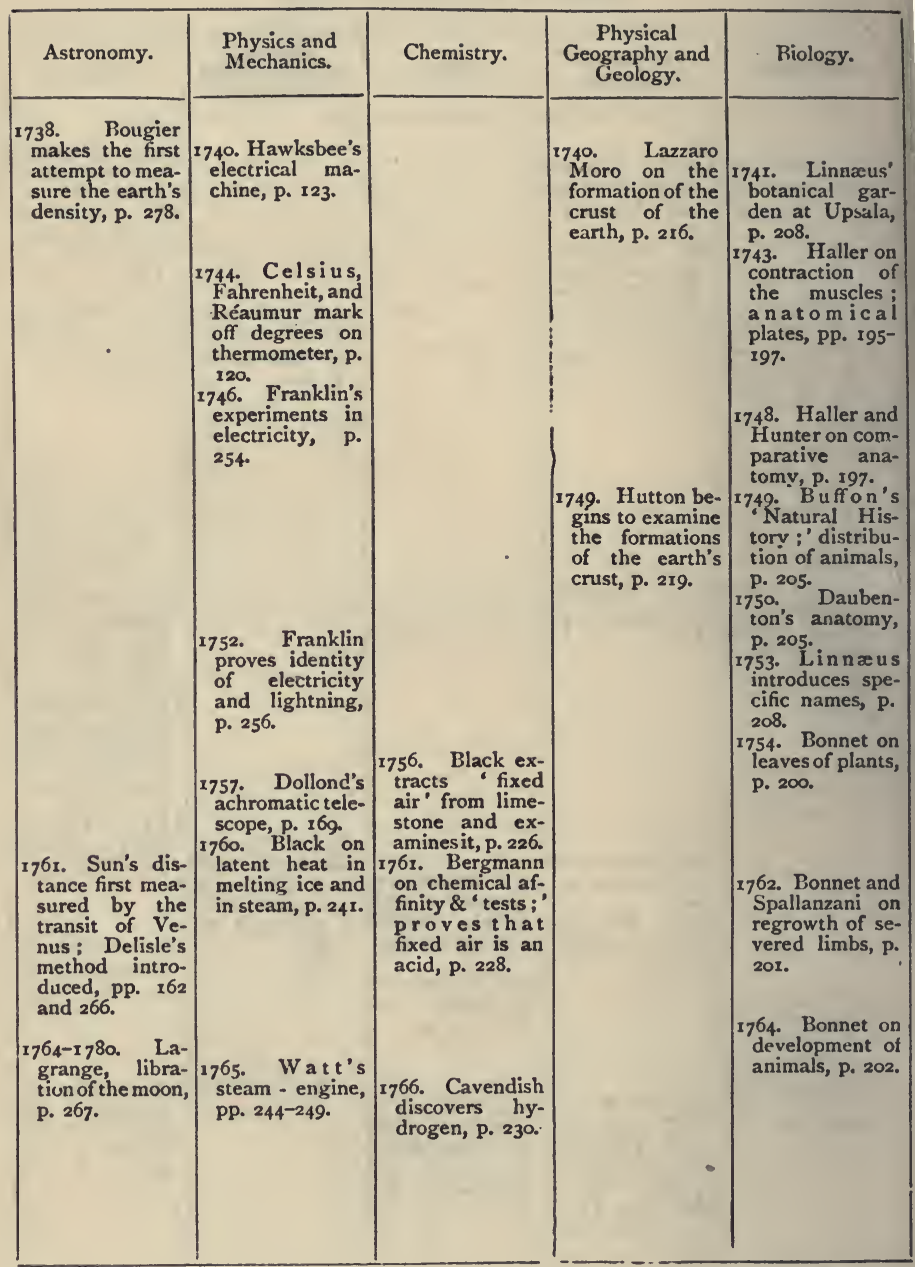




\section{PROGRESS OF MODERN SCIENCE.}

FROM A.D, 1769 TO 1789.

\begin{tabular}{|c|c|c|c|c|}
\hline Astronomy. & $\begin{array}{l}\text { Pliysics and } \\
\text { Mechanics. }\end{array}$ & Chemistry. & $\begin{array}{l}\text { Pliysical } \\
\text { Geography and } \\
\text { Geology. }\end{array}$ & Biology. \\
\hline $\begin{array}{l}\text { 1781. U ran us } \\
\text { discovered by } \\
\text { Herschel, p. } 272 . \\
1783 \text {. Proves the } \\
\text { rotation of bi- } \\
\text { nary stars, p. } \\
273 . \\
\\
1786 \text { He dis- } \\
\text { covers star-clus- } \\
\text { ters and nebul- } \\
\text { la, p. } 274 \text { : and } \\
\text { the motion of } \\
\text { the solar sys- } \\
\text { tem towards } \\
\text { Hercules, p- } \\
275 \text {. }\end{array}$ & 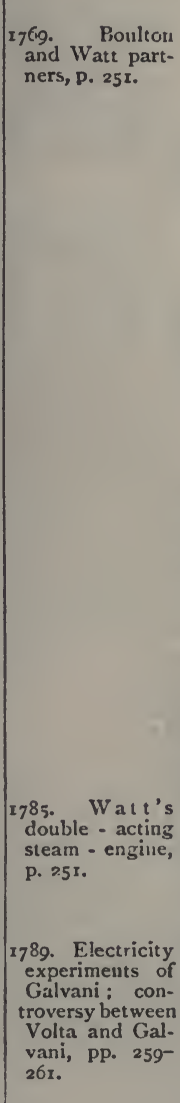 & 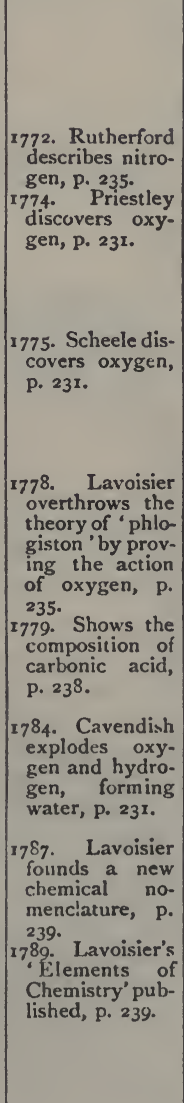 & $\begin{array}{l}\text { } \\
\\
\\
\text { r78. Disputes } \\
\text { between Nep- } \\
\text { tunists and Vul- } \\
\text { canists, p. 218. } \\
\text { 1785. Sir James } \\
\text { Hall on melted } \\
\text { rock : Hutton } \\
\text { on granite veins, } \\
\text { p. 221. } \\
\text { 1788. Hutton's } \\
\text { 'Theory of the } \\
\text { Earth'publish- } \\
\text { ed, p. } 219 . \\
\\
\end{array}$ & $\begin{array}{l}\text { 1783. Hunter's } \\
\text { museum begun } \\
\text { in Leicester } \\
\text { Square, p. I99. } \\
\\
\\
\\
789 . \text { Animal elec- } \\
\text { tricity disco- } \\
\text { vered by Gal- } \\
\text { vani, p. 259. } \\
\text { } 789 . \text { Jussieu } \\
\text { founds the Na- } \\
\text { tural Systen of } \\
\text { plants, p. } 382 \text {. }\end{array}$ \\
\hline
\end{tabular}




\section{PROGRESS OF MODERN SCIENCE.}

FROM A.D. 1790 TO I8II.

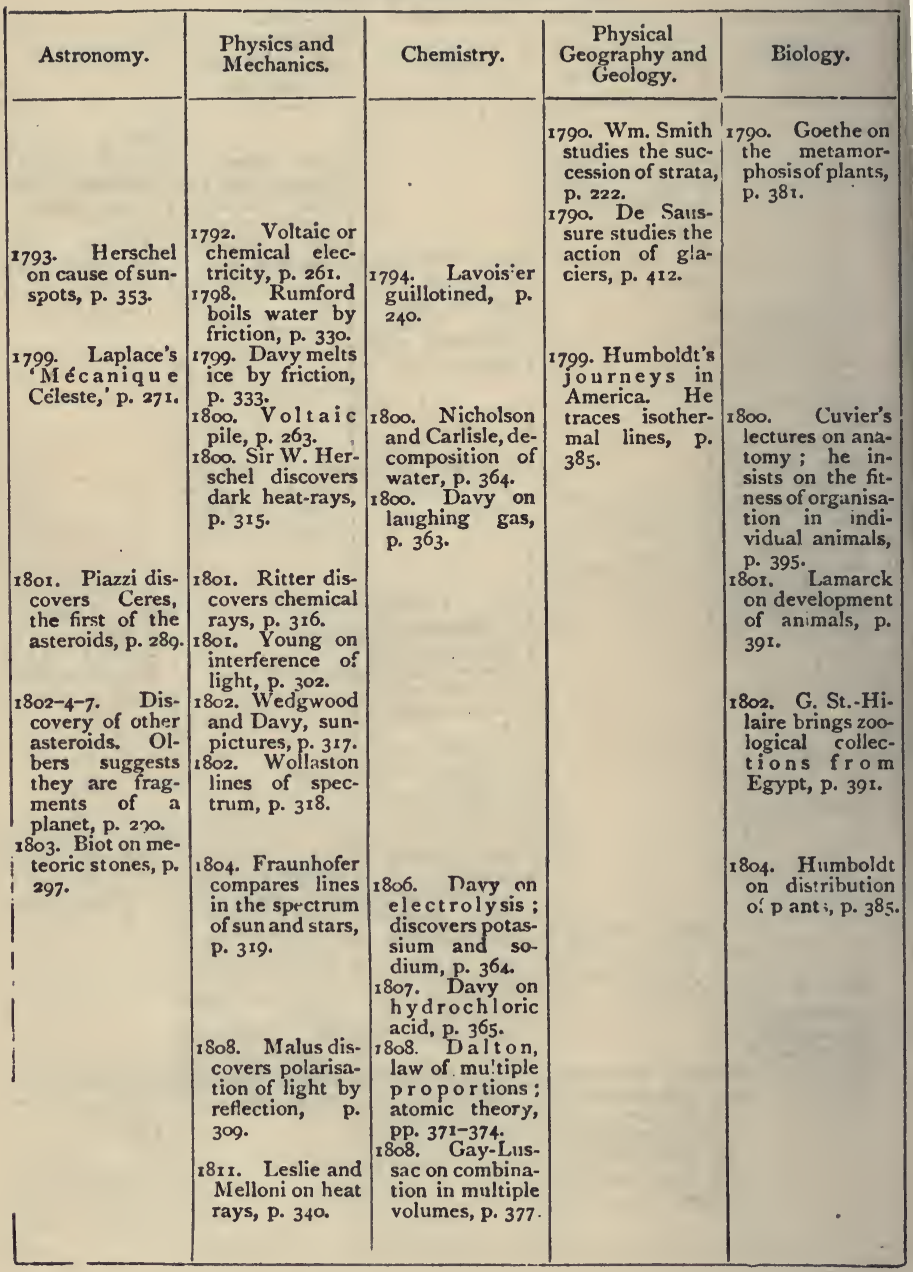




\section{RISE OF MODERN SCIENCE.}

FROM A.D. 1812 TO 1848.

\begin{tabular}{|c|c|c|c|c|}
\hline Astronomy. & $\begin{array}{l}\text { Physics and } \\
\text { Mechanics. }\end{array}$ & Chemistry. & $\begin{array}{l}\text { Physical } \\
\text { Geography and } \\
\text { Geology. }\end{array}$ & Biology. \\
\hline 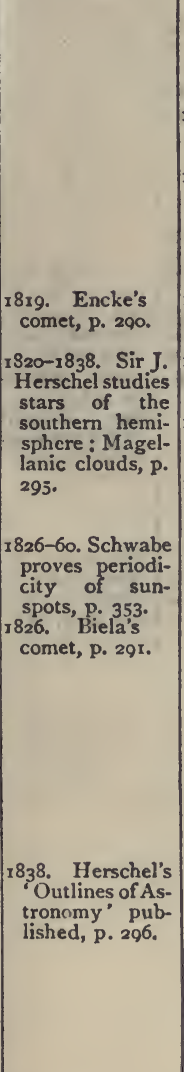 & 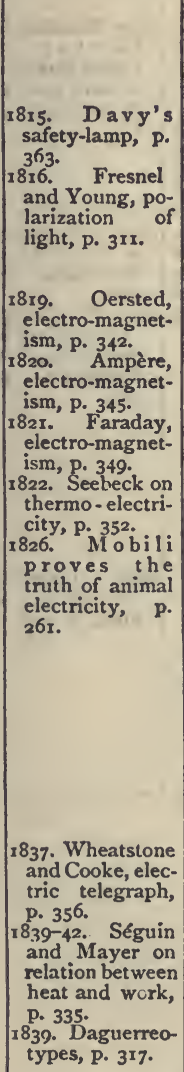 & 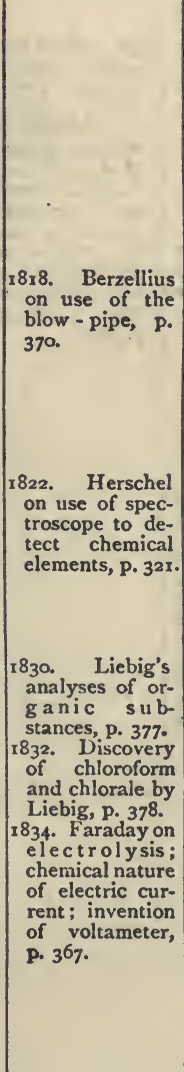 & $\begin{array}{l}\text { 1825. McEnery } \\
\text { discovers flint } \\
\text { tools, with bones } \\
\text { of extinct ani- } \\
\text { mals in Kent's } \\
\text { Cavern, p. } 416 . \\
1830 . \text { Lyell's 'Geo- } \\
\text { logy' he in- } \\
\text { sists on suff- } \\
\text { ciency of causes } \\
\text { like the present } \\
\text { to explain the } \\
\text { past history of } \\
\text { the globe, p. } \\
405 . \\
\text { 1840. Agassiz on } \\
\text { glacial period } \\
\text { and blocks car- } \\
\text { ried over Eu- } \\
\text { rope by ice, p. } \\
\text { 411. }\end{array}$ & 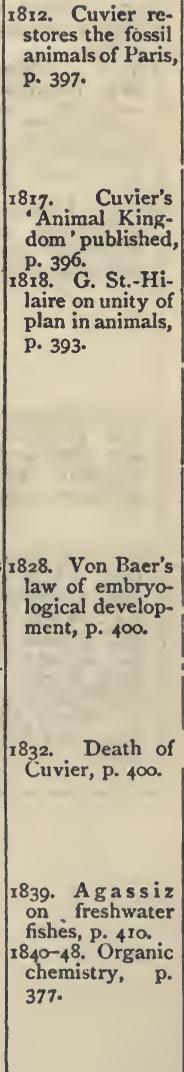 \\
\hline
\end{tabular}




\section{RISE OF MODERN SCIENCE.}

FROM A.D. 1843 TO 1874 .

\begin{tabular}{|c|c|c|c|c|}
\hline Astronomy. & $\begin{array}{l}\text { Physics and } \\
\text { Mechanics. }\end{array}$ & Chemistry. & $\begin{array}{l}\text { Physical } \\
\text { Geography and } \\
\text { Geology. }\end{array}$ & Biology. \\
\hline $\begin{array}{l}\text { 1845. Division of } \\
\text { Biela's comet, } \\
\text { p. } 290 . \\
1845-6 \text {. Adams } \\
\text { and Leverrier } \\
\text { work out the } \\
\text { position of Nep-- } \\
\text { tune; Galle finds } \\
\text { the planet, p. } \\
\text { 290. } \\
1850 \text {. Iamont, } \\
\text { periodicity of } \\
\text { inagnetic dis- } \\
\text { turbance, p. } 355 .\end{array}$ & $\begin{array}{l}\text { I86r. Bunsen and } \\
\text { Kirchhoff dis- } \\
\text { cover the mean- } \\
\text { ing of the lines } \\
\text { in the spectrum, } \\
\text { p. } 323 . \\
\text { 186. Huggins } \\
\text { a nd M ill er, } \\
\text { spectrum analy- } \\
\text { sis of the stars } \\
\text { and nebula, p. } \\
326 . \\
\text { Al ex a nder } \\
\text { Herschel, spec- } \\
\text { trum of falling } \\
\text { stars, p. } 328 \text {. }\end{array}$ & $\begin{array}{l}1848 . \text { W o h le r } \\
\text { makes organic } \\
\text { elements artifi- } \\
\text { cially, p. } 397 . \\
\text { 1861. Metals in } \\
\text { the atmosphere } \\
\text { of the sun and } \\
\text { stars discovered } \\
\text { by spectrum } \\
\text { analysis, p. } 326 . \\
1862 \text { Gases of } \\
\text { the nebula dis- } \\
\text { covered by spec- } \\
\text { trum analysis, } \\
\text { p. } 327 \text {. }\end{array}$ & $\begin{array}{l}\text { I847. Boucher de } \\
\text { Pert hes dis- } \\
\text { covers flint im- } \\
\text { plements at } \\
\text { Abbeville, p. } \\
\text { 4r5. } \\
\\
\\
\\
\text { I53. Discovery } \\
\text { of Swiss lake- } \\
\text { dwellings, p. } \\
4 \text { r6. } \\
\text { 1858. Humboldt's } \\
\text { Cosmos' pub- } \\
\text { lished; death of } \\
\text { Humboldt, p. } \\
386 .\end{array}$ & $\begin{array}{l}\text { 1858. Theory } \\
\text { natural selec } \\
\text { tion by Darwin } \\
\text { and Wallace } \\
\text { P. } 426 . \text { Darwin } \\
\text { 1859. Drigin of Spe } \\
\text { cies,'p. } 425 \text {. }\end{array}$ \\
\hline
\end{tabular}




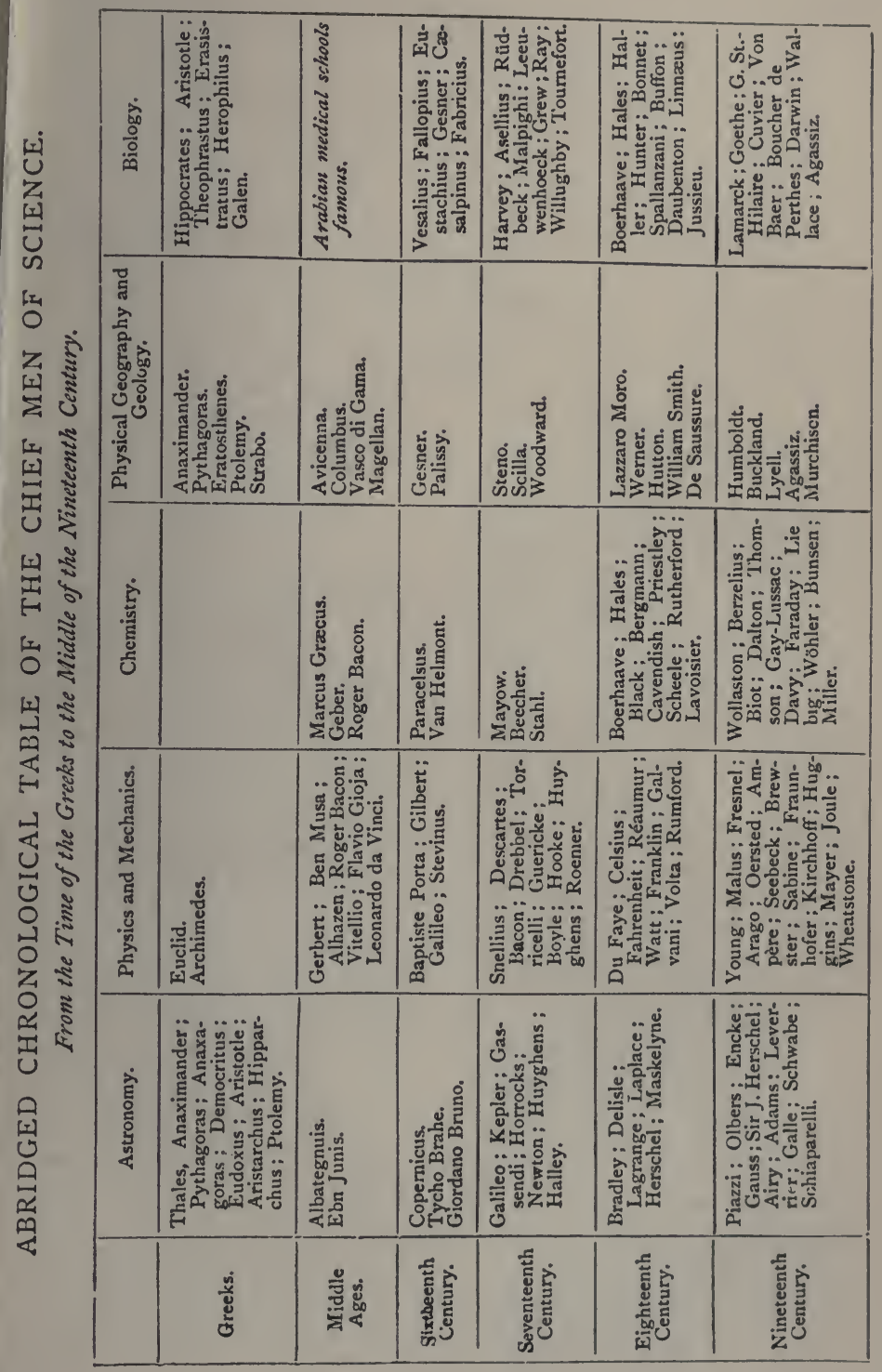





\section{N D E X.}

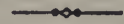

\section{ABREVILLE}

A BBEVILLE flint implements, 415

A Aberration of fixed stars, 265

Academies of science founded, 124

'Academy of Secrets' at Naples, 74

Achromatic telescopes, 169

Acids, strong, discovered by Geber, 45

Adams calculates the position of Neptune, 292 ; on November meteors, 299

Esculapius god of medicine, 15

Aerial acid, Bergmann on, 230

Agassiz, his history, 4to ; on glacial period, 41x-15; his natural history school, 41x; recognises glaciation in Scotland, 414

Aigle, meteoric stone-fall at, 297

Air, Boyle and Hooke, experiment on, r30 : Mayow on, 131; -cells studied by Malpighi, $13^{8}$; -pump, section of, 12x ; Guericke's, 121 ; -tubes of insects, 139

Airy, Adam's paper on Neptune sent to, 293

Albategnius calculates length of year, 45

Albinus, anatomical drawings of, 196

Alchemists, Arabian, 4I

Aldebaran, spectrum of, 327

Alembert, d', brings Laplace to Paric, 267

Alexandria, founding of the city of, 18 ; school of learning at, 18 ; taken by the Arabs, 39 ; Egyptian animals preserved at, 391

Algebra, an Arabian name, 46

Alhazen on eyesight, 47 ; on refraction, 47 ; on atmospheric refraction, 48 ; on magnifying power of lenses, 49

Alps, glaciers of the, 412

Amazons, closely related butterfies of the, 420

Amber, electric nature of, 77

America, Agassiz natural history school in, $4 \mathrm{II}$; glaciation of, $4 \mathrm{x} 4$

Ammonia, origin of name, 45

Ampère, early life of, 343 ; on direction of magnetic current, 345 ; on electro-mag-

\section{ANIMALS}

nets, 347 ; invents the galvanometer, $35 x$; on cause of terrestrial magnetism, 352 ; suggests electric telegraph, 357

Analysis term explained, 37x; of substances by tests, 229 ; of organic substances, 192, 377 ; different methods of, 369 ; Spectrum-, 315

Anatomy, Erasistratus and Herophilus on, 26: Vesalius on, 67 ; Eustachius and Fallopius on, 68 ; vegetable-, $x 40$; rise of comparative, r97: Haller and Hunter on, r99: Cuvier on, 395

Anatomical plates of Vesalius, 67 ; of Haller, Ig6

Anaxagoras on the moon and on eclipses, 13 ; banished, 14

Anaximander, science of, 9

Anderson brings Newcomen engine to Watt, 245

Anderson, Mr., gave Penikese island, 4 II

Animal, substances made of altered vegetable matter, 194; electricity, 259, 26r

Animalcules, discovery of, $x 40$

Animals, Cuvier on internal structure of, 396: fossil, restored by Cuvier, 397 ; Lamarck on development of, 393 : similarity of structure in, 394 ; difficulty in distinguishing species of, 420 ; useless organs in, 421 alike in the embryo, 421 ; living and fossil nearly related, 422 ; gradual succession of, on the globe, 422424 ; selection of by man, 428 ; natural selection of, 427,429 ; fossil, intermediate forms of, 424

Animals and plants, Aristotle on links between, 16: history of, by Gesner, 69: classified by Ray and Willughby, 142; Linnaus gives specific names to, 2ro; Buffon on distribution of, 205 ; Grew and Malpighi on, 137-142 : Darwin and Wallace on, 426 


\section{ANTIQUITY}

Antiquity of man, 415; Lyell's work on, 418

Aphides, Bonnet on, 200

Apollo, god of the sun, 8

Apple, Newton and the, 149 ; -leaf, skin of, showing stomates, $14 \mathrm{I}$

Aqueous rocks, Hutton on, 220

Arabs, conquests of the, 39 ; burn Alexandrian library, 39 ; science of the, 40 ; chemistry of the, $4 \mathrm{I}$; gunpowder known to the, 42 ; medical schools of the, 40

Arago on polarisation of light, 311 ; on electro-magnetism, 347 ; on Biela's comet, 291

Archimedes on the lever, 22 ; on Hiero's crown and specific gravity, 23 ; screw of, 25 ; killed in the Punic war, 25

Areas described by planets about their centre, 100

Aristarchus taught that the earth moves round the sun, 20 ; discovered obliquity of ecliptic, 21 ; and rotation of the earth on its axis, 21

Aristotelians, dogmatism of the, 81, 106

Aristotle on astronomy and zoology, 16; on development of animals, 419

Arteries, passage of blood in, III ; throbbing of explained, 112

Articulata, term explained, 396

Asellius on lacteals and nourishing fluid, 114

Astatic needle of the telegraph, 359

Asteroids, or minor planets, 289

Astrology of the Arabs, 45

Astronomy, definition of, 2 ; of Thales, 8 ; of Anaximander, 9; of Anaxagoras, 13 ; of Aristotle, 15; of Aristarchus, 20 ; of Hipparchus, 29; of Ptolemy, 32 ; of Albategnius, 45 ; of Ebn Junis, 46 ; of seventeenth century, $182-184$; of eighteenth century, 284 ; of nineteenth century, 288

Atmosphere, refraction of sun's rays in the, 48 ; varying weight of the, 118 ; pressure of the, 122

Atomic theory, 374 ; difficulties of the, 376

Atoms, definition of term, 375 ; weight of chemical, 374; of all the planets attract each other, $15 \mathrm{x}$

Attraction, by electricity, 77, 123: of gravitation decreases with square of the distance, 152

Aurora borealis coincident with outbreak of a sun-spot, 356

Australia, fossil and living pouched animals of 422

\section{BONNET}

Authority valued more than truth in the Dark Ages, 105

Avicenna on minerals, 50

B ACON, Roger, his 'Opus Majus,' 52

B Bacon, Francis, his influence on science, 10 3 ; on heat, 330

Bagdad, medical school of, 10

Bain's telegraph, ${ }_{36}$ r

Balloons, hydrogen used for filling, 231

Barometer, invention of the, $116-19$

Bartholinus on double refraction in Iceland spar, 180

Basalt, disputes about formation of, 219-2I

Bates on species of Amazon insects, 420

Battery, first electric, 262

Becher proposes theory of Phlogiston, 135

Beddoes, Dr., employs Davy, 363

Beehive, star-cluster called the, 275

Bees, clover fertilised by, 429

Ben Musa, Arabian mathematician, 46

Bergmann on chemical affinity, 228 ; on tests of mineral waters, 229 ; on 'fixed air,' 230

Berzellius-His discoveries by electrolysis, 367 ; on use of blowpipe, 367

Betelgeux, no hydrogen in light of, 327

Bichat cited, 380

Biela's comet alarmed the world, 291 ; divided into two, 292

Binary stars, Herschel discovers, 273

Biology, definition of, 2 ; of seventeenth century, 185; spread of in eighteenth century, 190

Biot on meteoric stone-fall, 298 ; on polarisation, 324

Birds, Ray and Willughby on, 144 ; rapid multiplication of, 429

Black discovers 'fixed air,' 226-228 ; on latent heat, 241-243; Young studies under, 303

Blood, circulation of the, $111-13$; earlier theories about, 1xo; air-bubbles drawn out of the, 134

Blowpipe, Berzellius on use of, $3^{67}$

Blumenbach cited, 380

Bode's law, 289

Boerhaave, his character and influence, 191; on organic chemistry, 192; on juices of plants, 193 ; on fluids of animals, 194: his death, 194

Bonnet's experiments on aphides and plants, 200; on regrowth of severed limbs, 201 ; on development of animals, 202 


\section{BOTANICAL}

Botanical garden of Gesner, 69

Botanist, Theophrastus the first, 17

Botany, different kinds of, 2 ; writers on, $17,70,7 x, 142,206,38 x, 385,3^{89}$

Boucher de Perthes finds ancient flint implements, 415

Bougier measures the density of the earth, 278

Boulton, partner of Watt, 252

Boyle one of the founders of Royal Society, 125 ; his air-pump, 124; his law of compressibility of gases, $x 28$; his experiments on air, 130

Bradley on aberration and nutation, 265

Brain described by Erasistratus, 26

Breathing, Mayow on, 832

Brewster, Sir D., on polarisation, 314 ; on spectrum analysis, 321-23

British Museum, meteoric stones in the, 297

Bronze tools of lake-dwellings, 4I7

Brougham, Lord, his article against Young, $31 x$

Bruno burnt at the stake, $8_{3}$

Buckland, his Cambridge lectures, 405 ; on glaciation of Wales, $4 \times 4$

Buffon, history of, 204 ; his work on natural history, 205; and Linnzus compared, 207 ; patronises Lamarck, 389

Bunsen on dark lines in solar spectrum, 323

( ESALPINUS on plants, $7 x$; on cirCulation of the blood, III

Cæsium discovered, 323

Cairo, medical school of, 40

Caloric, old term for heat, 330

Camera obscura, invention of the, 75

Camper cited, 380

Candolle, Auguste de, on metamorphosis of plants, $3^{84}$

Capillaries discovered by Malpighi, $13^{8}$

Carbonic acid obtained by Black, 226 : tested by Bergmann, 230 ; its nature discovered by Lavoisier, 238

Carlis'e on decomposition of water by electricity, 364

Carnot on heat converted into motion, $33^{8}$

Carrington, Mr., on outbreak of a sunspot, 355

Cassini on velocity of light, $\mathbf{x} 73$

Catastrophists in geology, 405

Cats, their indirect influence on growth of clover, 429

Caus' engine, 246

\section{COLUMBUS}

Cavendish discovers hydrogen, 230; on composition of water, 23I ; his experiment on weight of the earth, 279

Caxton the printer, 55

Cellular tissue, section of, 140

Celsius invents centigrade scale, $12 \mathrm{C}$

Centigrade scale, 120

Ceres discovered by Piazzi, 289

Charles I., riots in reign of, 124 ; II. grants Royal Society charter, 125 ; V. of Spain protects Vesalius, 68

Chemical, rays discovered, 315 ; rays of action in photography, $317:$ nomenclature of Lavoisier, 239 ; elements, weight of, 373 ; symbols, 376 ; or Voltaic electricity, 26r ; theory of electricity, 367

Chemical affinity, Bergmann on, 228 : Newton on, 229: power of electric current to overcome, 367

Chemistry, definition of, 2 ; of the Araos, 4I; of Geber, 43; of Paracelsus and Van Helmont, 72 ; of Boyle and Hooke, x30; of Mayow, 13x; Buerhaave on o1ganic, 194 ; of Black, 226 ; of Bergmann, 228 ; of Cavendish, 230 : of Priestley, $23 x$; birth of modern, 235; Newton's work on, destroyed, 170 ; methods of studying, 369

Chick, Harvey on development of, 114

Chinese, early science of, 4; mariner's compass known to the, 54

Chlorale, discovery of, 378

Chloroform, discovery of, $37^{8}$

Cinnamon tree, essences obtained from, 193

Cipher, word derived from Arabic, 46

Circulation of the blood, diagram of, II3

Circular polarisation in quartz crystals, 314

Circumference of earth measured by Eratosthenes, 28

Classifications of plants, 70-71, 142, 209, 382 : of animals, $69,143,210,396$

Clausen calculates the period of Biela's comet, $29 x$

Clifforc, Mr., befriends Linnæus, 207

Climate, Humboldt on causes of, 385 ; Lamarck on effects of, 393

Cod-fish, animalcules in roe of, 140

College of Surgeons, Hunter's collection in, 200

Colours, prismatic, 167 ; cause of in telescopes, 169 ; caused by inter'erence of light, 307 : on the soap bubble, 307: depend on light-vibrations, 177

Columbus, Christopher, his vuyages, 56 : discovers variation of magnetic needle. 57 


\section{COLUMBUS}

Columbus on circulation of the blood, III

Combustion, Hooke on, 130 ; Mayow on, 132 : Stahl's mistaken theory of, 135 ; cause of proved by Lavoisier, 238

Comet, Halley predicts return of, 163

Comets, Newton on orbits of, 155: returning, 298; and meteors, 297

Commutator of the telegraph, 360

Comparative anatomy, rise of, $x 97$ : Hunter's collection illustrating, 199: Haller on, 197; Cuvier on, 395-98

Compass, figure of first mariner's, 54

Compound flowers, $\mathbf{x} 45$

Concluding remarks, 433

Condenser, Watt's separate, 248-50

Conservation of energy, 339

Contraction of the muscles, 197

Cook's voyage to observe transit of Venus, 162

Cooke patents electric telegraph, 357

Copernican theory, 65 ; proofs of the truth of, $9 x$

Copernicus, life and work of, 65

Cordova, medical school of, 40

Corpuscular theory of light, 174,303

Correlation of the physical forces, 435

'Cosmos' of Humboldt, 386

Crabtree sees transit of Venus, $15^{8}$

Crookes discovers thallium, 323

Crown of cups, Volta's, 262

Crown-glass, dispersion of light in, 169

Crystals, double refraction in, 180 ; rassage of light-waves in, 313 ; circular polarisation in quartz, 314

Currents from an electric battery, 262; Humboldt on ocean, 385-86

Cuvier, history of, 389-95 : his museum, 391 ; on creation of animals, 394 ; his discussion with St.-Hilaire, 395-397; on comparative anatomy, 395 ; on classification and structure of animals, 396 ; on fossil animals of Paris, 397 ; his 'Ossemens Fossiles,' 399 ; death of, 400

Cycloidal pendulums, 175

ABURON, Ampère's visit to, 344

Daguerre fixes sun-pictures, 3I7

Dalton, life of, $37 \mathrm{x}$; on law of multiple proportions, 373 ; atomic theory, 374

Dark ages, science of, 39 et seg.

Iarwin, his history, 425: on origin of species, 426 ; his theory explained, 427$43 \mathrm{x}$; on causes of natural selection, 429

Daubenton's anatomical work, 205

Davy, Sir H., his history, 362 ; his experi-

\section{EARTHQUAKES}

ments on nitrous oxide, 363 ; on electrolysis, 364; discovers potassium and sodium, 365 ; his safety lamp, 363 ; on organic chemistry, 378 ; on sun-pictures, 317; Sir H. melts ice by friction, 333 : his kindness to Faraday, $34^{8}$

De Dominis on the rainbow, 164

Delisle's method of measuring transit of Venus, 266

Deltas, growth of, 12

Democritus on the Milky Way, 15

Denudation, Hutton on, 220

Descartes on light, 106, 164; on the value of doubt, 105

Development of animals, Lamarck on, 39x; Von Baer on, 402

Diagram showing how distances can be measured on the sun's face, 159

Diagrams of bent and broken rocks, 217, 218

Diameter of the sun, $16 \mathrm{r}$

Diamond, nature of, proved by Lavoisier, 238

Djafer, or Geber, Arabian alchemist, 43

Diæcious plants explained by Crsalpinus, 72

Dicotyledons term explained, 145

Differential calculus, by Leibnitz, 148

Disc, Newton's rotating, $x 68$

Dispersion of light discovered by Newton, $164:$ in different kinds of glass, 169

Distillation known to Geber, 43, 370

Distribution of animals, Buffon on, 206 ; of plants, Humboldt on, 385

Dogmatism of the sixteenth century, 67, 81,83

Döllinger, anatomist, $40 \mathrm{r}$

Dollond, Mr., makes achromatic telescope, 169

Double refraction, $\mathbf{2 7 9}, 180$

Doubt, Descartes on the value of, ro5

Drebbel makes alcohol thermometer, 120

Ducts of plants, 140

Du Faye on electricity, 254

Dynamical theory of heat, 335

FARL'S COURT, Hunter kept wild E animals at, 199

Earth declared by Aristotle to be a globe, 16; circumference of measured, 28; Picart measures the size of the, 150 : Newton on shape of the, 154 : measurement of density of the, 277

Earth-light on the moon, 89

Earthquakes, Pythagoras on, 12 ; Strabo 


\section{EBN}

on causes of, 33 ; changes of level caused by, 408

Ebn Junis, Arabian astronomer, 46

Eclipses explained by Anaxagoras, $x_{3}$

Ecliptic or sun's path, how traced out by the Greeks, I8; Anaxagoras discovers obliquity of, $2 x$

Egyptians, early science of, 4

Eighteenth century, work of the, 434 : summary of science of, 280

Elective affinities, Bergmann on, 229

Electric currents causing magnetic currents, 346 ; making electro-magnets, 347 power of to conquer chemical affinity, $3^{6} 7$

Electrical machines, Guericke's, 123 ; Hawksbee's, 123

Electric spark observed by Guericke, 124

Electric telegraph, invention of, 357 ; description and diagrams of, $357-60$; Bain's set on fire by magnetic storm, 356 ; Morse's and Steinheil's, 357

Electricity, Gilbert 012, 77, 123; attraction and repulsion by, 124: Du Faye on different kinds of, 254 ; Franklin on, 255 ; and lightning, 256; positive and negative, 256 ; animal, 259 ; chemical or voltaic, $26 \mathrm{r}$; chemical theory of, 367 ; produced by heat, 352

Electrolysis, discovery of, $36_{4}$ : Davy's experiments in, 365 : Faraday on, 367

Electro-magnetism, Oersted discovers, 34I ; Ampère on, 345 ; Faraday on, 349

Electro-magnets made by electric current, 347

'Electron,' root of word 'electricity,' 77

Elements, sixty-four known, 370

Ellipses, planets move in, 99

Embryology, Von Baer's law of, 400 ; confirms St.-Hilaire's view of homological structure, $40 x$

Embryos of animals alike in structure, $42 \mathrm{r}$

Emission theory of light, $\mathbf{3 7 4 , 3 0 3}$

Encke's comet, 290

Energy, potential and active, 337, 339 : conservation of, 339,353

Engines, history of, 245; the Newcomen, 246; Watt's double-acting, 250

England, geological map of, by W. Smith, 224

Epidermis studied by Malpighi, $\times 39$

Equinoxes observed by Thales, 9: Hipparchus discovers precession of, 30 .

Erasistratus on the brain, 26

Erratic blocks on the Jura, 4I3 ; a proof of former extension of ice, $4 \pi 4$

\section{FRENCII}

Eratosthenes lays down first parallel of latitude, 27 ; measures circumference of the earth, 28

Ether, light a vibration of the, 176

Euclid, some problems of, invented by Thales, 9

Euclid discovers that light travels in straight lines, $2 \mathrm{I}$

Eudoxus explains movements of the planets, I5

Eustachius the anatomist, 68

Evolution, theory of, 435

Extinct animals, restored by Cuvier, 328 ; man contemporary with, 4r5

Eye, Alhazen on the sight of the, 47 ; Porta on structure of the, $76 ;$ Kepler on the, 96

ABRICIUS Aquapendente discovers
valves in veins,

Fahrenheit thermometer, freezing point of, I20

Falling bodies, Galileo on rate of, 80

Fallopius, the anatomist, 68

Faraday, history of, $34^{8}$; on rotation of magnets and electric wires, 349; on electric current produced by a magnet, $35 x$; on connection between electricity and chemical changes, 367

Faust, John, the printer, 55

Fire-air discovered by Mayow, 132; its effect on the blood, 134

'Fixed air,' Black on, 226-228; Bergmann tests, 230

Flame consuming 'fire-air,' 132 ; spectra of different kinds of, $32 \mathrm{x}$

Flint implements of Abbeville, 4x5

Flint-glass, dispersion of light in, 169

Flood, attempt to explain fossils by a universal, 215

Flowers, plants classified by their, $x 45$

Fluxions, Newton's method of, 148,153

Force, convertibility of, 369 ; of gravitation, 149

Fossil animals restored by Cuvier, 327 ; intermediate forms of, 424

Fossil shells observed by Pythagoras, II

Fossils, Gesner on, 70 ; first attempts to explain, 215: used by W. Smith for classification, 223

Franklin's early li.e, 253 ; his experiments in electricity, 255; he proves lightning to be electricity, 256-258

Fraunhofer's early life, 319 ; lines, 320

French school of chemistry, 239 


\section{FRESNEL}

Fresnel, history of, $3 \mathrm{Ir}$ : on polarisation of light, $3 \mathrm{II}$; on circular polarisation, $3 \times 4$

Freyberg, Werner's lectures at, 217

Friction, ice melted and water boiled by, 333

Friendship of Ray and Willughby, ${ }_{43}$

Frog's leg, electricity in, 259-6r

GALEN, physiology of, 34 ; corrected $G$ by Vesalius, 67

Galileo on the pendulum, 79 ; on falling bodies, 80 ; on motion of heavy bodies, 82 ; on secondary light of the moon, $89 ;$ on Jupiter's moons, $9 \mathrm{I}$; on phases of Venus, $9 \mathrm{r}$; on sun-spots and rotation of sun on its axis, $9 \mathrm{x}$; demonstrates the truth of Copernican theory, 91, 102 ; his telescope, 89 ; his recantation, 93 ; his blindness and death, 94; on rising of water in a pump, 116 ; makes a water thermometer, I20 ; compared with Tycho and Kepler, 102

Galle finds Neptune, 294

Galvani on animal electricity, 259: his controversy with Volta, 260; his death, 26r

Galvanism, 260

Galvanometer invented by Ampère, 35x

Ganges, mud carried down by the, 407

'Gas,' term used by Van Helmont, 73 ; Nebula composed of, 275

Gases, Boyle's law of, 128 ; Bacon on, 52 ; Mayow on, $x 32$; discovery of the four important, 225 ; spectra of, 322 ; atmosphere of, round the sun, 325

Gassendi observes transit of Mercury, 157

Gauss rediscovers Ceres, 290

Gay-Lussac on multiple volumes, 377

Geber the founder of chemistry, 43-45

Geist, word 'gas' derived from, 73

Geography, Ptolemy's work on, 33 ; Strabo on, 33

Geology, definition of, 2 ; of Pythagoras, II, 215; neglected in dark ages, 214; Lazzaro Moro on, 216; Werner on, 217 ; Hutton on, 219; W. Smith on, 223 ; Sir C. Lyell on, 405 ; of eighteenth certury, $28 \mathrm{I}$; prejudices retarding, 404

George II. founds Göttingen University, I96

Geranium, Linnæus's definition of the, 209

Gerbert introduces Arabic numerals into Europe, 46

\section{GUTENBERG}

Germ, growth of the, I4I

Germany, Imperial Academy in, 126

Gesner, his life and character, 69-70; his cabinet and garden, 69: his history of animals, 69; his botanical classification, 70

Gilbert, first experiments on electricity, 77 , 123

Gioja discovers mariner's compass, 53

Glacial period, 414

Glacier, tern explained, $4 \mathrm{Ir}$; illustration of a, 412 ; of Switzerland, 413 ; carrying blocks to the Jura, 413

Gladstone, Dr., his life of Faraday, 349

Glass, angle of polarisation of light from, 3ro: index of refraction for: is; different dispersive powers of, 169

Graham on variations of magtstic needle, 355

Granite, Hutton on formation of, 221 ; veins in Glen Tilt, 222

Gravitation, law of, explained, 148-155: discovered by Newton, $x 48$; its action on the plant ts, $15 \mathrm{I}$; attraction acts from the centre of bodies, 150 ; decreases with the square of the distance, $15^{2}$; problems explained by, 155 ; holding distant stars together, 274

Gravity, action of, explained, $15 x$

Glen Tilt, granite veins in, 222

Gnomon at Alexandria, 28

Gold separated from amalgam by Paracelsus, 72

Gocthe on metamorphosis of plants, $38 \mathrm{r}$; on discussion between Cuvier and St.Hilaire, 395

Güttingen University founded, $\mathrm{r} 96$

Gough the patron of Dalton, $37 \mathrm{I}$

Gracus, Marcus, discovers gunpowder, 42

Gratz, Kepler professor at, 95

Greece, Roman conquest of, 35

Greek colonies in Ionia, 8

Greeks deficient in natural knowledge, 8 ; believed the sun moved round the earth, 19; knew electric nature of amber, 77 ; general remarks on science of the, 34

Grew on vegetable anatomy, $14 x$; on stomates, $14 \mathrm{I}$; on cellular tissue, 140

Grove cited, 434

Guericke's air-pump, 12I ; Magdeburg hemispheres, 122; first electrical machine, 123 ; his experiments on electricity, 124

Gunpowder known to the Arabs, 42

Gutenberg, John, the printer, 55 


\section{HALES}

I ALES, Dr., on gases, 226 ; on water in plants, 193

Hall, Mr. C. More, on flint and crown glass, 169

Hall, Sir J., on melted rocks, $22 \mathrm{r}$

Hallé, Dr., pleads for Lavoisier's life, 239

Haller, early life of, 195 ; his work with students, 196; his anatomical plates, 196 ; on contraction of the muscles, 197 ; on comparative anatomy, $\mathrm{r} 97$

Halley, his method of measuring transits, 158-r62; observes transit of Mercury, 158 ; predicts the return of a comet, $x 6_{3}$

Harding discovers Juno, 290

Harvey discovers circulation of the blood, I ro; the opposition to his views, $\mathrm{r}_{3}$; on development of the chick, $\mathrm{rr}_{3}$

Hawksbee's electrical machine, I $_{23}$

Heat, Bacon's examination of, ro4; early theories about, 329 ; produced by friction, 330 ; a vibration, 333 ; latent, 24r, 334 ; mechanical equivalent of, 336 ; Joule's experiments on, $335-33^{8}$; conversion of mction into, 332-337; converted into motion, $33^{8}$; production of electricity by, 352

Heat-rays discovered, 315

Heavy bodies, Galileo on motions of, $8_{2}$

Helmholtz cited, 434

Hercules, motion of our solar system towards, 275

Hermes and hermetic philosophers, 4 I

Hero's engine, 245

Herophilus on muscles, nerves, and the pulse, 27

Herschel, Sir W., makes his own telescopes, 272 ; discovers Uranus and receives a pension, 272 ; on binary stars, 273 ; on star-gauging, 273 ; on nebulx, 274, 327 ; on motion of solar system through space, 275 ; discovers heat-rays, $3 \times 5$; on cause of surf-spots, 353

Herschel, Sir J., work in astronomy, 295296; on Magellanic clouds, 295; his 'Outlines of Astronomy,' 296; on spectrum analysis, 322

Herschel, Miss C., her brother's assistant, 277

Herschel, Mr. A., on spectrum of falling stars, 328

Hiero's crown, Archimedes on, 23

Higgins on chemical law of proportions, 373

Hipparchus, astronomy of, 29 ; discovers precession of equinoxes, 30

II ippocrates the father of medicine, 14

\section{IRIDIUM}

Hirn, M., his experiments on heat converted into motion, $33^{8}$

Hodgson, Mr., on outbreak of a sun-spot, 355

Homology, St.-Hilaire on, 394

Hooke one of the founders of the Royal Society, r25 ; on air-pump, 128 ; on conlbustion, $\mathrm{r} 30$; on geology, $2 \mathrm{r} 6$

Horrocks observes transit of Venus, 157

Huen island, 'Tycho's observatory on, 78

Huggins, Ur., on spectrum analysis of the stars, 326 ; of nebula, 327

Human anatomy, Vesalius on, 67

Humboldt, history of, $3^{84}$; on isothermal lines, $3^{85}$; on distribution of plants, $3^{85}$; his 'Cosmos,' 386 ; on meteors, 297 ; pays expenses of Agassiz's work, 4 ro

Hunter, John, his birth and history, I98; on comparative anatomy, 198 ; his museum, $x 99$

Hutton on geology, 2r9-23: on granite veins, 222 ; and Werner, 222 ; on size and weight of Schehallien, 279

Huyghens, history of, 175 ; invents cycloidal pendulum, 175; describes Saturn's ring, $x 75$; his undulatory theory of light explained, $\mathbf{r} 75, \mathbf{1} 8 \mathrm{I}$; on refraction of light, $\mathbf{r} 78$; on double refraction, $\mathbf{I 7 9}$

Huxley on fossil bird-reptile, 424; on rapid multiplication of plants, 429

Hydrogen discovered by Cavendish, 230 : name given by Lavoisier, 239 ; amount of in water, 372

TCE, heat lost in melting, 242 ; melted 1 by friction, 333 ; rocks scratched and blocks carried by, $4 \mathrm{I}_{3}$; -period in the northern hemisphere, $4 x x$

Iceland spar, double refraction in, $r 80$

Igneous rocks, Hutton on, 220

Imperial Academy of Germany founded, 126

Index of refraction, ros

Indians, early science of, 4

Induction-coil, 35 I

Inquisition banishes Vesalius, 68 ; burns G. Bruno, 83 ; forces Galileo to recaist, 93

Insects, Ray's work on, 144 ; microscopic anatomy of, 139

Interference of light, $304^{-6}$; co'ours causcd by, 307

Invertebrate animals, Lamarck on, 391

Ionian school of learning, 8

Iridium discovered, 323 


\section{IRON}

Iron tools of lake-dwellings, 4I7

Islands, formation of, 12

Isothermal lines, Humboldt on, $3^{95}$

traly, early scientific societies in, 126

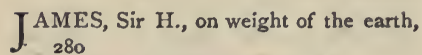
Jansen makes a telescope, 87

Jews, medical knowledge of the, 39

Joule, Dr., experiments on the mechanical equivalent of heat, $335-33^{8}$

Juno discovered, 290

Jupiter, atmosphere of, 327 ; his moons, 90 ; velocity of light measured by, 172 ; and Saturn, long inequality of, 269

Jura mountains, erratics of the, 4 I3

Jussieu's natural system of plants, 211, 382

K ENT'S Hole, flint implements in, Kepler, life and difficulties of, $95,10 x$; on structure of eye, 96 ; his telescope, 97 ; his first law, 97 ; second law, 99 ; third law, 100; his delight at Galileo's discoveries, 100 ; on refraction, 100 ; predicted transits of Mercury and Venus, 157 ; finished Rudolphine tables, ror; compared with Tycho and Galileo, 102

Kew gardens, 208

Kircher invents magic lantern, 76

Kirchhoff on dark lines in solar spectrum, 323 ; his spectroscope, 324

Kite, Franklin's, 257

Koran forbade dissection, 40

\section{ACTEALS discovered by Asellius,} Lagrange, 266: on libration of the moon, 267 ; on stability of planetary orbits, 270

Lake-dwellings of Switzerland, 416 ; tools and food found in, 417

Lamarck, history of, 389 ; on invertebrates, $39 \mathrm{x}$; on development of animals, $39 \mathrm{x}$; his 'Philosophie Zoologique,' 393 ; weak point in his theory, 393

Lamont on variations of magnetic needle, 355

Land, conversion of, into sea, II

Laplace, 267 ; on long inequality of Jupiter and Saturn, 269 ; on moon's acceleration, 270 ; on heat, 336

\section{LINNAEUS}

Lassell on Neptune's moon, 295

Latent heat, Black on, 24I ; of water, 243 ; theory of, applied by Watt, 244, 248; explained, 334

Latitude, first parallel of, laid dowwn, 27

Laughing-gas, I lavy's experiments with, $3^{6} 3$

Lavoisier the founder of modern chemistry, 235 ; his experiments, 237 ; his death, 239

Law of compressibility of gases, 128 ; of definite proportions in chemistry, 372 , of multiple proportions, 373 ; of gravitation, 151; of refraction discovered by Snellius, ro7

Laws of Kepler, 97, 99, I00

Leaves of plants, Bonnet on use of, 200

Leeuwenhoeck on animalcules, 139

Leibnitz on differential calculus, 148

Lenses, magnifying power of convex, 49 ; Alhagen on use of, 48 ; Porta on, 76 ; Galileo on, 88 ; Kepler on, 96

Leslie, Sir J., on refraction of heat, 340

Lever, Archimedes on the, 22

Leverrier calculates the position of Neptune, 292, 294; on November mcteors, 299

Leyden, medical school of, 190

Libration of the moon, 267

Liebig on organic chemistry, 377

Light, Euclid on rays of, $21 ;$ a vibration. 176 ; causing colour, 177 ; polarization of, 18x, 309 ; compared to sound, 176 , 178 ; dispersion of, 164,167 ; blending of colours into white, 168 ; interference of, 302-306; bands of, in shadows, 304 ; undulations compared to waves of a pond, 306 ; reflection of from a soapbubble, 308 : complex vibrations of, $3^{12}$; passage of through a crystal, $3^{13}$ : Roemer measures velocity of, 172 ; theories of, 174,303 ; undulatory theory explained, $174^{-179}$

Lightning, electric nature of proved by Franklin, 256; conductors, 258

Lilienthal, meeting of astronomers at, 289

Limestone, fixed air obtained from, 226 ; beds of Sicily, thickness of, 407

Lines in the spectrum, $3 \times 8,320$; their cause explained, 323

Linnzan system, 2xo; collection brought to England, 212

Linnzus, early life of, 205, 207 ; and Buffon compared, 207; his 'Excursions,' 208 : gives specific names to plants and animals, 208 ; creates an accurate nomenclature, 2II; modifies Ray's system, 


\section{LIPPERSHEY}

I 45 ; on metamorphosis of plants, 383 ; deash and character of, $2 \times 2$

Lippershey makes a telescope, 87

Lithuanian legend about falling stars, 297

Loadstone known to the Greeks, 53

Locke on heat, $33^{\circ}$

Lockyer on spectrum analysis of stars, 326

Locomotive-engine, date of first, 245

Looking-glass, cause of reflection of, 177

Lungs, circulation of blood through the, 112: studied by Malpighi, ${ }_{3} 8$

Luxembourg Palace, polarized light reflected from windows of, 3 to

Lyell, Sir C., his history, 405; on present causes of geological change, 406-4 10 ; his influence on geulugy, 409 ; on Darwin's work, 426

Lymphatics discovered by Rüdbeck, 115

MAC ENERY on flint implements of

MI Kent's Hole, 416

Magdeburg hemispheres, 122

Magellan's ship sails round the world, 57

Magelianic clouds, 295

- Magia Naturalis ' published, 74

Magic lantern invented, 76

Magnet, origin of name, 53: producing electric current, 350 ; and electric wires, mutual rotation of, 349 ; diagram of, 350

Magnetic currents caused by electric currents, 346 ; direction of, 345 ; affected by sun-spots, 355 ; needle, variations of the, 57 ; affected by electric current, 343 , $^{\circ}$ 345: Ampèrt on direction of, 345 ; sudden movement of at Kew, 355; periodical shifting of the, 355 ; of electric telegraph, 359

Magnetism, Gilbert on, 77 ; electro-, 34x$35^{2}$; terrestrial affected by sun-spots, 353

Magnifying glasses explained, 49

Malpighi applies the microscope to living structures, 137 ; history of, $13^{8}$; on aircells, 138: discovers Malpighian layer, r 39 : on silkworm, r39: on structure of plants, 140; on growth of germs and seeds, $x_{4} \mathrm{r}$

Malus on polarization of light, 309

Man, antiquity of, 415 ; selection of animals by, 428

Map made by Anaximander, 10: geological, made by W. Smith, 224

Marcus Graecus, gunpowder made by, $\$ 3$

Mariner's compass, 53
MOON

Marquis of Worcester's engine, 246

Marriotte's law, 130

Mars, atmosphere of, 327 ; movements of explained by Kepler, 97 ; occultation of observed by Aristotle, 16

Maskelyne measures the density of the earth, 277

Maury on division of Biela's comet, 292

Mayer, Dr., on mechanical equivalent of heat, 335

Mayow a conscientious observer, $13 \mathrm{I}$; he discovers 'fire-air,' 132 ; his experiments on combustion and respiration, 132 ; his early death prevented his theory being known, 135

'Mrécanique Céleste' of Laplace, $27 x$

Mechanical equivalent of heat, 336

Mechanics, definition of, 2

Medical school of Leyden, rgo

Medicine, Hippocrates the father of, 14 ; Galen on, 34

Melloni on passage of heat rays, 340

Men of science, lists of, $6,38,62,86$ 188

Mercurial thermometer, how made, 120

Mercuric oxide, Priestley obtains oxygen from, 233

Mercury obtained from cinnabar by Geber, 44 ; sustained in a tube by weight of air, I1 8 ; combining with oxygen, 373

Mercury, transits of observed, $257-158$

Metals, Geber notices increased weight of heated, 44: electric discharge from two, $26 \mathrm{x}$; discovered by spectrum analysis, 322

Metamorphosis of plants, $38 \mathrm{x}$

Meteors and their paths, 297-300: their compusition, 297; spectrum analysis of, 328

Microscope applied to living structures, 137 ; definition of, 137

Middle ages, science of the, 39-59

Milky Way studicd by Democritus, 15 ; by Galileo, 90

Miller, Dr., on spectrum analysis of the stars, 326

Mineral waters analysed by Bergmann, 229

Mineralogy, Gesner on, 70; Werner's lectures on, 217

Mollusca, term explained, 396

Monocotyledons, term explained, $x 45$

Monro cited, 380

Mont Blanc, erratic blocks carried from, 413

Miwn, Anaxagoras on the, 13 : phases of 


\section{MOONS}

explained by Anaximander, 10; Thales on reflection of the, 9 ; secondary light of the, 89 ; movement of used by Newton to test his law of gravitation, 150 ; Lagrange on libration of, 267 ; why she turns the same face to us, 268

Moons, Jupiter's, 90

Muraines of glaciers, 432

Moro, Lazzaro, on formation of strata, 216

Morse, his electric telegraph, 356, 36r

Mother-of-pearl, cause of colours in, 329

Motion, conversion of, into heat, 332, 337

Mountain-chains, Eratosthenes studies, 29

Mouse consuming air in a bell-jar, 132

Mud carried down by the Ganges, 407

Murchison cited, 4 of

Muscles, Haller on contraction of the, 197

M usical notes, Pythagoras on, 12

NAPOLEON I. takes St.-Hilaire tó Egypt, 39x

Natural history of seventeenth century, 137-x 45

Natural philosophy, Leonardo da Vinci on, 58

Natural selection, theory of, 426-428; objection to the theory of, 428 ; difficulties of natural history explained by, 431; does not exclude Divine Power, 432

Natural system of plants, $2 \times 1,382$

Nebula, Herschel on the nature of, 275 : spectrum analysis of, 327

Nebular hypothesis, 27x

Negative and positive electricity, 256, 262

Negro, colouring matter in skin of, $\times 39$

Neptune, position of found hy Adams and Leverrier, 292 ; seen by lialle, 294 ; his moons, 295

Neptunists and Vulcanists, 218

Nerves, Galen on two sets of, 34

Nestorians, science of the, 40

Neuchatel, erratic block near, 413

Newcomen's engine, 246

Newt, re-growth of eye of, 202

Newton, birth and early life of, 14; his law of gravitation, $148-155,183$; his method of fluxions, 348 ; on variation of attraction, 152 ; on cause of tides, 154 ; on specific gravity of planets, 154 ; on shape of the earth, $154:$ on precession of equinoxes, 354 ; on motion of comets, 255 ; on sound, 175 ; on chemical attraction, 229 ; on attraction of plumbline to a mountain, 278; on light and colour, 1.8; an dispersion of light, 164,185 ex-

\section{PAPIN}

plains the spectrum, 166 ; and compound nature of light, $165-167$; his rotating disc, 168; his work on chemistry destroyed, 170; his work on optics, 169 ; his theory of light, $x 74,303$; his character and death, 170

Newton, Prof., on falling stars, 229

Nicholson on decomposition of water by electricity, 364

Nile, mud carried down by, $x x$

Nineteenth century, tendency of science of, 434

Nitrogen, compounds of oxygen with, 373 ; Rutherford on, 235

Nitrous oxide, Davy's experiments on, $36_{3}$

Nobili on animal electricity, $26 \mathrm{x}$

'Novum Organuin,' 103

Numerals, Indian, introduced into Europe, 46

Nutation of earth's axis, 266

BLIQUITY of ecliptic, Anaxagoras on, 21

Observatory, Tycho's, 79

Oersted on electro-magnetism, 34x

Olbers, Dr., discovers Pallas and Vesta, 290

Optics, Alhazen on, 46 ; Porta on, 76 : Kepler on, 96: Newton's work on, 169

'Opus Majus' of Roger Bacon, $5 x$

Orbits of the planets, elliptical, 98 ; do not all lie in the same plane, 99; governed by gravitation, $15 x$

Organic chemistry, foundation of, 190 ; Liebig on, 377

Organic sciences of nineteentb century too difficult to follow, 380

Organs, of digestion arranged by Hunter, 199: modification of, 38x ; St. Hilaire on modification of, 393

'Ossemens Fossiles' published, 399

Ovid's 'Metamorphoses,' 11

Oviparous and viviparous animals, 143

Oxford, early meetings of Ruyal Society at, 125

Oxygen called 'fire-air' by Mayow, ${ }_{34}$ : discovered by Priestley and Scheele, 231234 ; amount of in water, 372 ; compounds of with nitrogen, 373

DADUA, Professors of, 67, 7x, 8x, 1 x०

1 Palissy on fossil shells, 215

Pallas discovered, 290

Papin's engine, 246 


\section{PARABOLAS}

Parabolas described by comets, 155

Paracelsus, chemistry of, 72

Paris, Cuvier on fossil animals of, 397

Pascal on pressure of the amosphere, Ixg

Pecquet on thoracic duct, II 4

Pericles pleads for Anaxagoras, I4

Perrier, M., carries a barometer up the

Puy de Dome, Ir

Pendulum, Galileo on the, 79

Phases of moon, ro ; of Venus, $9 \mathrm{x}$

Philosopher, name first given to Pythagoras, 12

Philosophical transactions begun, 127

Phlogiston, theory of, 135 : destroyed by Lavoisier, 238

Photography explained, $3 \times 7$

Physics, definition of, 2 ; of sixteenth century, 83 ; of seventeenth century, $\mathrm{II}_{4}$; of eighteenth century, 282

Physical, forces, correlation of the, 435 : geography, Humboldt on, $3^{86}$

Physiology, beginning of the study of, IIO-II5

Piazzi discovers Ceres, 289

Picart, size of the earth measured by, 150

Pierre-à-Bot, an erratic block, $4 \times 3$

Pigeons, common descent of different varieties of, 392

Pisa, Galileo and the men of, $8 \mathrm{I}$

Pith of elder, cells in, 140 ; ball attracted and repelled by rubbed sealing-wax, 124

Planets, Anaxagoras on, 14 ; Eudoxus on, 15 : Kepler's laws concerning the, 97100 ; held in their orbits by gravitation, 151 ; minor, or asteroids, 289 ; stability of their orbits proved by Lagrange, 270 : their weight and size calculated by Leverrier, 294

Plants, Aristotle on low organisation of, 16: Theophrastus on, 17; microscopic structure of, $x+0$; ashes of, examined by Boerhaave, 193: Hales on breathing of, 193 ; Bonnet on leaves of, 200 ; Gesner on, 70; Crsalpinus on, 71; Ray on, 142 ; Linnæus, artificial system of, 208 ; Jussieu, natural system of, 211,382 ; specific names given to, 209: Humboldt on distribution of, 385 ; metamorphosis of, $38 \mathrm{r}$; Priestley on breathing of, 232

Playfair's illustrations of Hutton, 219

Polarizs.tion of light, 18I ; by reflection, 309; circular, 314

Porta, his meetings in Naples, 74; his camera obscura, 75 ; on the eye, 76 ; his engine, 246

Positive and negative electricity, 256, 262

\section{RED}

Potassium discovered by Davy, 365

Potter, Humphrey, ties the engine-cocks 247

Ptolemaic system, 32

Ptolemies patrons of learning, $x 8$

Ptolemy, astronomy of, 32 ; geography of, 33 ; 'cloudy stars' seen by, 274

Precession of equinoxes discovered by Hipparchus, 30 ; Newton on, 154

Pressure and volume, relations of, 130

Prestwich on flint implements, 416

Priestley, his discoveries, 232 ; calls oxygen 'dephlogisticated air,' 234 ; his troubles and death, 235

Prism, light dispersed in a, 165

Prismatic colours, Newton on, 167

'Principia,' some problems discussed in the, 153

- Principles of Geology ' published, 4 ro

Printing, invention of, 55

Proctor on shooting stars, 299

Proportions, law of definite, 373

Proust on chemical law of proportions, 373

Pulmonary circulation of the blood, 113

Pulse studied by Herophilus, 27

Pump, height that water will rise in, 117

Pythagoras, science of, II, 215

Pythagorean system, 2I

UADRANT made by Copernicus, 66 Quadrupeds, Ray's work on, 143

Quicklime, nature of, 226

$\mathrm{R}$ ABrits descended from one wild $R$ stock, 392

Radiata, term explained, 396

Rain, denuding effects of, 406

Rainbow, De Dominis on, 164

Ramsay, Prof., cited, 218

Ray, on geology, 216; and Willughby, history of, 142 ; on quadrupeds, 143 ; on birds, fishes, and insects, 144 ; on plants, 145

Rays of light, index of refraction of, x08: Euclid on, 2I: Alhazen on refraction of, 47; Kepler on, 96; Young and Fresnel on, 305-309: Newton on refraction of coloured, 166 ; non-interference of ordinary and extraordinary, 312 ; paths of through a crystal, 313: discovery of chemical and heat, 315

Réaumur's scale, freezing point of, 120

Red fire made by burning strontium, 322 


\section{REFLECTION}

Reflection of light, 177; polarization of light by, 309

Refraction explained by Alhazen, 47 ; explained by Huyghens, 178 ; figures illustrating, 179 ; double, 179, 180; Snellius discovers law of, 106: method of measuring, ro8; of coloured rays, 166;

'Règne Animal,' Cuvier's, 397

Reptiles, gigantic fossil, 423

Repuision by electricity, 124

Respiration, Boyle on air used in, 131 ; Mayow on effects of fire-air in, 134

Richter on chemical law of proportions, 373 ; and Reich discover iridium, 323

Rieban, Mr. Faraday's master, 348

Ritter discovers chemical rays, 315

Rivinus on plants, 209

Robison on Watts, 245

Rocks, diagrams of, bent and broken, $2 \times 8$; new ones formed out of old, 220

Roe of codfish, animalcules in, 140

Roemer measures velocity of light, 172

Roger Bacon makes gunpowder, 52 ; his experiments on air, 52

Ronald's, Mr., attempt at electric telegraph, 356

Rose, modification of parts in the, 382 ; number of species of, 420

Rothmann, Dr., befriends Linnæus, 205, 207

Royal Institution, Young professorat, 303 ; Davy at, 363 ; Faraday at, $34^{8}$

Royal Society founded, 125 ; early members of, 127: Newton learns the real size of the earth at the, 150; Halley's method proposed to the, 158

Rubidium discovered, 323

Rüdbeck discovers lymphatics. I 15

Rudimentary organs, $42 x$

Rudolph II. protects Tycho and Kepler, 79, 95

Rudolphine tables, 79, ror ; used to predict transits, 157

Rumford, Count, his history, 330; produces heat by friction, $33^{x}$; appoints Davy to Royal Institution, $36_{3}$

Rutherford, Dr., on nitrogen, 235

SABINE, Sir E., on connection between

sun-spots and magnetic currents, 355 ; on weight of our earth, 280

St.-Hilaire, G., history of, 390 ; on Egyptian animals, $39 \mathrm{r}$; on homologous parts of animals, 393; his discussion with Cuvier, 395

\section{SLOUGH}

Salamanders, regrowth of limbs of, 201 Sal-ammoniac known to the Arabs, 45 Salerno, medical school of, 40

Salt, colour of burning, 322

Salts of plants extracted, 193

Sap, Ray and Willughby on, $x 43$

Satellites of Jupiter, 90 ; eclipses of, 173

Saturn, atmosphere of, 327 ; weight of, 254 ; his ring seen by Galileo, 92 ; and Jupiter, long inequality of, 269

Saussure, De, on glaciers, 412

Savery's engine, 246

Scheele, discoveries of, 232 ; on chemical rays of light, $3 \times 6$

Schehallien experiment, 277 ; diagram of, 279

Schiaparelli on August meteors, 298

Schœffer, Peter, the printer, 55

Schwabe on periodicity of sun-spots, 354

Science, definition of, I; of the Greeks, 7 ; decay of Greek, 35 ; of the Middle Ages, 39, 59 ; of the Arabs, 39, 50; rise of modern, $\sigma_{3}$ et seq. ; of sixteenth century, 82 ; seventeenth century, 182; eighteenth century, 280 ; academies of, 124: lists of chief men of, $6,38,62,86$, I88, 286

Scilla on Calabrian fossils, 216

Scotland, glaciation of, 414

Screw of Archimedes, 25

Sea, land eaten away by the, 406,408

Seasons caused by obliquity of ecliptic, 20

Section of the skin, 139

Seebeck, Professor, discovers thermo-electricity, 352

Seeds and germs, growth of compared, $14^{x}$; classification of plants by, $7 x$

Séguin, M., on mechanical equivalent of heat, 335

Selection of animals by man, 428 ; Natural, 429

Serapis, rise and sinking of temple of, 408

Servetus on circulation of blood, $\mathrm{IxI}$

Seventeenth century, characteristic work of, 433 ; summary of science of the, $x 82$, 186

Shooting-stars, a legend concerning, 297

Sicily, thickness of limestone rocks in, 407

Silkworm, Malpighi on structure of, 139

Simpson, Dr., on chloroform, 378

Sines of incident and refracted rays, 109

Sixteenth century, advance of science in the, 82,433

Skaptar Jokul, torrent of lava from, 408

Skin, section of, 139

Slough, Herschel's observatory at, 273, 295 


\section{SMITH}

Smith, Sir E., brings Linnæean collection to England, 213

Smith, William, surveys England, 223

Snails, regrowth of parts in, $20 x$

Snellius discovers law of refraction, ro6

Soap-bubble, Newton on the, 169 ; cause of colours on the, 307

Soda, composition of, 376

Sodium discovered by Davy, 365 ; power of to decompose water, 375 ; spectrum of, 322 ; Kirchhoff's experiments with vapour of, 325

Soho, manufactory of engines at, $25 \mathrm{x}$

Soil, substances taken from by plants, I93

Solar, spectrum, dark lines in, $3 \times 8$; and star-spectrum compared, 321 ; system, motion of through space, 275

Solstices observed by Thales, 9

Sound, Newton on, 175 ; light compared to, $x 76, x 78$

Spallanzani on regrowth of severed limbs, 201

Specific gravity first measured by Archimedes, 23

Specific names given by Linnæas, 208

Spectra, table of, 320

Spectrum studied by Newton, 165 ; dark lines on the, $3^{18} 8320$; their cause explained, 323 ; of different substances, 321 ; of gases, 322 ; of solids, 322

Spectrum analysis, history of, $3^{15-28}$ : metals discovered by, 323 ; of sunlight, 323 ; of stars, 326 ; of nebula, 327 ; of meteors, 328 ; use of in chemistry, 370

Spencer, Herbert, on evolution, 435

Spirit, Arabian name for gas, 42

Spirits of wine made by Geber, 44

Spots on the sun, periodicity of, 354

Stahl's work in chemistry, 135; on phlogiston, 135

Star, morning and evening, II ; -clusters and nebula, Herschel on, 274 ; -gauging by Sir W. Herschel, 273

Stars, binary, 273; spectrum analysis of the, 326

Statics, Stevinus on, 82

Statics, Stevinus on, 82
Steam, condensation of, 249 ; latent heat of, 243

Steam-engine, listory of the, 245; Newcomen's, 246; Watt's, 249

Steinheil on electric telegraph, 357 ; on earth acting as return wire, $35^{8}$

Steno on fossils in tine earth's crust, 215

Stereoscope, Sir J. Herschel on the, 320

Stevinus on statics, 82

\section{THERMOMETER}

Stokes, Professor, on dark lines in solar spectrum, 323

Stomachs of animals, peculiarities of, 199

Stone tools of lake-dwellings, $4^{17}$

Strabo on earthquakes and volcanoes, 33

Strata of England mapped by W. Smith, 223

Strix caused by glaciers, $4^{13}$

Struve on Neptune's moons, 295

Sublimation described by Geber, 44

Suction-tube, section of $\mathrm{a}, \mathrm{I}$ I7

Sulphuric acid made by Geber, 45

Sumrnary of science of sixteenth century, 82 ; of seventeenth century, 182 ; of eighteenth century, 280

Sun, experiment to explain the movement of the earth round the, 19 ; seen after setting by means of refraction, 48 ; rotation on its axis proved by Galileo, 92 ; his distance 108 times his diameter, 159 ; method of measuring the diameter, $159^{-}$ $16 \mathrm{r}$; distance from the earth, 162 ; holds the planets round it by gravitation, 152 : meteors falling into, 300; atmosphere of vapours surrounding the, 325 ; spectrum of the light of, 318

Sun-dial invented by Anaximander, to

Sun-spots seen by Galileo and Harriot, 92 ; Sir W. Herschel on cause of, 353: Schwabe on periodicity of, 354 ; their connection with magnetic currents, 355

Switzerland, glaciers of, 412 ; lake-dwellings of, $4 \times 6$

Syene, earth's circum'erence measured from, 29

Syntaxis of Ptolemy, 32

Synthesis, term explained, $37 x$

'System of the World,' by Galileo, 93

'Systema Naturæ ' published, 211

TALBOT, Fox, on sun-pictures, $3^{1} 7$; on spectra of flames, 323

Telegraph (see electric telegraph)

Telescope, Roger Bacon's idea of, 52 ; in. vention of the, 87 ; Ga!ileo's, 89 ; Kepler's, 97 ; achromatic, 169

Tessier, Abbé, meets Cuvier, $39 \circ$

Tests, Bergmann op chemical, 229

Thales, science of, 8

Thallium discovered, 323

Theophrastus the first botanist, 17

Theories about living beings, $38 \mathrm{I}$

Theory of the 'Earth' published, 219

Thermo-electricity, discovery of, 352

Thermometcr, invention of the, $1 x$ 


\section{THOMPSON}

Thompson, Benjamin (see Rumford)

Thomson, Dr., on Dalton's theory, 377 ;

Sir W. cited, 323,434

Thoracic duct, Pecquet on the use of, $\mathrm{II}_{4}$

Tides, Newton on cause of, 155

Torricelli on weight of atmosphere, 117 ; invents barometer, 118

Torricellian vacuum, 119

Tournefort's classification of plants, 145

Tower, Hunter dissects the wild beasts of the, 198

Transits of Mercury and Venus, 156-63 ; Halley's method of measuring, 160 ; Delisle's method of measuring, 266; diagrams of, $160-61$; expeditions, 162

Transparency of glass, cause of, $x 77$

Trianon, Jardin de, 208

Truth, our want of faith in the power of, 436

Tycho Brahe, his life and astronomical work, 78 ; Galileo and Kepler compared, $\mathrm{IO}_{2}$

Tychonic system, 78

Tylor, E. B., illustrations of refraction of light, 178

Tyndall, Dr., on heat, $34^{\circ}$

U NDULATORY theory of light, $\mathbf{x 7 5}$, 303 ; explains interference, 305

Uniform action of geological change, 409

Upsala, Linnzus's botanical garden at, 208

Uranienburg, Tycho's observatory at, 79

Uranus, discovery of, 272; its irregular movements lead to discovery of Neptune, 292-294

\section{VACUUM, Torricellian, $1 x 9$}

Valleys, excavation of, is

Valves in veins discovered by Fabricius, III; use of, 112

Van Helmont, chemistry of, 72

Varieties, useful ones alone survive, 430

Vasco de Gama sees southern stars, 57

Vegetable aratomy, 140

Veins, Galen on, 34 ; action of discovered by Harvey, III; valves in, discovered by Fabricius, III

Velocity of light measured, 172

Venus, phases of, agree with Copernican theory, $9 x$

Venus, transits of, 147 ; used to measure sun's distance, $15^{8}$; Halley's method of measuring, 160; diagrams illustrating,

\section{WILLIAM}

159, 160, 16r; Delisle's method of measuring, 266

Vertebrata, term explained, 396

Vesalius, his work in anatomy, 67 ; banishment and death of, 68

Vessels and fibres of plants, 140

Vesta discovered, 290

Vibrations, light a series of, 176 ; of light complex, 313

Vinci, Leonardo da, inventions of, 58

Vital fluids, belief of alchemists in, 192 ; spirits, belief in, $x$ ro

Vitellio on refraction, ro6

Viviparous and oviparous animals, 143

Volcanoes, Pythagoras on, 12; mass of lava thrown out from, 408

Voltaic electricity, 26x; pile, 263

Volta on electricity, 261; his crown of cups, 262 ; his controversy with Galvani, 260

Volume and pressure, relations of, 130

Von Baer on embryology, 400

Voyages round the world, 56

Vulcan, god of volcanoes, 7

Vulcanists and Neptunists, 218

WALES, moraines and erratic blocks of, 44

Wallace, Mr. A. R., figures drawn by, 97 ; on natural selection, 425,426 ; on prolificness of birds, 429

Wallis, Dr., his description of the Royal Society, 125

Water, composition of, 231, 239, 372 :rising in a vacuum, II7 ; latent heat of, 243; boiled by friction, 332 ; rise of temperature in by friction calculated, 336 ; decomposed by sodium, 375

Watt, his early life, 244 ; not the first to make a steam-engine, 245 ; his separate condenser, 248 ; his double-acting engine, 250 ; his partnership with Boulton, 251

Wave-theory of light, $x 75$; explains interference, 305

Waves of light in a crystal, $3{ }_{3}$

Wedgwood, Dr. T., on sun-pictures, 317

Weight of bodies explained by gravitation, 154 ; of chemical elements, 373

Wenzel on law of definite proportions, 373

Werner on rocks and fossils, 217

Westminsier Abbey, Newton buried in, I7x

Wheatstone patents electric telegraph, 357

William of Orange founds Leyden University, 191 


\section{WILLUGHBY}

ivillughby and Kay, 142 ; death of, 143 ; on classification of animals, 143

Wöhler on organic chemistry, 377

Wolff on metamorphosis of plants, $38_{3}$

Wollaston, Dr., observes dark lines in the spectrum, $3 \times 8$

Woodward, his geological collection, 216

Woolsthorpe, birthplace of Newton, $x 47$

World, first voyages round the, 56

Worm, re:rowth of divided parts of the,

\section{ZOOLOGY}

VAR, length of calculated, 45

Young, Dr., his life, 303 ; on interference of light, 304-306 ; and Frésnel on polarisation of light, 3IX

7ODIAC, or circle of animals, 19

2 Zoology, Aristotle on, 16; Gesner on, 69; Ray and Willughby on, 143: Linnæus on, 2ro ; Cuvier, St.-Hilaire, and Goethe on, $39 \mathrm{r}$ et seg. : Darwin on, 426 



\section{Works of Arabella B. Buckley.}

I.

\section{Life and her Children.}

By Arabela B. Buckley. With lllustrations. One vol, 12mo. Cloth. Price, $\$ 1.50$.

The work, with the anthor's usual felicity in captivating the youthful mind, discusses the structure and habits of the invertebrate animals.

II.

\section{Fairy-Land of Science.}

By Arabella B. Buckley, author of "A Short History of Natural Science," etc. With numerous Illustrations. 12mo. Cloth. Price, $\$ 1.50$.

"A child's reading-book admirahly adapted to the purpose intended. The young reader is referred to Nature itself rather than to books, and is tainght to ohserve and investigate, and not to rest satisfied with a collection of dull defini tions learned by rote and worthless to the possessor. The present work will be found a valuable and interesting addition to the somewhat overcrowded child"s iibrary."-Boston Gazette. Times.

"It deserves to take a permanent place in the literature of youth."-London

"So interesting that, having once opened the book, we do not know how to ieave off reading." - Saturday lieview.

III.

\section{A Short Hislory of Natural Scieice and the Progress of Discovery,}

FROM THE TIME OF TIE GREEKS TO TIIE PRESENT DAY. For Schools and Young Persons. By Arabella B. Buckiey. With Illustrations. $12 \mathrm{mo}$. Cloth. Price, $\$ 2.00$.

" The volume is attractive as a book of anecdotes of men of science and their discuverics. Its remarkable features are the sound jndgment with which the true landinarks of scientific history are selected, the conciseness of the iuformation conveyed, and the interest with which the whole subject is nevertheless invested. Its style is strictly adnpted to its avowed purpose of furnishing a textbook for the usc of schools and young persons."-London Daily News.

"A most admirable little volume. It is a classifled résumé of the chief diecoveries in physical science. To the young student it is a book to cpen up new worlits with every chapter."-Graphic.

"The book will be a valuable aid in the study of the clements of natural science."-Journal of Education.

D. APpletoN \& C0., Publisuers, 1, 3, \& 5 Bond Street, N. Y. 
THE

\section{EXPERIMENTAL SCIENCE SERIES.}

In neat $12 \mathrm{mo}$ volurnes, bound in cloth, fully illustrated. Price per volume, $\$ 1.00$.

THis series of scientific books for boys, girls, and students of every age, was aesigned by Prof. Alfred M. Mayer, Ph. 1., of the Stevens Institute of Technolo: $y_{\text {, }}$ Hoboken, New Jersey. Every book is addressed directly to the young student, sid he is taught to construct his own apparatus out of the cheapest and most common materials to be found. Should the reader make all the apparatus described in the first book of this series, he will spend only $\$ 12.40$.

\section{NOW READY: \\ I.-LIGHT.}

A Series of Simple, Entertaining, and Inexpensive Experiments in the Phenomena of Light, for Students of every Age.

By ALFRED M. MAYER and CHARLES BARNARD.

\section{II.-SOUND:}

A Series of Simple, Entertaining, and Inexpensive Experiments in the Phenomena of Sound, for the Use of Students of every Age.

BY ALFRED MARSHALL MAYER,

Professor of Physics in the Stevens Institute of Technology; Member of the National Academy of Sciences; of the American Philosophical Society, Philadelphia; of

the American Academy of Arts and Sciences, Boston; of the New York

Academy of Sclences; of the German A stronomical Society; of the American Otological Society; and Honorary Mem-

ber of the New Y ork Ophthalmological Society.

Iv Active Preparation:

III. Vision and the Nature of Light.

IV. Electricity and Magnetism.

V. Heat.

T1. Mechanics.

VII. Chemistry.

VIII. The Art of experimerting with Cheap and Simple In. struments.

D. APPLetoN \& CO., Publishers, 1, 3, \& 5 Bond Street, New York. 


\section{THE EXPERIMENTAL SCIENCE SERIES.}

\section{I G H T :}

$A$ Series of Simple, Entertaining, and Inexpensive Experiments in the Phenomena of Light, for the Use of Students of Every Age.

\section{BY ALFRED M. MAYER AND CHARLES BARNARD.}

Neat 12 yo volume, folly illustraten. - . Cloth, price, $\$ 1.00$.

"Professor Mayer has invented a series of experiments in Light which are described by Mr. Barnard. Nothing is more neecssary for sound-teaching than experiments made by the pupil, and this book, by coneidering the difficulty of costly apparatus, has rendered an important service to teacher and student alike. It deals with the sonrces of light. reflection, refraction, and decomposition of light. The experimeuts ure extremely simple aud well suited to young people." -Westminster Review.

"This work describes, in simple language, a number of experiments illnatrating the principal properties of light, by means of a beam of sunlight admitted into a dark room, and various contrivances. The experiments are highly ingenious, and the young student can not fail to learn a great deal from the book. As an example of the effective experimental method employed, we may specially mention the device for illustrating the refraction of light. This book is specially designed 'to give to every teacher and scholar the knowledge of the art of experimenting." "-The Quarterly Journal of Science (London).

"A singularly excellent little hand-book for the use of teachers, parents, and children. Thie book is admirable both in design and execution. The experiments for which it pruvides are so simple that an intelligent boy or girl can easily make them, and so beantifnl and interesting that even the youngest chil. dren must enjoy the exhibition. The experiments here described a re abundantly worth all that they cost in money and time in any family where there are boys and girls to be entertaincd." - New York Evening Post.

"The experiments are capitally selected, and equally as well described. The book is conspicuously free from the multiplicity of confusing directions with which works of the kind too often abound. There is an abundance of excellent Illustrations." - New York Scientific American.

"The experiments are for the most part new, and have the merit of combining precision in the methods with extreme simplicity and elegance of desinn. 'The vaine of the book is further enhanced by the numerous carefully-drawa cuts. which add greatly to its beauty."-American Journal of Science and Arts.

D. ApplitoN \& CO., Publishers, 1, 3, \& 5 Bond Street. New York. 


\section{THE EXPERIMENTAL SCIENCE SERIES.}

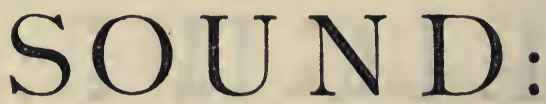

Series of Simple, Entertaining, and Inexpensive Experiments in the Phenomena of Sound, for the Use of Students of Every Age.

\section{By ALFRED MARSHALL MAYER,}

Professor of Physics in the Stevens Institute of Technology; Member of the Natlonal Academy of Sciences, etc.

Uniform with "LIGHT," first volume of the Series.

Neat 12mo volume, fully illustr.aten. - . Cloth, price, \$1.00.

"It would be difficult to find a better example of a scries which is excellent throughout. This little work is accurate in detail, popular in style, and lucid in arrangement. Every statement is accompanied with ample illustrations. We can heartily recommend it, elther as an introduction to the subject or as a satisfactory manual for those who have no time for perusing a larger work. It contains an excellent description, with diagrams, of Faber's Talking Machine and of Edison's Talking Phonograph, which can not fail to be interesting to any reader who takes an interest in the marvelous progress of natural science."British Quarterly.

"The style of the book is very clear, and the experiments interceting. It can not fail to have an important educational influence."-Westminster Feview.

"It would really be difficnlt to exaggerate the merit, in the sense of consummate adaptation to its modest end, of this little treatise on 'Sound.' It teaches the youthful student how to make experiments for himself, without the help of a trained operator, and at very little expense. These hand-books of Professor Mayer should be in the hands of every teacher of the young."-New York Sun.

"An admirably clear and interesting collection of experiments, described with just the right amount of abstract information and no more, and placed in progressive order. The recent inventions of the phonograph and microphone lend an extraordinary interest to this whole field of experiment, which makes Professor Mayer's manual especially opportune."-Boston Courier.

D. APPletoN \& CO., Publishers, 1, 3, \& 5 Bond Street, New York. 
PHYSICAL SCIENCE.

FORMING A SERIES OF

\section{TEXT-B00KS OF SCIENCE}

ADAPTED FOR THE USE OF

\section{ARTISANS AND STUDENTS IN PUBLIC AND SEIERCE SCHOOLS.}

Fully illustrated; size, $16 \mathrm{mo}$.

\section{VOLUMES ALREADY PUBLISHED:}

The Elements of Mechanism. By Professor T. M. GOodEVE, M. A. Cloth, $\$ 1.50$.

sletals: Their Properties and Treatment. By Professor C. L. Bloxak. Cloth, $\$ 1.50$.

Introduction to the Study of Inorganic Chemistry. By W. A. MILLER, M. D., D. C. L., LL. D. Cloth, $\$ 1.50$.

Theory of Heat. By Professor J. C. MAXWEL L, M. A., LL. D. Cloth, \$1.50.

The Strength of Materials and Structures. By J. Anderson, C. E, LL. D., F.R. S. E. Cloth, $\$ 1.50$.

Electricity and Mannetism. By Professor F. JExkiN, F. R. SS. L. \& E., M. I. C. E. Cloth, $\$ 1.50$.

Workshop Appliances, including MaehineTools used by Engineers. By C. P. B. Shelley, C. E. Cloth, \$1.50.

Principles of Mechanics. By Professor T. M. Gooveve, M. A. Cloth, \$1.5J.
Introduction to the Study of Organse Chemistry. By Professor H. E. Arustrong, Ph. D., F.C.S. Cloth, $\$ 1 \$ 0$.

Qualitative Chemical Analysis and Laboratory Practice. By l'rofessor T. E. TyorPE, Ph. D., F. R. S.E., and M. M. P. MuIn, F. R. S. E. Cloth, $\$ 1.50$.

Telegraphy. By W. H. Preece, C. E. and J. Sivewright, M. A. Cloth, $\$ 1.50$

Railway Appliances. By J.W. BARRY, C. E. Cloth, $\$ 1.50$.

The Art of Electro-Metallurgy. By $\mathrm{G}$. Gore, LL. D., F.R. S. Cloth, $\$ 2.50$.

Introduction to the Study of Chemical Philosophy. By W. A. TILden, D. Sc. Lonil., F. C. S. Cloth, $\$ 1.50$.

The Elements of Mrachine Deign. By Protessor iv. C. UnwiN, C. E. Cloth, $\$ 1.30$.

Treatise on Photography. By Captain W. De Wiveleslie ABNeY, F. R.S. Cloth, $\$ 1.50$.

\section{(Other volumes in preparation.)}

"This admirable sories of text-books is invalnable for the use for which it was originally planned. Several of the authors are preëminent in their own speclalty, and their works must have been of immense service to the numerous class of students for whom they are chiefly intended. Taking the serles as a whole, it would be a difficult task to single out another list of text-books on the same or collateral subjects in our language which could be compared with them, either in regard to quality and price, or that are so well fitted for the instruction of engineering students, or for students generally in our public and science schools."-London Examiner.

D. APPletoN \& CO.. Publishers, 1, 3, \& 5 Bond St. N. Y. 


\title{
INTERNATIONAL SCIENTIFIC SERIES.
}

\author{
NOW READY. In ramo and bound in cloth.
}

1. FORMS OF WATER, In.Clouds, Rain, Rivers, Ice, and Glaciers. By Prof. JoHN TYNDALL. $\$ 1.50$.

2. PHYSICS AND PULITICS; or, Thoughts on the Application of the Principles of "Natural Selection" and "Inheritance" to Political Society. By W ALTEz BAGEHOT. \$1.50.

8. FOODS. By EDWARD SNiTH, M. D., LL. B., F. R. S. $\$ 1.75$.

4. MIND AND BODY. By AleXANDER BAIN, LL. D. $\$ 1.50$.

5. THE STUDY OF SOCIOLOGY. By Herbert SPencer. \$1.50.

6. THE NEW CHEMISTRY. By Prof. Josiah P. Cooke, Jr., of llarvard University. $\$ 2.00$.

7. THE CONSERVÁtion of ENERgY. By Prof. Balfour Stewart, LL.D., F. R.S. $\$ 1.50$.

8. ANIMAL LOCOMOTION; or, Walking, Swimming, and Flying, with a Irssertation on Aerronautics. By J. B. Pettigkew, M. D. lilustrated. \$1.75.

9. ResponsibILITY iN MENTAL Disease. By H. Maudsley, M D. $\$ 1.50$.

10. THE SCIENCE OF LAW. By Prof. Smeldon Axos. \$1.75.

11. ANIMAl MECIANIsM. A Treatise on Terrestrial and Aërial Locomotion. By E. J. Marex. 117 Illustrations. $\$ 1.75$.

12. THE HISTORY OF THE CONFLICT BETWEEN RELIGION AND SCIENCE. BY JoHN WILliAM DRAPER, M. D., LL. D. \$1.75.

18. THE DOCTRINE OF DESCENT, AND DARWINISM. By Prof. Oscar ScImid, of Strasburg University. $\$ 1.50$.

14. THE CHEMISTRY OF LIGHT AND PHOTOGRAPHY. By Dr. HeRMANN VOGEL. 100 Illustrations. $\$ 2.00$.

15. FUNGI; their Nature, Influence, and Uses. By M. C. Cooke, IL. D. Edited by M. J. BERKkLEY. 109 Illustrations. $\$ 1.50$.

16. THE LifE AND GRoWTH OF LANGUAGE. By Prof. W. D. Waitney, of Yale College. $\$ 1.50$.

17. MONEY AND THE MECHANISM OF EXCIIANGE. By W. STANLEY JEVONS. M. A., F. R. S. \$1.75.

18. THE NATURE OF LIGHT, with an Account of Physical Optics. By Dr. k. Lommen, Professor in the University of Erlangen. 88 Illustrations and a Plate of Spectra in Chromo-lithography. $\$ 2.00$.

19. ANimal Parasites aNi) MESSMatés. By M. Van Beneden, Professor of the University of Louvain. 83 Illustrations. $\$ 1.50$.

20. ON FERMkNTATIONS. By P. SchŨTzENBERER, Director at the Chemical Laboratory at the Sorbonne. 28 Illustrations. \$1.50.

21. THE FIVE SENSES OF MAN. By J. Bernstein, 0. O. Professor in the University of Halle. 19 Illustrations. \$1.75.

22. THE THEORY OF SOUND IN ITS RELATION TO MUSIC. By Prof. Pietro Blaserna, of the Royal University of Rome. Numerous Wouteuts. $\$ 1.50$.

23. STUDIES IN SPECTRUM ANALYSIS. By J. NORMaN LOCKYER. Illustrations. $\$ 2.50$.

24. A HISTORY OF THE GROWTH OF THE STEAM-ENGINE. By ROBERT H. Thurston, A. M., C. E., Professor of Mechanical Engineering. 163 Illustrations. $\$ 2.50$.

25. EDUCATion as a SCIENCF. By Alexander Batn, LL. D., Professor of Logic in the University of Aberdeen. $\$ 1.75$.

26. MODERN CHROMATICS, with Applications to Art and Industry. By OGDEx N. Roop. Professor of Physics in Columbia College. 180 original Illustrations. $\$ 2.00$.

27. THE HUMAN SPECIES. By A. De Quatrefages, Professor of Anthropology in the Museum of Natural History, Paris. $\$ 2.00$.

28. THE CRAYFISH : An Introduction to the Study of Zoology. By Prof. T. H. HUXLEY. 82 Illustrations. $\$ 1.75$.

For sale by all booksellers. Any volume sent by mail, post-paid, to any address in the United States, on receipt of price.

D. APPLETON \& CO., Publishers, 1, 3, \& 5 Bond St.. Nero York. 


\section{EMINENT MODERN SCIENTISTS.}

\section{HERBERT SPENCER'S WORKS. 14 vols., $12 \mathrm{mo}$. Cloth, $\$ 25.25$.}

Frrst Princtiples.............\$2 00 Study of Snciologr. (International

Principles of Biology. 2 vols... 400 Scientific Series)...............

Princtiles of Psychology. 2 vols. 400 Education...................... 125

P'RiNCIPLes of Sociology. Vol. I.

I'arts I., II., and III...........2 200 PHY, and Morals............2 20

Cerenonial Institutions. Being 0

Part IV. of the Principles of Soci- Essays: Moral, Political, and As-

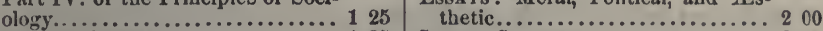

Data of Etrios................ 125 Social Statics.................. 200

Philosopix of Strux. 12mo. Flexible cloth, 50 cents.

Drscriptive Soctolog Y. To Subscribers, for the whole work, per part, \$3.50; single part. $\$$ t.10. Published in folio, with Tables. Six Parts now ready, namely: 1. English; 2. Ancient Americans; 3. Negritto and Malayo-Polynesian Races; 4. African Races; 5 . Asiatic Races; 6. North and South American Races.

\section{CHARLES DARWIN'S WORKS. 11 vols., 12 mo. Cloth, $\$ 24.00$.}

Origin of Spreies............. $\$ 200$

Driscent of MAN................ 300

JoURNAL OF RESEARCIIES........2 200

Emotional Expression.......... 350

Aninals and Plants undre Do-

MEstication. 2 vols........... 500
Insecxivorous Plants...........2 00

('linding Plants................ 125

ORCHIDS FERTILIZED BY INBEcts... 175

Fritilization in the Vegetable

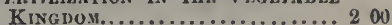

Forys of Flowers.............. 1 j0

\section{THOMAS H. HUXLEY'S WORKS.}

M.ax's Place in NatuRE........\$1 25

ON xite (1) Rigin of Species.......... 100

More Criticisus on Darwis, and Adinsistrative NiHLisi...... 50

A MaNual of tire ANatovy of VerterRated A:inals. Illus'd.. 250

A Manual of tire ANatuny of INvertebRated ANimal8. Hlirs'a.. 250

LAY SERuoNs, ADDRrases, AND REviEWs.................. 175
11 vols., $12 \mathrm{mo}$. Cloth, $\$ 18.00$.

Critiques and Andresses........ \$1 50 AMrrican ADDresses.............. 125

Phy

Elenents of Puysiologi ani il GIENE. By T. H. liuxley and W. J. Youmans................. 1 s0

The Crayfisir: in Introduction to Zoölogy. (International Scientific

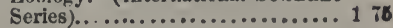

\section{JOHN TYNDALL'S WORKS. 10 yols., $12 \mathrm{mo}$. Cloth, $\$ 19.75$.}

Heat as a Mode of Motion.....\$2 00| Hovrs of Exercise in tine Alfs.\$2 100

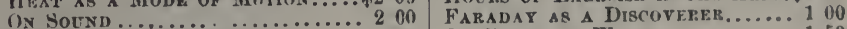

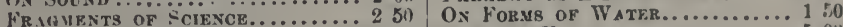

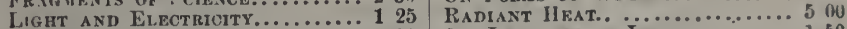
LFSSONB IN ELECTRICITY........... 1 00 SIX LECTURES ON LieHT......... 150 Banquet at Delmonicu's, paper, 50 cents; Belfast Address, paper, 50 cents.

D. APPletoN \& CO., PUblishers, 1, 8, \& 5 Bond Streat, Naw York. 


\section{WORKS OF H. ALLEYNE NICHOLSON, M.D.}

I.

Text-Book of Zoology, for Schools and Col-

leges. $12 \mathrm{mo}$. Half roan, $\$ 1.50$.

II.

Manual of Zoology, for the Use of Students, with a General Introduction to the Principles of Zoölogg. Second edition. Revised and enlarged, with 243 Woodeuts. $12 \mathrm{mo.}$ Cloth, \$2.б0.

III.

Text-Book of Geology, for Schools and Colleges. $12 \mathrm{mo}$. Half roan, $\$ 1.30$.

IV.

\section{Introduction to the Study of Biology.}

Illustrated. $12 \mathrm{mo}$. Cloth, 65 cents.

V.

\section{The Ancient Life-History of the} Earth. A Comprehensive Outline of the Principles and Leading Facts of Palæontological Science. 12mo. Cloth, $\$ 2.00$.

The Quarterly Journal of Science.

"A work by a master in the science who uuderstands the significance of every phenomenon which be records, and knows how to make it reveal its lessons. As regards its value there can scarcely exist two opinions. As a textbook of the historical phase of palæontology it will be indispensable to students, whether specially pursuing geology or hiology; and without it no man who aspires even to an outline knowledge of natural science can deem his library complete."

\section{Athencum.}

"The Professor of Natural History in the University of St. Andrews has. by his previous works on zoology and palæontology, so fully established his claim to be an exact thinker and a close reasoner, that scarcely any recommenclation of ours can add to the interest with which all students in na ural history will receive the present volume. It is, as its second titie expresses it, a comprehosive outline of the principles and leading facts of palæontological science. Numerons wooricut illustrations very delicately executed, a copious glosะary, and an admirable index, add much to the value of this volume."

D. APPLETON \& CO., Publishers, 1, 3, \& 5 Bond Streel, New York. 


\title{
WORKS OP HENRY THOMAS BUCKLE.
}

1.

\section{The Life and Writings of Henry Thomas Buckle.}

\section{By Alfred Henry Huth. 12mo. Cloth.}

"The book deals with Mr. Buckle less as a philosopher than as a man. . . Mr. Huth has done his part well and thoroughly."-Saturday Review.

"Mr. Huth has produced a striking and distivet portrait out of his materials, and he has done his work with a simplicity and modesty which are highly effective."-Pall Mall Gazette.

"This work, we think, will revolutionize popular opinion ahout the philosopher."-Loniton Dai'y News.

"Buckle was a man whose story must excite interest aud rouse sympathy." -Scotsman.

\section{History of Civilization in England.}

\author{
2 vols., 8 vo. Cloth, $\$ 4.00$; half calf, extra, $\$ 8.00$.
}

"Whoever misses reading this book will miss reading what is, in varions re. spects, to the best of our judgment and experience, the most rinarkible bouk of the day-one, indeed, that no thouglitful, inquiring mind would nise reading for a good deal. Let the reader be as adverse as he nay be to the witer's philcsophy, let hi:n be as devoted to the obstructive as Mr. Buckle is to the progress partv, let him be as orth dox in church creed as the other is heterodiox. as coginatic as the author is skeprical-let him, in short, find his prejudics sl.ocked at evary tarn of the aroument, and all his prepossestit.ns whistleci cown the wit $\mathrm{d}$ - still, there is so much in this extraordinary volume to ftimulate reflection and excits to inquiry. and provoke to earnest investiqulion, pertiaps (to Hlis o $r$ thict realer) on a track hitherto untrodden, and across the virsin foil of untilic cields, freah woods and pa-tures new, that we may fairly defy tl e most inttile Ejirit, the mo:t miscrustful and least sympathetic, to read it thrugh wit!ol being slatl of liaving done so, or, having begun it, or even glanced at almost ray cue of its pages, to pass away unread."-London Times.

"We have re:ld Mr. Backle's volumes with the decpest interest. We cwe hin a profound debt of gratitude. His infuence on the theught of tle pres. int a., can not but be enormous, and if he gives u* no more than "e alrcady lave in the two volumes of the marnus opus, he will still te clased a mong the fathers and foundert of the Science of History." - New I'crk Times.

"siurnlarly acuts, possessed of rare analyical pewer, imaginative hut yot. fancifa, unwearied in research, and gifted with woncerfil taient in arrausing and molding his material, the anthor is as fascinaling us l.e is learned. His erudition is immense-so immense as not to be cumbersume. It ls the result of is luing and steady growth-a part of himself."-Buston Jour nal.

\section{Essays.}

III.

ITith a Bingraphy of the Author. Portrait. 12mo. Cloth, $\$ 1.00$; half culf, extra, 2.50 .

D. APPLETON \& CO., Publishers, 1, 3, \& 5 Bond St., Neno York. 


\section{A Treatise on Chemistry,}

BY

H. E. ROSCOE, F. R.S.,

AND

C. SCHORLEMMER, F. R. S.,

Professors of Chemistry in Owens College, Manchester.

\section{IIIUSTRATED.}

NOW READY.

VoLUME I.-THE NON-METALLIC ELEMENT:

8vo. Cloth, \$5.0n. Containing a Portrait of DaLtoN, engraved by C. H. Jeens.

Voldure II.-Part I.-IMETALS. 8vo. Cloth, $\$ 3.00$.

Volume II.-Part II.-METALS. 8vo. Cloth, $\$ 3.00$.

"It has been the aim of the authors, in writing their present treatise, to place before the reader a fairly complete and yet a clear and succinct atatement of the facts of Modern Chemistry, while at the same time entering 80 far into a discursion of chemical theory as the size of the work and the present transition state of the science will permit.

"Special attention has been paid to the accurate description of the more important processes in technical chemistry, and to the careful representation of the most approved forms of apparatus employed.

"Much attention has likewise been given to the representation of apparatus adopted for lecture-room experiment, and the numerous new illustrations required for this purpose have all bsen taken from photographs of apparatus actually in use." Extract from Preface.

The above will be sent by mail, post-paid, to any address in the United States, upon receipt of price.

D. APPLETON \& CO., Publishers, New York. 


\title{
APPLETONS' SCHOOL READERS,
}

\section{Consisting of Five Books.}

BX
WM. T. HARB'S, LI. D., A. J. RICKOFF, A. M., MARK BAILEY, A. M., Superintendent of Schools, St. Louis, Ma.
Superintendent of Inatruction, Cleveland, 0 .
Inatructor in Elocution, Tale College.

\begin{abstract}
APPLETONS' FIRST READER...........Child's Quarto, 90 pages. APPLETONS' SECOND READER............12mo, 142 66 APPLETONS' THIRD READER.............12mo, 214 "6 APPLETONS' FOURTII READER............12mo, 248 " APPLETONS' FITTII READER..............12mo, 471 "6
\end{abstract}

\section{CHIEF MERITS.}

These Readers, while avoiding extremes and one sided tendencies, combine into one harmonious whole the several results disirable to be attained in a series of school reading-books. These include good pictorial illustrations, a combination of the word and phonic methods, careful grading, drill on the peculiar combinations of letters that represent vowel-sounds, correct spelling, exercises well arranged for the pupil's preparation by himself (so that he shall learn the great lessons of self-help, self-dependence, the habit of application), exercises that develop a practical command of correct forms of expression, good literary taste, close critical power of thought, and ability to interpret the entire meaning of the language of others.

\section{THE AUTHORS.}

The high rank which the authors have attained in the educational field and their long and successful experience in practical school-work especially fit them for the preparation of text-books that will embody all the best elements of modern educative ideas. In the schools of St. Lnuis and Cleveland, over which two of them have long presided, the subject of reading has received more than usual attention, and with results that have established for them a wide reputation for superior elocutionary discipline and accomplishments. Feeling the need of a geries of reading-books harmonizing in all respects with the modes of instruction growing out of their long tentative work, they have carefully prepared these roiumes in the belief that the special features enumerated will commend then to practical teachers everywhere.

Of Professor Bailey, Instructor of Elocution in Yale College, it is needless to speak, for he is known throughout the Union as being without a peer in bis profession. His metiods make natural, not mechanical readers.

D. APPleton \& CO., Publishers, 1, 3, \& 5 Bond Street, New York. 



\section{PLEASE DO NOT REMOVE CARDS OR SLIPS FROM THIS POCKET}

\section{UNIVERSITY OF TORONTO LIBRARY}

BbM 
